\title{
THREE ESSAYS ON THE U.S. TREASURY MARKET
}

by

\section{RUI QIAO}

\author{
A thesis \\ submitted to the Victoria University of Wellington \\ in fulfilment of the requirements for the degree of \\ Doctor of Philosophy in Finance.
}

Victoria University of Wellington

(2020) 

To mom, dad \& grandparents. 


\section{Abstract}

My thesis consists of three essays on market microstructure. Focusing on the U.S. Treasury market, I investigate several interesting research questions by using twelve years of BrokerTec order books of 2-, 5-, and 10-year on-the-run U.S. Treasury notes from January 1, 2004 to December 31, 2015, and five years of BrokerTec order books of 3-, 7- and 30-year on-the-run U.S. Treasury securities from January 1, 2011 to December 31, 2015. In the U.S. Treasury market, BrokerTec is one of the two dominant electronic communication networks (ECNs). According to my calculations by using BrokerTec order books from 2011 to 2015, the average daily trading volume of BrokerTec on-the-run U.S. Treasury securities is about 134.9 billion U.S. dollars, which accounts for about $26 \%$ of that of the total U.S. Treasury primary dealer activity. To help a wider audience better understand the importance of the research questions in the following three chapters, Chapter 1 gives a brief introduction to the U.S. Treasury market.

In Chapter 2, I investigate the impact of scheduled macroeconomic news announcements on the U.S. Treasury market efficiency. To control the microstructure noise, I employ a robust method to construct market inefficiency measures. I find that the U.S. Treasury market becomes less efficient starting from five minutes before news arrivals. The finding is robust for different sample periods, macroeconomic news announcements, and market inefficiency measures. Investor heterogeneity could explain the decreased market efficiency before scheduled news announcements.

In Chapter 3, I investigate the impact of workup trading protocols on the U.S. Treasury market quality. Each transaction on the lit pool opens a workup window, during 
which the BrokerTec trading platform continues to receive order submissions and modifications, but only matches workup orders that have the same prices. Each workup transaction starts a new counting down of the workup clock. A workup window naturally closes either after the workup times out or when a limit order is submitted at a better price. I find that the workup trading activities decrease the market quality, in aspects of market efficiency and market liquidity.

In Chapter 4, I empirically examine the role of heterogeneity in traders' beliefs and public information shocks on traders' order submission decisions around news announcements in the U.S. Treasury market. I find that during both the pre-announcement period and the post-announcement period, the traders tend to submit more market orders and aggressive limit orders when the market uncertainty is high. I also find that the belief heterogeneity influences investors' trading behavior and order submission strategies around news announcements. The role of the belief heterogeneity on order aggressiveness depends on the type of news, and the magnitude of the information shocks. The impact of market uncertainty and belief heterogeneity influences traders' submission of both of the market orders and aggressive limit orders.

In Chapter 5, I provide a summary on the research findings in Chapter 2, Chapter 3 and Chapter 4. I also discuss the contributions of this thesis to the literature. 


\section{Acknowledgments}

My Ph.D. research is funded by Victoria Doctoral Scholarships and Victoria Doctoral Submission Scholarship. I thank Victoria University of Wellington, Wellington Faculty of Graduate Research, Wellington School of Business and Government, and School of Economics and Finance for all the sufficient support.

I would like to express my sincere gratitude to my amazing Ph.D. supervisors, Professor Hai Lin and Dr. Ingrid Lo, for their unstinted instructions, and immense knowledge. Their patience and motivation open a door for me in research. Their guidance helped me all the time in my Ph.D. study. Words are so limited to express how grateful I feel to them. I am so lucky to have them as my supervisors. They are my lifelong role models.

I also feel thankful for the helpful comments and valuable suggestions my research papers have received from but not limited to Yacine Aït-Sahalia, Jonathan Berk, Toby Daglish, Ian Eggleton, Omar Al Farooque, Olesya Grishchenko, Ivan Indriawan, Gbenga Ibikunle, Martien Lubberink, Ben Marshall, Per Mykland, Nick Nguyen, Richard Roll, Nuttawat Visaltanachoti, Peiming Wang, Jeff Wongchoti, and the seminar participants at the 2017 Financial Markets and Corporate Governance Conference, the Society for Financial Econometrics (SoFiE) Summer School 2018, Massey University and Auckland University of Technology. In particular, I want to thank the revise and resubmission opportunity provided by the Journal of Banking and Finance.

My sincere thanks also go to my Ph.D. examination committee - Douglas Foster, Jinji Hao, Nhut (Nick) Nguyen Hoang, and John Miller, together with all the faculty and Ph.D. students at the School of Economics and Finance. All the good times we 
have had in the last four years and five months will last long forever in my memory. I could not imagine how my life would be like without them.

Last but not least, I would like to thank my family and friends overseas for their love and support. I want to thank Bing Zhao and Dan Zhou, for making ordinary moments extraordinary all the time since we were teenagers. I also thank Travis Christensen for inspiring me to pursue an academic career. They make me understand life is more about cherishing every present moment we could have. 


\section{Contents}

1 Preliminaries 1

$1.1 \quad$ U.S. Treasury Market . . . . . . . . . . . . . . . . . . . 1

1.1.1 U.S. Treasury Auctions . . . . . . . . . . . . . . . . 2

1.1.2 Secondary U.S. Treasury Market . . . . . . . . . . . . . . 2

1.1.3 BrokerTec U.S. Treasury Historical Data $\ldots \ldots \ldots$

1.2 Thesis Outline . . . . . . . . . . . . . . . . . . . 4

1.3 Figures and Tables $\ldots \ldots \ldots \ldots \ldots \ldots \ldots$

2 Macroeconomic News Announcements and Market Efficiency: Evidence from the U.S. Treasury Market 9

2.1 Introduction . . . . . . . . . . . . . . . . . 9

2.2 Data and Variables Construction . . . . . . . . . . . . . . 13

2.2.1 On-the-Run U.S. Treasury Notes: BrokerTec Order Books . . 13

2.2.2 U.S. Macroeconomic News Announcements . . . . . . . . . 14

2.2.3 Market Inefficiency Measure . . . . . . . . . . . . . . . . 17

2.2.4 Market Liquidity and Order Flow Imbalance $\ldots \ldots \ldots \ldots$

2.3 Event Study . . . . . . . . . . . . . . . . . . . 20

2.4 Empirical Results . . . . . . . . . . . . . . . . . . . 22

2.4.1 How Do Macroeconomic News Announcements Influence Market Efficiency? . . . . . . . . . . . . . . . . . 2 22

2.4.2 Impacts of Market Liquidity, Order Flow Imbalance and Information Asymmetry on Market Efficiency . . . . . . . . . . . 24 
2.4.3 Controlling the Liquidity and Information Asymmetries . . . . 26

2.4.4 The Market Microstructure Noise . . . . . . . . . . . . . . 27

2.5 Robustness Tests . . . . . . . . . . . . . . . . . 28

2.5.1 Global Financial Crisis . . . . . . . . . . . . . . . 29

2.5.2 Good News vs. Bad News . . . . . . . . . . . . 30

2.5.3 Slow Reaction of Investors . . . . . . . . . . . . . . . . 31

2.5.4 News Selection: The U.S. Macroeconomic News Released at

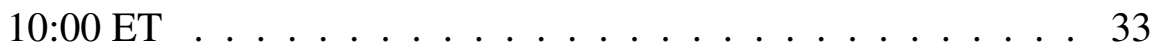

2.5.5 One Alternative Market Inefficiency Measure . . . . . . . . . . 34

2.6 What Drives the Early Reaction? . . . . . . . . . . . . . 35

2.6.1 Superior Private Information . . . . . . . . . . . . 36

2.6.2 Heterogeneous Information . . . . . . . . . . . 37

2.6.3 Regressing Changes in Variables . . . . . . . . . . . . . 38

2.7 Conclusion . . . . . . . . . . . . . . . . . 40

2.8 Figures and Tables . . . . . . . . . . . . . . . . 4 40

\section{Workup and Market Quality: Evidence from the U.S. Treasury Market 61}

3.1 Introduction . . . . . . . . . . . . . . . 61

3.2 U.S. Treasury Market and Workup Protocol . . . . . . . . . . . . 65

3.2.1 The U.S. Treasury Market . . . . . . . . . . . . . 65

3.2.2 The Workup Protocol . . . . . . . . . . . . . 66

3.3 Data and Variables Constructions . . . . . . . . . . . . . . 68

3.3.1 BrokerTec On-the-Run U.S. Treasury Order Books . . . . . . 68

3.3.2 U.S Macroeconomic News . . . . . . . . . . . . . . . 70

3.3.3 Workup Volume Ratios . . . . . . . . . . . . . . 71

3.3.4 Market Quality Measures and Other Control Variables . . . . . 73

3.3.5 Data Summary . . . . . . . . . . . . . 8 80

3.4 Workup Trading Volume and Market Quality . . . . . . . . . . 80

3.4.1 Impact on Informational Efficiency . . . . . . . . . . 81 
3.4.2 Impact on Liquidity Supply and Market Liquidity . . . . . . . . 82

3.5 Robustness Tests . . . . . . . . . . . . . . . . . . 84

3.5.1 Workup Trading Frequency and Market Quality . . . . . . . . . 84

3.5.2 Workup Trading Impact around the 8:30 ET Announcements . . 86

3.5.3 Another Market Liquidity Measure . . . . . . . . . . . . . 87

3.6 Conclusion . . . . . . . . . . . . . . . . 88

3.7 Figures and Tables . . . . . . . . . . . . . . . . . 89

4 Belief Heterogeneity, Market Liquidity, and Order Submission Strategies in the U.S. Treasury Market 105

4.1 Introduction . . . . . . . . . . . . . . . . . . 105

4.2 Data and Variables Construction . . . . . . . . . . . . . 110

4.2.1 BrokerTec U.S. Treasury Data . . . . . . . . . . . . . . 110

4.2.2 Bloomberg News Announcements and Economists Forecasts . . 111

4.2.3 Variables Construction . . . . . . . . . . . . . 113

4.3 Order Submissions Strategies . . . . . . . . . . . . . . 118

4.3.1 A Multivariate Analysis of Order Aggressiveness . . . . . . . . 119

4.3.2 Impact of Information Shocks . . . . . . . . . . . . . 123

4.3.3 Order Choice . . . . . . . . . . . . . . . . 125

4.3.4 Limit Order Aggressiveness . . . . . . . . . . . . . . . . 127

4.4 Conclusion ........................... 129

4.5 Figures and Tables . . . . . . . . . . . . . . . . . . . 129

5 Summary 151

5.1 Research Questions . . . . . . . . . . . . . . . . . 151

5.2 Findings and Contributions . . . . . . . . . . . . . 151

5.2.1 Macroeconomic News Announcements and Market Efficiency . 152

5.2.2 Workup and Market Quality . . . . . . . . . . . . 155

5.2.3 Belief Heterogeneity, Market Liquidity, and Order Submission

Strategies ....................... 156 
X

Bibliography

159 


\section{List of Tables}

1.1 The Average Daily Trading Volume of U.S. Treasury Securities . . . . . 7

2.1 Definitions of the 15 Types of Major Announcements . . . . . . . . . 45

2.2 Summary Statistics of the Major Macroeconomic Announcements . . . 46

2.3 Variance-Ratio Market Inefficiency Measures . . . . . . . . . . . . . . 47

2.4 Market Liquidity, Information Variables and Changes in Market Efficiency around $8: 25 \mathrm{ET} \ldots \ldots . . \ldots 48$

2.5 Difference-in-Difference Regressions . . . . . . . . . . . . . . . . . . 49

2.6 News Impact by Using the Variance-Ratio Market Inefficiency Measures calculated from Mid-Quotes Directly . . . . . . . . . . . . 50

2.7 Sub-period Analysis . . . . . . . . . . . . . . . . . 51

2.8 News Impact on the Market Efficiency: Good News vs. Bad News . . . 52

2.9 News Impact by Using the Three Best Quotes in the Bid and the Ask Side to Construct Market Inefficiency Measure . . . . . . . . . . . . 53

2.10 Impacts of Macroeconomic News Released at 10:00 ET . . . . . . . . . 54

2.11 One Alternative Market Inefficiency Measure: Absolute Value of Return Autocorrelation . . . . . . . . . . . . . . 55

2.12 Percentages of Negative First-order Return Autocorrelation . . . . . . . 56

2.13 Market Order Flow Imbalances and Return Predictability . . . . . . . . 57

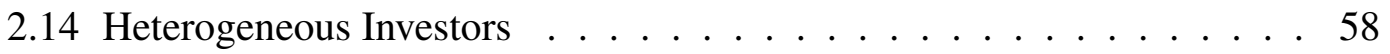

2.15 Change Regressions . . . . . . . . . . . . . . . . . 59 
3.1 Significant U.S. Macroeconomic News Announcement Events . . . . . 97

3.2 Summary Statisitcs . . . . . . . . . . . . . . . . . . 98

3.3 Regressions of the Impact of Workup Volume Ratio on Informational

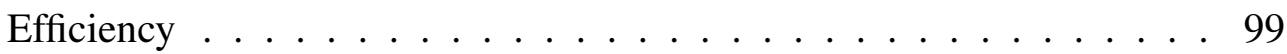

3.4 Impact of Workup Trading Volume on Liquidity Supply and Market Liquidity . . . . . . . . . . . . . . . 100

3.5 Impact of Workup Frequency Ratio on Informational Efficiency . . . 101

3.6 Impact of Workup Trading Frequency on Liquidity Supply and Market Liquidity . . . . . . . . . . . . . . . . 102

3.7 Impact of Workup Trading on the Market Informational Efficiency around $8: 25 \mathrm{ET} \ldots \ldots \ldots \ldots . \ldots \ldots \ldots$

3.8 The Impact of Workup Ratios on Modified Depth Imbalances . . . . . . 104

4.1 Macroeconomic Announcements . . . . . . . . . . . . . . . 136

4.2 Summary Statistics of Belief Heterogeneity and Uncertainty . . . . . . 137

4.3 Summary Statistics of Market Activities . . . . . . . . . . . . . 138

4.4 Mulitvariate Analysis of Order Aggressiveness, Belief Heterogeneity,

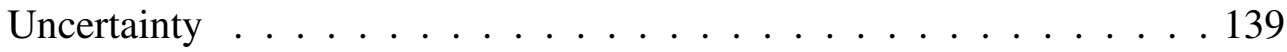

4.5 Mulitvariate Analysis of Order Aggressiveness, Belief Heterogeneity, Uncertainty in Sub-Periods . . . . . . . . . . . . . . . . 140

4.6 Mulitvariate Analysis of Order Aggressiveness, Belief Heterogeneity, Uncertainty During the Post-Announcement Period . . . . . . . . . . . 141

4.7 Mulitvariate Analysis of Order Aggressiveness, Belief Heterogeneity, Uncertainty from 8:30 ET to 8:45 ET . . . . . . . . . . . . . . 142

4.8 Mulitvariate Analysis of Order Aggressiveness, Belief Heterogeneity, Uncertainty from 8:45 ET to 9:00 ET . . . . . . . . . . . . 143

4.9 Mulitvariate Analysis of Order Choice During the Pre-announcement

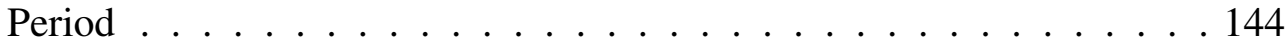


4.10 Mulitvariate Analysis of Order Choice During the Post-announcement

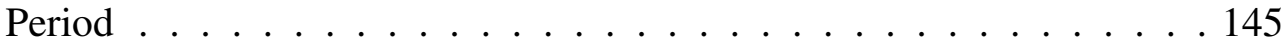

4.11 Mulitvariate Analysis of Order Choice During the Post-announcement Period and Sub-Periods . . . . . . . . . . . . . . . 146

4.12 Mulitvariate Analysis of Limit Order Aggressiveness During the Preannouncement Period . . . . . . . . . . . . . . . . . . 147

4.13 Mulitvariate Analysis of Limit Order Aggressiveness During the Postannouncement Period . . . . . . . . . . . . . . . . . . . 148

4.14 Multivariate Analysis of Limit Order Aggressiveness During the Postannouncement Period and Sub-Periods . . . . . . . . . . . . . . . . . 149 
xiv 


\section{List of Figures}

1.1 Average 1-minute BrokerTec Trading Frequencies of On-the-Run U.S. Treasury Securities . . . . . . . . . . . . . . . 6

2.1 Average Five-Minute Trading Frequency and Trading Volume around $8: 30 \mathrm{ET} \ldots \ldots \ldots \ldots \ldots \ldots \ldots \ldots \ldots$

2.2 The Selection of Announcement Days and Non-announcement Days . . 42

2.3 Impacts of 8:30 ET News Arrivals on Market Efficiency . . . . . . . . 43

2.4 Market Liquidity and Order Flow Imbalance around 8:30 ET . . . . . 44

3.1 The Workup Window . . . . . . . . . . . . . . . . . . 90

3.2 Daily BrokerTec Order Book Activities of On-The-Run U.S. Treasury

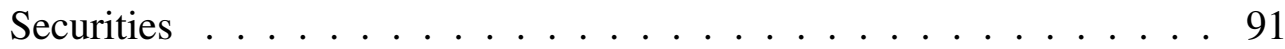

3.3 Intraday BrokerTec Order Book Activities of On-The-Run U.S. Treasury Securities . . . . . . . . . . . . . . . . . . . . 92

3.4 Three Categories of Intraday Intervals. . . . . . . . . . . . . 93

3.5 Intraday BrokerTec Trading Volumes of On-The-Run U.S. Treasury Securities . . . . . . . . . . . . . . . . . . . . . . . 994

3.6 Intraday BrokerTec Workup Volume Ratios of On-The-Run U.S. Treasury Securities by 30 -Minute Intervals . . . . . . . . . . . . . 95

3.7 Illustration on Depth Decompositions at Different Quote-Levels . . . 96

4.1 Order Submission Activities around All Sample News Announcements . 130

4.2 Transactions around All Sample News Announcements . . . . . . . . 131 
4.3 Order Submission Activities around Influencial News Announcements . 132

4.4 Transactions around Influencial News Announcements . . . . . . . . 133

4.5 Order Submission Activities around Non-Influencial News Announce-

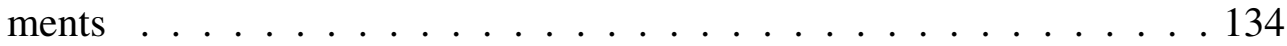

4.6 Transactions around Non-Influencial News Announcements . . . . . . . 135 


\section{Chapter 1}

\section{Preliminaries}

\subsection{U.S. Treasury Market}

The U.S. Treasury market is one of the largest and most liquid financial markets in the world. According to the statistics from the Securities Industry and Financial Markets Association (SIFMA), by 31 October 2019, the average daily trading volume of the U.S. Treasury market ${ }^{1}$ in 2019 is 603.90 billion U.S. dollars, which accounts for about $66.42 \%$ of the total average daily trading volume of U.S. bond markets. ${ }^{2}$ The average daily trading volume of the U.S. Treasury is 279.40 billion U.S. dollars more than that of the U.S. stock market. In the second quarter of 2019, the total amount of U.S. Treasury securities held by investors is $18,002.70$ billion U.S. dollars. The foreign and international investors (37.59\%), pension funds and retirement funds (14.47\%), monetary authority (12.86\%), mutual funds, money market funds, closed-end funds and exchange-traded funds (11.70\%), and households and nonprofit organizations (11.20\%) hold 90 percent of U.S. Treasury securities.

\footnotetext{
${ }^{1}$ Primary dealer activity.

${ }^{2}$ The U.S. bond markets include the markets of municipal securities, Treasury securities, mortgagebacked securities, asset-backed securities, corporate debt, and Federal agency securities.
} 


\subsubsection{U.S. Treasury Auctions}

The U.S. federal government issues new U.S. Treasury securities to the public at the Treasury auctions. Auctions schedules and results of U.S. Treasury securities are available to the public on the website of TreasuryDirect. Individuals and institutional investors can participate in the auctions to purchase U.S. Treasury securities on TreasuryDirect accounts and Treasury Automated Auction Processing System (TAAPS), respectively. They can submit either a competitive bid or a non-competitive bid at the auctions. $^{3}$

\subsubsection{Secondary U.S. Treasury Market}

Investors can buy or sell the securities in the secondary U.S. Treasury market without the necessity to hold until maturities. Since the early 2000s, with the introduction of two main electronic communication platforms - eSpeed and BrokerTec, the trading activities have begun to migrate from broking operations (recorded in GovPX data sets) to electronic trading networks.

On the secondary market of U.S. Treasury securities, transactions occur between dealers and clients, dealers and dealers, dealers and principal trading firms, and principal trading firms and principal trading firms. Based on Trade Reporting and Compliance Engine (TRACE) data from August 1, 2017 to July 31, 2018, the average daily trading volume by interdealer brokers accounts for roughly $50 \%$ of the daily average Treasury trading volume, and about $70 \%$ of which occurs on electronic and automated platforms. $^{4}$

The trading of U.S. Treasury securities on ECNs takes place twenty-two hours a day on workdays, except for a few close or early close days due to U.S. national holidays. Based on Eastern Time (ET), there is no trading between 17:30 ET and 19:30

\footnotetext{
${ }^{3}$ TreasuryDirect. How Treasury Actions Work. Retrieved from https://www. treasurydirect. gov/instit/auctfund/work/work.htm.

${ }^{4}$ Source: Board of Governors of the Federal Reserve System (September 28, 2018).Unlocking the Treasury Market through TRACE. Retrieved from https://www.federalreserve.gov/econres/ notes/feds-notes/unlocking-the-treasury-market-through-trace-20180928.htm.
} 
ET (Fleming, 1997) - trading in New York area ends at 17:30 ET, and trading in Tokyo area starts from 19:30 ET.

\subsubsection{BrokerTec U.S. Treasury Historical Data}

BrokerTec trading platform of the 2-, 3-, 5-, 7-, 10-, 30-year on-the-run U.S. Treasury securities is an anonymous trading platform for institutional investors. ${ }^{5}$ The BrokerTec order books contain tick-by-tick information of the on-the-run U.S. Treasury securities, including the time stamp, transaction side, price and quantity information, for each of the order submitted, altered or canceled. The bid or ask quotes, and transaction prices are recorded in 256th's for Treasury activities. For 2-, 3- and 5-year U.S. Treasury notes, the minimum price change is $\frac{2}{256}$ of $1 \%$ of par. For $7-, 10-$ and 30year U.S. Treasury notes or bonds, the minimum price change is $\frac{4}{256}$ of $1 \%$ of par. In the case of a transaction, an aggressor indicator indicates whether the deal is buyer- or seller-initiated. The minimum time unit of BrokerTec is one millisecond.

I have the access to BrokerTec historical order books of on-the-run U.S. Treasury securities as follows. The data of 2-, 5- and 10-year notes include all trading days from 2004 to 2015. The data of 3-, 7- and 30-year notes or bonds include all trading days from 2011 to 2015 . I calculate the average daily trading volume of the on-the-run U.S. Treasury securities in Table 1.1.

\section{[Place Table 1.1 about here]}

Panel A of Table 1.1 shows that the BrokerTec on-the-run U.S. Treasury securities trading volume accounts for about $26 \%$ of the U.S. Treasury primary deal activity (about 525.6 billion U.S. dollars per day) over the five years from 2011 to 2015. Panel B shows the average daily trading volume from 2011 to 2015 by month. The average total daily trading volumes of the on-the-run U.S. Treasury securities traded on

\footnotetext{
${ }^{5}$ BrokerTec is an anonymous, wholesale trading platform for dealers, banks, HFT firms, proprietary trading firms, and hedge funds. Source: CME Group. Frequently Asked Questions: BrokerTec U.S. Treasury Historical Data. Retrieved from https : //www . cmegroup . com/market-data/ brokertec-us-treasury/faq-brokertec-us-treasury-data.html\#about
} 
BrokerTec in December, November, and April are the lower than the other months. It might be due to U.S. national holidays, such as Christmas and New Year holidays, U.S. Thanksgiving Day, and Good Friday and Easter Monday.

Figure 1.1 plots the average 1-minute trading frequencies of the 2-, 3-, 5-, 7-, $10-$ and 30-year on-the-run U.S. Treasury securities by using all trading days between January 1, 2011, and December 31, 2015. The New York trading hours are from 7:30 ET to 17:30 ET. We can directly observe that the trading frequencies during New York trading hours are higher than the other trading hours. The average 1-minute trading frequencies of the 10-year U.S. Treasury notes are the highest, followed by the 5-year U.S. Treasury notes and the 30-year U.S. Treasury bonds. Besides, we can also observe that the trading frequencies increase sharply around the scheduled U.S. macroeconomic news announcement times.

\section{[Place Figure 1.1 about here]}

\subsection{Thesis Outline}

I investigate several interesting research questions on the U.S. Treasury market by using BrokerTec order books of the on-the-run U.S. Treasury securities. The rest of this thesis is organized as follows.

In Chapter 2, I investigate the impact of scheduled U.S. macroeconomic news announcements on the U.S. market efficiency by using 5-, 10- and 15-minute intervals around the announcements from 2004 to 2015. I employ a robust method to control the microstructure noise (Aït-Sahalia and Yu, 2009), and estimate market inefficiency measures. The results suggest that the U.S. Treasury market efficiency decreases significantly starting from five minutes before news arrivals. I find evidence that belief heterogeneity could explain the phenomenon.

In Chapter 3, I study the impact of workup trading on market quality by using all available 2-, 3-, 5-, 7-, 10- and 30-year U.S. Treasury securities BrokerTec order books between 7:30 ET and 17:30 ET. I construct market inefficiency measures by adopting 
the method I use in Chapter 2 to control market microstructure noise. I also use a linear time trend model to estimate the detrended workup ratio (Rapach, Ringgenberg, and Zhou, 2016). I find the workup trading activities decrease market quality, which is different from the literature on equity markets (Foley and Putniņš, 2016).

In Chapter 4, I examine whether the market information environment could influence the investors' order submission behaviors and their investment decisions by using the 5-year U.S. Treasury notes from 2011 to 2015. Following Barron, Kim, Lim, and Stevens (1998), I construct the market uncertainty and belief heterogeneity measures. I investigate how market uncertainty and belief heterogeneity affect the traders' order aggressiveness. I also examine the impact of the market information environment on order aggressiveness by market orders and limit orders separately. I find that the market information environment affects traders' order submission strategies significantly.

\subsection{Figures and Tables}




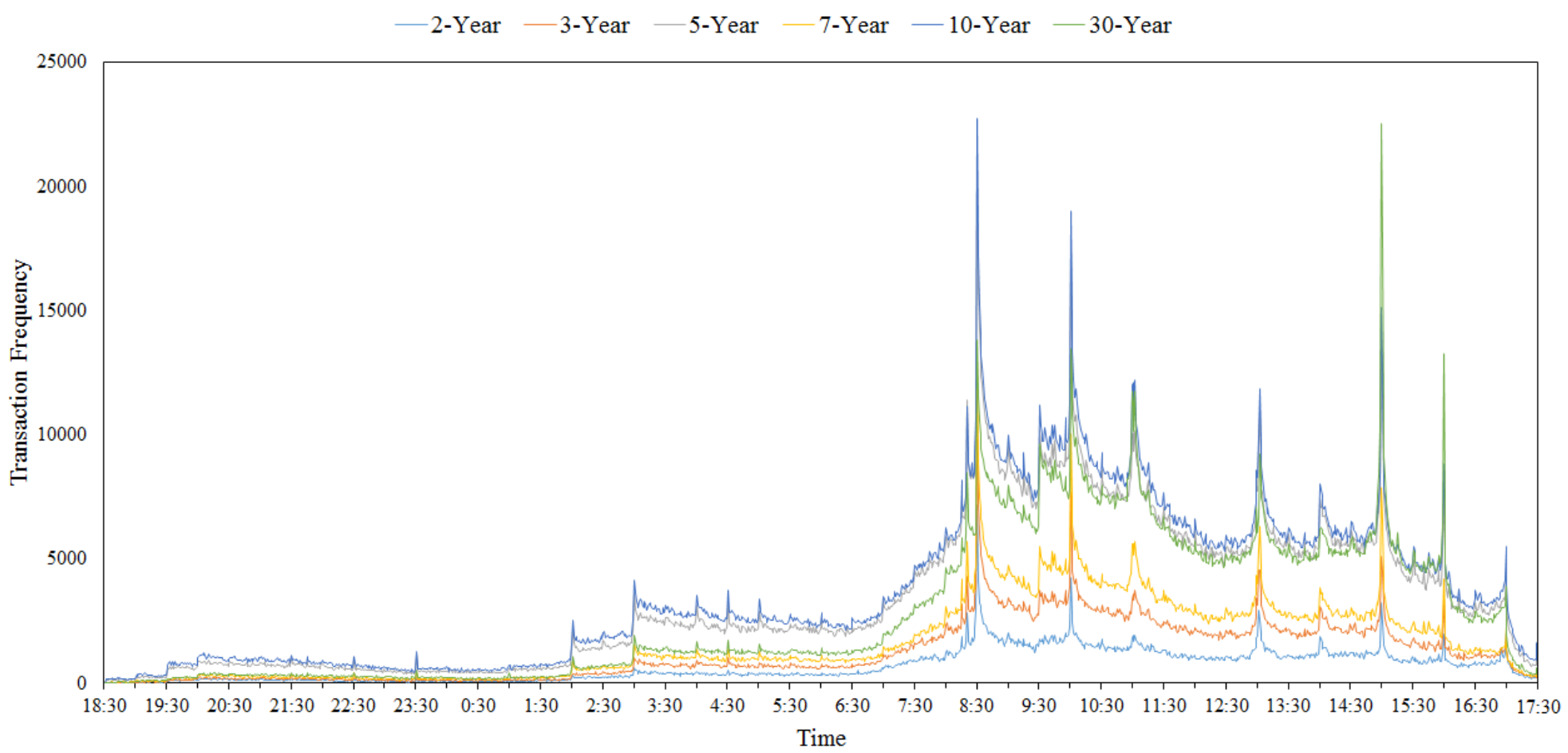

Figure 1.1: Average 1-minute BrokerTec Trading Frequencies of On-The-Run U.S. Treasury Securities. This figure plots the average 1-minute trading frequencies of the 2-, 3-, 5-, 7-, 10- and 30-year on-the-run U.S. Treasury securities by using all trading days between January 1, 2011, and December 31, 2015. The New York trading hours are from 7:30 ET to 17:30 ET. 
Table 1.1: The Average Daily Trading Volume of U.S. Treasury Securities

\begin{tabular}{|c|c|c|c|c|c|c|c|c|c|}
\hline \multicolumn{10}{|c|}{ Panel A: Average Daily Trading Volume by Year } \\
\hline \multirow{2}{*}{ Year } & \multirow{2}{*}{$\begin{array}{l}\text { Primary Dealer Activity } \\
\text { (Source: SIFMA) }\end{array}$} & \multicolumn{7}{|c|}{ BrokerTec on-the-run U.S. Treasury Securities } & \multirow{2}{*}{ Percentage } \\
\hline & & 2-year & 3-year & 5-year & 7-year & 10-year & 30-year & Total & \\
\hline 2004 & 497.8 & 18.3 & & 16.3 & & 13.1 & & 47.7 & \\
\hline 2005 & 549.0 & 27.2 & & 23.4 & & 22.1 & & 72.7 & \\
\hline 2006 & 509.6 & 31.1 & & 28.7 & & 26.6 & & 86.3 & \\
\hline 2007 & 566.0 & 44.2 & & 38.1 & & 31.9 & & 114.2 & \\
\hline 2008 & 557.5 & 47.8 & & 40.3 & & 31.1 & & 119.3 & \\
\hline 2009 & 411.1 & 25.6 & & 24.6 & & 23.1 & & 73.3 & \\
\hline 2010 & 523.9 & 28.2 & & 34.5 & & 31.5 & & 94.2 & \\
\hline 2011 & 567.8 & 24.6 & 17.7 & 38.0 & 10.2 & 31.5 & 6.1 & 128.0 & $22.54 \%$ \\
\hline 2012 & 520.3 & 11.6 & 13.3 & 30.4 & 11.8 & 31.5 & 6.8 & 105.4 & $20.25 \%$ \\
\hline 2013 & 545.4 & 12.8 & 16.3 & 43.9 & 10.6 & 42.1 & 9.9 & 135.5 & $24.85 \%$ \\
\hline 2014 & 504.2 & 17.8 & 21.1 & 48.0 & 15.3 & 40.2 & 9.9 & 152.3 & $30.21 \%$ \\
\hline 2015 & 490.1 & 21.4 & 21.8 & 47.2 & 13.4 & 39.0 & 10.6 & 153.3 & $31.29 \%$ \\
\hline \multicolumn{10}{|c|}{ Panel B: Average Daily Trading Volume by Month (2011 - 2015) } \\
\hline \multirow{2}{*}{ Month } & \multirow{2}{*}{$\begin{array}{l}\text { Primary Dealer Activity } \\
\text { (Source: SIFMA) }\end{array}$} & \multicolumn{7}{|c|}{ BrokerTec on-the-run U.S. Treasury Securities } & \multirow{2}{*}{ Percentage } \\
\hline & & 2-year & 3-year & 5-year & 7-year & 10-year & 30-year & Total & \\
\hline Jan & 509.2 & 18.7 & 19.2 & 43.6 & 13.9 & 38.1 & 8.4 & 141.8 & $27.86 \%$ \\
\hline $\mathrm{Feb}$ & 586.9 & 20.7 & 20.0 & 43.3 & 14.1 & 38.0 & 9.1 & 145.2 & $24.73 \%$ \\
\hline Mar & 557.9 & 21.5 & 20.4 & 43.2 & 13.0 & 37.0 & 8.4 & 143.5 & $25.72 \%$ \\
\hline Apr & 490.8 & 16.4 & 16.3 & 37.8 & 11.9 & 33.4 & 8.0 & 123.9 & $25.24 \%$ \\
\hline May & 532.6 & 17.5 & 18.7 & 45.5 & 14.9 & 41.6 & 9.4 & 147.7 & $27.73 \%$ \\
\hline Jun & 562.5 & 21.2 & 19.9 & 47.5 & 15.1 & 42.9 & 9.8 & 156.5 & $27.82 \%$ \\
\hline Jul & 491.4 & 17.0 & 16.7 & 38.0 & 11.7 & 34.5 & 7.9 & 125.8 & $25.60 \%$ \\
\hline Aug & 526.0 & 17.9 & 17.7 & 41.0 & 10.5 & 37.2 & 8.6 & 132.9 & $25.27 \%$ \\
\hline Sep & 549.4 & 17.7 & 17.7 & 42.9 & 10.8 & 37.7 & 9.4 & 136.2 & $24.79 \%$ \\
\hline Oct & 514.8 & 16.4 & 18.9 & 43.2 & 10.9 & 38.3 & 8.9 & 136.6 & $26.54 \%$ \\
\hline Nov & 521.3 & 13.2 & 16.2 & 37.9 & 9.3 & 33.9 & 8.4 & 118.9 & $22.80 \%$ \\
\hline Dec & 467.4 & 13.4 & 14.9 & 34.0 & 10.8 & 29.3 & 7.6 & 110.1 & $23.55 \%$ \\
\hline
\end{tabular}

This table reports the summary statistics of average daily trading volume (in billion U.S. dollars) of the U.S. Treasury securities in our sample period. The numbers of average daily trading volume of U.S. Treasury primary dealer activity are from the SIFMA website. We calculate the BrokerTec average daily trading volume by using the BrokerTec order books of on-the-run U.S. Treasury securities. Panel A presents the results by year from 2004 to 2015. Panel B presents the results by month from 2011 to 2015 . 
Chapter 1 


\section{Chapter 2}

\section{Macroeconomic News Announcements and Market Efficiency: Evidence from the U.S. Treasury Market}

\subsection{Introduction}

How the market price adjusts to new information is a crucial research question in finance. Many papers use intraday data to study the public news impact on financial markets. See, for example, Barclay and Litzenberger (1988), Ederington and Lee (1993), Lee, Mucklow, and Ready (1993), Ederington and Lee (1995), Andersen and Bollerslev (1998), Balduzzi, Elton, and Green (2001), Huang, Cai, and Wang (2002), Green (2004), Evans and Lyons (2008), Chen and Ghysels (2011), Boudt and Petitjean (2014), Bradley, Clarke, Lee, and Ornthanalai (2014), Lucca and Moench (2015), Balduzzi and Moneta (2017), and Fleming, Mizrach, and Nguyen (2018). Compared with daily data, intraday data makes it possible to study how market prices react to the arrivals of public information around announcement times, with the improved time accuracy and precision (Rigobon and Sack, 2008).

Meanwhile, literature also documents that high-frequency observable prices contain market microstructure noise, which might affect the calculation of market efficiency measures (Aït-Sahalia, Mykland, and Zhang, 2005; Bandi and Russell, 2006; Griffin, 
Kelly, and Nardari, 2010; Chen and Ghysels, 2011; Han and Lesmond, 2011). These findings suggest it is also essential to control for microstructure noise when using highfrequency data.

In this paper, we employ a robust method to control the microstructure noise and extract variables from an intraday dataset to investigate the impact of scheduled macroeconomic news announcements on the U.S. Treasury market efficiency. The U.S. Treasury market is one of the largest and most liquid financial markets in the world. ${ }^{1}$ Study on how prices respond to new information on the U.S. Treasury market is not only of interest to academics but also to practitioners and regulators. For example, market participants look for opportunities to take advantage of new information and gain extra profits. Regulators of financial markets aim to improve the efficiency and effectiveness of the markets.

Regarding the news impact on the U.S. Treasury market, most of the studies construct the market inefficiency or price impact variables directly from transaction prices or bid and ask quotes that are affected by microstructure noise. ${ }^{2}$ For example, Ederington and Lee (1995) use 10-second return volatility extracted from the U.S. Treasury bonds futures order books from November 1988 to October 1992 to investigate how prices adjust to the macroeconomic announcements. They also estimate serial autocorrelations by using second-level returns, and find that market prices adjust to macroeconomic news within 10 seconds after news releases and finish within 40 seconds. Green (2004) study the impact of the macroeconomic announcements at 8:30 Eastern Time (ET) by using the transaction data of the on-the-run five-year U.S. Treasury notes in the GovPX database from July 1991 to September 1995. He finds that the informational

\footnotetext{
${ }^{1}$ According to the statistics from the Securities Industry and Financial Markets Association (SIFMA), the average daily trading volume of the U.S. Treasury market in April 2019 is 551.6 billion US dollars, which accounts for $64.40 \%$ of the average daily trading volume of the U.S. fixed income markets. Source: SIFMA (May 2, 2019). US Bond Market Trading Volume. Retrieved from https: //www . sifma.org/ resources/research/us-bond-market-trading-volume/

${ }^{2}$ See, for example, Ederington and Lee (1993), Ederington and Lee (1995), Fleming (1997), Jones, Lamont, and Lumsdaine (1998), Fleming and Remolona (1999), Balduzzi et al. (2001), Huang et al. (2002), Green (2004), Pasquariello and Vega (2007), Brenner, Pasquariello, and Subrahmanyam (2009), He, Lin, Wang, and Wu (2009), Jiang, Lo, and Verdelhan (2011), Lucca and Moench (2015), and Fleming et al. (2018).
} 
role of trading is stronger within fifteen minutes after news announcements. Fleming et al. (2018) use tick data of the BrokerTec order books from 2010 to 2011 to study the trading activity and market liquidity of the on-the-run U.S. Treasury market. Alongside that they find the market microstructure changes substantially after the migration from voice-assisted brokers to two electronic trading networks in the early 2000s, they also find that the price impact of the major macroeconomic announcements in the 60 -minute interval after news arrivals is significantly stronger than it in the 60-minute interval before news arrivals.

To control the microstructure noise, we introduce a robust two-step measure to estimate the variances of true market returns. First, we use the mid-quotes rather than transaction prices. Several papers use mid-quotes to minimize the influence of market microstructure noise (Chen and Ghysels, 2011; Han and Lesmond, 2011). ${ }^{3}$ Second, we follow Aït-Sahalia and Yu (2009) and adopt the generalized method of moments (GMM) (Madhavan, Richardson, and Roomans, 1997) to estimate the variances of the unobservable true returns.

In our empirical analysis, we focus on the scheduled announcements made at 8:30 ET. We use a large sample from 2004 to 2015 and document several findings. First, we estimate the variance-ratio market inefficiency measures, $V R$, in the twelve fiveminute intervals from 8:00:00 ET to 8:59:59 ET on each trading day and find that the market inefficiency measures on announcement days become significantly larger than those on non-announcement days starting from five minutes before the 8:30 ET news release time. Thus, we adopt the event study methodology and set the five minutes before news releases as the cut-off point (Balduzzi et al., 2001; Rigobon and Sack, 2008). More specifically, in the primary analysis, we study the 8:30 ET news impact by setting 8:25 ET as the cut-off point. In the robust check, we set 9:55 ET as the cut-off point when analyzing the 10:00 ET news impact.

Second, we estimate the variance-ratio market inefficiency measures in five-, ten-

\footnotetext{
${ }^{3}$ Mid-quotes can reflect the supply and demand information of the market faster than transaction prices since the submission of the orders is more frequent than transactions.
} 
and fifteen-minute intervals around 8:25 ET. We find that the differences in change of $V R$ around 8:25 ET between announcement days and non-announcement days are significant in the three intervals. We then estimate three difference-in-difference (DID) regression models and control the impact of market liquidity and information asymmetries on market efficiency. We find that after controlling the impact of other factors, the news impact on decreasing market efficiency is significant in the five-minute interval around 8:25 ET. Our robustness test by using 10:00 ET announcements shows the same results that the news impact on decreasing market efficiency is significant in the five-minute interval before the news releases.

Third, we compare our results with those calculated from mid-quotes directly. The results show that market microstructure noise influences our empirical results. Our robust method effectively reduces the impact of microstructure noise on the calculation of market inefficiency measures.

Last, we study two possible reasons of decreased market efficiency before the scheduled news announcements. We first examine the informed trading hypothesis by investigating whether the predictive power of order imbalance on the returns is different between announcement and non-announcement days. We find no evidence of any advanced information on the scheduled news. Using high-frequency volatility as a measure of investor heterogeneity, we find that high-frequency volatility dramatically increases on announcement days five minutes before the scheduled announcements. Empirical results suggest that the investor heterogeneity explains the decreased market efficiency of the U.S. Treasury market before the scheduled news announcements.

We also run several robustness tests. We test the impact of 10:00 ET macroeconomic news announcements, compare the impact of good news with bad news, examine the influence of the global financial crisis, use more quotes deeper in the order books to control the existence of slow reaction by investors, and adopt an alternative market inefficiency measure. The main results still hold.

Our research contributes to the literature in several ways. We document the importance of controlling for microstructure noise when using high-frequency data and con- 
tribute to the literature about market microstructure. Our finding that the U.S. Treasury market becomes less efficient starting from five minutes before news arrivals brings new insights on how the U.S. Treasury market participants react to scheduled information release. We find that the decrease in market efficiency is due to investor heterogeneity. This finding helps understand the relationship between investors' beliefs and market efficiency.

This paper is organized as follows. In Section 2.2, we introduce the data of the U.S. Treasury notes order books, the U.S. macroeconomic news, and the construction of variables. In Section 2.3, we explain the event study research methodology. We report our empirical results in Section 2.4. Section 2.5 reports the results of several robustness tests. Section 2.6 explains what drives market efficiency change. Finally, Section 2.7 summarizes our main findings and concludes the paper.

\subsection{Data and Variables Construction}

In this section, we explain how we construct the variables based on the U.S. macroeconomic announcements data from Bloomberg and the on-the-run U.S. Treasury notes order books from BrokerTec. Our sample period is from January 5, 2004, to December 15, 2015. To control the impacts of Christmas and New Year holidays, we exclude the days either before January 5 or after December 15 in each year.

\subsubsection{On-the-Run U.S. Treasury Notes: BrokerTec Order Books}

In the early 2000s, the U.S. Treasury secondary market has begun to migrate from voice-assisted brokers to electronic trading platforms. ${ }^{4}$ We obtain the order books of the on-the-run U.S. Treasury notes from BrokerTec, one of the two main electronic

\footnotetext{
${ }^{4}$ The GovPX dataset contains the information on the brokers market, while eSpeed and BrokerTec are two main electronic trading platforms. Mizrach and Neely (2006) compare the trading activities, spreads, and price impacts between GovPX data and eSpeed. Man, Wang, and Wu (2013) examine the contribution to price discovery by electronic and voice-based trading systems in the U.S. Treasury market. Fleming et al. (2018) study the microstructure of BrokerTec by using BrokerTec order books from 2010 to 2011 and explain the evolution of the market in details.
} 
communication networks (ECNs) for the secondary U.S. Treasury market. The BrokerTec order books contain tick-by-tick information of the on-the-run U.S. Treasury securities, including the time stamp, transaction side, price, and quantity information, for each of the order submitted, altered or canceled. The minimum amount of each order is $\$ 1$ million par. In the case of a transaction, an aggressor indicator indicates whether the deal is buyer- or seller-initiated. The minimum time unit of BrokerTec is one millisecond.

In this paper, we investigate the scheduled news impact on the U.S. Treasury market by using two of the most frequently traded on-the-run notes, the 5- and 10-year U.S. Treasury notes. ${ }^{5}$ Our sample contains 2621 trading days, with more than 4 billion observations recorded in the BrokerTec order books. Figure 2.1 shows the average trading volumes and trading frequencies of the 5- and 10-year U.S. Treasury notes from 8:00 ET to 9:00 ET in our sample period. The tick size for the 5-year U.S. Treasury notes is $2 / 256$ of the $1 \%$ of $\$ 1$ million par, which is $\$ 78.1250$. The tick size for the 10 -year U.S. Treasury notes is $4 / 256$ of the $1 \%$ of $\$ 1$ million par, which is $\$ 156.2500$.

\section{[Place Figure 2.1 about here]}

\subsubsection{U.S. Macroeconomic News Announcements}

The U.S. macroeconomic news is one key factor of price fluctuations of the U.S. Treasury market (Ederington and Lee, 1995; Jones et al., 1998; Balduzzi et al., 2001; Green, 2004; Brenner et al., 2009; Fleming et al., 2018). These macroeconomic news contents become available to all market participants at the scheduled times precisely. This feature enables us to capture all the information inflows and to divide the sample data into control and treatment groups accurately.

We collect the news relevance numbers, the actual release contents, and the economist forecasts of the U.S. macroeconomic announcements from Bloomberg. Bloomberg cal-

\footnotetext{
${ }^{5}$ Fleming et al. (2018) and Fleming and Nguyen (2018) also provide a summary of the average trading volume and frequency of the on-the-run U.S. Treasury notes traded on BrokerTec with different maturities.
} 
culates a relevance number for each macroeconomic index, which is a percentile range from 0 to 100, based on the subscription rate among all U.S. news announcement alerts set. A higher relevance number suggests that the type of news has a more significant impact on the U.S. financial markets. In this paper, we select the major announcements released at 8:30 ET as our sample announcements, which are the news with a relevance number larger than 80 (Fleming and Remolona, 1999; Balduzzi et al., 2001; Jiang et al., 2011). These announcements are actively followed and forecasted by economists so that we could construct measures of market uncertainty and dispersion accurately. ${ }^{6}$ Table 2.1 reports the description of the 15 types of macroeconomic news used in our study.

\section{[Place Table 2.1 about here]}

As multiple news could be released at the same time on one trading day, we regard the announcement with the largest relevance number as the effective announcement of that day. ${ }^{7}$ Following Balduzzi et al. (2001), Green (2004), Pasquariello and Vega (2007), Bernile, Hu, and Tang (2016), we calculate the analyst coverage, market uncertainty, and information surprise as follows.

\subsubsection{Analyst Coverage}

The analyst coverage, Analysts $s_{d}$, is the number of economist forecasts made for the announcement event on the day $d$. Each announcement event has one analyst coverage

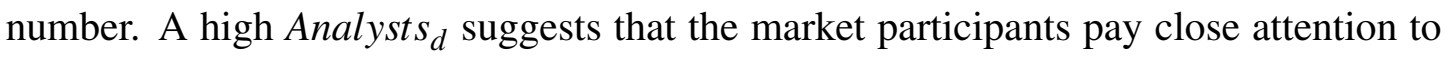
the news announcement event.

\footnotetext{
${ }^{6}$ Among all the major news, the 8:30 ET news has the highest announcement frequency, followed by the 10:00 ET news. The other release times are 7:00, 8:15, 9:15, 9:45, 12:30, 14:00 and 14:15 ET. The main findings of this paper are robust regardless of the news selection. Formal test results are available upon request.

${ }^{7}$ The Personal Income has the same relevance number as Personal Spending. These two indexes are always released at the same time. We use Personal Income because it has a higher level of analyst coverage than Personal Spending.
} 


\subsubsection{Market Uncertainty}

The market uncertainty on day $d$ of each announcement, Uncertainty $y_{d}$, is the standard deviation of all economists' forecasts on day $d$ adjusted by the standard deviation of all the economists' forecasts made for this type of news within the past two years.

$$
\text { Uncertaint }_{d}=\frac{\sigma_{d}^{\text {Forecasts }}}{\sigma_{\text {past }, d}^{\text {Forecsts }}}
$$

where $\sigma_{d}^{\text {Forecasts }}$ is the standard deviation of all the economist forecasts for the announcement, and $\sigma_{\text {past }, d}^{\text {Forecasts }}$ is the standard deviation of all the economists' forecasts in the past two years. Market uncertainty measures the belief dispersion of the market before each scheduled news arrival.

\subsubsection{Information Surprise}

The information surprise on day $d$, Surprise $_{d}$, measures the information shock after the news arrival. Surprise $d$ is the absolute difference between the announcement content and the forecasts median, divided by the forecast errors on day $d$.

$$
\text { Surprise }_{d}=\frac{\mid \text { Release }_{d}-\text { ForecastMedian }_{d} \mid}{{\text { Forecast } S T D_{d}}}
$$

where Release $e_{d}$ is the announcement content, and ForecastMedian ${ }_{d}$ is the median of all the forecasts for that announcement.

Table 2.2 reports the summary statistics of the major announcements in our sample period from January 5, 2004 to December 15, 2015. The fifth to seventh columns report the mean of analyst coverage, market uncertainty, and information surprise of the 15 announcements. The last three columns report the release frequency, announcement schedule, and the total number of announcements used in our analysis.

\section{[Place Table 2.2 about here]}




\subsubsection{Market Inefficiency Measure}

In this part, we explain the construction of the variance-ratio market inefficiency measure after controlling market microstructure noise. We adopt a two-step approach. First, we use mid-quotes rather than transaction prices. Second, we follow Ait-Sahalia and $\mathrm{Yu}(2009)$ to estimate the variances of the unobservable true returns.

We extract snapshots of mid-quotes of the 5- and 10-year U.S. Treasury notes from the order books at the end of each one-second interval (Hasbrouck, 1991; Boehmer and Kelley, 2009). When there are multiple orders within one second, we take the last mid-quote; if there is no order submitted within one second, we use the last available mid-quote before that. The mid-quote is mean value of the best ask quote and the best bid quote.

$$
\text { MidQuote } e_{t}=\frac{A_{t}+B_{t}}{2},
$$

where $A_{t}$ and $B_{t}$ refer to the best ask quote and the best bid quote, respectively. The logarithmic $n$-second mid-quote return at time $t$ is: $R_{n, t}^{M Q}=\ln \left(\right.$ MidQuote $\left._{t}\right)-\ln \left(\right.$ MidQuote $\left._{t-n}\right)$.

To eliminate the impact of market microstructure noise, we adopt the method of Ait-Sahalia and Yu (2009) to estimate the variance of the unobservable true returns. Assume the observed mid-quote includes the unobservable true price and a noise part.

$$
\ln \left(\text { MidQuote }_{t}\right)=\ln \left(P_{t}^{\text {True }}\right)+\varepsilon_{t},
$$

where $P_{t}^{\text {True }}$ is the unobservable true price at time $t$, and $\varepsilon_{t}$ is the microstructure noise which follows i.i.d. $\left(0, a^{2}\right)$. Return of mid-quote follows $R_{t}^{M Q}=R_{t}^{\text {True }}+\varepsilon_{t}-\varepsilon_{t-1} \cdot{ }^{8}$ Assuming the true price follows a random walk process, we have $\operatorname{Var}\left(R_{t}^{M Q}\right)=\operatorname{Var}\left(R_{t}^{\text {True }}\right)+$ $2 a^{2}$, and $\operatorname{Cov}\left(R_{t}^{M Q}, R_{t-1}^{M Q}\right)=-a^{2}$.

We use the generalized method of moments (GMM) (Madhavan et al., 1997) to

\footnotetext{
${ }^{8} \ln \left(\right.$ MidQuote $\left._{t}\right)-\ln \left(\right.$ MidQuot $\left._{t-1}\right)=\left(\ln \left(P_{t}^{\text {True }}\right)+\varepsilon_{t}\right)-\left(\ln \left(P_{t-1}^{\text {True }}\right)+\varepsilon_{t-1}\right)=\left(\ln \left(P_{t}^{\text {True }}\right)-\right.$ $\left.\ln \left(P_{t-1}^{\text {True }}\right)\right)+\varepsilon_{t}-\varepsilon_{t-1}$.
} 
estimate the variances of the true returns, $\widehat{\operatorname{Var}}\left(R_{t}^{\text {True }}\right)$, as follows,

$$
\left\{\begin{array}{l}
E\left[\widehat{\operatorname{Var}}\left(R_{t}^{T r u e}\right)+2 a^{2}-\operatorname{Var}\left(R_{t}^{M Q}\right)\right]=0 \\
E\left[\operatorname{Cov}\left(R_{t}^{M Q}, R_{t-1}^{M Q}\right)+a^{2}\right]=0
\end{array} .\right.
$$

Based on the non-overlapping one-second and five-second returns, the varianceratio market inefficiency measure of interval $j$ on day $d$ is:

$$
V R_{j, d}=\left|\frac{\widehat{\operatorname{Var}}\left(R_{5, j, d}^{T r u e}\right)}{5 \widehat{\operatorname{Var}}\left(R_{1, j, d}^{\text {True }}\right)}-1\right|
$$

where $\widehat{\operatorname{Var}}\left(R_{n, j, d}^{T r u e}\right)$ is the variance of $n$-second true returns of interval $j$ on day $d$. If the true prices follow a random walk, $\frac{\widehat{\operatorname{Var}}\left(R_{5, j, d}^{\text {True }}\right)}{5 \widehat{\operatorname{Var}}\left(R_{1, j, d}^{\text {True }}\right)}$ should be equal to 1 and $V R_{j, d}$ should be equal to zero (Lo and MacKinlay, 1988; Ben-David, Franzoni, and Moussawi, 2018). A larger value of $V R_{j, d}$ indicates that the market is less efficient.

\subsubsection{Market Liquidity and Order Flow Imbalance}

\subsubsection{Spreads}

We measure the quoted spread $\left(s_{j, d}\right)$ and the effective spread $\left(s_{j, d}^{e}\right)$ in basis point (Foley and Putniņš, 2016). A high spread indicates a less liquid market situation. The quoted spread, $s_{j, d}$, is calculated by using all the orders in interval $j$ on day $d$.

$$
s_{j, d}=\frac{1}{N_{j, d}^{L}} \sum_{i \in j} \frac{A_{i, d}-B_{i, d}}{\text { MidQuote }_{i, d}}
$$

where $A_{i, d}$ and $B_{i, d}$ refer to the best ask quote and the best bid quote of the $i$ th limit order on day $d$. MidQuote $e_{i, d}$ is $\frac{A_{i, d}+B_{i d}}{2}$ as Eq. (2.3). $N_{j, d}^{L}$ is the total number of limit orders within the interval $j$ on day $d$.

The effective spread, $s_{j, d}^{e}$, is calculated by using all the transactions in interval $j$ on day $d$.

$$
s_{j, d}^{e}=\frac{1}{N_{j, d}^{T}} \sum_{i \in j} \frac{2 \times \mid P_{i, d}^{\text {Transaction }}-\text { MidQuote }_{i, d} \mid}{\text { MidQuote }_{i, d}},
$$


where $P_{i, d}^{\text {Transaction }}$ is the $i$ th transaction price on day $d . N_{j, d}^{T}$ represents the total number of transactions within the interval $j$ on day $d$.

\subsubsection{Depths and Depth Imbalances}

Market depth is the capacity of a market to maintain the current trading price of a security. If one market has a higher depth on both of the ask and bid sides, the market will have the ability to match a greater number of orders at the same price. If the orders cluster on one side of the order book, the market is less liquid.

Following Jiang et al. (2011) and Fleming et al. (2018), we construct the total depth and the best five quotes depth to measure the market depth. The total depth, Depth $h_{j, d}^{\text {Total }}$, is the average limit order volume across all the price levels in the order book within the interval $j$ on day $d$.

$$
\operatorname{Depth}_{j, d}^{\text {Total }}=\frac{1}{N_{j, d}^{L}} \sum_{i \in j}\left(\operatorname{Depth}_{i, d}^{A}+\operatorname{Depth}_{i, d}^{B}\right)
$$

where $D e p t h_{i, d}^{A}$ and $D e p t h_{i, d}^{B}$ are the total ask-side and bid-side depths of the $i$ th limit order on day $d$. The best five quotes depth, Depth $h_{j, d}^{\text {BestFive }}$, is the mean order volume of the best five prices within the interval $j$ on the day $d$.

$$
\text { Depth }_{j, d}^{\text {BestFive }}=\frac{1}{N_{j, d}^{L}} \sum_{i \in j}\left(\text { Depth }_{i, d}^{\text {BestFive,A }}+\text { Depth }_{i, d}^{\text {BestFive }, B}\right),
$$

where Depth $h_{i, d}^{\text {BestFive,A }}$ and Depth $h_{i, d}^{\text {BestFive,B }}$ are the ask-side depth and the bid-side depth of the best five quotes of the $i$ th limit order on day $d$.

The depth imbalance at (or behind) the best quote of an order is the distance between the depth at (or behind) the best quote from the ask side and the depth at (or behind) the best quote from the bid side. The depth imbalance at (or behind) the best quote in the interval $j$ on day $d, D I_{a t, j, d}$ ( or $D I_{b h d, j, d}$ ), is the mean value of all the depth imbalances at (or behind) the best quote within the interval $j$ on day $d$ (Jiang et al., 2011; Brogaard, 
Hendershott, and Riordan, 2019).

$$
D I_{a t, j, d}=\frac{1}{N_{j, d}^{L}} \sum_{i \in j}\left|D e p t h_{a t, i, d}^{A}-\operatorname{Depth}_{a t, i, d}^{B}\right|,
$$

and

$$
D I_{b h d, j, d}=\frac{1}{N_{j, d}^{L}} \sum_{i \in j}\left|\operatorname{Depth}_{b h d, i, d}^{A}-\operatorname{Depth}_{b h d, i, d}^{B}\right|,
$$

where Depth $h_{a t, i, d}$ and Depth $h_{b h d, i, d}$ are the depth at the best quote and behind the best quote of the $i$ th limit order on day $d$, respectively.

\subsubsection{Order Flow Imbalance}

Order flow imbalance is a proxy for information asymmetry to measure how the market reacts to the arrivals of new information (Lee and Ready, 1991). The order flow imbalance of the $j$ th-interval on the day $d$ is the sum of all order flow imbalances within interval $j$ on the day $d$.

$$
O F I_{j, d}=\sum_{i \in j}\left|O F_{i, d}^{A}-O F_{i, d}^{B}\right|,
$$

where $O F_{i, d}^{A}$ and $O F_{i, d}^{B}$ refer to the volume of the $i$ th market order on day $d$ from the ask side and the bid side, respectively.

\subsection{Event Study}

We define the trading days with our sample news releases as the announcement days (ann). To control for the impact of other major news released around 8:30 ET, we exclude the days with major news announced between 07:30:00 ET to 09:29:59 ET but not at 8:30 ET. The non-announcement days (non) are the trading days without any U.S. macroeconomic news announcements during the time interval from 07:30:00 ET to 09:29:59 ET. Figure 2.2 illustrates how we select the announcement days and non-announcement days among the trading days in our sample period.

[Place Figure 2.2 about here] 
To study when the market efficiency starts to respond to the news announcements, we calculate the variance-ratio market inefficiency measures $(V R)$ for the 12 fiveminute intervals from 8:00:00 ET to 8:59:59 ET. Figure 2.3 plots the mean market inefficiency measures in these 12 intervals. The black and white bars are the mean $V R \mathrm{~s}$ on the announcement and non-announcement days, respectively. Panels A and B plot the results of 5-year and the 10-year notes separately. Both of the panels in Figure 2.3 shows that, on announcement days, the market efficiency starts to decrease sharply in the five-minute interval from 8:25:00 ET to 8:29:59 ET. On the other hand, the mean $V R$ s before 8:25 ET on the announcement and non-announcement days are close to each other. The U.S. Treasury market becomes much less efficient from 8:25 ET on announcement days compared with non-announcement days. In the following analysis, we use 8:25 ET as the cut-off point to study the impact of macroeconomic news announcements on the U.S. Treasury market efficiency.

\section{[Place Figure 2.3 about here]}

The news announcements also affect market liquidity and order flow imbalance. Figure 2.4 shows the mean quoted spread, effective spread, total depth, best five quotes depth, depth imbalance at the best quote, depth imbalance behind the best quote, and order flow imbalance in the 12 five-minute intervals from 8:00:00 ET to 8:59:59 ET during our sample period. The black and white bars represent the announcement days and non-announcement days, respectively. Panel A plots the results of 5-year U.S. Treasury notes, while Panel B shows the results of 10-year U.S. Treasury notes.

\section{[Place Figure 2.4 about here]}

Before 8:25 ET, the mean values of the quoted spread, effective spread, and depth imbalances on the announcement and non-announcement days are similar to each other in Figure 2.4. Their differences start to show up from 8:25 ET onwards. For example, the mean quoted spreads on the announcement and non-announcement days stay at similar levels in the five five-minute intervals from 8:00 ET to 8:25 ET. However, the mean quoted spread on announcement days becomes much larger than that on non- 
announcement days from 8:25 ET. The difference remains for at least ten minutes. The average depth imbalance at the best quote and the average depth imbalance behind the best quote dramatically decline between 8:25 ET and 8:30 ET on announcement days. We also observe a significant increase in the order flow imbalance after 8:30 ET on announcement days.

\subsection{Empirical Results}

\subsubsection{How Do Macroeconomic News Announcements Influence Mar- ket Efficiency?}

Table 2.3 reports the mean $V R$ s of different time-length intervals around 8:25 ET. Panels A, B and C report the results of five-, ten- and fifteen-minute intervals, respectively. We report the results for all days (All), announcement days (ann) and nonannouncement days (non). before and after are the intervals before and after 8:25 ET, respectively. $\Delta_{1}$ represents the average change of $V R$ s around 8:25 ET: after-before. $\Delta_{2}$ represents the average difference of $V R \mathrm{~s}$ in the same interval between announcement days and non-announcement days: ann-non.

\section{[Place Table 2.3 about here]}

Results of all days in Table 2.3 show that the changes in $V R$ s around 8:25 ET are significant for the five-, ten- and fifteen-minute intervals. For example, for the 5-year U.S. Treasury notes, the $\Delta_{1} \mathrm{~s}$ of all days are $0.027,0.018$, and 0.020 , respectively, for the five-, ten- and fifteen-minute intervals. They are all significant at the $1 \%$ level. This result indicates that the market becomes less efficient starting from 8:25 ET, which is five minutes before scheduled news arrivals.

Results in Table 2.3 also show that the significant change in market efficiency around 8:25 ET is due to the arrivals of macroeconomic news. For example, in Panel A of Table 2.3, the $\Delta_{1}$ on announcement days is 0.060 , and significant at $1 \%$ level, whereas the $\Delta_{1}$ on non-announcement days is insignificant. Results of other intervals 
and the 10-year notes are similar. This result indicates that the changes in market efficiency around 8:25 ET happen only on announcement days, and shows the impact of news announcements on decreasing market efficiency.

Results of $\Delta_{2}$ in Table 2.3 suggest that there is no significant difference in market efficiency between announcement and non-announcement days before 8:25 ET. However, the U.S. Treasury market becomes significantly less efficient after 8:25 ET on announcement days, compared with the non-announcement days. These results are consistent with Figure 2.3 that the U.S. Treasury market becomes less efficient five minutes before the announcements.

To formally test whether the change in market inefficiency measure around 8:25 ET is significantly different between announcement days and non-announcement days, we run the difference-in-difference (DID) model. In the DID regression, the announcement and non-announcement days are used as treatment and control groups, respectively. The DID test model is as follows.

\section{Model 1:}

$$
V R_{j, d}=\alpha+\beta_{1} A F T E R_{j, d}+\beta_{2} A N N_{d}+\beta_{3} A F T E R_{j, d} \times A N N_{d}+\varepsilon_{j, d} .
$$

$A F T E R_{j, d}$ and $A N N_{d}$ are dummy variables for after-8:25 intervals and announcement days, respectively. If $j$ refers to an after-8:25 interval, $A F T E R_{j, d}$ equals to 1 ; otherwise, $A F T E R_{j, d}$ equals to 0. If day $d$ is an announcement day, $A N N_{d}$ equals to 1 ; otherwise, $A N N_{d}$ equals to 0 . The coefficient of $A F T E R_{j, d} \times A N N_{d}, \beta_{3}$, is the difference in change of $V R$ around 8:25 ET on the announcement and non-announcement days. We report the results of $\beta_{3}$ in the last row of each panel in Table 2.3.

In Panels $\mathrm{A}, \mathrm{B}$, and $\mathrm{C}$ of Table 2.3 , all $\beta_{3} \mathrm{~s}$ are significantly positive at the $1 \%$ level. The results show that the changes in market efficiency around 8:25 ET on the announcement days are significantly different from those on the non-announcement days and last as long as fifteen minutes after 8:25 ET. The U.S. Treasury market becomes significantly less efficient five minutes before news arrivals on announcement days. 
The decreasing magnitudes of $\beta_{3}$ s also indicate that the significant differences in change of $V R$ might be dominated by the intervals shorter than fifteen minutes around 8:25 ET. For example, the $\beta_{3}$ s of 10 -year notes are $0.108,0.028$ and 0.020 in five-, tenand fifteen-minute intervals around 8:25 ET. The values of $\beta_{3} \mathrm{~s}$ in the ten- and fifteenminute intervals are smaller but still significant. These results show that the strongest impact of the macroeconomic news announcements on the U.S. Treasury market efficiency happens during the five-minute interval between 8:25 ET and 8:30 ET.

The impact of macroeconomic news announcements is also economically significant. For example, in the five-minute interval around 8:25 ET (Panel A of Table 2.3), the difference in change of $V R$ between announcement days and non-announcement days for 5-year notes is 0.069 when Model 1 is used. Comparing this result with the mean $V R$ of all days in the five-minute interval before 8:25 ET in Table 2.3, 0.267, it suggests that macroeconomic news announcements are related to a drop in the market efficiency of about $26 \%(0.069 / 0.267)$.

\subsubsection{Impacts of Market Liquidity, Order Flow Imbalance and In- formation Asymmetry on Market Efficiency}

The arrivals of new information are associated with changes in market liquidity. Literature shows that market liquidity has impacts on market efficiency and activities (Chordia, Roll, and Subrahmanyam, 2008; Boehmer and Kelley, 2009; Joint Staff Report, 2015). In this part, we test the univariate impacts of liquidity variables on market efficiency. We first calculate the change of each liquidity variable in five-, ten- and fifteen-minute intervals around 8:25 ET. For example, the change in quoted spread on day $d$ around 8:25 ET is $\Delta s_{d}=s_{a f t e r, d}-s_{b e f o r e, d}$. We then independently sort the days into quintiles by the change in each variable around 8:25 ET. The high group includes the days that lie on the top $20 \%$, while the low group includes the days that lie on the bottom $20 \%$. To control the impact of news announcements, we analyze announcement days and non-announcement days separately. 
Table 2.4 reports the differences in the change of $V R$ around 8:25 ET between the high group and the low group, sorted by each of the variables listed in the first column. We report the results of five-, ten- and fifteen-minute intervals. Results show that most liquidity variables, except for the change in depth imbalance behind the best quotes $\left(\Delta D I_{b h d, d}\right)$, have impacts on the U.S. Treasury market efficiency on announcement days. For example, when we sort the announcement days by the change in quoted spread $\left(\Delta s_{d}\right)$, the difference in change of $V R$ around 8:25 ET between the high and low groups is 0.125 and significant at the $1 \%$ level for 10 -year Treasury notes in the five-minute interval. The difference is 0.088 , and also significant at the $1 \%$ level when sorted by the change in effective spread $\left(\Delta s_{d}^{e}\right)$. When sorted by the change in depth imbalance at the best quotes $\left(\Delta D I_{a t, d}\right)$, the average difference in change of $V R$ around 8:25 ET between the high and low groups is 0.068 and significant at the $1 \%$ level for 5 -year notes in the fifteen-minute interval. These results suggest that the U.S. Treasury market becomes less efficient when the market is less liquid.

\section{[Place Table 2.4 about here]}

We next study the impact of information asymmetry on market efficiency. Examples of information asymmetry variables include the order flow imbalance (Chordia, Sarkar, and Subrahmanyam, 2005), analyst coverage (Boehmer and Kelley, 2009), market uncertainty (Zhang, 2006), and information surprise (Bernile et al., 2016). ${ }^{9}$ In Table 2.4, when sorted by the analyst coverage $\left(\right.$ Analyst $\left._{d}\right)$, the difference in change of $V R$ around 8:25 ET between the high and low groups is 0.060 and significant at the 5\% level for 5-year notes in the ten-minute interval. These results suggest that the U.S. Treasury market becomes less efficient when the news is more important. In our following regressions, we control these variables to study the impact of macroeconomic news announcements on the U.S. Treasury market efficiency.

\footnotetext{
${ }^{9}$ Analyst $_{d}$, Uncertainty $_{d}$ and Surprise $_{d}$ are only available for the announcement days. Surprise S $_{d}$ is calculated after the release of news at 8:30 ET, so we do not test the impact of information surprise in the five-minute interval around 8:25 ET.
} 


\subsubsection{Controlling the Liquidity and Information Asymmetries}

In this section, we run difference-in-difference (DID) regressions again to test whether the changes in VR around 8:25 ET $\left(\Delta_{1}\right)$ are still significantly different between announcement days and non-announcement days, after controlling the liquidity and information asymmetries. ${ }^{10}$ In the DID regressions, the announcement and non-announcement days are used as treatment and control groups, respectively. We estimate the two regression models as follows:

Model 2:

$$
\begin{aligned}
V R_{j, d}= & \alpha+\beta_{1} \text { AFTER }_{j, d}+\beta_{2} \text { ANN }_{d}+\beta_{3} A F T E R_{j, d} \times A N N_{d}+\beta_{4} s_{j, d}+\beta_{5} s_{j, d}^{e} \\
& +\beta_{6} \text { Depth }_{j, d}^{\text {Total }}+\beta_{7} \text { Depth }_{j, d}^{\text {BestFive }}+\beta_{8} D I_{a t, j, d}+\beta_{9} D I_{b h d, j, d}+\beta_{10} O F I_{j, d}+\varepsilon_{j, d}
\end{aligned}
$$

Model 3:

$$
\begin{aligned}
V R_{j, d}= & \alpha+\beta_{1} A F T E R_{j, d}+\beta_{2} A N N_{d}+\beta_{3} \text { AFTER }_{j, d} \times A N N_{d}+\beta_{4} s_{j, d}+\beta_{5} s_{j, d}^{e} \\
& +\beta_{6} \text { Depth }_{j, d}^{\text {Total }}+\beta_{7} \text { Depth }_{j, d}^{\text {BestFive }}+\beta_{8} \text { DI }_{a t, j, d}+\beta_{9} \text { DI }_{\text {bhd }, j, d}+\beta_{10} \text { OFI I }_{j, d} \\
& +\beta_{11} \text { Rlvc }_{d}+\beta_{12} \text { Analyst }_{d}+\beta_{13} \text { Uncertainty }_{d}+\beta_{14} \text { Surprise }_{d}+\varepsilon_{j, d} .
\end{aligned}
$$

In Model 2, we add the market liquidity variables and the order flow imbalance to control for the impact of limit order book information in the regression, while Model 3 incorporates all variables. The coefficient of $A F T E R_{j, d} \times A N N_{d}, \beta_{3}$, shows the difference in change of $V R$ around 8:25 ET on the announcement and non-announcement days. ${ }^{11}$ Table 2.5 reports the regression results in the five-, ten- and fifteen-minute intervals around 8:25 ET, respectively.

\section{[Place Table 2.5 about here]}

Results of Model 2 in Table 2.5 show that the impact of macroeconomic news an-

\footnotetext{
${ }^{10}$ We winsorize each variable at its 1 st and 99th percentile values to control the impact of outliers.

${ }^{11}$ Since Surprise $_{d}$ can be only calculated after the news releases at 8:30 ET, it is not used in the regression in the five-minute interval around 8:25 ET.
} 
nouncements on market efficiency is robust after controlling limit order book variables in the five-minute interval around 8:25 ET. For example, the $\beta_{3}$ of 5-year notes in the five-minute interval is 0.058 , and significant at the $1 \%$ level. The $\beta_{3}$ s are smaller and insignificant in the ten- and fifteen-minute intervals. In Model 3 of Table 2.5, when controlling for both liquidity and information asymmetries, the impact of the news announcements on the market efficiency continues to be significant in the five-minute interval, and becomes insignificant in the ten- and fifteen-minute intervals.

Consistent with the results of Table 2.4, we also find that liquidity and information variables are significantly related to market efficiency. The U.S. Treasury market tends to be more efficient when the market liquidity is increased. For example, in Model 2 of Panel A, the coefficients of quoted spread, effective spread, depth imbalance at the best quote and order flow imbalance in the five-minute interval are 6.502, 4.546, 4.284 and 1.749 , respectively, for 5-year notes. All of them are significant at the 5\% level or above. The results of 10-year U.S. Treasury notes in Model 3 of Panel A show that

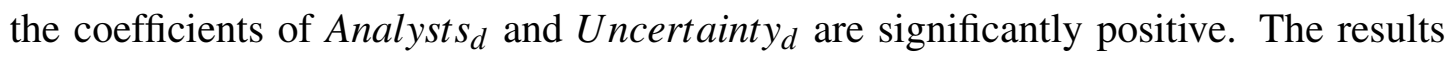
suggest that the news announcements that are closely followed or have greater uncertainties influence the market efficiency more than those that are less closely followed or have lower uncertainty levels. ${ }^{12}$

\subsubsection{The Market Microstructure Noise}

In this part, we investigate whether the market microstructure noise affects our research findings empirically. We construct the variance-ratio market inefficiency measures (Lo and MacKinlay, 1988; Foley and Putninš̌, 2016), $V R_{j, d}^{M Q}$, by using the variances of the logarithmic five-second and one-second mid-quote returns directly.

\footnotetext{
${ }^{12}$ In this paper, we construct the variance-ratio market inefficiency measure using five- and one-second

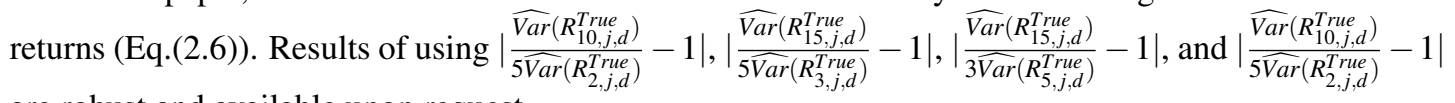
are robust and available upon request.
} 


$$
V R_{j, d}^{M Q}=\left|\frac{\widehat{\operatorname{Var}}\left(R_{5, j, d}^{M Q}\right)}{5 \widehat{\operatorname{Var}}\left(R_{1, j, d}^{M Q}\right)}-1\right|
$$

where $\widehat{\operatorname{Var}}\left(R_{n, j, d}^{M Q}\right)$ refers to the variance of logarithmic $n$-second mid-quote returns.

We re-run the analysis in Section 2.4.1 and Section 2.4.3, and report the results in Table 2.6. The differences between the results using $V R_{j, d}^{M Q}$ and those using $V R_{j, d}$, reflect the influence of market microstructure.

\section{[Place Table 2.6 about here]}

Table 2.6 reports the estimation results of $\beta_{3}$ s in the three DID regressions. We use the same regression equations as Eq. (2.14), Eq. (2.15) and Eq. (2.16), whereas the dependent variables are $V R_{j, d}^{M Q}$. Results document that within five minutes, the differences in change of $V R^{M Q}$ around 8:25 ET on the announcement and non-announcement days, $\beta_{3}$ s, are significantly positive at the $1 \%$ level in Model 1, Model 2 and Model 3. However, they become negative at the ten- and fifteen-minute intervals. These DID regression results are quite different from those in Table 2.5. Results of Table 2.6 show that indeed market microstructure noise affects the calculation of market inefficiency measure.

\subsection{Robustness Tests}

In this section, we run several robustness tests. First, we study the impact of the global financial crisis on our findings. Second, we investigate the difference between good news and bad news. Third, we use more information from the order books to calculate the mid-quotes to account for the slow reactions of investors. Fourth, we test whether our results are robust by using 10:00 ET macroeconomic announcements. Last, we investigate whether our results are robust to the choice of market inefficiency measure. 


\subsubsection{Global Financial Crisis}

Following Dick-Nielsen, Feldhtter, and Lando (2012) and Engle, Fleming, Ghysels, and Nguyen (2012), we define the period from July 1, 2007 to June 30, 2009 as the global financial crisis (GFC) period; the time before GFC from January 5, 2004 to June 30, 2007 as the pre-GFC period; and the time after GFC from July 1, 2009 to December 15, 2015 as the post-GFC period. We run the three regressions (Eq. (2.14) to Eq. (2.16)) in each group, and report the estimation results on the differences in change of VR around 8:25 ET on the announcement and non-announcement days, $\beta_{3} \mathrm{~s}$, for each of the three groups in Table 2.7. Panels A, B, and C report the results of pre-GFC, GFC, and post-GFC periods, respectively.

The coefficients of $\beta_{3}$ are significantly positive in the five-minute interval around 8:25 ET for all three sub-periods. Results are also robust when we control for the impact of market liquidity and information asymmetry variables. Results in Table 2.7 suggest that our findings are robust for different sub-periods.

\section{[Place Table 2.7 about here]}

It is also interesting to note that the impact of macroeconomic news announcements on the U.S. Treasury market efficiency is the strongest during the GFC period. The $\beta_{3} \mathrm{~s}$ of the GFC period in the three models are greater than those of the other two non-GFC periods. For example, when Model 1 (Eq. (2.14)) is used for the five-minute interval of 5-year notes, the $\beta_{3}$ during GFC period is 0.112 , and significant at the $1 \%$ level, while they are only 0.083 and 0.042 , during the pre- and post-GFC periods, respectively. In addition, the news announcements during the GFC period continue to significantly affect the 5-year notes' efficiency during the ten- and fifteen-minute intervals in Model 2 (Eq. (2.15)) and Model 3 (Eq. (2.16)). Nevertheless, they become insignificant during the pre-GFC and post-GFC periods in the ten- and fifteen-minute intervals. This result shows the impact of GFC on the performance of a financial market. The significant news impact on decreasing the market efficiency in the five-minute interval following 8:25 ET is robust across the three sub-periods, whereas the news impact lasts longer 
during the GFC period. ${ }^{13}$

\subsubsection{Good News vs. Bad News}

Is the influence of good news on the U.S. Treasury market efficiency different from that of bad news? To address this question, we follow Brown, Harlow, and Tinic (1988) and divide the announcements into good news and bad news by the market reactions. We calculate the mean one-second return from 8:30:00 ET to 8:34:59 ET on an announcement day and compare it with the mean one-second return of the same period on the non-announcement days in the same month of the same year. If the mean return on an announcement day is higher than the mean return of the non-announcement days in the same month and year, we define this news as a piece of good news; otherwise, we define it as a piece of bad news. Table 2.8 reports the comparison results between the good news impact and the bad news impact.

\section{[Place Table 2.8 about here]}

We first calculate the average changes of $V R$ around 8:25 ET on good-news $\left(\Delta_{1, \text { Good }}\right)$ and bad-news $\left(\Delta_{1, B a d}\right)$ announcement days separately. Panel A of Table 2.8 reports the results. Results show that the U.S. Treasury market becomes less efficient five minutes before the announcement on both good-news and bad-news days. The impact of good news on decreasing market efficiency only lasts for five minutes, whereas the impact of bad news lasts up to fifteen minutes. This result suggests that the market reacts to good and bad news differently. The impact of bad news lasts longer than good news.

We next test formally whether the changes of $V R$ around 8:25 ET on good-news and bad-news announcement days are significantly different. We run the following DID regressions,

\section{Model 1:}

$$
V R_{j, d}=\alpha+\beta_{1} A F T E R_{j, d}+\beta_{2} G O O D_{d}+\beta_{3} A F T E R_{j, d} \times G O O D_{d}+\varepsilon_{j, d} ;
$$

\footnotetext{
${ }^{13}$ Musto, Nini, and Schwarz (2018) find that the liquidity gap is enlarged during the GFC, which also helps explain the mispricing of the US Treasury securities along with fundamental information.
} 
Model 2:

$$
\begin{aligned}
V R_{j, d}= & \alpha+\beta_{1} \text { AFTER }_{j, d}+\beta_{2} \text { GOOD }_{d}+\beta_{3} A F T E R_{j, d} \times G O O D_{d}+\beta_{4} s_{j, d}+\beta_{5} s_{j, d}^{e} \\
& +\beta_{6} \text { Depth }_{j, d}^{\text {Total }}+\beta_{7} \text { Depth }_{j, d}^{\text {BestFive }}+\beta_{8} D I_{a t, j, d}+\beta_{9} D I_{b h d, j, d}+\beta_{10} O F I_{j, d}+\varepsilon_{j, d}
\end{aligned}
$$

\section{Model 3 :}

$$
\begin{aligned}
V R_{j, d}= & \alpha+\beta_{1} \text { AFTER }_{j, d}+\beta_{2} \text { GOOD }_{d}+\beta_{3} \text { AFTER } R_{j, d} \times \text { GOOD }_{d}+\beta_{4} s_{j, d}+\beta_{5} s_{j, d}^{e} \\
& +\beta_{6} \text { Depth }_{j, d}^{\text {Total }}+\beta_{7} \text { Depth }_{j, d}^{\text {BestFive }}+\beta_{8} D I_{a t, j, d}+\beta_{9} D I_{b h d, j, d}+\beta_{10} O F I_{j, d} \\
& +\beta_{11} \text { Rlvc }_{d}+\beta_{12} \text { Analyst }_{d}+\beta_{13} \text { Uncertaint }_{d}+\beta_{14} \text { Surprise }_{d}+\varepsilon_{j, d} .
\end{aligned}
$$

where $G O O D_{d}$ is the dummy variable for good news. If day $d$ is a good-news announcement day, $G O O D_{d}$ equals to 1 ; otherwise, $G O O D_{d}$ equals to 0 . The variable of our interest is $\beta_{3}$, which measures the difference in change of $V R$ around 8:25 ET on good-news and bad-news announcement days.

Panel B of Table 2.8 reports the coefficient estimates of $\beta_{3}$ s. All $\beta_{3}$ s are negative. In the ten-minute interval around 8:25 ET, the $\beta_{3}$ s of 10-year U.S. Treasury notes are negative and significant at the $5 \%$ level in three models. These results suggest that the impact of bad news is stronger than that of good news, and show how the market reacts to good and bad news differently.

\subsubsection{Slow Reaction of Investors}

Literature has also documented that some investors react slowly to an announcement (McQueen, Pinegar, and Thorley, 1996; Hong, Lim, and Stein, 2002; Hirshleiger, Lim, and Teoh, 2009). These slow reactions will make the mid-quote price calculated from the best ask and bid less informative. To address this concern, we calculate the mid-quote by combining more information from the limit order books. Specifically, we use the information from the best three ask and bid quotes to calculate the average ask 
quote $\left(\bar{A}_{t}\right)$ and the average bid quote $\left(\bar{B}_{t}\right)$ at time $t$.

$$
\bar{A}_{t}=\frac{A_{t}+A 2_{t}+A 3_{t}}{3}, \quad \bar{B}_{t}=\frac{B_{t}+B 2_{t}+B 3_{t}}{3}
$$

where $A 2_{t}$ and $A 3_{t}\left(B 2_{t}\right.$ and $\left.B 3_{t}\right)$ are the second and third best ask (bid) quotes, respectively. The mid-quote at time $t$ is calculated as:

$$
\text { MidQuote }_{t}^{R 3}=\frac{\bar{A}_{t}+\bar{B}_{t}}{2}
$$

Then, we use GMM to estimate $\widehat{\operatorname{Var}}\left(R_{n, j, d}^{\operatorname{True}, R 3}\right)$, the variances of unobservable true returns from MidQuote $e_{t}^{R 3}$. The variance-ratio market inefficiency measure by using deeper levels of the order books is calculated as:

$$
V R_{j, d}^{R 3}=\left|\frac{\widehat{\operatorname{Var}}\left(R_{5, j, d}^{\text {True }, R 3}\right)}{\widehat{5 \operatorname{Var}}\left(R_{1, j, d}^{\text {True }, R 3}\right)}-1\right| .
$$

We re-run the DID regression models (Eq. (2.14) to Eq. (2.16)) using this measure and report the coefficient estimates of $\beta_{3}$ s in Table 2.9. ${ }^{14}$

\section{[Place Table 2.9 about here]}

All $\beta_{3}$ s in Table 2.9 are positive and significant at the $1 \%$ level. The results continue to show that the U.S. Treasury market becomes less efficient starting from five minutes before the scheduled release time.

\footnotetext{
${ }^{14} \mathrm{We}$ also use the weighted average of the best three ask and bid quotes in the calculation of midquotes. Similarly, the mid-quote at time $t$ calculated from weighted average bid and ask quotes is:

$\operatorname{MidQuote}_{t}^{R 3 w}=\frac{\bar{A}_{t}^{w}+\bar{B}_{t}^{w}}{2}=\frac{1}{2}\left(\frac{A_{t} \times Q_{t}^{A}+A 2_{t} \times Q_{t}^{A 2}+A 3_{t} \times Q_{t}^{A 3}}{Q_{t}^{A}+Q_{t}^{A 2}+Q_{t}^{A 3}}+\frac{B_{t} \times Q_{t}^{B}+B 2_{t} \times Q_{t}^{B 2}+B 3_{t} \times Q_{t}^{B 3}}{Q_{t}^{B}+Q_{t}^{B 2}+Q_{t}^{B 3}}\right)$, where $Q_{t}^{A}, Q_{t}^{A 2}$ and $Q_{t}^{A 3}\left(Q_{t}^{B}, Q_{t}^{B 2}\right.$ and $\left.Q_{t}^{B 3}\right)$ are the order volumes of the best, second and third best ask (bid) quotes, respectively. Results are similar and available upon request.
} 


\subsubsection{News Selection: The U.S. Macroeconomic News Released at 10:00 ET}

In this section, we re-run our DID regressions using the macroeconomic announcements at 10:00 ET. We select the announcements with relevance numbers larger than 80. Announcement days and non-announcement days are defined by the same rules as Figure 2.2. If more than one piece of news is released at 10:00 ET on the same announcement day, we take the piece of news with the largest relevance number as the effective news of that day. During our sample period, the effective 10:00 ET announcements are: the Institute of Supply Management (ISM) Manufacture Index, the Consumer Confidence Index, the New Home Sales Index, the Existing Home Sales Index, the Factory Orders Index, the Leading Index, the Chicago Purchasing Manager Index, the Wholesale Inventories Index, and the Construction Spending Index. ${ }^{15}$ There are 530 announcement days and 961 non-announcement days in our sample period from January 5, 2004 to December 15, 2015.

Table 2.10 reports the regression results. Similar to the macroeconomic news of 8:30 ET, we use five minutes before the announcement time, 9:55 ET, as the cut-off point to calculate the market efficiency changes around the announcements. For brevity, we only report the results of the DID regression coefficients, $\beta_{3}$ s. When we do not include any controlling variables in the regression (Model 1), the DID coefficients are 0.048 and 0.035 , respectively, for the 5- and 10-year Treasury notes during the fiveminute interval around 9:55 ET. They are significant at the 5\% level or above. These

\footnotetext{
${ }^{15}$ We exclude the University of Michigan Sentiment Index as effective news, due to the early releases of the University of Michigan Index to a certain group of subscribers. "CNBC reported on 12 June 2013 that the University of Michigan provides Thomson Reuters news service with the data early, so that Reuters can release the CSI to select, paying clients at 9:55 ET, five minutes before it releases the data to the general public on its website at 10:00 ET. Besides, Reuters releases the data via highspeed communication channels to select clients two seconds earlier. CNBC revealed that trading activity increases dramatically within milliseconds of 9:54:58 ET. Traders who subscribe to either service can take advantage of the CSI before the university releases it to the public. Former Securities and Exchange Commission Chairman Harvey Pitt opined that this might present a fairness issue and destroy confidence in the market by the public." Source: Wikipedia (2018). University of Michigan Consumer Sentiment Index. Retrieved from https://en.wikipedia.org/wiki/University_of_Michigan_Consumer_ Sentiment_Index. We also run the empirical analysis by including the announcement days with the University of Michigan Index as effective news. The results are similar.
} 
results show that the changes in $V R$ around 9:55 ET during the five-minute interval are significantly greater on the announcement days than those on the non-announcement days. This finding confirms our main results and verifies the impact of macroeconomic news announcements on decreasing the U.S. Treasury market efficiency.

The DID coefficients continue to be significant after we control for the impact of liquidity and information variables (Model 2 and Model 3). They are insignificant for the ten- and fifteen-minute intervals. The impact of macroeconomic news announcements at 10:00 ET on the U.S. Treasury market efficiency is thus robust and lasts for at least five minutes from 9:55:00 ET to 9:59:59 ET.

\section{[Place Table 2.10 about here]}

\subsubsection{One Alternative Market Inefficiency Measure}

The first-order autocorrelation of returns (Madhavan et al., 1997; Boehmer and Kelley, 2009; Foley and Putniņš, 2016) is also widely used to measure market efficiency when using intraday high-frequency data. Similar to the variance-ratio measure, the return autocorrelation measures the return's serial correlation. We use this measure to investigate whether our results are robust to the use of a different market inefficiency measure.

Similar to the variance-ratio measure, we control for the impact of market microstructure noise by using the unobservable efficient returns. We calculate the absolute value of the first-order autocorrelation using two-second returns, $\left|A R_{j, d}\right|$.If the market is efficient with prices fully reflecting all of the information immediately, the true price follows a random walk so that $\left|A R_{j, d}\right|=0$; otherwise, $0<\left|A R_{j, d}\right| \leq 1$.

As a comparison, we also calculate the absolute value of first-order autocorrelation $\left(A R_{j, d}^{M Q}\right)$ using the mid-quote prices directly. Table 2.11 reports the DID regression results in the five-, ten- and fifteen-minute intervals around 8:25 ET using these two measures.

[Place Table 2.11 about here] 
The results reported in Panel A of Table 2.11 confirm our main finding that market efficiency decreases significantly in the five minutes before news arrivals. As a comparison, in Panel B, the first-order return autocorrelation measures calculated directly by using mid-quotes, $A R_{j, d}^{M Q}$, show a reverse pattern in the ten- and fifteen-minute intervals around 8:25 ET, due to the market microstructure noise. This result again shows the importance of controlling for market microstructure noise.

Ederington and Lee (1995) show that market microstructure noise contributes to negative return autocorrelation. Following this, we examine whether our robust method could effectively reduce the microstructure noise and generate a lower percentage of negative return autocorrelation. Table 2.12 reports the percentages of negative $A R$ s and

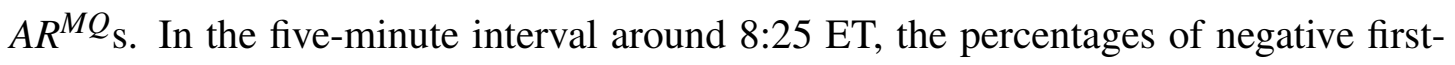
order return autocorrelations for one- and two-second returns are $90.26 \%$ and $90.07 \%$, respectively, when the mid-quotes are used directly. They decrease to $64.37 \%$ and $71.35 \%$, respectively, when the unobservable true prices are used. The results of other periods are similar. The results in Table 2.12 show that our robust method effectively controls the market microstructure noise.

\section{[Place Table 2.12 about here]}

\subsection{What Drives the Early Reaction?}

In this part, we aim to explore what drives the early reaction of the U.S. Treasury market before the scheduled macroeconomic news announcements. Our empirical results show that the scheduled macroeconomic news announcements provide a transitory shock to the market efficiency of the U.S. Treasury market. This shock could be driven by market participants' private information with clustered market orders on one side of the order book, or caused by the investors' different beliefs. 


\subsubsection{Superior Private Information}

If some market participants have superior private information before the news arrivals and trade according to their private information, they tend to submit bid orders before good news and ask orders before bad news. Thus, if the early reaction is driven by those traders with superior private information, we could observe that on announcement days, the marketable order imbalance before news arrivals has predictive power on the returns after news announcement. We follow Kelley and Tetlock (2013) and Hautsch and Horvath (2019) to calculate the market order imbalance in interval $j$ on day $d$,

$$
I M B A L_{j, d}=\frac{\sum_{i \in j} O F_{i, d}^{A}-\sum_{i \in j} O F_{i, d}^{B}}{\sum_{i \in j} O F_{i, d}^{A}+\sum_{i \in j} O F_{i, d}^{B}},
$$

where $\sum_{i \in j} O F_{i, d}^{A}$ and $\sum_{i \in j} O F_{i, d}^{B}$ are the order flows at the ask side and the bid side in interval $j$ on day $d$.

The market participants tend to submit market orders when they are urgent to trade, regardless of bearing the transaction costs. If the Treasury securities holders predict or know that the price will drop after the scheduled news announced, they will try to sell before the news releases. Thus, $\sum_{i \in j} O F_{i, d}^{A}-\sum_{i \in j} O F_{i, d}^{B}>0$, which means that the amount of market sell orders from the ask side is more than the number of market buy orders from the bid side. Similarly, if the market participants predict or know the price will increase, they will submit more market buy orders, that is, $\sum_{i \in j} O F_{i, d}^{A}-$ $\sum_{i \in j} O F_{i, d}^{B}<0$. As a result, $I M B A L_{j, d}$ before the news announcements is negatively related to the market returns after news announcements on announcement days (Chan and Fong, 2000).

We run DID regressions to compare the return predictability using market order imbalance between the announcement days and non-announcement days.

$$
R_{5-\min , d}^{\text {after }}=\alpha+\beta_{1} A N N_{d}+\beta_{2} I M B A L_{\eta, d}^{\text {before }}+\beta_{3} A N N_{d} \times I M B A L_{\eta, d}^{\text {before }}+\varepsilon_{t},
$$

where $R_{5-\min , d}^{a f t e}$ is the 5-minute return after 8:30 ET. $\eta$ refers to the interval length be- 
fore 8:30 ET ( $\eta=5-, 10$ - and 15-minute) that we use to calculate the $I M B A L_{j, d}$. Our variable of interest is $\beta_{3}$, which measures the difference in return predictability using market order imbalance on the announcement and non-announcement days.

Table 2.13 reports the regression results. Panel A reports the results of the whole sample period, while Panel B reports the results of the GFC period. None of $\beta_{3}$ is significantly negative. Thus, we find no evidence that informed trading drives the decrease of market efficiency before the scheduled announcements. The results suggest the sources of investors' private information might be mostly their market observations, individual expectations, and forecasts based on their own experience. All these private information are much likely to be heterogenous, based on which they hold different beliefs on market direction. Thus, Table 2.13 shows that they are not informed - these traders do not have inside information on what exactly the news contents would be. Next, we test whether the heterogeneous information in the market driving the market less efficient starting from the five-minute interval before news arrivals.

\section{[Place Table 2.13 about here]}

\subsubsection{Heterogeneous Information}

In this section, we test whether the investors' heterogeneous expectations on scheduled news content contribute to the early reaction. Xiong and Yan (2009) find that heterogeneous expectations of investors amplify return volatility. Orders submitted by the investors with various beliefs on future price movements directions contribute to the increased market volatility. Thus, we use the return volatility to measure the level of market participants' heterogeneity. We re-run the DID regressions (Eqs. (2.14), (2.15) and (2.16)) by using return volatility as the dependent variable. To control the market microstructure noise, we use the volatility of two-second true returns in the regression,

$$
\text { HFVolatility }_{j, d}=\sqrt{\widehat{\operatorname{Var}}\left(R_{2, j, d}^{\text {True }}\right)}
$$

Table 2.14 reports the coefficient estimates of $\beta_{3}$. Most of the $\beta_{3}$ s are positive 
and significant at the $1 \%$ level. These results suggest that market volatility becomes larger starting from five-minute before news arrivals. For example, according to the results of Model 3, in the five minutes around 8:25 ET, the $\beta_{3}$ s of 5- and 10-year U.S. Treasury notes are 0.102 and 0.112 , respectively. They are both significant at the $1 \%$ level. These results show that market volatility increases significantly from 8:25 ET on announcement days relative to non-announcement days, and support the hypothesis of investor heterogeneity. Our finding is consistent with the literature that, for example, Carlé, Lahav, Neugebauer, and Noussair (2019) shows that belief heterogeneity is a key factor when explaining the market activity.

\section{[Place Table 2.14 about here]}

\subsubsection{Regressing Changes in Variables}

To testify the impact of news announcements on the market efficiency and the influence channel, we introduce the following two regressions. $\Delta$ represents the differences of a variable between the after-8:25 ET interval and the before-8:25 ET interval: $\Delta=$ after-before. ${ }^{16}$

\section{Model 4:}

$$
\Delta y_{d}=\alpha+\beta_{1} A N N_{d}+\varepsilon_{d}
$$

Model 5:

$$
\begin{aligned}
\Delta y_{d}= & \alpha+\beta_{1} A N N_{d}+\left(\beta_{2}+\beta_{3} A N N_{d}\right) \times \Delta s_{d}+\left(\beta_{4}+\beta_{5} A N N_{d}\right) \times \Delta s_{d}^{e} \\
& +\left(\beta_{6}+\beta_{7} A N N_{d}\right) \times \Delta D e p t h_{d}^{\text {Total }}+\left(\beta_{8}+\beta_{9} A N N_{d}\right) \times \Delta D e p t h_{d}^{\text {BestFive }} \\
& +\left(\beta_{10}+\beta_{11} A N N_{d}\right) \times \Delta D I_{a t, d}+\left(\beta_{12}+\beta_{13} A N N_{d}\right) \times \Delta D I_{b h d, d} \\
& +\left(\beta_{14}+\beta_{15} A N N_{d}\right) \times \Delta O F I_{d}+\varepsilon_{d}
\end{aligned}
$$

In Model 4 and Model 5, $y$ is either the variance-ratio market inefficiency measure $(V R)$ or the high-frequency volatility measure (HFVolatility). Both of the literature and our

\footnotetext{
${ }^{16}$ Figure 2.3 and Figure 2.4 show that the market inefficiency, market liquidity and order flow imbalance start to change as response to scheduled 8:30 ET news arrivals from 8:25 ET.
} 
former tables show that the market liquidity also influence the market efficiency that the decreased market liquidity have negative impact on the market efficiency. Model 5 improves Model 4 by introducing the control variables of the change in market liquidity and the change in asymmetric information. We report the coefficient estimates of $A N N$ in Table 2.15. We report the coefficient estimates of $A N N_{d}$ in Table 2.15. The dependent variables in Panel A and Panel B are $\Delta V R_{d}$ and $\Delta H F V_{\text {Volatility }}$, respectively.

In Panel A of Table 2.15, the coefficient estimates of $A N N_{d}$ report the impact of news announcement on the market inefficiency, which is measured by $V R_{a f t e r, d}-$ $V R_{\text {before }, d}$. If the market becomes less efficient, we have $V R_{a f t e r, d}>V R_{b e f o r e, d}$, so that $\Delta V R_{d}>0$. The significantly positive $\beta_{1} \mathrm{~s}$ in Panel A suggest that the scheduled news announcements decrease the U.S. Treasury market efficiency. And the impact is the strongest in the five-minute interval after 8:25 ET among the five-, ten- and fifteenminute intervals. This finding is consistent with our finding in Table 2.5 that the market efficiency decreases starting from five minutes before scheduled news arrivals, and it lasts for at least five minutes from 8:25 ET to 8:30 ET.

In Panel B of Table 2.15, we report the impact of macroeconomic announcements on the change in HFVolatility: HFVolatility ${ }_{a f t e r, d}-H F$ Volatility $_{b e f o r e, d}$. We use HFVolatility to measure the heterogeneous beliefs of investors. If $\Delta H F$ Volatility $_{d}>$ 0 , it means that the investor beliefs on the scheduled news contents become more heterogeneous in the after-8:25 ET interval. For example, in five-minute intervals around 8:25 ET, the $\beta_{1}$ s of 5- and 10-year U.S. Treasury notes are 0.136 and 0.163 , respectively. And they are significant at the $1 \%$ level. The results confirm our finding in Table 2.14 that the scheduled news announcements associated with increased belief heterogeneity decrease the U.S. Treasury market efficiency starting from 8:25 ET onwards.

[Place Table 2.15 about here] 


\subsection{Conclusion}

In this paper, we employ a robust market inefficiency measure to investigate the impact of macroeconomic news announcement on the U.S. Treasury market efficiency. We follow Aiit-Sahalia and Yu (2009) to estimate the unobservable true price using high-frequency data, which is then used to construct the market inefficiency measure. We document a significant impact of news announcements. The U.S. Treasury market becomes less efficient, starting from five minutes before the release time. This impact continues for at least five minutes after controlling market liquidity and information asymmetry. We also show that the market microstructure noise of high-frequency data affects the calculation of market inefficiency measures and our empirical results. We finally investigate what drives decreased market efficiency before the news releases. We find that investor heterogeneity could explain the early reaction.

The findings in this paper provide several interesting implications for future research. First, we show the importance of controlling for microstructure noise in empirical studies using high-frequency data. Second, understanding how the scheduled news affects the U.S. Treasury market efficiency helps to improve the models of the yield curve and to develop strategies for hedging and investment purposes (Fleckenstein, Longstaff, and Lustig, 2014).

\subsection{Figures and Tables}


(A) Trading Frequency

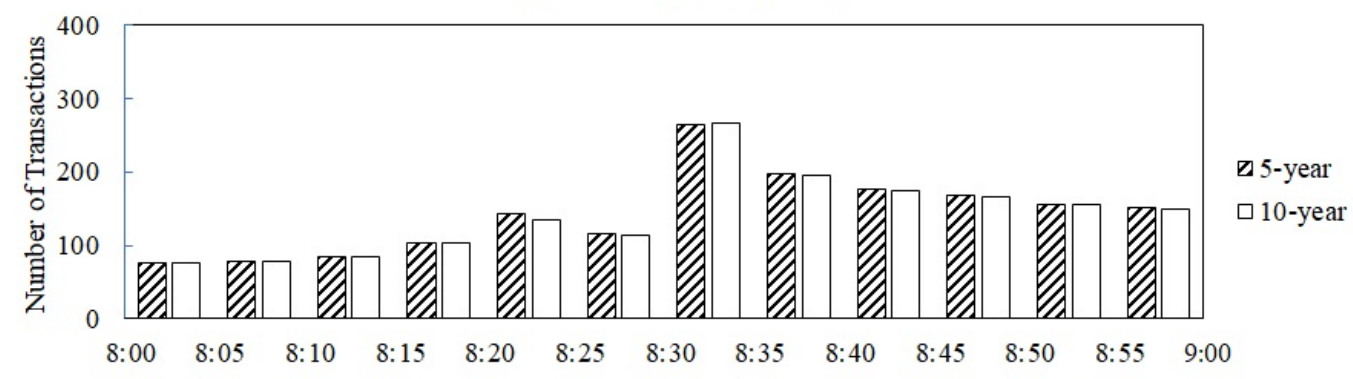

(B) Trading Volume

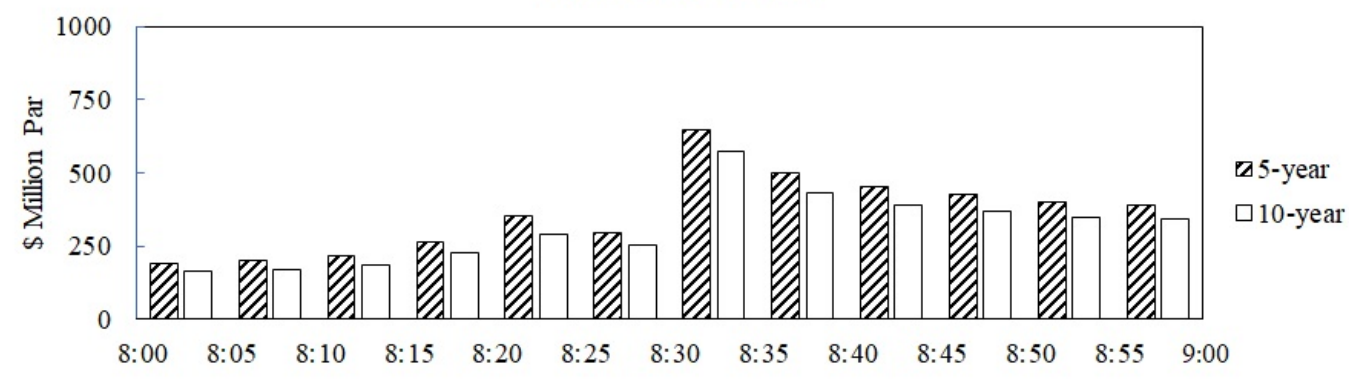

Figure 2.1: Average Five-Minute Trading Frequency and Trading Volume around 8:30 ET. This figure reports the average trading frequency and trading volume in the 12 five-minute intervals from 8:00 ET to 9:00 ET during our sample period from January 5, 2004 to December 15, 2015. The bars filled with striped lines represent the 5-year U.S. Treasury notes. The white bars represent the 10-year U.S. Treasury notes. 
A. Announcement days (ann)

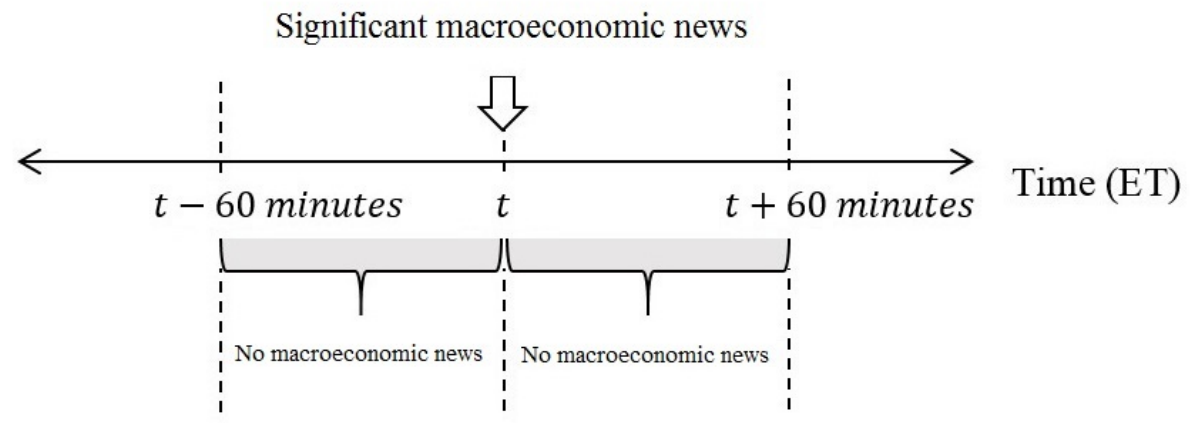

B. Non-announcement days (non)

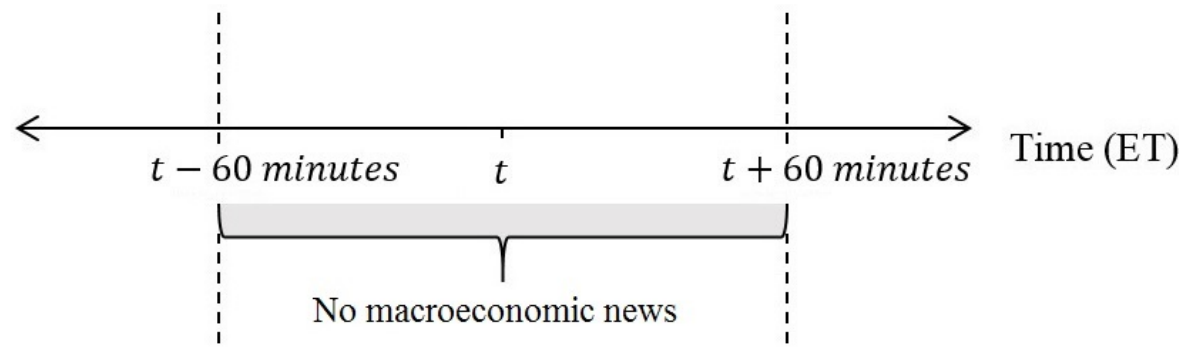

Figure 2.2: The Selection of Announcement Days and Non-announcement Days. This figure illustrates how we define the announcement days and the nonannouncement days, based on the sample U.S. macroeconomic news released at time $t$. Announcement days (ann) are the trading days with at least one announcement event, and there is no other U.S. macroeconomic news announced within the $60 \mathrm{~min}$ utes around $t$. Non-announcement days (non) are the trading days without any news announced in the one-hour intervals around $t$. 
(A) 5-year maturity

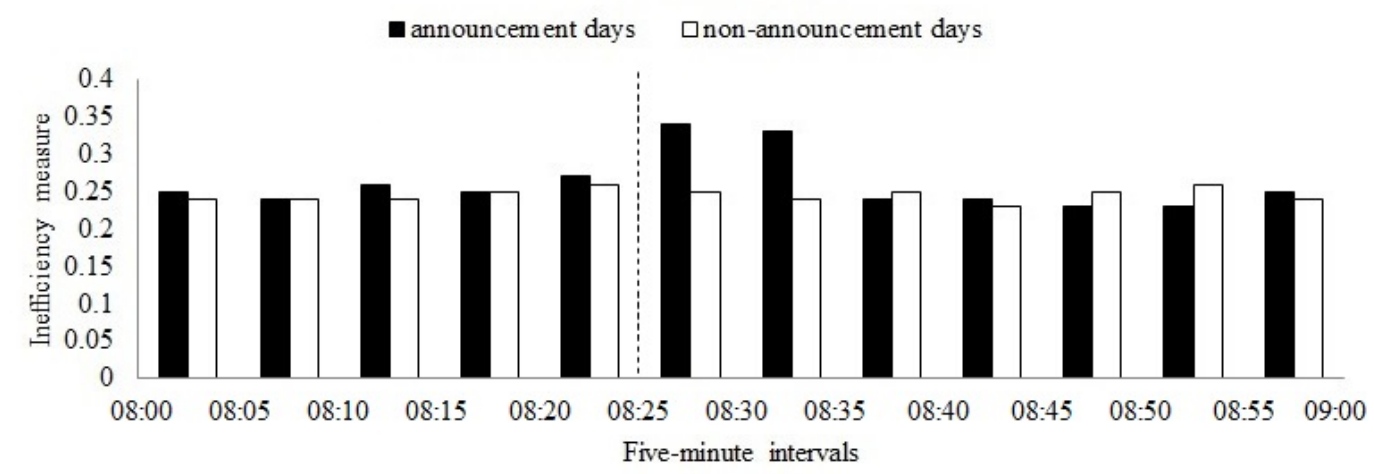

(B) 10-year maturity

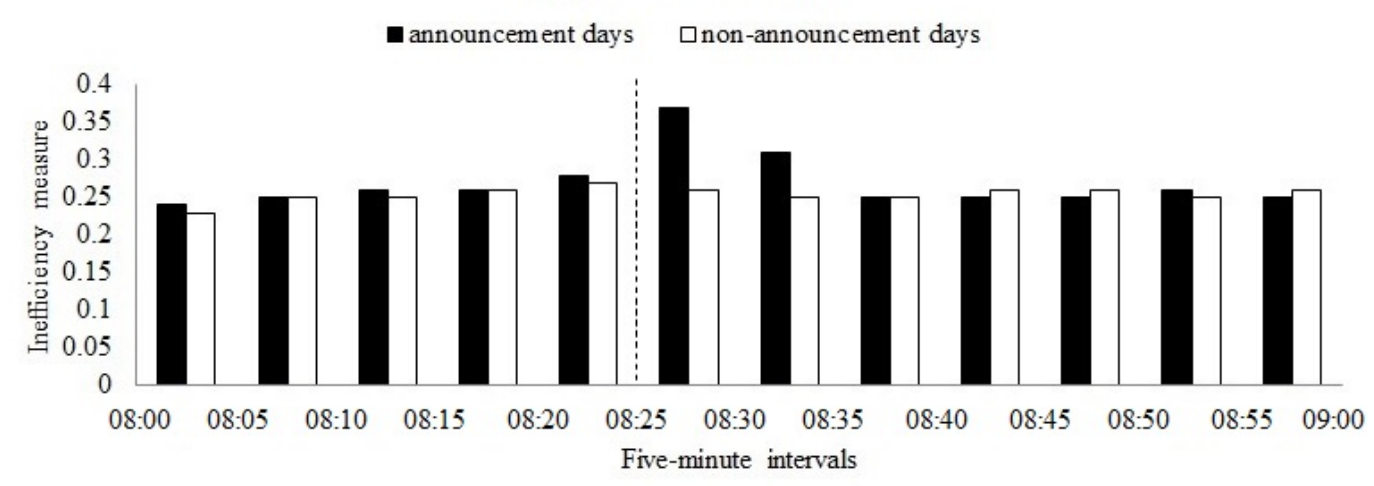

Figure 2.3: Impacts of 8:30 ET News Arrivals on Market Efficiency. This figure reports the average market inefficiency measures of 5- and 10-year U.S. Treasury notes in the 12 five-minute intervals from 8:00:00 ET to 8:59:59 ET during our sample period. The black and white bars represent the announcement and non-announcement days, respectively. 
(A) 5-year U.S. Treasury notes

- Announcement days $\square$ Non-Announcement days

Quoted Spread (in bps)

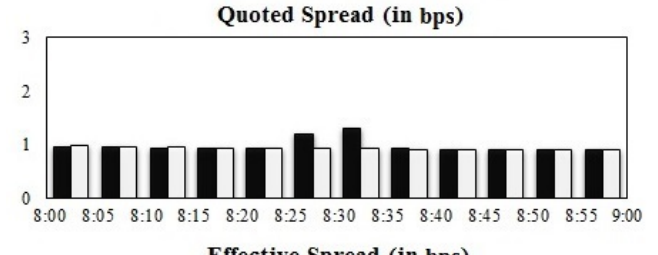

Effective Spread (in bps)

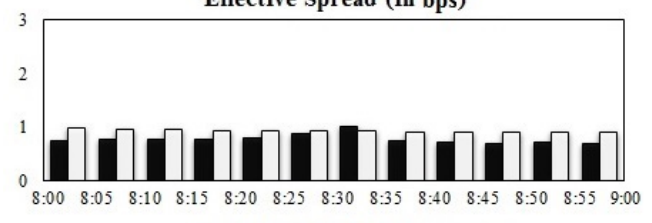

Total Depth (in \$ billion par)

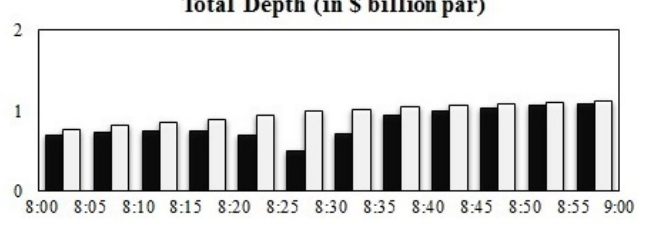

Best Five Quotes Depth (in \$ billion par)
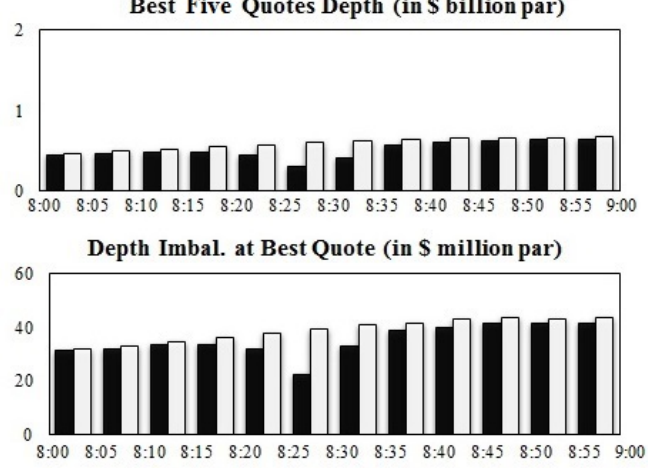

Depth Imbal. behind Best Quote (in \$ million par)

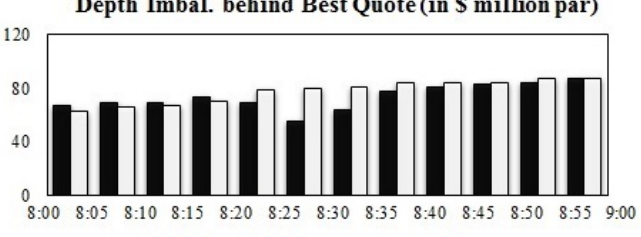

Order Flow Imbalance (in \$ million par)

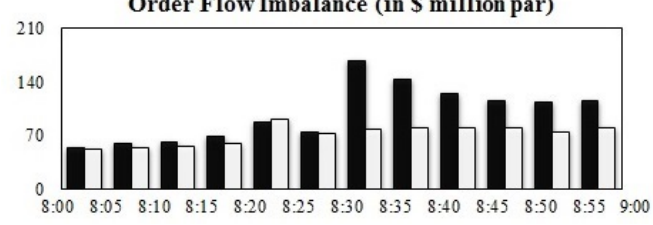

(B) 10-year U.S. Treasury notes

- Announcement days $\square$ Non-Announcement days
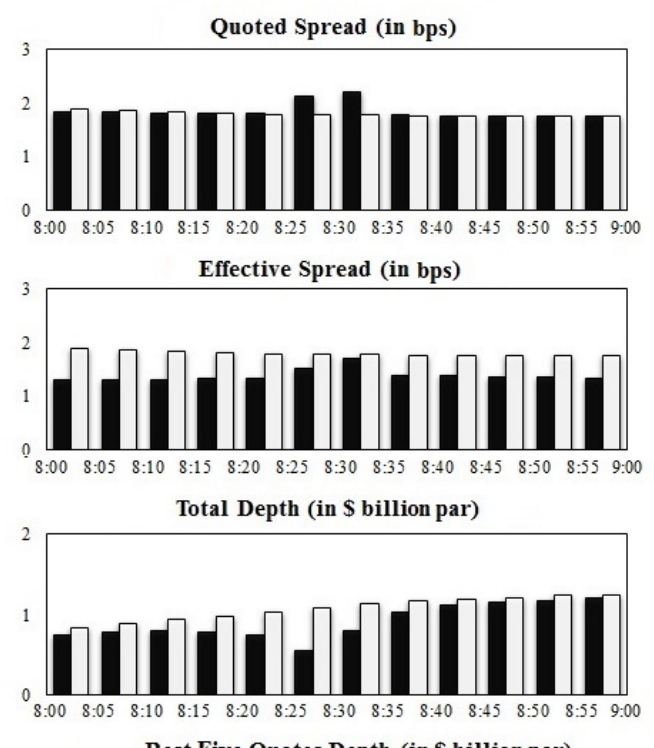

Best Five Quotes Depth (in \$ billion par)
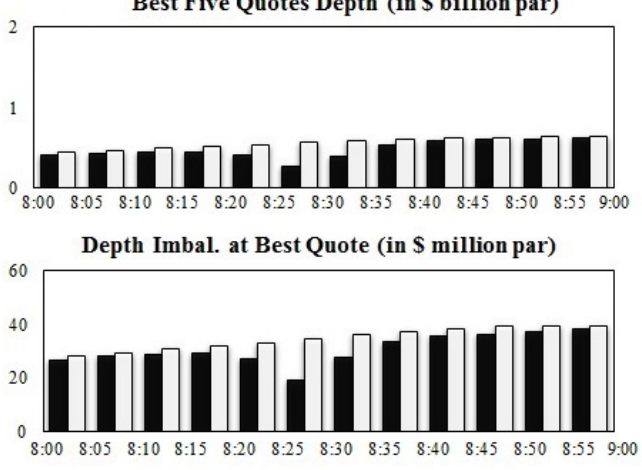

Depth Imbal. behind Best Quote (in \$ million par)
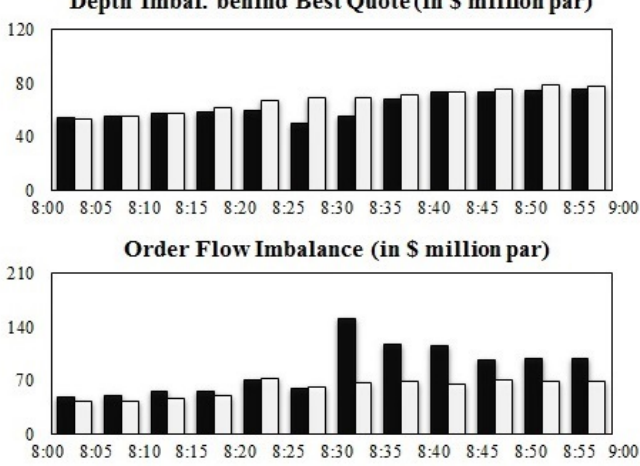

Figure 2.4: Market Liquidity and Order Flow Imbalance around 8:30 ET. This figure reports the average quoted spread, effective spread, depth, depth imbalance, and order flow imbalance of 5- and 10-year U.S. Treasury notes in the 12 five-minute intervals from 8:00:00 ET to 8:59:59 ET during our sample period. The black and white bars represent the announcement and non-announcement days, respectively. 
Table 2.1: Definitions of the 15 Types of Major Announcements

\begin{tabular}{|c|c|}
\hline Events and Indexes & Definition \\
\hline $\begin{array}{l}\text { 1. Change in Nonfarm Payrolls } \\
\text { NFP TCH Index }\end{array}$ & $\begin{array}{l}\text { This indicator measures the number of employees on business payrolls. It is also sometimes referred to as establishment } \\
\text { survey employment to distinguish it from the household survey measure of employment. }\end{array}$ \\
\hline $\begin{array}{l}\text { 2. Initial Jobless Claims } \\
\text { INJCJC Index }\end{array}$ & $\begin{array}{l}\text { Initial Unemployment Claims (new claims) claims track the number of people who have filed jobless claims for the first } \\
\text { time during the specified period with the appropriate government labor office. This number represents an inflow of people } \\
\text { receiving unemployment benefits. }\end{array}$ \\
\hline $\begin{array}{l}\text { 3-5. GDP P/A/F } \\
\text { GDP CQOQ Index }\end{array}$ & $\begin{array}{l}\text { Gross domestic product (GDP) measures the final market value of all goods and services produced within a country. It is } \\
\text { the most frequently used indicator of economic activity. The GDP by expenditure approach measures total final } \\
\text { expenditures (at purchasers' prices), including exports less imports. This concept is adjusted for inflation. }\end{array}$ \\
\hline $\begin{array}{l}\text { 6. Producer Price Index } \\
\text { PPI CHNG \& FDIDFDMO Index }\end{array}$ & Producer Price Index (PPI) measures the average change of selling prices recieved by domestice producers over time. \\
\hline $\begin{array}{l}\text { 7. Consumer Price Index } \\
\text { CPI CHNG Index }\end{array}$ & $\begin{array}{l}\text { Consumer Prices Index (CPI) is a measure of prices paid by consumers for a marketbasket of consumer goods and } \\
\text { services. The growth rates represent the inflation rate. }\end{array}$ \\
\hline $\begin{array}{l}\text { 8. Durable Goods Orders } \\
\text { DGNOCHNG Index }\end{array}$ & $\begin{array}{l}\text { This concept tracks the value of new orders received during the reference periods. Orders are typically based on a legal } \\
\text { agreement between two parties in which the producer will deliver goods or services to the purchaser at a future date. }\end{array}$ \\
\hline $\begin{array}{l}\text { 9. Retail Sales Advance } \\
\text { RSTAMOM Index }\end{array}$ & $\begin{array}{l}\text { Retail sales (also referred to as retail trade) tracks the resale of new and used goods to the general public, for personal or } \\
\text { household consumption. This concept is based on the value of goods sold. }\end{array}$ \\
\hline $\begin{array}{l}\text { 10. Housing Starts } \\
\text { NHSPSTOT Index }\end{array}$ & $\begin{array}{l}\text { Housing (or building) starts track the number of new housing units (or buildings) that have been started during the } \\
\text { reference period. }\end{array}$ \\
\hline $\begin{array}{l}\text { 11. Unemployment Rate } \\
\text { USURTOT Index }\end{array}$ & $\begin{array}{l}\text { The unemployment rate tracks the number of unemployed persons as a percentage of the labor force (the total number of } \\
\text { employed plus unemployed). These figures generally come from a household labor force survey. }\end{array}$ \\
\hline $\begin{array}{l}\text { 12. Personal Income } \\
\text { PITLCHNG Index }\end{array}$ & $\begin{array}{l}\text { Consumer or Household Income (often referred to as personal income) tracks all income received by households including } \\
\text { such things as wages and salaries, investment income, rental income, transfer payments, etc. This concept is not adjusted } \\
\text { for inflation. }\end{array}$ \\
\hline $\begin{array}{l}\text { 13. Personal Spending } \\
\text { PCE CRCH Index }\end{array}$ & $\begin{array}{l}\text { Consumer or Household Spending (or consumption) tracks consumer expenditures on goods and services. This concept is } \\
\text { not adjusted for inflation. }\end{array}$ \\
\hline $\begin{array}{l}\text { 14. Trade Balance } \\
\text { USTBTOT Index }\end{array}$ & $\begin{array}{l}\text { The international trade balance measures the difference between the movement of merchandise trade leaving a country } \\
\text { (exports) and entering a country (imports). This measure tracks the value of the merchandise trade balance. }\end{array}$ \\
\hline $\begin{array}{l}\text { 15. Empire Manufacturing } \\
\text { EMPRGBCI Index }\end{array}$ & $\begin{array}{l}\text { This survey, conducted on a monthly basis by the Federal Reserve Bank of New York, tracks sentiment among } \\
\text { manufacturers in the state of New York. Target Audience: manufacturing executives in the state of New York. } \\
\text { (Sample Size: } 200 \text { individuals) }\end{array}$ \\
\hline
\end{tabular}


Table 2.2: Summary Statistics of the Major Macroeconomic Announcements

\begin{tabular}{|c|c|c|c|c|c|c|c|c|c|}
\hline No. & Time $(E T)$ & Event & $\begin{array}{l}\text { Bloomberg } \\
\text { Relevance }\end{array}$ & $\begin{array}{l}\text { Analyst } \\
\text { Coverage }\end{array}$ & $\begin{array}{c}\text { Market } \\
\text { Uncertainty }\end{array}$ & $\begin{array}{c}\text { Information } \\
\text { Surprise }\end{array}$ & $\begin{array}{c}\text { Release } \\
\text { Frequency }\end{array}$ & Announcement Schedule & Number \\
\hline 1 & $8: 30$ & Change in Nonfarm Payrolls & 99.2 & 83 & 0.47 & 1.89 & Monthly & The first Friday & 142 \\
\hline 2 & $8: 30$ & Initial Jobless Claims & 98.5 & 43 & 0.51 & 1.80 & Weekly & Each Thursday & 592 \\
\hline 3 & $8: 30$ & Preliminary GDP & 97.0 & 80 & 0.36 & 1.17 & Quarterly & Around 28th of Jan/Apr/Jul/Oct & 47 \\
\hline 4 & $8: 30$ & Advanced GDP & 97.0 & 76 & 0.15 & 1.14 & Quarterly & Around 27th of Feb/May/Aug/Nov & 48 \\
\hline 5 & $8: 30$ & Final GDP & 97.0 & 74 & 0.10 & 1.47 & Quarterly & Around 29th of Mar/Jun/Sep/Dec & 36 \\
\hline 7 & $8: 30$ & Consumer Price Index & 96.2 & 77 & 0.40 & 0.95 & Monthly & Around the 16th business day & 138 \\
\hline 8 & $8: 30$ & Durable Goods Orders & 93.2 & 72 & 0.55 & 1.55 & Monthly & Around 26th & 134 \\
\hline 9 & $8: 30$ & Retail Sales Advance & 92.4 & 77 & 0.43 & 1.50 & Monthly & Around 12th & 144 \\
\hline 10 & $8: 30$ & Housing Starts & 90.2 & 73 & 0.30 & 2.29 & Monthly & After the 2 nd or the 3 rd week & 130 \\
\hline 11 & $8: 30$ & Unemployment Rate & 89.3 & 79 & 1.07 & 1.81 & Monthly & The first Friday & 142 \\
\hline 12 & $8: 30$ & Personal Income & 86.4 & 68 & 0.48 & 1.28 & Monthly & Around the 1 st business day & 132 \\
\hline 13 & $8: 30$ & Personal Spending & 86.4 & 62 & 0.43 & 1.03 & Monthly & Around the 1st business day & 132 \\
\hline 15 & $8: 30$ & Empire Manufacturing & 83.3 & 48 & 0.34 & 2.75 & Monthly & Around 15 th or 16 th & 132 \\
\hline
\end{tabular}

This table reports the summary statistics of the major announcements at 8:30 ET from January 5, 2004 to December 15, 2015. To eliminate the Christmas and New Year holidays effect, we exclude announcements after December 15 or before January 5 in each year. Bloomberg provides the relevance number for each type of macroeconomic news. The analyst coverage is the number of economist forecasts made for the announcement event. The market uncertainty is the forecast error adjusted by the standard deviation of forecast error in the past two years. The information surprise is the absolute difference between the announcement content and the median of the forecasts, divided by the forecast errors. The mean values of the analyst coverage, market uncertainty, and information surprise of the 15 types of news are listed in the table. 
Table 2.3: Variance-Ratio Market Inefficiency Measures

Panel A: 5-minute interval around 8:25 ET

\begin{tabular}{|c|c|c|c|c|c|c|}
\hline & \multicolumn{3}{|c|}{ 5-year U.S. T-notes } & \multicolumn{3}{|c|}{ 10-year U.S. T-notes } \\
\hline & before & after & $\Delta_{1}$ & before & after & $\Delta_{1}$ \\
\hline all & 0.267 & 0.294 & $0.027^{* * *}$ & 0.273 & 0.321 & $0.048^{* * *}$ \\
\hline ann & 0.272 & 0.332 & $0.060^{* * *}$ & 0.278 & 0.377 & $0.100^{* * *}$ \\
\hline non & 0.261 & 0.253 & -0.009 & 0.269 & 0.260 & -0.009 \\
\hline$\Delta_{2}$ & 0.011 & $0.080^{* * *}$ & & 0.009 & $0.118^{* * *}$ & \\
\hline$\beta_{3}(\mathrm{DID})$ & & & $0.069^{* * *}$ & & & $0.108^{* * *}$ \\
\hline \multicolumn{7}{|c|}{ Panel B: 10-minute interval around 8:25 ET } \\
\hline & \multicolumn{3}{|c|}{ 5-year U.S. T-notes } & \multicolumn{3}{|c|}{ 10-year U.S. T-notes } \\
\hline & before & after & $\Delta_{1}$ & before & after & $\Delta_{1}$ \\
\hline all & 0.223 & 0.242 & $0.018^{* * *}$ & 0.235 & 0.241 & 0.006 \\
\hline ann & 0.228 & 0.268 & $0.039^{* * *}$ & 0.233 & 0.253 & $0.020^{* * *}$ \\
\hline non & 0.217 & 0.213 & -0.004 & 0.237 & 0.229 & -0.008 \\
\hline$\Delta_{2}$ & 0.011 & $0.054^{* * *}$ & & -0.003 & $0.025^{* * *}$ & \\
\hline$\beta_{3}(\mathrm{DID})$ & & & $0.043^{* * *}$ & & & $0.028^{* * *}$ \\
\hline \multicolumn{7}{|c|}{ Panel C: 15 -minute interval around 8:25 ET } \\
\hline & \multicolumn{3}{|c|}{ 5-year U.S. T-notes } & \multicolumn{3}{|c|}{ 10-year U.S. T-notes } \\
\hline & before & after & $\Delta_{1}$ & before & after & $\Delta_{1}$ \\
\hline all & 0.206 & 0.226 & $0.020^{* * *}$ & 0.217 & 0.227 & $0.010^{* *}$ \\
\hline ann & 0.212 & 0.251 & $0.038^{* * *}$ & 0.220 & 0.239 & $0.020^{* * *}$ \\
\hline non & 0.199 & 0.198 & -0.001 & 0.214 & 0.214 & 0.000 \\
\hline$\Delta_{2}$ & $0.013^{* *}$ & $0.053^{* * *}$ & & 0.005 & $0.025^{* * *}$ & \\
\hline$\beta_{3}(\mathrm{DID})$ & & & $0.039^{* * *}$ & & & $0.020^{* *}$ \\
\hline
\end{tabular}

This table reports the average variance-ratio market inefficiency measures $(V R)$ in the five-, ten- and fifteen-minute intervals around 8:25 ET on all trading days (all), announcement days (ann) and non-announcement days (non) separately. $\Delta_{1}$ represents the average change in $V R$ around 8:25 ET: after-before. $\Delta_{2}$ represents the average difference in $V R$ between announcement days and non-announcement days in the same interval: ann - non. In each panel, we also report $\beta_{3}$ s, the difference-in-difference (DID) test results, in the last row for the 5- and 10-year U.S. Treasury notes. The DID test model is:

$$
V R_{j, d}=\alpha+\beta_{1} A F T E R_{j, d}+\beta_{2} A N N_{d}+\beta_{3} A F T E R_{j, d} \times A N N_{d}+\varepsilon_{j, d} .
$$

$A F T E R_{j, d}$ and $A N N_{d}$ are dummy variables for after-8:25 intervals and announcement days, respectively. If $j$ refers to an after-8:25 interval, $A F T E R_{j, d}$ equals to 1; otherwise, $A F T E R_{j, d}$ equals to 0 . If day $d$ is an announcement day, $A N N_{d}$ equals to 1 ; otherwise, $A N N_{d}$ equals to 0 . The coefficient of $A F T E R_{j, d} \times A N N_{d}, \beta_{3}$, is the difference in change of $V R$ around 8:25 ET on the announcement and non-announcement days. ${ }^{*},{ }^{* *}$ and ${ }^{* * *}$ indicate significance at the $10 \%, 5 \%$, and $1 \%$ level, respectively. 
Table 2.4: Market Liquidity, Information Variables and Changes in Market Efficiency around 8:25 ET

\begin{tabular}{|c|c|c|c|c|c|c|c|c|c|c|c|c|}
\hline & \multicolumn{6}{|c|}{ 5-year U.S. T-notes } & \multicolumn{6}{|c|}{ 10-year U.S. T-notes } \\
\hline & \multicolumn{2}{|c|}{ 5-minute } & \multicolumn{2}{|c|}{ 10-minute } & \multicolumn{2}{|c|}{ 15-minute } & \multicolumn{2}{|c|}{ 5-minute } & \multicolumn{2}{|c|}{ 10-minute } & \multicolumn{2}{|c|}{ 15-minute } \\
\hline & ann & non & ann & non & ann & non & ann & non & ann & non & ann & non \\
\hline$\Delta s_{d}$ & $0.070^{* *}$ & -0.019 & $0.109^{* * *}$ & -0.016 & $0.067^{* * *}$ & 0.026 & $0.089^{* * *}$ & $-0.060^{* *}$ & $0.067^{* * *}$ & -0.018 & $0.054^{* *}$ & 0.026 \\
\hline$\Delta s_{d}^{e}$ & $0.055^{* *}$ & $0.047^{*}$ & $0.052^{* *}$ & -0.002 & $0.050^{* *}$ & 0.016 & $0.088^{* * *}$ & 0.034 & $0.039^{*}$ & 0.010 & $0.038^{*}$ & -0.022 \\
\hline$\Delta$ Depth $h_{d}^{\text {Total }}$ & -0.003 & 0.028 & $0.051^{* *}$ & 0.002 & $0.057^{* * *}$ & 0.017 & $-0.085^{* * *}$ & -0.013 & -0.013 & 0.005 & -0.009 & 0.027 \\
\hline$\Delta$ Depth $h_{d}^{\text {TopFive }}$ & 0.009 & 0.023 & -0.008 & -0.003 & 0.008 & 0.028 & $-0.061^{* *}$ & -0.019 & -0.007 & 0.015 & -0.018 & 0.026 \\
\hline$\Delta D I_{a t, d}$ & 0.027 & $0.059^{* *}$ & 0.019 & 0.010 & $0.061^{* * *}$ & -0.012 & -0.026 & -0.001 & 0.023 & 0.001 & 0.000 & 0.012 \\
\hline$\Delta D I_{\text {bhd }, d}$ & $-0.054^{*}$ & -0.015 & 0.005 & -0.027 & 0.008 & -0.014 & -0.004 & 0.019 & 0.013 & -0.005 & 0.023 & -0.011 \\
\hline$\Delta O F I_{d}$ & $0.046^{*}$ & $0.054^{* *}$ & 0.016 & 0.004 & 0.003 & -0.025 & 0.035 & $0.072^{* * *}$ & $0.074^{* * *}$ & $0.060^{* * *}$ & $0.042^{* *}$ & $0.038^{* *}$ \\
\hline Analysts $_{d}$ & -0.031 & & $0.060^{* *}$ & & $0.066^{* * *}$ & & -0.010 & & -0.011 & & 0.008 & \\
\hline Uncertainty $_{d}$ & 0.012 & & -0.010 & & -0.016 & & 0.005 & & -0.015 & & 0.006 & \\
\hline Surprise $_{d}$ & & & -0.024 & & -0.022 & & & & 0.029 & & $0.039^{*}$ & \\
\hline
\end{tabular}

This table reports the average difference in change of $V R$ around 8:25 ET between high and low groups of liquidity and information variables in the five-, ten- and fifteen-minute intervals. We first sort the days into quintiles by each of the variables listed in the first column. They are the change of quoted spread $\left(\Delta s_{d}\right)$, the change of effective spread $\left(\Delta s_{d}^{e}\right)$, the change of total depth $\left(\Delta D e p t t_{d}^{\text {Total }}\right)$, the change of best five quotes depth $\left(\Delta D e p t h_{d}^{B e s t F i v e}\right)$, the change of depth imbalance at the best quote $\left(\Delta D I_{a t, d}\right)$, the change of depth imbalance behind the best quote $\left(\Delta D I_{b h d, d}\right)$, and the change of order flow imbalance $\left(\Delta O F I_{d}\right)$ around $8: 25 \mathrm{ET}$, together with the variables about information content, including the analyst coverage $\left(\right.$ Analyst $\left._{d}\right)$, market uncertainty $\left(\text { Uncertainty }_{d} \text { ) and information surprise (Surprise }\right)_{d}$ ). The high group includes the days that lie on the top $20 \%$ of the variable, while the low group consists of the days that lie on the bottom $20 \%$ of the variable. ${ }^{*},{ }^{* *}$ and ${ }^{* * *}$ indicate significance at the $10 \%, 5 \%$, and $1 \%$ level, respectively. 
Table 2.5: Difference-in-Difference Regressions

\begin{tabular}{|c|c|c|c|c|c|c|c|c|c|c|c|c|}
\hline & \multicolumn{6}{|c|}{ 5-year U.S. T-notes } & \multicolumn{6}{|c|}{ 10-year U.S. T-notes } \\
\hline & \multicolumn{2}{|c|}{ 5-minute } & \multicolumn{2}{|c|}{ 10-minute } & \multicolumn{2}{|c|}{ 15-minute } & \multicolumn{2}{|c|}{ 5-minute } & \multicolumn{2}{|c|}{ 10-minute } & \multicolumn{2}{|c|}{ 15-minute } \\
\hline & Model 2 & Model 3 & Model 2 & Model 3 & Model 2 & Model 3 & Model 2 & Model 3 & Model 2 & Model 3 & Model 2 & Model 3 \\
\hline Intercept & $0.169^{* * *}$ & $0.170^{* * *}$ & $0.134^{* * *}$ & $0.135^{* * *}$ & $0.094^{* * *}$ & $0.094^{* * *}$ & $0.114^{* * *}$ & $0.114^{* * *}$ & $0.143^{* * *}$ & $0.141^{* * *}$ & $0.089^{* * *}$ & $0.087^{* * *}$ \\
\hline$A F T E R_{j, d}$ & -0.007 & -0.007 & -0.004 & -0.004 & -0.001 & -0.001 & -0.005 & -0.005 & -0.007 & -0.007 & 0.000 & 0.000 \\
\hline$A N N_{d}$ & 0.012 & -0.029 & 0.010 & $-0.071^{* * *}$ & $0.013^{*}$ & $-0.060^{* * *}$ & 0.009 & $-0.049^{* * *}$ & -0.006 & $-0.058^{* * *}$ & 0.002 & $-0.046^{* * *}$ \\
\hline$A F T E R_{j, d} \times A N N_{d}$ & $0.060^{* * *}$ & $0.060^{* * *}$ & $0.022^{* *}$ & $0.024^{* *}$ & $0.021^{* *}$ & $0.022^{* *}$ & $0.095^{* * *}$ & $0.095^{* * *}$ & 0.005 & 0.006 & 0.001 & 0.002 \\
\hline$s_{d}$ & $2.958^{* * *}$ & $3.052^{* * *}$ & $3.875^{* * *}$ & $4.363^{* * *}$ & $4.782^{* * *}$ & $5.272^{* * *}$ & $2.418^{* * *}$ & $2.443^{* * *}$ & $1.118^{* *}$ & $1.300^{* * *}$ & $2.856^{* * *}$ & $3.039^{* * *}$ \\
\hline$s_{d}^{e}$ & $6.149^{* * *}$ & $5.893^{* * *}$ & $5.824^{* * *}$ & $5.061^{* * *}$ & $7.133^{* * *}$ & $6.478^{* * *}$ & $6.159^{* * *}$ & $5.996^{* * *}$ & $4.635^{* * *}$ & $4.410^{* * *}$ & $4.610^{* * *}$ & $4.430^{* * *}$ \\
\hline Depth $h_{d}^{\text {Total }}$ & 0.090 & 0.081 & 0.157 & 0.142 & $0.252^{* *}$ & $0.237^{* *}$ & 0.144 & 0.127 & 0.084 & 0.060 & -0.151 & -0.173 \\
\hline Depth $h_{d}^{\text {TopFive }}$ & -0.258 & -0.221 & $-0.477^{*}$ & -0.417 & $-0.603^{* *}$ & $-0.547^{* *}$ & -0.508 & -0.415 & $-0.690^{*}$ & -0.582 & 0.034 & 0.131 \\
\hline$D I_{a t, d}$ & $4.263^{*}$ & $4.304^{* *}$ & 2.596 & 2.812 & $4.024^{*}$ & $4.284^{*}$ & $5.644^{*}$ & $5.417^{*}$ & $7.433^{* *}$ & $7.361^{* *}$ & 3.130 & 3.096 \\
\hline$D I_{\text {bhd, } d}$ & -0.519 & -0.597 & 0.055 & -0.128 & -0.281 & -0.466 & -0.332 & -0.382 & -0.240 & -0.305 & 0.022 & -0.040 \\
\hline$O F I_{d}$ & $1.757^{* * *}$ & $1.724^{* * *}$ & $0.719^{* * *}$ & $0.596^{* * *}$ & $0.632^{* * *}$ & $0.545^{* * *}$ & $3.189^{* * *}$ & $3.130^{* * *}$ & $1.458^{* * *}$ & $1.367^{* * *}$ & $1.157^{* * *}$ & $1.064^{* * *}$ \\
\hline Analysts $_{d}$ & & $0.052^{* *}$ & & $0.123^{* * *}$ & & $0.109^{* * *}$ & & $0.067^{7 * *}$ & & $0.079^{* * *}$ & & $7.319^{* * *}$ \\
\hline Uncertainty $_{d}$ & & 2.210 & & 1.175 & & 1.390 & & $4.122^{* * *}$ & & $2.373^{* *}$ & & 1.655 \\
\hline Surprise $_{d}$ & & & & 0.142 & & 0.046 & & & & -0.339 & & -0.183 \\
\hline Ad j. $R^{2}$ & 0.039 & 0.040 & 0.034 & 0.042 & 0.038 & 0.046 & 0.082 & 0.085 & 0.026 & 0.031 & 0.025 & 0.029 \\
\hline
\end{tabular}

This table reports the difference-in-difference (DID) regression results around 8:25 ET between announcement days and non-announcement days in five-, ten- and fifteen-minute intervals, respectively. The dependent variable is market inefficiency measure, $V R_{j, d}$. We run the two regressions as follows:

Model 2: $V R_{j, d}=\alpha+\beta_{1} A F T E R_{j, d}+\beta_{2} A N N_{d}+\beta_{3} A F T E R_{j, d} \times A N N_{d}+\beta_{4} s_{j, d}+\beta_{5} s_{j, d}^{e}+\beta_{6}$ Depth $_{j, d}^{T o t a l}+\beta_{7}$ Depth $_{j, d}^{\text {BestFive }}+\beta_{8} D I_{a t, j, d}+\beta_{9} D I_{b h d, j, d}+\beta_{10} O F I_{j, d}+\varepsilon_{j, d} ;$

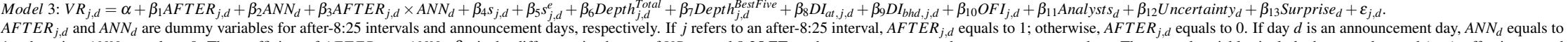
1 ; otherwise, $A N N_{d}$ equals to 0 . The coefficient of $A F T E R_{j, d} \times A N N_{d}, \beta_{3}$, is the difference in change of $V R$ around 8:25 $\mathrm{ET}$ on the announcement and non-announcement days. The control variables include the quoted spread $\left(s_{j, d}\right)$, effective spread $\left(s_{i, d}^{e}\right)$, total depth $\left(D e p t h_{d}^{T o t a l}\right)$, best five quotes depth $\left(D e p t h_{d}^{\text {Bess Five }}\right)$, depth imbalance at the best quote $\left(D I_{a t, j, d}\right)$, depth imbalance behind the best quote $\left(D I_{b h d, j, d}\right)$, order flow imbalance $\left(O F I_{j, d}\right)$, analyst coverage $\left(A n a l y s t s_{d}\right)$, market uncertainty (Uncertaintyd), and information surprise (Surprised). Since Surprise $e_{d}$ can be only calculated after the news releases at 8:30 ET, it is not used in the regression of 5-minute interval. ${ }^{*}$, ${ }^{* *}$ and ${ }^{* * *}$ indicate significance at the $10 \%, 5 \%$, and $1 \%$ level, respectively. 
Table 2.6: News Impact by Using the Variance-Ratio Market Inefficiency Measures calculated from Mid-Quotes Directly

\begin{tabular}{|c|c|c|c|c|c|c|}
\hline & \multicolumn{2}{|c|}{ Model 1} & \multicolumn{2}{|c|}{ Model 2} & \multicolumn{2}{|c|}{ Model 3} \\
\hline & 5-year & 10-year & 5-year & 10-year & 5-year & 10-year \\
\hline 5-minute & $0.113^{* * *}$ & $0.117^{* * *}$ & $0.093^{* * *}$ & $0.101^{* * *}$ & $0.093^{* * *}$ & $0.102^{* * *}$ \\
\hline 10-minute & 0.002 & $-0.021^{* *}$ & $-0.024^{* *}$ & $-0.040^{* * *}$ & $-0.023^{* *}$ & $-0.040^{* * *}$ \\
\hline 15-minute & 0.006 & 0.001 & -0.005 & -0.007 & -0.005 & -0.008 \\
\hline
\end{tabular}

This table reports the results of three DID regressions as follows:

Model $1: V R_{j, d}^{M Q}=\alpha+\beta_{1} A F T E R_{j, d}+\beta_{2} A N N_{d}+\beta_{3} A F T E R_{j, d} \times A N N_{d}+\varepsilon_{j, d}$;

Model 2: $V R_{j, d}^{M Q}=\alpha+\beta_{1} A F T E R_{j, d}+\beta_{2} A N N_{d}+\beta_{3} A F T E R_{j, d} \times A N N_{d}+\beta_{4} s_{j, d}+\beta_{5} s_{j, d}^{e}+\beta_{6}$ Depth $_{j, d}^{\text {Total }}+\beta_{7}$ Depth $_{j, d}^{\text {BestFive }}+$ $\beta_{8} D I_{a t, j, d}+\beta_{9} D I_{b h d, j, d}+\beta_{10} O F I_{j, d}+\varepsilon_{j, d}$

Model 3: VR $R_{j, d}^{M Q}=\alpha+\beta_{1} A F T E R_{j, d}+\beta_{2} A N N_{d}+\beta_{3} A F T E R_{j, d} \times A N N_{d}+\beta_{4} s_{j, d}+\beta_{5} s_{j, d}^{e}+\beta_{6}$ Depth $_{j, d}^{\text {Total }}+\beta_{7}$ Depth $_{j, d}^{\text {BestFive }}+$ $\beta_{8} D I_{a t, j, d}+\beta_{9} D I_{b h d, j, d}+\beta_{10}$ OFI I $_{j, d}+\beta_{11}$ Analysts $_{d}+\beta_{12}$ Uncertainty $_{d}+\beta_{13}$ Surprise $_{d}+\varepsilon_{j, d}$.

$V R_{j, d}^{M Q}$ is the variance-ratio market inefficiency measure calculated from mid-quotes. $A F T E R_{j, d}$ and $A N N_{d}$ are dummy variables for after-8:25 intervals and announcement days, respectively. If $j$ refers to an after-8:25 interval, $A F T E R_{j, d}$ equals to 1 ; otherwise, $A F T E R_{j, d}$ equals to 0 . If day $d$ is an announcement day, $A N N_{d}$ equals to 1 ; otherwise, $A N N_{d}$ equals to 0 . The control variables include the quoted spread $\left(s_{j, d}\right)$, effective $\operatorname{spread}\left(s_{j, d}^{e}\right)$, total depth $\left(\right.$ Dept $\left._{d}^{\text {Total }}\right)$, best five quotes depth $\left(\right.$ Dept $\left.h_{d}^{\text {BestFive }}\right)$, depth imbalance at the best quote $\left(D I_{a t, j, d}\right)$, depth imbalance behind the best quote $\left(D I_{b h d, j, d}\right)$, order flow imbalance $\left(O F I_{j, d}\right)$, analyst coverage $\left(\right.$ Analyst $\left._{d}\right)$, market uncertainty $\left(\right.$ Uncertainty $\left._{d}\right)$, and information surprise $\left(\right.$ Surprise $\left._{d}\right)$. Since Surprise $e_{d}$ can be only calculated after the news releases at 8:30 ET, it is not used in the regression of 5-minute interval.

The table reports the results of $\beta_{3}$ s, which measure the differences in change of $V R^{M Q}$ around 8:25 ET on the announcement and non-announcement days. ${ }^{*},{ }^{* *}$ and ${ }^{* *}$ indicate significance at the $10 \%, 5 \%$, and $1 \%$ level, respectively. 
Table 2.7: Sub-period Analysis

\begin{tabular}{|c|c|c|c|c|c|c|}
\hline \multicolumn{7}{|c|}{ Panel A: The pre-GFC period (Janurary 5, 2004 - June 30, 2007) } \\
\hline & \multicolumn{2}{|c|}{ Model 1} & \multicolumn{2}{|c|}{ Model 2} & \multicolumn{2}{|c|}{ Model 3} \\
\hline & 5 -year & 10-year & 5-year & 10-year & 5 -year & 10-year \\
\hline 5-minute & $0.083^{* * *}$ & $0.124^{* * *}$ & $0.061^{* * *}$ & $0.108^{* * *}$ & $0.062^{* * *}$ & $0.109^{* * *}$ \\
\hline 10-minute & $0.051^{* * *}$ & $0.044^{* *}$ & 0.011 & 0.008 & 0.012 & 0.008 \\
\hline 15-minute & $0.041^{* *}$ & 0.014 & 0.002 & -0.013 & 0.004 & -0.012 \\
\hline \multicolumn{7}{|c|}{ Panel B: The GFC period (July 1, 2007 - June 30, 2009) } \\
\hline & \multicolumn{2}{|c|}{ Model 1} & \multicolumn{2}{|c|}{ Model 2} & \multicolumn{2}{|c|}{ Model 3} \\
\hline & 5-year & 10-year & 5-year & 10-year & 5 -year & 10-year \\
\hline 5-minute & $0.112^{* * *}$ & $0.148^{* * *}$ & $0.103^{* * *}$ & $0.140^{* * *}$ & $0.103^{* * *}$ & $0.141^{* * *}$ \\
\hline 10-minute & $0.117^{* * *}$ & $0.039^{*}$ & $0.093^{* * *}$ & 0.036 & $0.095^{* * *}$ & 0.038 \\
\hline 15-minute & $0.098^{* * *}$ & 0.023 & $0.077^{* * *}$ & 0.023 & $0.079^{* * *}$ & 0.024 \\
\hline \multicolumn{7}{|c|}{ Panel C: The post-GFC period (July 1, 2009 - December 15, 2015) } \\
\hline & \multicolumn{2}{|c|}{ Model 1} & \multicolumn{2}{|c|}{ Model 2} & \multicolumn{2}{|c|}{ Model 3} \\
\hline & 5 -year & 10-year & 5-year & 10-year & 5-year & 10-year \\
\hline 5-minute & $0.042^{* *}$ & $0.082^{* * *}$ & 0.025 & $0.053^{* * *}$ & 0.026 & $0.057^{* * *}$ \\
\hline 10-minute & 0.009 & 0.012 & -0.015 & -0.015 & -0.007 & -0.010 \\
\hline 15-minute & 0.015 & 0.023 & 0.000 & 0.001 & 0.005 & 0.004 \\
\hline
\end{tabular}

This table reports the results of DID regressions in three sub-periods. Panels A, B, and C indicate the results of pre-GFC, GFC, and post-GFC periods, respectively. The three regressions are as follows.

Model 1: $V R_{j, d}=\alpha+\beta_{1} A F T E R_{j, d}+\beta_{2} A N N_{d}+\beta_{3} A F T E R_{j, d} \times A N N_{d}+\varepsilon_{j, d}$;

Model 2: $V R_{j, d}=\alpha+\beta_{1} A F T E R_{j, d}+\beta_{2} A N N_{d}+\beta_{3} A F T E R_{j, d} \times A N N_{d}+\beta_{4} s_{j, d}+\beta_{5} s_{j, d}^{e}+\beta_{6}$ Depth $_{j, d}^{\text {Total }}+\beta_{7}$ Depth $_{j, d}^{\text {BestFive }}+$ $\beta_{8} D I_{a t, j, d}+\beta_{9} D I_{b h d, j, d}+\beta_{10} O F I_{j, d}+\varepsilon_{j, d}$

Model 3: VR $R_{j, d}=\alpha+\beta_{1} A F T E R_{j, d}+\beta_{2} A N N_{d}+\beta_{3} A F T E R_{j, d} \times A N N_{d}+\beta_{4} s_{j, d}+\beta_{5} s_{j, d}^{e}+\beta_{6}$ Depth $_{j, d}^{\text {Total }}+\beta_{7}$ Depth $_{j, d}^{\text {BestFive }}+$ $\beta_{8} D I_{a t, j, d}+\beta_{9} D I_{b h d, j, d}+\beta_{10}$ OFI $_{j, d}+\beta_{11}$ Analyst $_{d}+\beta_{12}$ Uncertainty $_{d}+\beta_{13}$ Surprise $_{d}+\varepsilon_{j, d}$.

The dependent variable is market inefficiency measure, $V R_{j, d}$. $A F T E R_{j, d}$ and $A N N_{d}$ are dummy variables for after-8:25 intervals and announcement days, respectively. If $j$ refers to an after-8:25 interval, $A F T E R_{j, d}$ equals to 1; otherwise, $A F T E R_{j, d}$ equals to 0 . If day $d$ is an announcement day, $A N N_{d}$ equals to 1 ; otherwise, $A N N_{d}$ equals to 0 . The control variables include the quoted spread $\left(s_{j, d}\right)$, effective spread $\left(s_{j, d}^{e}\right)$, total depth $\left(\right.$ Dept $\left._{d}^{\text {Total }}\right)$, best five quotes depth $\left(\right.$ Dept $\left._{d}^{\text {BestFive }}\right)$, depth imbalance at the best quote $\left(D I_{a t, j, d}\right)$, depth imbalance behind the best quote $\left(D I_{b h d, j, d}\right)$, order flow imbalance $\left(O F I_{j, d}\right)$, analyst coverage $\left(\right.$ Analyst $\left._{d}\right)$, market uncertainty $\left(\right.$ Uncertainty $\left._{d}\right)$, and information surprise (Surprise $e_{d}$ ). Since Surprise $e_{d}$ can be only calculated after the news releases at 8:30 ET, it is not used in the regression of 5-minute interval.

The table reports the results of $\beta_{3}$ s, which measure the differences in change of $V R$ around 8:25 ET on the announcement and non-announcement days. ${ }^{*},{ }^{* *}$ and ${ }^{* * *}$ indicate significance at the $10 \%, 5 \%$, and $1 \%$ level, respectively. 
Table 2.8: News Impact on the Market Efficiency: Good News vs. Bad News

\begin{tabular}{|c|c|c|c|c|c|c|}
\hline \multicolumn{7}{|c|}{ Panel A: Changes in $V R$ around 8:25 ET } \\
\hline & \multicolumn{2}{|c|}{ 5-year U.S. T-notes } & \multicolumn{2}{|c|}{ 10-year U.S. T-notes } & & \\
\hline & $\Delta_{1, \text { Good }}$ & $\Delta_{1, B a d}$ & $\Delta_{1, \text { Good }}$ & $\Delta_{1, B a d}$ & & \\
\hline 5-minute & $0.065^{* * *}$ & $0.103^{* * *}$ & $0.098^{* * *}$ & $0.110^{* * *}$ & & \\
\hline 10-minute & 0.019 & $0.051^{* *}$ & 0.000 & $0.068^{* * *}$ & & \\
\hline 15-minute & 0.001 & $0.042^{* *}$ & 0.004 & $0.034^{*}$ & & \\
\hline \multicolumn{7}{|c|}{ Panel B: DID regression results } \\
\hline & \multicolumn{2}{|c|}{ Model 1} & \multicolumn{2}{|c|}{ Model 2} & \multicolumn{2}{|c|}{ Model 3} \\
\hline & 5-year & 10-year & 5-year & 10-year & 5-year & 10-year \\
\hline 5-minute & -0.038 & -0.012 & -0.036 & -0.017 & -0.034 & -0.016 \\
\hline 10-minute & -0.032 & $-0.068^{* *}$ & -0.023 & $-0.071^{* *}$ & -0.019 & $-0.068^{* *}$ \\
\hline 15-minute & -0.040 & -0.030 & -0.033 & -0.028 & -0.028 & -0.025 \\
\hline
\end{tabular}

This table reports the impact of good and bad news on the market efficiency of the U.S. Treasury market. According to the market reactions after the news arrivals, we define the good-news and bad-news announcement days. Panel A reports the average changes in market inefficiency measures around 8:25 ET on good-news and bad-news announcement days separately.

In Panel B, we run three DID regressions to test whether the differences in change of $V R$ around 8:25 ET between goodnews and bad-news announcement days are significant.

Model 1: VR $R_{j, d}=\alpha+\beta_{1} A F T E R_{j, d}+\beta_{2} G O O D_{d}+\beta_{3} A F T E R_{j, d} \times G O O D_{d}+\varepsilon_{j, d}$;

Model 2: $\quad V R_{j, d}=\alpha+\beta_{1}$ AFTER $_{j, d}+\beta_{2}$ GOOD $_{d}+\beta_{3} A F T E R_{j, d} \times G O O D_{d}+\beta_{4} s_{j, d}+\beta_{5} s_{j, d}^{e}+\beta_{6}$ Depth $_{j, d}^{\text {Total }}+$ $\beta_{7}$ Depth $_{j, d}^{\text {BestFive }}+\beta_{8} D I_{a t, j, d}+\beta_{9} D I_{b h d, j, d}+\beta_{10} O F I_{j, d}+\varepsilon_{j, d}$

Model 3: $V R_{j, d}=\alpha+\beta_{1}$ AFTER $_{j, d}+\beta_{2}$ GOOD $_{d}+\beta_{3} A F T E R_{j, d} \times G O O D_{d}+\beta_{4} s_{j, d}+\beta_{5} s_{j, d}^{e}+\beta_{6}$ Depth $_{j, d}^{\text {Total }}+$ $\beta_{7}$ Depth $_{j, d}^{\text {BestFive }}+\beta_{8} D I_{a t, j, d}+\beta_{9}$ DI $_{\text {bhd }, j, d}+\beta_{10}$ OFI $_{j, d}+\beta_{11}$ Analyst $_{d}+\beta_{12}$ Uncertainty $_{d}+\beta_{13}$ Surprise $_{d}+\varepsilon_{j, d}$.

The dependent variable is market inefficiency measure, $V R_{j, d}$. AFTER $R_{j, d}$ and $G O O D_{d}$ are dummy variables for after8:25 intervals and good-news announcement days, respectively. If $j$ refers to an after-8:25 interval, $A F T E R_{j, d}$ equals to 1 ; otherwise, $A F T E R_{j, d}$ equals to 0 . If day $d$ is a good-news announcement day, $G O O D_{d}$ equals to 1 ; otherwise, $G O O D_{d}$ equals to 0 . The control variables include the quoted spread $\left(s_{j, d}\right)$, effective spread $\left(s_{j, d}^{e}\right)$, total depth $\left(\right.$ Depth $\left.h_{d}^{\text {Total }}\right)$, best

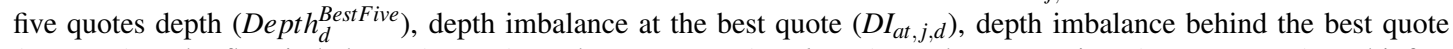
$\left(D I_{b h d, j, d}\right)$, order flow imbalance $\left(O F I_{j, d}\right)$, analyst coverage $\left(\right.$ Analyst $\left.s_{d}\right)$, market uncertainty $\left(\right.$ Uncertaint $\left._{d}\right)$, and information surprise $\left(\right.$ Surprise $_{d}$ ). Since Surprise $_{d}$ can be only calculated after the news releases at 8:30 ET, it is not used in the regression of 5-minute interval.

Panel $\mathrm{B}$ of this table reports the results of $\beta_{3} \mathrm{~s}$, which measure the differences in change of $V R$ around 8:25 ET on the good news and bad news days. ${ }^{*},{ }^{* *}$ and ${ }^{* * *}$ indicate significance at the $10 \%, 5 \%$, and $1 \%$ level, respectively. 
Table 2.9: News Impact by Using the Three Best Quotes in the Bid and the Ask Side to Construct Market Inefficiency Measure

\begin{tabular}{|c|c|c|c|c|c|c|}
\hline & \multicolumn{2}{|c|}{ Model 1} & \multicolumn{2}{|c|}{ Model 2} & \multicolumn{2}{|c|}{ Model 3} \\
\hline & 5-year & 10-year & 5-year & 10-year & 5-year & 10-year \\
\hline 5-minute & $0.141^{* * *}$ & $0.106^{* * *}$ & $0.117^{* * *}$ & $0.096^{* * *}$ & $0.118^{* * *}$ & $0.096^{* * *}$ \\
\hline 10-minute & $0.107^{* * *}$ & $0.074^{* * *}$ & $0.070^{* * *}$ & $0.042^{* * *}$ & $0.072^{* * *}$ & $0.044^{* * *}$ \\
\hline 15-minute & $0.104^{* * *}$ & $0.063^{* * *}$ & $0.068^{* * *}$ & $0.040^{* * *}$ & $0.068^{* * *}$ & $0.042^{* * *}$ \\
\hline
\end{tabular}

This table reports the differences in change of $V R^{R 3}$ around 8:25 ET between the announcement and non-announcement days. To account for the slow reaction of investors, we use the information of the best three ask and bid quotes to calculate the midquote and construct the market inefficiency measure. We run the three regressions as follows:

Model 1: $V R_{j, d}^{R 3}=\alpha+\beta_{1} A F T E R_{j, d}+\beta_{2} A N N_{d}+\beta_{3} A F T E R_{j, d} \times A N N_{d}+\varepsilon_{j, d}$;

Model 2: $V R_{j, d}^{R 3}=\alpha+\beta_{1} A F T E R_{j, d}+\beta_{2} A N N_{d}+\beta_{3} A F T E R_{j, d} \times A N N_{d}+\beta_{4} s_{j, d}+\beta_{5} s_{j, d}^{e}+\beta_{6}$ Depth $_{j, d}^{\text {Total }}+\beta_{7}$ Depth $_{j, d}^{\text {BestFive }}+$ $\beta_{8} D I_{a t, j, d}+\beta_{9} D I_{b h d, j, d}+\beta_{10} O F I_{j, d}+\varepsilon_{j, d}$

Model 3: VRR R3,d $=\alpha+\beta_{1} A F T E R_{j, d}+\beta_{2} A N N_{d}+\beta_{3} A F T E R_{j, d} \times A N N_{d}+\beta_{4} s_{j, d}+\beta_{5} s_{j, d}^{e}+\beta_{6}$ Depth $_{j, d}^{\text {Total }}+\beta_{7}$ Depth $_{j, d}^{\text {BestFive }}+$ $\beta_{8} D I_{a t, j, d}+\beta_{9} D I_{b h d, j, d}+\beta_{10}$ OFI $_{j, d}+\beta_{11}$ Analysts $_{d}+\beta_{12}$ Uncertainty $_{d}+\beta_{13}$ Surprise $_{d}+\varepsilon_{j, d}$.

The dependent variable, $V R_{j, d}^{R 3}$, is the market inefficiency measure estimated using the best three bid and ask quotes. AFTER $R_{j, d}$ and $A N N_{d}$ are dummy variables for after-8:25 intervals and announcement days, respectively. If $j$ refers to an after-8:25 interval, $A F T E R_{j, d}$ equals to 1 ; otherwise, $A F T E R_{j, d}$ equals to 0 . If day $d$ is an announcement day, $A N N_{d}$ equals to 1 ; otherwise, $A N N_{d}$ equals to 0 . The control variables include the quoted spread $\left(s_{j, d}\right)$, effective spread $\left(s_{j, d}^{e}\right)$, total depth $\left(D e p t h_{d}^{T o t a l}\right)$, five best quotes depth (Depth $\left.h_{d}^{\text {BestFive }}\right)$, depth imbalance at the best quote $\left(D I_{a t, j, d}\right)$, depth imbalance behind the best quote $\left(D I_{b h d, j, d}\right)$, order flow imbalance $\left(O F I_{j, d}\right)$, analyst coverage $\left(\right.$ Analyst $\left._{d}\right)$, market uncertainty (Uncertainty $\left.)_{d}\right)$, and information surprise $\left(\right.$ Surprise $\left._{d}\right)$.

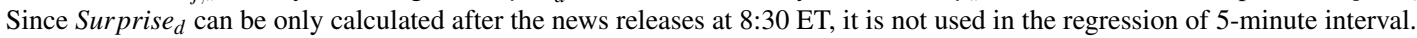
This table reports the results of $\beta_{3} \mathrm{~s}$, which measure the differences in change of $V R^{R 3}$ around 8:25 ET on the announcement and non-announcement days. ${ }^{*},{ }^{* *}$ and ${ }^{* * *}$ indicate significance at the $10 \%, 5 \%$, and $1 \%$ level, respectively. 
Table 2.10: Impacts of Macroeconomic News Released at 10:00 ET

\begin{tabular}{|c|c|c|c|c|c|c|}
\hline & \multicolumn{2}{|c|}{ Model 1} & \multicolumn{2}{|c|}{ Model 2} & \multicolumn{2}{|c|}{ Model 3} \\
\hline & 5-year & 10-year & 5-year & 10-year & 5-year & 10-year \\
\hline 5-minute & $0.048^{* * *}$ & $0.035^{* *}$ & $0.052^{* * *}$ & $0.034^{* *}$ & $0.052^{* * *}$ & $0.034^{* *}$ \\
\hline 10-minute & 0.012 & 0.012 & 0.010 & 0.009 & 0.010 & 0.009 \\
\hline 15-minute & -0.007 & 0.003 & -0.014 & -0.002 & -0.014 & -0.002 \\
\hline
\end{tabular}

This table reports the differences in change of $V R$ around 9:55 ET between the announcement and non-announcement days. We use the 10:00 ET announcements with a relevance number greater than 80 to define announcement days and non-announcement days using the same procedure as Figure 2.2. We run the three regressions as follows:

Model 1: $V R_{j, d}=\alpha+\beta_{1} A F T E R_{j, d}+\beta_{2} A N N_{d}+\beta_{3} A F T E R_{j, d} \times A N N_{d}+\varepsilon_{j, d}$;

Model 2: $\quad V R_{j, d}=\alpha+\beta_{1} A F T E R_{j, d}+\beta_{2} A N N_{d}+\beta_{3} A F T E R_{j, d} \times A N N_{d}+\beta_{4} s_{j, d}+\beta_{5} s_{j, d}^{e}+\beta_{6}$ Depth $_{j, d}^{\text {Total }}+$ $\beta_{7}$ Depth $_{j, d}^{\text {BestFive }}+\beta_{8} D I_{a t, j, d}+\beta_{9} D I_{b h d, j, d}+\beta_{10} O F I_{j, d}+\varepsilon_{j, d}$;

Model 3: $\quad V R_{j, d}=\alpha+\beta_{1} A F T E R_{j, d}+\beta_{2} A N N_{d}+\beta_{3} A F T E R_{j, d} \times A N N_{d}+\beta_{4} s_{j, d}+\beta_{5} s_{j, d}^{e}+\beta_{6}$ Depth $_{j, d}^{\text {Total }}+$ $\beta_{7}$ Depth $_{j, d}^{\text {BestFive }}+\beta_{8} D I_{a t, j, d}+\beta_{9} D I_{\text {bhd }, j, d}+\beta_{10}$ OFI $_{j, d}+\beta_{11}$ Analyst $_{d}+\beta_{12}$ Uncertainty $_{d}+\beta_{13}$ Surprise $_{d}+\varepsilon_{j, d}$.

The dependent variable is market inefficiency measure, $V R_{j, d}$. AFTER $R_{j, d}$ and $A N N_{d}$ are dummy variables for after-9:55 intervals and announcement days, respectively. If $j$ refers to an after-9:55 interval, $A F T E R_{j, d}$ equals to 1; otherwise, $A F T E R_{j, d}$ equals to 0 . If day $d$ is an announcement day, $A N N_{d}$ equals to 1 ; otherwise, $A N N_{d}$ equals to 0 . The control variables include the quoted spread $\left(s_{j, d}\right)$, effective spread $\left(s_{j, d}^{e}\right)$, total depth $\left(\operatorname{Dept}_{d}^{\text {Total }}\right)$, best five quotes depth $\left(\right.$ Dept $\left._{d}^{\text {Best Five }}\right)$, depth imbalance at the best quote $\left(D I_{a t, j, d}\right)$, depth imbalance behind the best quote $\left(D I_{b h d, j, d}\right)$, order flow imbalance $\left(O F I_{j, d}\right)$, analyst coverage $\left(\right.$ Analyst $\left._{d}\right)$, market uncertainty (Uncertainty $\left.y_{d}\right)$, and information surprise $\left(\right.$ Surprise $\left._{d}\right)$. Since Surprise $_{d}$ can be only calculated after the news releases at 8:30 ET, it is not used in the regression of 5-minute interval. This table reports the results of $\beta_{3}$ s, which measure the differences in change of $V R$ around 9:55 ET on the announcement and non-announcement days. ${ }^{*}{ }^{* *}$ and ${ }^{* * *}$ indicate significance at the $10 \%, 5 \%$, and $1 \%$ level, respectively. 
Table 2.11: One Alternative Market Inefficiency Measure: Absolute Value of Return Autocorrelation

\begin{tabular}{|c|c|c|c|c|c|c|}
\hline \multicolumn{7}{|c|}{ Panel A: $y_{j, d}=\left|A R_{j, d}\right|$} \\
\hline & \multicolumn{2}{|c|}{ Model 1} & \multicolumn{2}{|c|}{ Model 2} & \multicolumn{2}{|c|}{ Model 3} \\
\hline & 5-year & 10-year & 5-year & 10-year & 5-year & 10-year \\
\hline 5-minute & $0.066^{* * *}$ & $0.030^{* * *}$ & $0.020^{* * *}$ & $0.031^{* * *}$ & $0.020^{* *}$ & $0.031^{* * *}$ \\
\hline 10-minute & $0.043^{* * *}$ & $0.033^{* * *}$ & 0.009 & $0.020^{* * *}$ & 0.009 & $0.021^{* * *}$ \\
\hline 15-minute & $0.038^{* * *}$ & $0.067^{* * *}$ & $0.034^{*}$ & 0.023 & $0.037^{* *}$ & 0.019 \\
\hline \multicolumn{7}{|c|}{ Panel B: $y_{j, d}=\left|A R_{j, d}^{M Q}\right|$} \\
\hline & \multicolumn{2}{|c|}{ Model 1} & \multicolumn{2}{|c|}{ Model 2} & \multicolumn{2}{|c|}{ Model 3} \\
\hline & 5-year & 10-year & 5-year & 10-year & 5-year & 10-year \\
\hline 5-minute & $0.039^{* * *}$ & $0.023^{* * *}$ & $0.029^{* * *}$ & $0.018^{* *}$ & $0.029^{* * *}$ & $0.018^{* * *}$ \\
\hline 10-minute & 0.000 & $-0.024^{* * *}$ & $-0.014^{* *}$ & $-0.035^{* * *}$ & $-0.013^{* *}$ & $-0.035^{* * *}$ \\
\hline 15-minute & -0.004 & $-0.018^{* * *}$ & $-0.012^{* *}$ & $-0.026^{* * *}$ & $-0.012^{* *}$ & $-0.026^{* * *}$ \\
\hline
\end{tabular}

This table reports the differences in change of $|A R|$ (Panel A) or $\left|A R^{M Q}\right|$ (Panel B) around 8:25 ET between the announcement and non-announcement days. $\left|A R_{j, d}\right|$ is the absolute value of the first-order return autocorrelation using the unobservable true price estimated by GMM, while $\left|A R_{j, d}^{M Q}\right|$ is the absolute value of the first-order return autocorrelation using mid-quotes. In Panel $\mathrm{C}$ and Panel $\mathrm{D}$, we regress $A R$ and $A R^{M Q}$ with signs to test the overall impacts. We report $\beta_{3}$ s from the three DID regression models as follows:

Model 1: $y_{j, d}=\alpha+\beta_{1} A F T E R_{j, d}+\beta_{2} A N N_{d}+\beta_{3} A F T E R_{j, d} \times A N N_{d}+\varepsilon_{j, d}$;

Model 2: $y_{j, d}=\alpha+\beta_{1} A F T E R_{j, d}+\beta_{2} A N N_{d}+\beta_{3} A F T E R_{j, d} \times A N N_{d}+\beta_{4} s_{j, d}+\beta_{5} s_{j, d}^{e}+\beta_{6}$ Depth $_{j, d}^{\text {Total }}+\beta_{7}$ Depth $_{j, d}^{\text {BestFive }}+$ $\beta_{8} D I_{a t, j, d}+\beta_{9} D I_{b h d, j, d}+\beta_{10} O F I_{j, d}+\varepsilon_{j, d}$

Model 3: $y_{j, d}=\alpha+\beta_{1} A F T E R_{j, d}+\beta_{2} A N N_{d}+\beta_{3} A F T E R_{j, d} \times A N N_{d}+\beta_{4} s_{j, d}+\beta_{5} s_{j, d}^{e}+\beta_{6}$ Depth $_{j, d}^{\text {Total }}+\beta_{7}$ Depth $_{j, d}^{\text {BestFive }}+$ $\beta_{8} D I_{a t, j, d}+\beta_{9} D I_{b h d, j, d}+\beta_{10}$ OFI $_{j, d}+\beta_{11}$ Analyst $_{d}+\beta_{12}$ Uncertainty $_{d}+\beta_{13}$ Surprise $_{d}+\varepsilon_{j, d}$.

$A F T E R_{j, d}$ and $A N N_{d}$ are dummy variables for after-8:25 intervals and announcement days, respectively. If $j$ refers to an after-8:25 interval, $A F T E R_{j, d}$ equals to 1; otherwise, $A F T E R_{j, d}$ equals to 0 . If day $d$ is an announcement day, $A N N_{d}$ equals to 1 ; otherwise, $A N N_{d}$ equals to 0 . The control variables include the quoted spread $\left(s_{j, d}\right)$, effective spread $\left(s_{j, d}^{e}\right)$, total depth $\left(\right.$ Depth $\left.h_{d}^{\text {Total }}\right)$, best five quotes depth $\left(\right.$ Depth $\left.h_{d}^{\text {BestFive }}\right)$, depth imbalance at the best quote $\left(D I_{a t, j, d}\right)$, depth imbalance behind the best quote $\left(D I_{b h d, j, d}\right)$, order flow imbalance $\left(O F I_{j, d}\right)$, analyst coverage (Analyst $\left.s_{d}\right)$, market uncertainty $\left(\right.$ Uncertainty $\left._{d}\right)$, and information surprise (Surprise ) $_{\text {). Since Surprise }}$ can be only calculated after the news releases at 8:30 ET, it is not used in the regression of 5-minute interval. $\beta_{3}$ measures the differences in change of $\left|A R_{j, d}\right|$ or $\left|A R_{j . d}^{M Q}\right|$ around 8:25 ET on the announcement and non-announcement days. ${ }^{*},{ }^{* *}$ and ${ }^{* *}$ indicate significance at the $10 \%, 5 \%$, and $1 \%$ level, respectively. 


\section{Table 2.12: Percentages of Negative First-order Return Autocorrelation}

\begin{tabular}{|c|c|c|c|c|c|c|c|c|c|}
\hline \multicolumn{10}{|c|}{ Panel A: 5-year U.S. Treasury Notes } \\
\hline & & \multicolumn{4}{|c|}{ Two-second return } & \multicolumn{4}{|c|}{ One-second return } \\
\hline & & \multicolumn{2}{|c|}{$A R_{j, d}$} & \multicolumn{2}{|c|}{$A R_{j, d}^{M Q}$} & \multicolumn{2}{|c|}{$A R_{j, d}$} & \multicolumn{2}{|c|}{$A R_{j, d}^{M Q}$} \\
\hline & & before & after & before & after & before & after & before & after \\
\hline 5-minute & ann & $71.35 \%$ & $75.55 \%$ & $90.07 \%$ & $92.07 \%$ & $64.37 \%$ & $66.67 \%$ & $90.26 \%$ & $88.35 \%$ \\
\hline 5-minute & non & $70.05 \%$ & $66.70 \%$ & $87.02 \%$ & $83.98 \%$ & $60.73 \%$ & $64.50 \%$ & $86.39 \%$ & $85.03 \%$ \\
\hline 10-minute & ann & $73.16 \%$ & $66.48 \%$ & $93.89 \%$ & $76.60 \%$ & $62.75 \%$ & $66.86 \%$ & $92.65 \%$ & $82.62 \%$ \\
\hline 10-minute & non & $69.42 \%$ & $67.54 \%$ & $90.99 \%$ & $91.73 \%$ & $62.72 \%$ & $65.13 \%$ & $90.26 \%$ & $89.63 \%$ \\
\hline 15-minute & ann & $69.82 \%$ & $68.58 \%$ & $94.27 \%$ & $80.80 \%$ & $44.79 \%$ & $66.86 \%$ & $93.12 \%$ & $87.30 \%$ \\
\hline 15-minute & non & $66.81 \%$ & $69.74 \%$ & $91.31 \%$ & $94.14 \%$ & $40.52 \%$ & $64.50 \%$ & $92.77 \%$ & $92.98 \%$ \\
\hline \multicolumn{10}{|c|}{ Panel B: 10-year U.S. Treasury Notes } \\
\hline & & \multicolumn{4}{|c|}{ Two-second return } & \multicolumn{4}{|c|}{ One-second return } \\
\hline & & \multicolumn{2}{|c|}{$A R_{j, d}$} & \multicolumn{2}{|c|}{$A R_{j, d}^{M Q}$} & \multicolumn{2}{|c|}{$A R_{j, d}$} & \multicolumn{2}{|c|}{$A R_{j, d}^{M Q}$} \\
\hline & & before & after & before & after & before & after & before & after \\
\hline 5-minute & ann & $70.33 \%$ & $76.94 \%$ & $91.67 \%$ & $93.40 \%$ & $61.44 \%$ & $65.45 \%$ & $90.43 \%$ & $90.53 \%$ \\
\hline 5-minute & non & $69.63 \%$ & $70.26 \%$ & $90.26 \%$ & $88.06 \%$ & $61.88 \%$ & $60.63 \%$ & $90.26 \%$ & $87.33 \%$ \\
\hline 10-minute & ann & $74.55 \%$ & $66.51 \%$ & $95.50 \%$ & $80.10 \%$ & $61.91 \%$ & $68.04 \%$ & $94.93 \%$ & $87.37 \%$ \\
\hline 10-minute & non & $70.79 \%$ & $71.94 \%$ & $93.61 \%$ & $94.66 \%$ & $66.18 \%$ & $65.76 \%$ & $92.88 \%$ & $92.57 \%$ \\
\hline 15-minute & ann & $64.40 \%$ & $67.46 \%$ & $92.82 \%$ & $85.36 \%$ & $15.02 \%$ & $69.38 \%$ & $95.89 \%$ & $91.29 \%$ \\
\hline 15-minute & non & $61.88 \%$ & $74.24 \%$ & $91.41 \%$ & $96.44 \%$ & $18.85 \%$ & $64.29 \%$ & $95.29 \%$ & $95.08 \%$ \\
\hline
\end{tabular}

This table reports the percentage of negative first-order return autocorrelations. Panels A and B report the results of 5- and 10-year notes, respectively. $A R_{j, d}$ is the first order return auto-correlation of interval $j$ in day $d$ using the unobservable true returns estimated by GMM, while $A R_{j, d}^{M Q}$ is the first order return auto-correlation of the same period using mid-quotes directly. The left and right columns report the results of two- and one-second returns, respectively. 
Table 2.13: Market Order Flow Imbalances and Return Predictability

\begin{tabular}{|c|c|c|c|c|c|c|}
\hline \multicolumn{7}{|c|}{ Panel A: Whole Sample Period (From January 5, 2004 to December 15, 2015) } \\
\hline & \multicolumn{3}{|c|}{ 5-year notes } & \multicolumn{3}{|c|}{ 10-year notes } \\
\hline & $\eta=5-\min$ & $\eta=10-\min$ & $\eta=15-\min$ & $\eta=5-\min$ & $\eta=10-\min$ & $\eta=15-\min$ \\
\hline Intercept & $-0.079^{*}$ & $-0.079^{*}$ & $-0.080^{*}$ & $-0.194^{* * *}$ & $-0.190^{* * *}$ & $-0.192^{* * *}$ \\
\hline$A N N$ & 0.155 & 0.162 & 0.159 & 0.365 & 0.352 & 0.342 \\
\hline$I M B A L$ & 0.164 & 0.129 & 0.214 & $0.449^{* *}$ & -0.018 & 0.195 \\
\hline$A N N \times I M B A L$ & 0.247 & $0.925^{*}$ & $1.035^{*}$ & 0.351 & $1.601^{*}$ & 1.730 \\
\hline \multicolumn{7}{|c|}{ Panel B: GFC period (From July 1, 2007 to June 30, 2009) } \\
\hline & \multicolumn{3}{|c|}{ 5-year notes } & \multicolumn{3}{|c|}{ 10-year notes } \\
\hline & $\eta=5-\min$ & $\eta=10-\min$ & $\eta=15-\min$ & $\eta=5-\min$ & $\eta=10-\min$ & $\eta=15-\min$ \\
\hline Intercept & $-0.364^{*}$ & $-0.362^{*}$ & $-0.364^{*}$ & $-0.580^{*}$ & $-0.580^{*}$ & $-0.585^{*}$ \\
\hline$A N N$ & $1.227^{*}$ & $1.295^{*}$ & $1.270^{*}$ & 1.158 & 1.190 & 1.218 \\
\hline$I M B A L$ & 0.632 & -0.279 & 0.109 & 0.406 & -0.680 & -0.364 \\
\hline$A N N \times I M B A L$ & -0.066 & 1.995 & 2.018 & 0.957 & $8.023^{*}$ & $8.253^{*}$ \\
\hline
\end{tabular}

We use DID regressions to compare the return predictability using market order flow imbalance (IMBAL) between the announcement and non-announcement days.

$$
R_{5-\min , d}^{\text {after }}=\alpha+\beta_{1} A N N_{d}+\beta_{2} I M B A L_{\eta, d}^{\text {before }}+\beta_{3} A N N_{d} \times I M B A L_{\eta, d}^{\text {before }}+\varepsilon_{t},
$$

where $R_{5-\min , d}^{a f t e r}$ is the 5-minute return after 8:30 ET, $\eta$ refers to the interval length before 8:30 ET ( $\eta=5-, 10-$ and 15 -minute) that we use to calculate the IMBAL, and $A N N_{d}$ is the dummy variable for announcement days.

This table reports the regression results of $\beta_{3}$ s, which measure the differences of return predictability using market order flow imbalance on the announcement and non-announcement days. ${ }^{*},{ }^{* *}$ and ${ }^{* * *}$ indicate significance at the $10 \%, 5 \%$, and $1 \%$ level, respectively. 
Table 2.14: Heterogeneous Investors

\begin{tabular}{|c|c|c|c|c|c|c|}
\hline & \multicolumn{2}{|c|}{ Model 1} & \multicolumn{2}{|c|}{ Model 2} & \multicolumn{2}{|c|}{ Model 3} \\
\hline & 5-year & 10-year & 5-year & 10-year & 5-year & 10-year \\
\hline 5-minute & $0.229^{* * *}$ & $0.299^{* * *}$ & $0.102^{* * *}$ & $0.110^{* * *}$ & $0.102^{* * *}$ & $0.112^{* * *}$ \\
\hline 10-minute & $0.396^{* * *}$ & $0.583^{* * *}$ & $0.219^{* * *}$ & $0.242^{* * *}$ & $0.226^{* * *}$ & $0.253^{* * *}$ \\
\hline 15-minute & $0.291^{* * *}$ & $0.231^{* * *}$ & $0.152^{* * *}$ & -0.085 & $0.157^{* * *}$ & -0.100 \\
\hline
\end{tabular}

We run three DID regressions using return volatility, $H F$ Volatility, which measures investor heterogeneity:

Model 1: HFVolatility ${ }_{j, d}=\alpha+\beta_{1}$ AFTER $_{j, d}+\beta_{2} A N N_{d}+\beta_{3} A F T E R_{j, d} \times A N N_{d}+\varepsilon_{j, d}$;

Model 2: HFVolatility H,d $_{j, d}=\alpha+\beta_{1} A F T E R_{j, d}+\beta_{2} A N N_{d}+\beta_{3} A F T E R_{j, d} \times A N N_{d}+\beta_{4} s_{j, d}+\beta_{5} s_{j, d}^{e}+\beta_{6}$ Depth $_{j, d}^{\text {Total }}+$ $\beta_{7}$ Depth $_{j, d}^{\text {BestFive }}+\beta_{8} D I_{a t, j, d}+\beta_{9} D I_{b h d, j, d}+\beta_{10} O F I_{j, d}+\varepsilon_{j, d}$

Model 3: $\quad$ HFVolatility j,d $_{j}=\alpha+\beta_{1}$ AFTER $R_{j, d}+\beta_{2} A N N_{d}+\beta_{3} A F T E R_{j, d} \times A N N_{d}+\beta_{4} s_{j, d}+\beta_{5} s_{j, d}^{e}+\beta_{6}$ Depth $_{j, d}^{\text {Total }}+$ $\beta_{7}$ Depth $_{j, d}^{\text {BestFive }}+\beta_{8} D I_{a t, j, d}+\beta_{9} D I_{\text {bhd }, j, d}+\beta_{10}$ OF $I_{j, d}+\beta_{11}$ Analyst $_{d}+\beta_{12}$ Uncertainty $_{d}+\beta_{13}$ Surprise $_{d}+\varepsilon_{j, d}$.

HFVolatility $_{j, d}$ is calculated using the unobservable true returns estimated by GMM. $A F T E R_{j, d}$ and $A N N_{d}$ are dummy variables for after-8:25 intervals and announcement days, respectively. If $j$ refers to an after-8:25 interval, $A F T E R_{j, d}$ equals to 1; otherwise, $A F T E R_{j, d}$ equals to 0 . If day $d$ is an announcement day, $A N N_{d}$ equals to 1 ; otherwise, $A N N_{d}$ equals to 0 . The control variables include the quoted spread $\left(s_{j, d}\right)$, effective spread $\left(s_{j, d}^{e}\right)$, total depth $\left(\operatorname{Depth}_{d}^{\text {Total }}\right)$, best five quotes depth $\left(\right.$ Depth $\left.h_{d}^{\text {BestFive }}\right)$, depth imbalance at the best quote $\left(D I_{a t, j, d}\right)$, depth imbalance behind the best quote $\left(D I_{b h d, j, d}\right)$, order flow imbalance $\left(O F I_{j, d}\right)$,

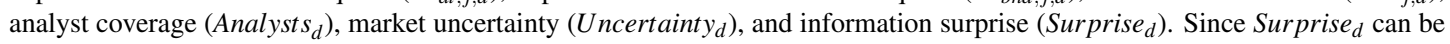
only calculated after the news releases at 8:30 ET, it is not used in the regression of 5-minute interval.

This table reports the results of $\beta_{3}$ s, which measure the differences in change of HFVolatility around 8:25 ET on the announcement and non-announcement days. ${ }^{*},{ }^{* *}$ and ${ }^{* * *}$ indicate significance at the $10 \%, 5 \%$, and $1 \%$ level, respectively. 
Table 2.15: Change Regressions

\begin{tabular}{|c|c|c|c|c|c|c|}
\hline & \multicolumn{2}{|c|}{ 5-minute } & \multicolumn{2}{|c|}{ 10-minute } & \multicolumn{2}{|c|}{ 15-minute } \\
\hline & Model 4 & Model 5 & Model 4 & Model 5 & Model 4 & Model 5 \\
\hline 5-year & $0.069^{* * *}$ & $0.054^{* * *}$ & $0.043^{* * *}$ & $0.023^{*}$ & $0.039^{* * *}$ & $0.033^{* * *}$ \\
\hline 10-year & $0.108^{* * *}$ & $0.059^{* * *}$ & $0.027^{* * *}$ & 0.009 & $0.020^{* *}$ & 0.018 \\
\hline & \multicolumn{2}{|c|}{ 5-minute } & \multicolumn{2}{|c|}{ 10-minute } & \multicolumn{2}{|c|}{ 15-minute } \\
\hline & Model 4 & Model 5 & Model 4 & Model 5 & Model 4 & Model 5 \\
\hline 5-year & $0.229^{* * *}$ & $0.136^{* * *}$ & $0.396^{* * *}$ & $0.172^{* * *}$ & $0.291^{* * *}$ & $0.205^{* * *}$ \\
\hline 10-year & $0.299^{* * *}$ & $0.163^{* * *}$ & $0.583^{* * *}$ & $0.227^{* * *}$ & $0.231^{* * *}$ & $-0.328^{* * *}$ \\
\hline
\end{tabular}

This table reports the coefficient estimates of $A N N$ from the two regressions in five-, ten- and fifteen-minute intervals around 8:25 ET during our sample period from 5 Janaury 2004 to 15 December 2015. $\Delta$ represents the differences of a variable between the after-8:25 ET interval and the before-8:25 ET interval: $\Delta=$ after-before. The two regression models are as follows:

Model 4: $\Delta y_{d}=\alpha+\beta_{1} A N N_{d}+\varepsilon_{d}$;

Model 5: $\Delta y_{d}=\alpha+\beta_{1} A N N_{d}+\left(\beta_{2}+\beta_{3} A N N_{d}\right) \times \Delta s_{d}+\left(\beta_{4}+\beta_{5} A N N_{d}\right) \times \Delta s_{d}^{e}+\left(\beta_{6}+\beta_{7} A N N_{d}\right) \times \Delta \operatorname{Depth}_{d}^{\text {Total }}+\left(\beta_{8}+\right.$ $\left.\beta_{9} A N N_{d}\right) \times \Delta$ Depth BestFive $+\left(\beta_{10}+\beta_{11} A N N_{d}\right) \times \Delta D I_{a t, d}+\left(\beta_{12}+\beta_{13} A N N_{d}\right) \times \Delta D I_{b h d, d}+\left(\beta_{14}+\beta_{15} A N N_{d}\right) \times \Delta O F I_{d}+\varepsilon_{d}$. $A N N_{d}$ is the dummy variable for an announcement day. If day $d$ is an announcement day, $A N N_{d}$ equals to 1; otherwise, $A N N_{d}$ equals to 0 . The coefficient of $A N N_{d}, \beta_{1}$, is the news announcements impact on the change of $y$ around 8:25 ET on the announcement and non-announcement days. The control variables include the change in quoted spread $\left(\Delta s_{d}\right)$, the change in effective spread $\left(\Delta s_{d}^{e}\right)$, the change in total depth $\left(\Delta D e p t h_{d}^{T o t a l}\right)$, the change in best five quotes depth

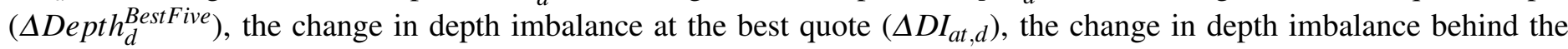
best quote $\left(\Delta D I_{b h d, d}\right)$, and the change in order flow imbalance $\left(\Delta O F I_{d}\right)$ around 8:25 ET. The $\Delta y_{d}$ is the change in the variance-ratio market inefficiency measures in Panel A, and the change in the high-frequency volatility measures in Panel B. ${ }^{*},{ }^{* *}$ and ${ }^{* * *}$ indicate significance at the $10 \%, 5 \%$, and $1 \%$ level, respectively. 
Chapter 2 


\section{Chapter 3}

\section{Workup and Market Quality: Evidence from the U.S. Treasury Market}

\subsection{Introduction}

A dark pool is a trading venue with no pre-trade transparency, which is the opposite of a lit pool. On a lit pool, order contents, such as prices and volumes, are transparent and available for all the market participants. For example, when you enter New York Stock Exchange to trade as an individual investor, for each of the stocks listed in the market, you can check its current prevailing transaction price, and several bid quotes and ask quotes together with their volumes, ranked according to the price-time priority rule. However, on a dark pool, no such information on prices or volumes are available to investors directly.

Many financial markets feature dark pool trading mechanisms. The proportions of trading volumes through dark pools have been increasing continuously in the past years. Despite the prolonged waiting time due to the opacity ${ }^{1}$, submitting orders in dark pools benefits the traders by avoiding the price pressure resulted from huge demands,

\footnotetext{
${ }^{1} \mathrm{Zhu}$ (2014) mentions that uninformed traders tend to submit their orders in dark pools, whereas informed traders tend to submit their orders in lit pools.
} 
which gets unanimous identification among researchers. However, former studies fail to reach an agreement on the impacts of dark pools. Some papers suggest that dark pools of equity markets are no harm or beneficial (Zhu, 2014; Robert, Maureen, and Gideon, 2015; Foley and Putninsš, 2016; Buti, Rindi, and Werner, 2017; Gresse, 2017); some papers show that dark pool trading or dark trading could be harmful (ComertonForde and Putninsš, 2015; Degryse, de Jong, and van Kervel, 2015). ${ }^{2}$

Workup trading in the secondary U.S. Treasury ECN market could be regarded as a type of dark trading with hidden volume. Compared with the equity markets, the workup protocol makes the dark trading on the U.S. Treasury market unique in several ways. First, all the workup transactions during the same workup window have the same workup price. There are no minimum price improvement rules as the dark pools on the equity markets. Second, the traders on the market could submit any quantity on both of the ask side and the bid side, which means that the executions of dark trades are on both sides. However, dark pools on the equity markets could be one-sided or two-sided (Foley and Putniņš, 2016). Third, the workup trading volume proportion is much higher than the dark trading proportion on the equity markets. In 2016, the workup trading volume of the on-the-run Treasury notes are about $60 \%$ to $70 \%$ of the total trading volumes on BrokerTec (Fleming and Nguyen, 2018), whereas dark pools of U.S. and Europen equity markets executed about $15 \%$ of the U.S. equity trading volume and less than $10 \%$ of the European equity volume. ${ }^{3}$

In the literature, Fleming and Nguyen (2018) study the price discovery role of the workup protocol by using the on-the-run U.S. Treasury securities data from 2006 to 2016. Our paper differs from Fleming and Nguyen (2018) in the initial recognition of a workup transaction. In their paper, they treat the whole workup process as one workup transaction, which might have more than one workup order matches. However, there might be zero to multiple workup trades during one workup window, and each

\footnotetext{
${ }^{2}$ Degryse et al. (2015) define dark trading as all of the trading activities on markets without pre-trade transparency, including dark pools, internalized trades, and over-the-counter (OTC) trading.

${ }^{3}$ Source: Rosenblatt Securities Inc. (2017). Let There Be Light. Retrieved from http://rblt .com/ letThereBeLight. aspx?year $=2017$
} 
workup order matches opens a new workup public phase (Figure 3.1). In this paper, we distinguish the workup trades within each workup window. It is important to count the workup trading frequency within one workup window as each workup order match reset the public workup duration timer. The workup trading frequency within a workup window conveys private information of the traders. Our BrokerTec order books enable us to capture the pre-workup market information, which was not captured in the paper of Zhu (2014).

In this paper, we investigate whether the workup trading affects the market quality by constructing variables from the BrokerTec order books of the 2-, 3-, 5-, 7-, 10- and 30-year on-the-run U.S. Treasury securities from January 15, 2004 to December 15, 2015. ${ }^{4}$ To control holiday effects, we exclude all of the early-close days, together with the trading days after December 15 or before January 1 each year.

We focus on New York trading hours on each trading day and divide the period from 7:30 ET to 17:30 ET into twenty 30-minute intervals. To measure market quality, we construct information efficiency measures and market liquidity measures. Following Rapach et al. (2016), we estimate the detrended workup trading measure based on workup volume ratios. Similarly, in the robustness test part, we adopt an alternative measure of detrended workup trading measure based on workup frequency ratios and show the consistent results of the workup trading impact on decreasing the market quality.

This paper contributes to the literature with some novel findings on the BrokerTec U.S. Treasury market. We find that the workup trading decreases the market efficiency and market liquidity, which is different from the findings on the equity market (Foley and Putninšs, 2016).

Workup is a special type of dark trading with hidden transaction volume and preknown fixed transaction price. Besides, the BrokerTec platform continuous to accept order submissions, alterations, or cancellation, but only matches workup orders while

\footnotetext{
${ }^{4}$ We only have the BrokerTec order books of 3-, 7- and 30-year on-the-run U.S. Treasury securities from the Year 2011 to Year 2015.
} 
the workup window opens. These characteristics of the workup protocol are different from most of the dark trading protocols on equity markets. As a result, the workup trading accounts for more than half of the total trading volume on each trading day, which is about four times that of many equity markets.

This paper provides evidence for regulation authorities to reconsider the trading protocol setting. Dark trading provides benefits for traders who do not want to expose their trading interests. If these traders who need to transact a huge amount of securities and participate in lit pool transactions, their trading behavior will create the price pressure. Dark trading resolves this problem. But dark trading on equity markets has the minimum price improvement rule, which could effectively protect the fairness of trading by increasing the information costs. But on the BrokerTec U.S. Treasury market, all workup trades within the same workup window have the same transaction prices. Only the aggressive side pays the commission fees. This creates an opportunity for traders to take informational advantage of others by strategically submitting orders. For example, if the traders have private knowledge on the upcoming scheduled news announcement and they expect the price will increase. These traders would like to buy the securities now and sell later. To save trading costs and waiting time, they would submit a sell market order to transact at the lit pool and opens a workup window. Then, those traders buy the securities at the pre-fixed transaction price and become the passive side in the workup window. This strategy works as long as the traders' beliefs are heterogeneous. According to Dungey, Henry, and McKenzie (2013), the average workup duration increases around scheduled news announcements.

The remainder of this paper is organized as follows. Section 3.2 explains the workup trading protocol in the BrokerTec U.S. Treasury market. Section 3.3 present our research data and variables constructions. Section 3.4 explore the workup trading impact on the U.S. Treasury market quality by using the detrended workup volume ratios. Section 3.5 shows the robustness of our findings. Section 3.6 concludes. 


\subsection{U.S. Treasury Market and Workup Protocol}

\subsubsection{The U.S. Treasury Market}

The U.S. Treasury market is one of the most liquid financial markets in the world (Joint Staff Report, 2015). Transactions of the secondary U.S. Treasury securities happen either in the DtC (Dealer-to-Customer) market or on the IDB (Interdealer Brokerage) platforms. The trading volume proportions of the DtC market and the IDB platforms share on a fifty-fifty basis. ${ }^{5}$ The other institutional investors, besides the primary dealers, participate in the trading on IDB relatively more actively. ${ }^{6}$

The secondary U.S. Treasury market has two main ECNs (Electronic Communications Networks) - BrokerTec and eSpeed. The platform only matches market orders with limit orders in the central limit order book (CLOB), following the price-time priority rule. ${ }^{7}$ First, all of the limit orders on each of the ask and bid sides are ranked according to the quotes they submitted, separately. The limit ask orders with lower quotes are ranked ahead of the limit ask orders with higher quotes, and the limit bid orders with higher quotes are ranked in front of the limit bid orders with lower quotes. Next, if multiple limit orders have the same quote on either ask or bid side of the limit order book, these orders are then ranked by the order submission times.

A transaction happens when a market sell order hit the limit bid order(s), or when a market buy order take the limit ask order(s). In such transactions in the lit pool with transparent trading prices and volumes, the market order submitters are the aggressive sides of the transactions and pay commission fees. As the same as many equity markets

\footnotetext{
${ }^{5}$ Calculations based on data from BrokerTec, DealerWeb, eSpeed, and the Federal Reserve in 2014 reveal that the primary dealers are the predominant players in the secondary U.S. Treasury market. However, the estimated daily trading volume of the primary dealers on the IDB platforms are less than 30\%. Source: Michael Fleming, Frank Keane, and Ernst Schaumburg (2016, February 12). Primary Dealer Participation in the Secondary U.S. Treasury Market. Retrieved from https://libertystreeteconomics.newyorkfed.org/2016/02/ primary-dealer-participation-in-the-secondary-us-treasury-market.html

${ }^{6}$ Currently, the New York Fed has 24 trading counterparties, which are institutional investors participating in all Treasury auctions. The list of primary dealers is on the website of the Federal Reserve Bank of New York: https://www. newyorkfed.org/markets/primarydealers.html

${ }^{7}$ Ask or bid limit orders are orders with specified transaction prices and quantities to sell or buy the securities, whereas market orders only specify the quantities to transact at any prices.
} 
that the liquidity providers are exempt from commission fee payments (Malinova and Park, 2015). Only the aggressive traders pay commission fees.

\subsubsection{The Workup Protocol}

Each transaction in the lit pool opens a workup window, which is a period with a default minimum duration. During the workup window, the central limit order books continue to process order submissions, alterations, or cancellations for traders. However, the platform only matches workup trades during the workup window. The lit pool transactions are therefore paused until the workup window closes.

There are a few unique trading characteristics of the workup protocol as follows. First, all the workup transactions within the same workup window have the same preknown transaction price, which is the same as the transaction price of the lit pool trade that opens the workup window. Second, any market participants can buy or sell the securities at the pre-fixed workup price without exposing their transaction interests. All the workup activities are hidden from the public, thus nobody knows the trading interests and volumes. Third, all the traders on the same side as the aggressive side of the pre-workup lit pool transaction are the aggressive traders and pay the commission fees. Fourth, the workup window originally has a default duration. The workup window closes when the workup timer counts down to zero. Each workup transaction restarts the workup timer. Fifth, the workup window closes either when there are no on-going trading interests or there are marketable limit orders with improved quotes (either lower ask quote or higher bid quote) submitted to the limit order book. ${ }^{8}$ The "no on-going trading interests" means that there is no workup transaction matched during the default workup duration.

The workup protocol has been modified a few times on the workup phases and the workup duration. In recent years after the changes, the workup process has two public phases, which allow all the market participants to submit additional volume to

\footnotetext{
${ }^{8}$ Source: Cleaves et al. (2011). United States Patent No. US7949599B1. https://patentimages . storage. googleapis . com/12/02/dd/257195112e0ae3/US7949599.pdf
} 
transact at the pre-known workup transaction price within each workup window. The work trading interests determine the workup length, which has the default duration to 3 seconds. ${ }^{9}$ The first public phase might end earlier than 3 seconds when a workup transaction happens. The second public phase starts after the first workup transaction. Each workup transaction starts a new duration. ${ }^{10}$

Figure 3.1 illustrates the open and close of a workup window. A workup window opens immediately after a transaction in the lit pool. During the workup window, all market participants could submit buy or sell orders at the pre-fixed workup price to attend the workup trading. The workup window could be composed of multiple public workup phases, each of which has a default duration. Any workup transaction opens a new workup phase. The workup window closes when there is no continuous workup trading interest. Alternatively, the workup window closes when someone submits a limit order with a better quote - if a market participant submits an ask (or bid) limit order at a lower (or higher) quote than the pre-fixed workup price, the workup window closes immediately and a new trade commerces in the lit pool, which starts another workup window.

\section{[Place Figure 3.1 about here]}

Compared with the dark trading in equity markets, both the workup trading on the U.S. Treasury market and the dark trading in equity markets allows the market participants to transact additional hidden volumes without exposing their trading interests to the public and create any negative price pressure. However, the workup protocol

\footnotetext{
${ }^{9}$ According to the calculations based on BrokerTec data, “... the mode (most common) workup length for the on-the-run ten-year note was 9 seconds at the start of 2003 and has generally trended down to just 3 seconds in 2015." Source: Fleming, M., Scharumburg, E., and Yang, R. (2015, August 12). The Evolution of Workups in the U.S. Treasury Securities Market. Retrieved from https://libertystreeteconomics.newyorkfed.org/2015/08/ the-evolution-of-workups-in-the-us-treasury-securities-market.html

${ }^{10}$ The traditional workup system has one private phase and multiple public phasis. As a result, it might have trading delays. "... the present system is adapted to provide a plurality of workup phases each of which is designated a 'public' phase and during which all trading is conducted on a first-come-first-served basis." Source: Cleaves et al. (2014). United States Patent No. US8762256B1. Retrieved from https://patentimages.storage.googleapis.com/30/1a/d3/ c7110da62ab566/US8762256.pdf
} 
makes the workup trading on the U.S. Treasury market unique in several ways. First, all the workup transactions during the same workup window have the same workup price. There are no minimum price improvement rules as the dark pools on the equity markets. Second, the traders on the market could submit any quantity on both of the ask side and the bid side, which means that the executions of dark trades are on both sides. However, dark pools on the equity markets could be one-sided or two-sided (Foley and Putniņš, 2016). Third, the workup trading volume proportion is much higher than the dark trading proportion on the equity markets. In 2016, the workup trading volume of the on-the-run Treasury notes are about $60 \%$ to $70 \%$ of the total trading volumes on BrokerTec (Fleming and Nguyen, 2018), whereas dark pools of U.S. and Europen equity markets executed about $15 \%$ of the U.S. equity trading volume and less than $10 \%$ of the European equity volume. ${ }^{11}$ Fourth, the U.S. Treasury electronic trading platforms only match workup trades during the workup window that transactions in the lit pool are paused. The lit pool trading window and the workup trading window are mutually exclusive. However, in equity markets, the dark pool transactions could happen at the same time with the lit pool transactions - the dark pool and lit pool are overlapping and independent.

\subsection{Data and Variables Constructions}

\subsubsection{BrokerTec On-the-Run U.S. Treasury Order Books}

We obtain the order books of the on-the-run 2-, 3-, 5-, 7-, 10- and 30-year U.S. Treasury securities from BrokerTec. The BrokerTec ECN is one of the two dominant electronic trading platforms of U.S. Treasury securities. The order books record all the order submission, alteration, and cancellation information in chronological order by milliseconds. ${ }^{12}$ The minimum tick sizes of the six maturities securities are 0.78125 ,

\footnotetext{
${ }^{11}$ Source: Rosenblatt Securities Inc. (2017). Let There Be Light. Retrieved from http://rblt.com/ letThereBeLight. aspx?year $=2017$

${ }^{12}$ From April 2015 onwards, the order book improves its time accuracy to record order activities in chronological order by 0.001 milliseconds.
} 
$0.78125,0.78125,1.56250,1.56250,1.56250$ cents per $\$ 100$ par value, respectively. The volume and price of each order allow us to measure the depth of the market and construct liquidity variables. Order numbers enable us to track the status of each submitted order and to match any changes or cancellations. We can also distinguish order types. Fleming et al. (2018) examine the microstructure of the BrokerTec ECN by using tick data of the one-the-run U.S. Treasury securities from 2010 to 2011.

Trading on the BrokerTec U.S. Treasury platform continues in three geographic areas - New York, London, and Tokyo. The order book activities and the trading volumes during New York trading hours from 7:30 to 17:30 (Eastern Time Zone, ET) are more intense. ${ }^{13}$ In this paper, we focus on the trading hours from 7:30 to 17:30 ET on each non-early-close trading day.

Our sample period includes the trading days between 1 January 2004 and 31 December 2015. Figure 3.2 describes the total daily amount of observations recorded in the order books of the on-the-run U.S. Treasury securities during our sample period. For the 3-, 7- and 30-year U.S. Treasury securities, we only have the order books starting from the Year 2011. We exclude the early-close days, which accounts for about $2.65 \%$ of the trading days. The order book records all the order submissions, alternations, and deletions activities, alongside the transactions matched. On some trading days, the order activities are abnormally high. Joint Staff Report (2015) study the secondary U.S. Treasury market structure in the event of sharply increased market volatility on October 15, 2014.

\section{[Place Figure 3.2 about here]}

Similar to trading on stock markets, the investors on the U.S. Treasury electronic trading platforms can submit, cancel, or alter their market orders and limit orders. Figure 3.3 shows the average order submission, alteration, and deletion frequencies, to-

\footnotetext{
${ }^{13}$ Fleming (1997) shows the breaking down of the global trading day by the interdealer trading locations in New York, Tokyo, and London. New York trading starts from 7:30 a.m. to 5:30 p.m. (New York daylight saving time). According to the data from GovPX between April 4, 1994 and August 19, 1994, the New York trading accounts for about $94.66 \%$ of the daily trading volume of the on-the-run U.S. Treasury securities. Fleming and Nguyen (2018) shows that the intraday workup probability during the New York trading hours are higher than the other trading hours.
} 
gether with the transaction frequency within a trading day from 18:30 ET on the previous trading day to $17: 30$ ET on the current trading day. ${ }^{14}$ We can directly observe that transactions only account for a very small proportion in terms of the order book activities (Fleming, 1997; Fleming and Nguyen, 2018). The order submission and cancellation activities are roughly more than $90 \%$ of the order activities during New York trading hours.

\section{[Place Figure 3.3 about here]}

\subsubsection{U.S Macroeconomic News}

We collect all the U.S. macroeconomic news information on Bloomberg terminal from January 1, 2002 to December 31, 2015. Bloomberg records all of the U.S. macroeconomic news arrival times, news contents, and economist forecasts for each announcement event. Bloomberg also calculates a relevance number (from 0 to 100) for each news during our selected sample periods, which indicates how important each type of news is to the U.S. markets. In the literature, people usually study the impact of U.S. macroeconomic news with a relevance number larger than 80 .

Table 3.1 lists all the 27 types of U.S. macroeconomic news with Bloomberg relevance numbers larger than 80 from January 1, 2004 to December 31, 2015. All of the news are ranked according to news relevance numbers. During our sample period, the majority release times are 7:00, 8:15, 8:30, 8:58, 9:15, 9:45, 9:55, 10:00, 14:00 and 14:15 (Eastern Time, ET), which have 629, 117, 2401, 44, 147, 220, 126, 1305, 23 and 16 announcement events, respectively. Among the 5375 news announcement events, about $45 \%$ and $24 \%$ are 8:30 ET and 10:00 ET announcements, respectively.

\section{[Place Table 3.1 about here]}

Figure 3.4 illustrates how we define each intraday interval into significant news announcement interval $(A N N)$, non-announcement interval $(N O N)$, or other news an-

\footnotetext{
${ }^{14}$ First, we calculate the intraday BrokerTec order book activities in 5-minute intervals on each trading day. Next, we calculate the average amount of order activities in each 5-minute intervals by using all of the non-early-close days.
} 
nouncement interval (OTHER). Each significant news (news with Bloomberg relevance number larger than 80) announcement has a two-hour event window. For example, the event window of an 8:30 ET significant news announcement starts from 7:30 ET (one hour before 8:30 ET) and ends at 9:30 ET (one hour after 8:30 ET). Similarly, the event window of a 10:00 ET significant news announcement starts from 9:00 ET (one hour before 10:00 ET) and ends at 11:00 ET (one hour after 10:00 ET). Any intraday interval overlaps with the event window of a significant news announcement is defined as a significant news announcement interval $(A N N)$. Suppose a trading day has various types of significant news announced at 8:30 ET and 10:00 ET. ANNs are the intraday intervals overlapping with the period from 7:30 ET to 11:00 ET on that trading day.

A non-news announcement period is identified as long as the following two conditions are jointly satisfied: (1) there is no U.S. macroeconomic news released during that period ; and (2) there is no U.S. macroeconomic news released during within two hours before and after that period. For example, if there are no U.S. macroeconomic news arrivals from 11:00 ET to 16:00 ET on a trading day, we identify the period from 13:00 ET to 14:00 ET as a non-news announcement period. Any intraday interval overlaps with the non-news announcement period is defined as a non-announcement interval $(N O N)$. The rest of the intervals identified neither as $A N N$ nor as $N O N$ are other news announcement intervals (OTHER).

\section{[Place Figure 3.4 about here]}

\subsubsection{Workup Volume Ratios}

The workup volume ratio in the time interval $j$ on the trading day $d$ is calculated as follows:

$$
\text { VolumeRatio }_{j, d}^{\text {Workup }}=\frac{\text { WorkupVolume }_{j, d}}{\text { WorkupVolume }_{j, d}+\text { LitVolume }_{j, d}},
$$


where WorkupVolume $_{j, d}$ and LitVolume ${ }_{j, d}$ are the workup transaction volume and lit transaction volume in interval $j$ on day $d$, measured in $\$$ million par. Figure 3.6 plots the workup ratios in the twenty 30-minute intervals between 7:30 ET and 17:30 ET. The figures show that the workup ratios increase in recent years (Fleming and Nguyen, 2018). There also exists intraday seasonality. This time trend and intraday seasonality overclouds the true information conveys in the workup ratios (Romano and Wolf, 2001; Lo and Wang, 2015; Rapach et al., 2016). To capture the information contained in the workup ratio, we use the detrended measure.

\section{[Place Figure 3.6 about here]}

To de-trend the workup volume ratios, we add the interval dummy, INTERVAL ${ }_{j}$, to the linear time trend model (Rapach et al., 2016) as follows. ${ }^{15}$

$$
\ln \left(\text { VolumeRatio }_{j, d}^{\text {Workup }}\right)=\alpha+\beta_{1} \times d+\sum_{j=2}^{J} \beta_{2, j} \operatorname{INTERVAL}_{j}+\mu_{j, d}^{\text {Volume }}
$$

$d$ is the non-early-close trading days ranked in ascending date order. For example, the 2-year U.S. Treasury notes in our sample has 2994 trading days, and 2923 trading days are non-early-close days. $d$ of the 2-year U.S. Treasury notes ranges from 1 to 2923 as we exclude the early-close days. INTERVAL $L_{j}$ is the dummy variable for time intervals: $I N T E R V A L_{j}=1$, when the interval is $j$; otherwise, INTERVAL $L_{j}=0$. A trading day has $J$ intervals between 7:30 ET and 17:30 ET. The residuals for the linear time series model as Equation (3.2) are $\mu_{j, d}^{\text {Volume }}$, which is:

$$
\begin{aligned}
\mu_{j, d}^{\text {Volume }} & =\ln \left(\text { VolumeRatio }_{j, d}^{\text {Workup }}\right)-\ln \left(\text { VolumeRatio }_{j, d}^{\text {Workup }}\right) \\
& =\ln \left(\text { VolumeRatio }_{j, d}^{\text {Workup }}\right)-\left(\alpha+\beta_{1} \times d+\sum_{j=2}^{J} \beta_{2, j} I_{\text {INTERVAL }}\right) .
\end{aligned}
$$

The $\ln \left(\right.$ VolumeR $_{\text {atio }}$ Workup $\left._{j, d}\right)$ part incorporates a time trend and the interval fixed effect.

\footnotetext{
${ }^{15}$ In the paper of Rapach et al. (2016), the authors also compare the alternative non-linear detrending methods, and find the results are robust across the alternative detrending methods, including the quadratic model, the cubit model, and the stochastic model.
} 
$\alpha$ is the same across all intervals on all trading days. In the interval $j$ on the day $d$, the detrended workup volume ratios is $\hat{\mu}_{j, d}^{\text {Volume }} .{ }^{16}$ We use it as the independent variable and study how workup trading affects the market quality of the U.S. Treasury ECN market.

\subsubsection{Market Quality Measures and Other Control Variables}

\subsubsection{Informational inefficiency measures}

Market efficiency captures how fast the market price reflects market information. Following Foley and Putninsš (2016), we use the absolute values of first-order autocorrelations of returns $(|A R|)$, and the absolute values of variance ratios $(V R)$ to measure the informational efficiency of the market. ${ }^{17}$ A larger $|A R|$ or $V R$ means that the market is less efficient.

The returns are calculated by using mid-quotes and expressed in basis points (bps). First, we calculate the midquote of each observation in the order book, which is the mean of the best ask quote $\left(A_{t}\right)$ and the best bid quote $\left(B_{t}\right)$ :

$$
\text { MidQuote }_{t}=\frac{A_{t}+B_{t}}{2}
$$

Second, we extract the midquotes by second: (1) if there is one to multiple observations within the second, we take the last midquotes as the midquote of that second; or (2) if there is no observation within one second, we take the last available midquotes as the midquote of that second. Third, we calculate 1-, 2-, 4- and 5-second log returns as follows:

$$
\begin{aligned}
& r_{1 \text { sec }, t}=\ln \left(\frac{\text { MidQuot }_{t}}{\text { MidQuote }_{t-1}}\right) \times 10000 \\
& r_{2 s e c, t}=\ln \left(\frac{\text { MidQuot }_{t}}{\text { MidQuote }_{t-2}}\right) \times 10000
\end{aligned}
$$

\footnotetext{
${ }^{16}$ In the robustness test, we use the workup frequency ratios and apply the same method to calculate the detrended measure.

${ }^{17}$ Foley and Putninsš (2016) explains the absolute value of first-order autocorrelations of returns measures both under-reaction and over-reaction to new information arrivals. If the market is highly efficient, the market participants could react to any new information arrivals immediately and accurately. The market price or mid quote captures the speed of the traders' adjustments to new information.
} 


$$
\begin{aligned}
& r_{4 s e c, t}=\ln \left(\frac{\text { MidQuote }_{t}}{\text { MidQuote }_{t-4}}\right) \times 10000 \\
& r_{5 s e c, t}=\ln \left(\frac{\text { MidQuote }_{t}}{\text { MidQuote }_{t-5}}\right) \times 10000 .
\end{aligned}
$$

To control the market microstructure noise, we continue to use the generalized method of moments (GMM) (Madhavan et al., 1997) to estimate the variances of the true returns from mid-quotes as Section 2.2.3 in Chapter 2 as follows. ${ }^{18}$

$$
\left\{\begin{array}{l}
E\left[\widehat{\operatorname{Var}}\left(R_{t}^{\text {True }}\right)+2 a^{2}-\operatorname{Var}\left(R_{t}^{M Q}\right)\right]=0 \\
E\left[\operatorname{Cov}\left(R_{t}^{M Q}, R_{t-1}^{M Q}\right)+a^{2}\right]=0
\end{array} .\right.
$$

Based on the non-overlapping one-second and five-second returns, the varianceratio market inefficiency measure of interval $j$ on day $d$ is:

$$
V R_{j, d}=\left|\frac{\widehat{\operatorname{Var}}\left(R_{5, j, d}^{T r u e}\right)}{5 \widehat{\operatorname{Var}}\left(R_{1, j, d}^{T r u e}\right)}-1\right|,
$$

where $\widehat{\operatorname{Var}}\left(R_{n, j, d}^{T r u e}\right)$ is the variance of $n$-second true returns of interval $j$ on day $d$. If the true prices follow a random walk, $\frac{\widehat{\operatorname{Var}}\left(R_{5, j, d}^{\text {True }}\right)}{5 \widehat{\operatorname{Var}}\left(R_{1, j, d}^{\text {True }}\right)}$ should be equal to 1 and $V R_{j, d}$ should be equal to zero (Lo and MacKinlay, 1988; Ben-David et al., 2018). A larger value of $V R_{j, d}$ indicates that the market is less efficient.

Similarly to Chapter 2, we use the estimated variance of true returns to calculate the

\footnotetext{
${ }^{18}$ According to Ait-Sahalia and Yu (2009), the observed mid-quote includes the unobservable true price and a noise part.

$$
\ln \left(\text { MidQuote }_{t}\right)=\ln \left(P_{t}^{\text {True }}\right)+\varepsilon_{t},
$$

where $P_{t}^{\text {True }}$ is the unobservable true price at time $t$, and $\varepsilon_{t}$ is the microstructure noise which follows i.i.d. $\left(0, a^{2}\right)$. Return of mid-quote follows $R_{t}^{M Q}=R_{t}^{\text {True }}+\varepsilon_{t}-\varepsilon_{t-1}$.

$$
\begin{aligned}
& \ln \left(\text { MidQuote }_{t}\right)-\ln \left(\text { MidQuote }_{t-1}\right)=\left(\ln \left(P_{t}^{\text {True }}\right)+\varepsilon_{t}\right)-\left(\ln \left(P_{t-1}^{\text {True }}\right)+\varepsilon_{t-1}\right) \\
& =\left(\ln \left(P_{t}^{\text {True }}\right)-\ln \left(P_{t-1}^{\text {True }}\right)\right)+\varepsilon_{t}-\varepsilon_{t-1} .
\end{aligned}
$$

Assuming the true price follows a random walk process, we have $\operatorname{Var}\left(R_{t}^{M Q}\right)=\operatorname{Var}\left(R_{t}^{\text {True }}\right)+2 a^{2}$, and $\operatorname{Cov}\left(R_{t}^{M Q}, R_{t-1}^{M Q}\right)=-a^{2}$.
} 
absolute value of first-order autocorrelation of true returns as follows. ${ }^{19}$ Since

$$
\widehat{\operatorname{Var}}\left(R_{4, j, d}^{T r u e}\right)=2 \widehat{\operatorname{Var}}\left(R_{2, j, d}^{\text {True }}\right)+2 A R_{j, d} \widehat{\operatorname{Var}}\left(R_{2, j, d}^{\text {True }}\right)
$$

we have:

$$
|A R|_{j, d}=\left|\frac{\widehat{\operatorname{Var}}\left(R_{4, j, d}^{\text {True }}\right)}{2 \widehat{\operatorname{Var}}\left(R_{2, j, d}^{\text {True }}\right)}-1\right| .
$$

If the market prices fully reflect all of the information immediately, we have $|A R|_{j, d}=0$; otherwise, a larger $|A R|_{j, d}$ indicates a lower level of market efficiency.

\subsubsection{Market Liquidity Measures}

\section{Quotes or Prices-Related Measures}

Quotes or prices-related liquidity measures, such as the quoted spread and the effective spread, are well used in the literature as proxies for market liquidity (Degryse et al., 2015; Foley and Putninšs, 2016; Fleming et al., 2018). A high spread indicates a less liquid market situation.

However, these measures could not capture the change in market liquidity caused by workup trading for the following reasons. First, during the same workup window, all the transaction prices are pre-fixed at the lit transaction price that opens the workup window. As a result, the transaction prices $\left(P_{i, d}^{\text {Transaction }}\right)$ of all the workup trades within one workup window is always the same, regardless of the workup trading activities.

Second, any transaction in the lit pool opens a workup window, during which the BrokerTec or eSpeed U.S. Treasury platform stops matching any orders in the lit pool but only matching workup orders. Each workup transaction restarts the counting down the clock of workup. Traders can still submit limit orders at various quotes that are different from the pre-fixed workup prices to the limit order books. The aggressive side of the pre-workup lit transaction is the aggressive side of all the transactions in the workup window. The traders on the aggressive side pay commission fees. The

\footnotetext{
${ }^{19}$ According to the definition of $|A R|_{j, d}$, any correlation number should range from -1 to 1 , so that $0 \leq|A R|_{j, d} \leq 1$. We use 1 to replace any estimated $|A R|_{j, d}$ values larger than 1.
} 
bid-ask spread could not measure how liquid the market is within a workup window when a huge amount of traders from both of the ask and bid sides submit market (or equivalent) orders to attend workup trading. The continuous workup trading activities within the same workup window are not captured by the bid-ask spread.

Third, a workup window closes either when there is no continuous trading interest, or when there is a limit order submitted at a better quote in the lit pool. These rules indicate that within a workup window, the best ask quote could not be any lower than the workup transaction price, and the best bid quote could not be any higher than the workup price; otherwise, a workup window closes and a transaction happens in the lit pool, which opens a new workup window. Whether to attend workup trading depends on the investors' tradeoff between waiting time and price premium. Suppose the aggressive side of a workup window is the bid side. Since only the aggressive side pays the commission fee, the traders on the aggressive side have no price advantage to continuously submit the workup orders as they pay the workup transaction prices ( $P^{\text {workup }}$ ) and the commission fees $(C)$, which makes their total cost $C$ higher than their counterparty's total cost $\left(P^{\text {workup }}\right)$. However, if they want to make savings and take a pass of the workup trading, they could submit a limit order at any quote lower than $P^{\text {workup }}+C$. The traders on the ask side (workup liquidity suppliers) in this workup window pays no commission fees. This provides direct price benefits to those traders who intended to submit market orders to sell at any price no higher than $P^{\text {workup }}+C$. In this situation, no traders on the ask side would like to transact lower than the workup price given that they are all rational. The uncertain workup duration becomes the pressure on the liquidity suppliers to encourage them to transact at the workup window. However, these liquidity suppliers are not captured by the best quotes on the ask or bid side.

As a result, we do not use these measures in our empirical analysis, we use depth and depth imbalance measures to capture the liquidity relevant to the workup protocol.

\section{Depth}

Depth is the accumulative limit order quantity on both of the ask and bid sides, which has been used a lot in the literature to measure liquidity supply (Harris, 1994; 
Goldstein and Kavajecz, 2000; Chordia, Roll, and Subrahmanyam, 2001; Hendershott, Jones, and Menkveld, 2011; Chung and Chuwonganant, 2014; Fleming et al., 2018). Market orders consume liquidity while limit orders supply liquidity (Malinova and Park, 2015). However, this is a rough estimation of market liquidity for two reasons. First, depth is an accumulative amount of limit orders submitted at various quotes - the accumulative depth could not measure how easy a trader can buy or sell at his or her preferred price. Second, depth is an accumulative amount of limit orders submitted on both sides of the order book - the accumulative depth could not measure whether the order book is liable for both bid and ask market orders to be matched without a big price movement.

We calculate the accumulative depth at different quote levels of the bid and ask quotes by using all the limit orders. Limit order submitters are the market liquidity suppliers. The depth measure captures the aggregate market liquidity supply. ${ }^{20}$ The total depth, Depth $h_{a l l, j, d}$, is the average limit order volume across all the price levels in the order book within the interval $j$ on the day $d$.

$$
\operatorname{Depth}_{a l l, j, d}=\frac{1}{N_{j, d}^{L}} \sum_{i \in j}\left(\operatorname{Depth}_{a l l, i, d}^{A}+\operatorname{Depth}_{a l l, i, d}^{B}\right)
$$

where $D e p t h_{i, d}^{A}$ and $D e p t h_{i, d}^{B}$ are the total ask-side and bid-side depths of the $i$ th limit order on day $d . N_{j, d}^{L}$ is the total number of limit orders within the interval $j$ on day $d$. For example, Figure 3.7 illustrates the market depth decompositions of the 5-year U.S. Treasury notes at the time stamp of 08:45:17:434240 ET on August 10, 2015.

\section{[Place Figure 3.7 about here]}

Liquidity supplied at front levels are more important as those orders will be matched ahead of other limit orders with less competitive quotes as the principle of price/time priority. Following Fleming et al. (2018) and Álvaro Cartea, Payne, Penalva, and Tapia

\footnotetext{
${ }^{20}$ In the U.S. Treasury ECNs, transactions in the lit pool are matched between market orders and limit orders. The market order submitters pay commission fees. Each transaction in the lit pool opens a workup window, during which all of the orders submitted at the same side with the market order submitters in the lit pool transaction pay commission fees.
} 
(2019), we also construct depth at the best level of quotes (Depth $\left.h_{a t, j, d}\right)$, depth at the top three levels of quotes $\left(\right.$ Depth $\left._{3, j, d}\right)$, depth at the top five levels of quotes $\left(\right.$ Depth $\left._{5, j, d}\right)$, and depth at the top ten levels of quotes $\left(\right.$ Depth $\left._{10, j, d}\right)$. The depth at the best level of quotes, Depthat,j,d , is the mean limit order volume of the best quotes on both sides of the limit order book within the interval $j$ on day $d$.

$$
\operatorname{Depth}_{a t, j, d}=\frac{1}{N_{j, d}^{L}} \sum_{i \in j}\left(\operatorname{Depth}_{a t, i, d}^{A}+\operatorname{Depth}_{a t, i, d}^{B}\right)
$$

where Depthat,i,d $A$ and Depthat,i,d $h^{B}$ are the ask-side depth at the best quote and the bidside depth at the best quote of the $i$ th limit order on day $d$. Similarly, the depth at the top $K$ levels of quotes, Dept $_{K, j, d}$, is the mean limit order volume of the top $K$ levels of quotes on both sides of the limit order book within the interval $j$ on day $d$.

$$
\operatorname{Depth}_{K, j, d}=\frac{1}{N_{j, d}^{L}} \sum_{i \in j}\left(\text { Dept }_{K, i, d}^{A}+\operatorname{Depth}_{K, i, d}^{B}\right), \quad(K=3,5, \text { or 10) }
$$

where $D e p t h_{K, i, d}^{A}$ and $D e p t h_{K, i, d}^{B}$ are the ask-side depth at the top $K$ levels of quotes and the bid-side depth at the top $K$ levels of quotes of the $i$ th limit order on day $d$.

\section{Depth Imbalances}

Depth imbalance measures the distance between ask side supply and bid side supply. If the liquidity supply tilts towards one side, the depth measure might not be able to capture the liquidity supply gap between the ask side and the bid side. Thus, depth imbalance is one of the most informative market liquidity variables (Boudt and Petitjean, 2014). Following Jiang et al. (2011) and Brogaard et al. (2019), we construct depth imbalances at different levels in the order books. A high level of depth imbalance shows that the market is less liquid given the accumulative depth is stable.

The depth imbalance at the best quote in the interval $j$ on day $d, D I_{a t, j, d}$, is the mean value of all the depth imbalances at the best quote within the interval $j$ on day $d$.

$$
D I_{a t, j, d}=\frac{1}{N_{j, d}^{L}} \sum_{i \in j}\left|D e p t h_{a t, i, d}^{A}-D e p t h_{a t, i, d}^{B}\right|
$$


Similarly, the depth imbalance at top $K$ levels of quotes, $D I_{K, j, d}$, is the mean value of all the depth imbalances at $K$ levels of quotes within the interval $j$ on day $d$.

$$
D I_{K, j, d}=\frac{1}{N_{j, d}^{L}} \sum_{i \in j}\left|\operatorname{Depth}_{K, i, d}^{A}-\operatorname{Depth}_{K, i, d}^{B}\right|, \quad(K=3,5, \text { or } 10)
$$

\subsubsection{Other Control Variables}

\section{Trading Volume}

The trading volume $\left(\$\right.$ Volume $\left._{j, d}\right)$ within each interval $j$ on the trading day $d$ is the natural log of total transaction quantity of U.S.Treasury contracts (in \$ million par).

\section{High-to-Low Volatility}

The high-to-low (HL) market volatility measure (Parkinson, 1980; Hendershott et al., 2011; Foley and Putniņš, 2016), HLVolatility, enables us to estimate the market volatility by capturing the extreme prices. For example, to calculate the HLVolatility in a 5-minute interval, we firstly find out the highest price $(H)$ and the lowest price $(L)$ within each 10-second period, so that $l_{i}=\ln \left(\frac{H_{i}}{L_{i}}\right)$. The HLVolatility of the $j$-th interval on trading day $d$ is:

$$
\text { HLVolatility }_{j, d}=\hat{\sigma}_{l, j, d}=\sqrt{\frac{1}{30-1} \sum_{i=1}^{30}\left(l_{i}-\bar{l}\right)^{2}}
$$

where $\bar{l}$ is the average of all the $l_{i}$ within this 5-minute interval.

\section{Market Order Flow Imbalance}

Order flow imbalance is a proxy for information asymmetry to measure how the market reacts to the arrivals of new information (Lee and Ready, 1991; Álvaro Cartea et al. (2019)). The order flow imbalance of the $j$ th-interval on day $d$ is the sum of all order flow imbalances within interval $j$ on day $d$.

$$
O F I_{j, d}=\sum_{i \in j}\left|O F_{i, d}^{A}-O F_{i, d}^{B}\right|
$$

where $O F_{i, d}^{A}$ and $O F_{i, d}^{B}$ refer to the volume of the $i$ th market order on day $d$ from the ask 
side and the bid side, respectively.

\subsubsection{Data Summary}

The sample period of the 2-, 5- and 10-year U.S. Treasury notes is from January 5, 2004 to December 15, 2015. The sample period of the 3- and 7-year U.S. Treasury notes, and the 30-year U.S. Treasury bonds are from January 5, 2011 to December 15, 2015. To control the holidays' influence on the U.S. Treasury market, we exclude the full-close and early-close days, together with the days before January 5 or after December 15 in each year. Table 3.2 shows the value ranges of the variables we use in our analysis. On each non-early-close trading day, we divide the New York Trading hours (from 7:30 ET to 17:30 ET) into twenty 30-minute intervals. In each of the twenty intervals, we winsorize each variable at the $1 \%$ and $99 \%$ levels. Then, for each interval, we sort all days into quintiles by each variable and calculate the mean values in each group. Table 3.2 reports the mean values of the variables for each group across all intervals.

[Place Table 3.2 about here]

\subsection{Workup Trading Volume and Market Quality}

In this paper, we investigate whether the workup trading in the U.S. Treasury secondary market influences the market quality by focusing on New York Trading hours from 7:30 ET to 17:30 ET, during which the trading is more active (Figure 3.2 and Figure 3.3). We run the panel regression model by dividing the New York Trading hours into 120 5-minute intervals from 7:30 ET to 17:30 ET (Foley and Putninš̌, 2016; Álvaro Cartea et al., 2019). We control the fixed effects of different trading days and intraday intervals. Also, we introduce two dummy variables to control the impact of U.S. macroeconomic news announcement on market quality - ANN and NON are the dummy variables for significant news announcement intervals and non-announcement 
intervals as defined in Figure 3.4. The shorter the intraday intervals we study, the more accurately we divide those intraday intervals into $A N N, N O N$ and $O T H E R .^{21}$ Thus, we report the panel regression results of 5-minute intraday intervals.

The panel regression model is:

$$
\begin{aligned}
y_{j, d}= & \alpha_{1, j}+\alpha_{2, d}+\beta_{1} \hat{\mu}_{j, d}^{\text {Volume }}+\beta_{2} \text { SVolume }_{j, d}+\beta_{3} \text { HLVolatility }_{j, d}+ \\
& \beta_{4} \text { OFI }_{j, d}+\gamma_{1} A N N_{j, d}+\gamma_{2} N O N_{j, d}+\varepsilon_{j, d}
\end{aligned}
$$

where $j$ is the interval and $d$ is the trading day. $y_{j, d}$ is the market quality measure. $\alpha_{1, j}$ is the unobservable fixed effect of intraday intervals (as the same as the firm effect in the classic fixed effect model), and $\alpha_{2, d}$ is the unobservable fixed effects of trading days (as the same as the time effect in the classic fixed effect model). $\hat{\mu}_{j, d}^{\text {Volume }}$ is the detrended workup volume ratio, estimated by using Equation (3.2) in Section (3.3.3). $\$$ Volume $_{j, d}$

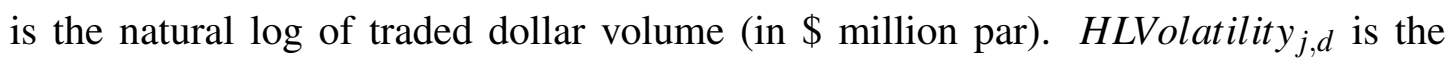
high-to-low volatility as Equation (3.17). $O F I_{j, d}$ is the market order flow imbalance as Equation 3.18.

The coefficient of our interest is $\beta_{1}$. A significantly positive $\beta_{1}$ means that more workup activities are associated with a higher level of $y_{j, d}$. For example, a higher level of market inefficiency measures suggests the market is less efficient. Thus, a significantly positive $\beta_{1}$ shows that workup trading decreases the market efficiency; and vice versa.

\subsubsection{Impact on Informational Efficiency}

Table 3.3 reports the estimated coefficients of $\hat{\mu}_{j, d}^{\text {Volume }}$, when we use $V R$ or $|A R|$ as the dependent variable. All of the estimates of $\beta_{1}$ s are significantly positive across the six maturities during our sample period. For example, for 10-year U.S. Treasury notes, the coefficients, $\beta_{1}$ s, are 0.090 and 0.008 , and all significant at the $1 \%$ level, when regressing $V R$ and $|A R|$, respectively. The positive correlation between detrended

\footnotetext{
${ }^{21} A N N_{j, d}+N O N_{j, d}+O T H E R_{j, d}=1$
} 
workup volume ratios and market inefficiency measures shows that workup trading in the U.S. Treasury market deteriorates market efficiency. This finding is opposite from the literature on dark trading impacts in the equity markets (Foley and Putninšs, 2016).

As we mentioned in Section 3.1 that the workup protocol of the U.S. Treasury secondary market ECNs differs from the dark trading rules of equity markets in several ways. Our finding of workup trading's negative impact on the U.S. Treasury market is valuable for both of the market regulators and the market participants.

[Place Table 3.3 about here]

\subsubsection{Impact on Liquidity Supply and Market Liquidity}

Table 3.4 shows the estimates of regressing depth and depth imbalance measures on the detrended workup volume ratios and other control variables. For different maturities of the U.S. Treasury securities in our sample period, we report the results in two main columns. The cumulative depths at different quote-levels reflects the market liquidity supplier's activities, while the cumulative depth imbalances at different quote-levels reflect the market liquidity.

\section{[Place Table 3.4 about here]}

Results on workup trading impact on limit orders submitters' activities in the first main column in Table 3.4 shows consistent relation between workup trading activities and limit order supplies in each maturity. An increase in workup volume ratios in the 2-, 3- and 5-year U.S. Treasury notes market is associated with the decrease in limit order supply, measured by the accumulated depths at the best quotes, at the top 3 levels of quotes, at the top 5 levels of quotes, and at the top 10 levels of quotes on both sides of the market. However, an increase in workup volume ratios in the 7-, 10- and 30-year U.S. Treasury securities market is associated with an increase in limit order supply.

We will leave the formal tests on how to explain the results of the workup trading impact on limit order supplies for future research. Here we briefly provide some explanation in the following two aspects. First, the limit order supplies are measured by 
the total depth at different quote levels, which are the sum of the limit orders on both of the ask side and the bid side. As we have explained in Section 3.3.4.2 on depth measures, the total depth cannot accurately reflect how easily the securities could be bought or sold at a fair price. Sometimes, when the total depth is high, it might be caused by either both of the ask and bid sides have quite a lot of liquidity supplies, or only one side has much more depth than the depth of the other side. The consistent impact among each maturity on one hand shows that the market characteristics of the U.S. Treasury securities with shorter maturities differ from those with longer maturities; on the other hand, if we compare the results of workup trading on total depth with the results of workup trading on depth imbalance, it confirms our former claiming that depth imbalance is a more suitable measure for market liquidity than the total depth.

Second, the finding that the workup trading impact on the limit order supplies varies by maturities could also be explained by the workup protocol setting and market competition among traders. There is no transaction in the lit pool while the workup window opens. If the traders have the urgency to trade, they might either to accept the workup transaction price ( $P^{\text {workup }}$ ) by participating workup trading or to re-submit marketable limit orders with improved quotes. Which method they choose depends on which side pays the commission fees in the workup transactions and how patient the traders are. They would benefit from participating in workup trading if they are the passive side and exempt from commission fees $(C)$ rather than submitting marketable limit orders, as traders on the aggressive side have to pay commission fees, which will increase the purchasing price $\left(P^{\text {workup }}+C\right)$ or decrease the selling income $\left(P^{\text {workup }}-C\right)$. However, it does not guarantee that they could find a counterparty to trade during the workup window. The trader who intended to participate workup trading but not (fully) matched has to extend the waiting time by submitting the limit order with the same price to wait in the limit order book, submitting a market order, or submitting a marketable limit order. Thus, the patient levels of traders influence their order submission behaviors. Order submission behaviors of traders influence the total depth at different levels of quotes in the limit order books. Investors themselves are different, which could explain 
for the pattern differences between 2-, 3- and 5-year U.S. Treasury notes and the 7-, 10- and 30-year U.S. Treasury securities. For example, Jiang et al. (2011) find that the investors' private information is higher for longer-maturity bonds.

Results on workup trading impact on market liquidity in the second main column Table 3.4 suggests that workup trading decreases the U.S. Treasury market liquidity at various quote-levels. $92 \%\left(=\frac{22}{24}\right)$ of $\beta_{1} \mathrm{~s}$, are positive, and significant at the $1 \%$ level, among which all of the coefficients estimated by regressing $D I_{a t}$ and $D I_{3}$ measures are positive and significant at the $1 \%$ level. For example, the $\beta_{1}$ s are $63.305,33.582,9.695$, 25.629, 12.649 and 1.861 when regressing the $D I_{a t}$ measures of the 2-, 3-, 5-, 7-, $10-$ and 30-year U.S. Treasury notes.

Thus, Table 3.4 shows that workup trading activities significantly decrease the U.S. Treasury market liquidity, and influence the limit order submitters behaviors.

\subsection{Robustness Tests}

In this section, we run several robustness tests. First, we test the workup frequency impact on market quality. Second, we examine our finding that workup trading decreases market efficiency by focusing on 8:30 ET announcements. Third, we adopt modified depth imbalances to measure market liquidity.

\subsubsection{Workup Trading Frequency and Market Quality}

The workup frequency ratio in the time interval $j$ on the non-early-close trading day $d$ is calculated as follows:

$$
\text { FreqRatio }_{j, d}^{\text {Workup }}=\frac{\text { WorkupFreq }_{j, d}}{\text { WorkupFreq }_{j, d}+\text { LitFreq }_{j, d}},
$$

where WorkupFreq $_{j, d}$ and LitFreq $_{j, d}$ are the workup transaction frequency and lit transaction frequency in interval $j$ on day $d$, measured in $\$$ million par. We estimate the detrended workup frequency ratios $\left(\hat{\mu}_{j, d}^{F r e q}\right)$ by using the linear time trend model as 
Equation (3.2), where the dependent variable is FreqRatio ${ }_{j, d}^{\text {Workup }}$.

\subsubsection{Impact on Informational Efficiency}

Table 3.5 reports the regression results of workup trading frequency on the U.S. Treasury market efficiency. All of the coefficients estimated in the fixed effect regressions are significantly positive across the six maturities in our sample period. For example, for the 5-year U.S. Treasury notes in our sample period, the coefficients of $\hat{\mu}^{\text {Freq }}$ are 0.181 and 0.083 , and significant at the $1 \%$ level, when regressing $V R$ and $|A R|$, respectively. The positive correlation between the detrended workup frequency ratios and the market inefficiency measures suggest that any increase in working trading frequency decreases the market efficiency. The finding in this part is consistent with the finding in Section 3.4.1.

\section{[Place Table 3.5 about here]}

\subsubsection{Impact on Liquidity Supply and Market Liquidity}

Table 3.6 reports the regression results of workup trading frequency on the liquidity supplies and market liquidity at different quote-levels in two main columns. The first main column shows that the workup trading frequency significantly influences the aggregate limit order submissions in each maturity. The impact varies that in the 2- and 3-year U.S. Treasury notes market, the more frequent workup trading, the less limit order submissions; however, in 5-, 7-, 10- and 30-year U.S. Treasury securities market, the limit order submissions is positively correlated with the workup trading frequency. The correlation between liquidity supply and workup trading in the 5-year U.S. Treasury market is opposite to the finding in Section 3.4.2.

Workup trading volume and frequency has some differences. The workup volume ratio measures the percentage of trading volume that is matched in workup windows. The workup frequency ratio measures the number of workup transactions to the total number of transactions, which is irrelevant to the trading volume. But workup fre- 
quency could be an indicator of the workup duration, which is the length of the workup window. Each workup transaction restarted the counting down of the workup clock. The higher workup frequency could also indicate the ongoing trading interest at the workup price. We leave the discussion on this aspect to further studies.

The second main column in Table 3.6 reports the workup trading frequency impact on the U.S. Treasury market liquidity. All the $\beta_{1}$ s are significantly positive. For example, the $\beta_{1}$ s estimated by regressing $D I_{10}$ are $9.644,4.183,18.010,5.968,15.834$ and 5.383, and all significant at the $1 \%$ level. The significant coefficients suggest that workup trading decreases the market liquidity, which is the same as the finding in Section 3.4.2.

\section{[Place Table 3.6 about here]}

\subsubsection{Workup Trading Impact around the 8:30 ET Announcements}

To check the robustness of our finding that workup trading decreases the U.S. Treasury market efficiency, we focus on the 5-, 10- and 15-minute intervals around 8:25 ET and repeat the analysis in Chapter 2. In this analysis, we could better control new information impacts by using only news announcement days and non-announcement days as defined in Figure 2.2 of Chapter 2.

We add the detrended workup volume ratio or the detrended workup frequency ratio as one additional independent variable, and report its coefficients. The new differencein-differences regression model is:

$$
\begin{aligned}
y_{j, d}= & \alpha+\beta_{1} A F T E R_{j, d}+\beta_{2} A N N_{d}+\beta_{3} A F T E R_{j, d} \times A N N_{d}+\beta_{4} \hat{\mu}_{j, d}^{X}+ \\
& \gamma_{1} s_{j, d}+\gamma_{2} s_{j, d}^{e}+\gamma_{3} \text { Depth }_{j, d}^{\text {Total }}+\gamma_{4} \text { Depth }_{j, d}^{\text {BestFive }}+\gamma_{5} D I_{a t, j, d}+\gamma_{6} D I_{b h d, j, d}+ \\
& \gamma_{7} \text { OFI }_{j, d}+\gamma_{8} \text { Analyst }_{d}+\gamma_{9} \text { Uncertainty }_{d}+\gamma_{10} \text { Surprise }_{d}+\varepsilon_{j, d} .
\end{aligned}
$$

$y_{j, d}$ is the market inefficiency measure $-V R_{j, d}$ or $|A R|_{j, d} . A F T E R_{j, d}$ and $A N N_{d}$ are 
dummy variables for after-8:25 intervals and announcement days, respectively. If $j$ refers to an after-8:25 interval, $A F T E R_{j, d}$ equals to 1 ; otherwise, $A F T E R_{j, d}$ equals to 0 . If day $d$ is an announcement day, $A N N_{d}$ equals to 1 ; otherwise, $A N N_{d}$ equals

to $0 . \hat{\mu}_{j, d}^{X}$ is $\hat{\mu}_{j, d}^{\text {Volume }}$ or $\hat{\mu}_{j, d}^{\text {Freq }}$. The control variables include the quoted spread $\left(s_{j, d}\right)$, effective spread $\left(s_{j, d}^{e}\right)$, total depth (Dept $\left.h_{j, d}^{\text {Total }}\right)$, best five quotes depth $\left(\right.$ Depth $\left.h_{j, d}^{\text {TopFive }}\right)$, depth imbalance at the best quote $\left(D I_{a t, j, d}\right)$, depth imbalance behind the best quote $\left(D I_{b h d, j, d}\right)$, order flow imbalance $\left(O F I_{j, d}\right)$, analyst coverage (Analyst $\left.s_{d}\right)$, market uncer-

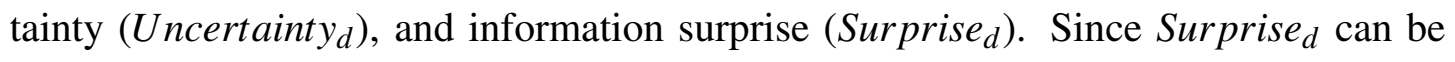
only calculated after the news releases at 8:30 ET, it is not used in the regression using five-minute interval around 8:25 ET. $*, * *$ and $* * *$ indicate significance at the $10 \%$, $5 \%$, and $1 \%$ level, respectively.

\section{[Place Table 3.7 about here]}

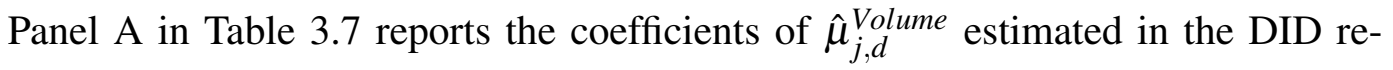
gression as Equation (3.21). The results in Table 3.7 confirms the impact of workup activities on decreasing informational efficiency. All the coefficients of $\hat{\mu}_{j, d}^{\text {Volume are }}$ positive. For example, in 10-minute intervals around 8:25 ET of 5-year U.S. Treasury notes, the $\beta_{4}$ s estimated by regressing $V R$ and $|A R|$ measures are 0.119 and 0.063 , and significant at the $1 \%$ level. Thus, our finding of workup activities' negative impact on market quality is robust, in the aspect of market information efficiency.

Similarly, Panel B in Table 3.7 reports the coefficients of $\hat{\mu}_{j, d}^{F r e q}$ estimated in the DID regression as Equation (3.21). The regression results show that increased workup trading frequency decreases the market informational efficiency. The results confirm our main finding that workup trading decreases the market information efficiency.

\subsubsection{Another Market Liquidity Measure}

Modified depth imbalance is a more rigorous market liquidity measure. To control the accumulative depth impact on the depth imbalance, we introduce the modified depth imbalances at top $K$ level(s), where $K=a t, 3$, or 5 , to measure the depth imbalance of 
each unit of depth as follows (Corwin, Harris, and Lipson, 2004):

$$
D I_{K, j, d}^{M}=\frac{D I_{K, j, d}}{\operatorname{Depth}_{K, j, d}}=\frac{\frac{1}{N_{j, d}^{L}} \sum_{i \in j}\left|\operatorname{Depth}_{K, i, d}^{A}-\operatorname{Depth}_{K, i, d}^{B}\right|}{\frac{1}{N_{j, d}^{L}} \sum_{i \in j}\left(\operatorname{Depth}_{K, i, d}^{A}+\operatorname{Depth}_{K, i, d}^{B}\right)} .
$$

We construct the modified depth imbalance measures at the best quotes, the top 3 levels of quotes, and the top 5 levels of quotes. Table 3.8 reports the regression results of Equation (3.19) by maturities from Panel A to Panel F. In the first main column, we report the coefficient estimates of $\hat{\mu}_{j, d}^{\text {Volume }}$. In the second main column, we report the coefficient estimates of $\hat{\mu}_{j, d}^{\text {Freq }}$.

\section{[Place Table 3.8 about here]}

In Table 3.8, all of the coefficients of $\hat{\mu}_{j, d}^{\text {Volume }}$ and $\hat{\mu}_{j, d}^{\text {Freq }}$ are significantly positive, when regressing $D I_{a t, j, d}^{M}$ and $D I_{3, j, d}^{M}$. About $92 \%$ of the results show that workup trading decreases U.S. Treasury market liquidity. For example, for 5-year U.S. Treasury notes, the coefficients of $\hat{\mu}_{j, d}^{\text {Volume }}$ are $0.103,0.027$ and 0.020, and significant at the $1 \%$ level, when regressing $D I_{a t, j, d}^{M}, D I_{3, j, d}^{M}$ and $D I_{5, j, d}^{M}$; and the coefficients of $\hat{\mu}_{j, d}^{F r e q}$ are 0.038 , 0.062 and 0.056 , and significant at the $1 \%$ level, when regressing $D I_{a t, j, d}^{M}, D I_{3, j, d}^{M}$ and $D I_{5, j, d}^{M}$. Thus, our finding of workup activities' negative impact on market quality is robust, in the aspect of market liquidity.

\subsection{Conclusion}

In this paper, we study the workup trading impact on the U.S. Treasury market quality, in the aspects of market efficiency and market liquidity. This paper contributes a few novel findings to the literature. First, we show that workup trading activities decrease market efficiency and market liquidity. The results are robust across all the six maturities of the U.S. Treasury securities, and for both the detrended workup volume ratios and the detrended workup frequency ratios.

Second, we find evidence that workup trading is associated with the limit order submissions in the U.S. Treasury market. Besides, we also find that workup duration 
might have an influence on the market quality, and thus influence our main findings. We leave these aspects to the later study.

In conclusion, we find that workup trading decreases the U.S. Treasury market quality. The finding is opposite to some literature on the dark trading impact on equity markets (Zhu, 2014; Robert et al., 2015; Foley and Putninš̌, 2016; Buti et al., 2017; Gresse, 2017), whereas it is consistent with Comerton-Forde and Putniņš (2015) and Degryse et al. (2015).

\subsection{Figures and Tables}




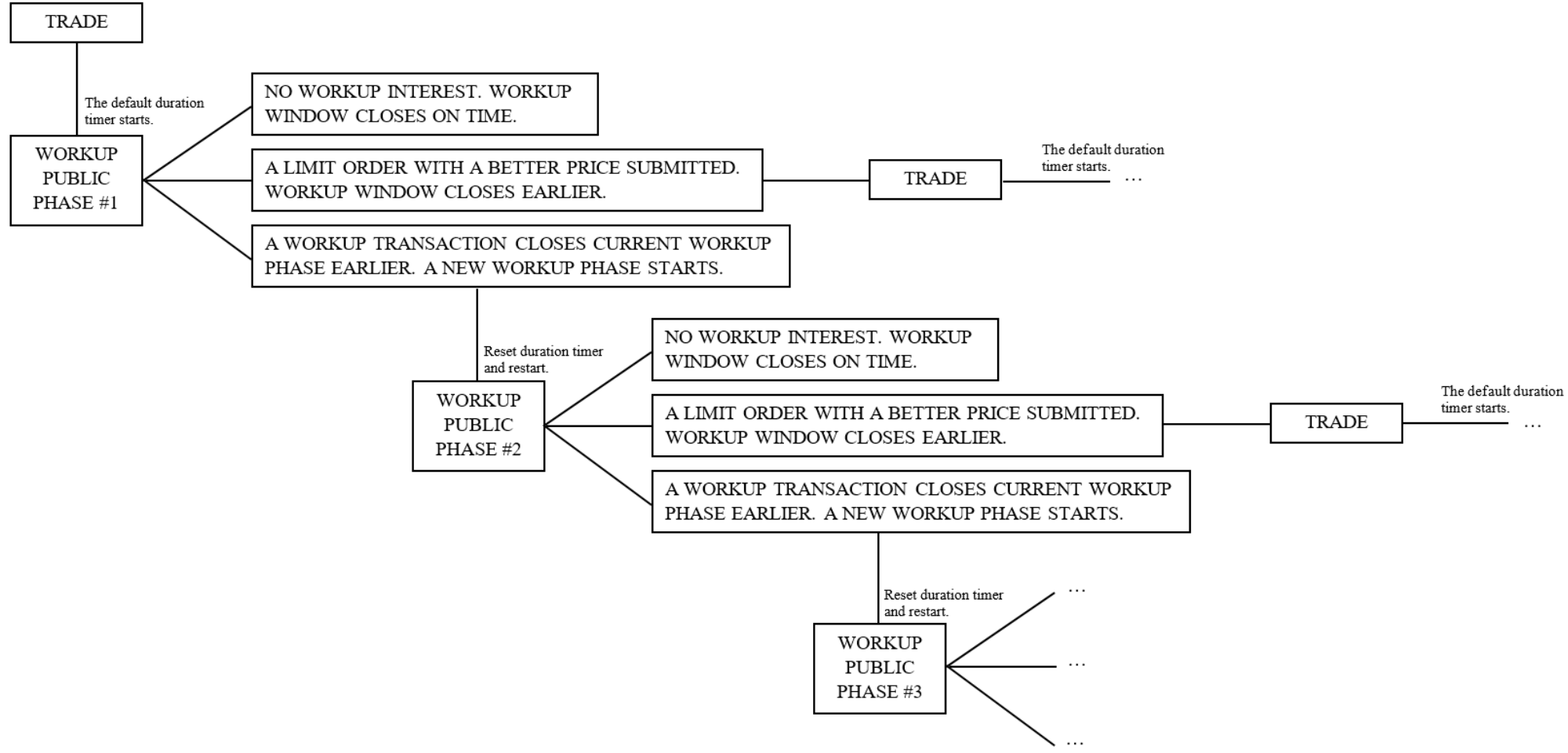

Figure 3.1: The Workup Window. This figure illustrates the open and close of a workup window. A workup window opens immediately after a transaction in the lit pool. During the workup window, all market participants could submit buy or sell orders at the pre-fixed price. The workup window could be composed of multiple public workup phases, each of which has a default duration. If there is no workup transaction interest, the workup window closes after the first public phases. Any workup transaction opens a new workup phase. The workup window closes if there is no more trading interest at the fixed workup price by the end of the default duration. If a market participant submit a limit order at a better price, the workup window closes earlier and a new trade will be matched, which will start a new workup window. 


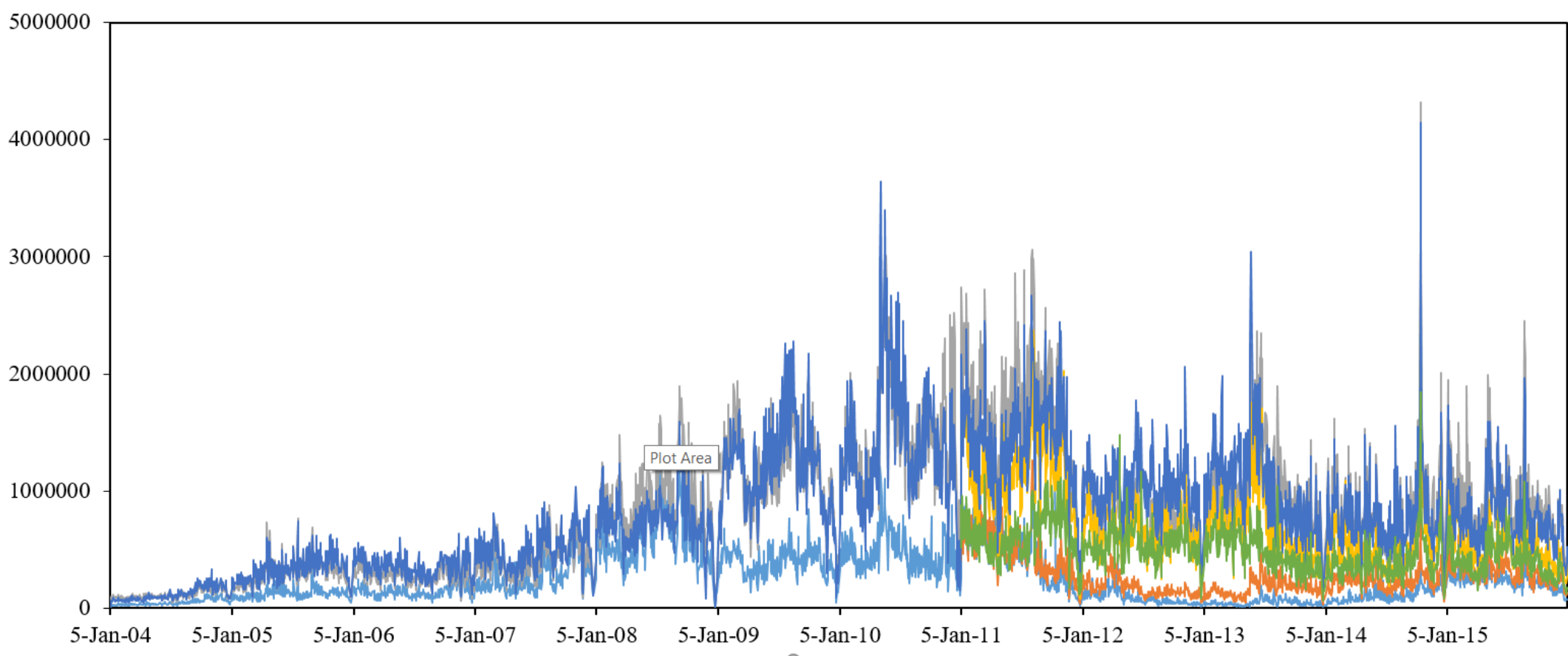

Figure 3.2: Daily BrokerTec Order Book Activities of On-The-Run U.S. Treasury Securities. This figure describes the total daily amount of observations recorded in the order books of the on-the-run U.S. Treasury securities on all of the non-early-close trading days from 1 January 2004 to 31 December 2015. The 3-, 7- and 30-year U.S. Treasury securities are from 1 January 2011 to 31 December 2015. We exclude the early-close days, which accounts for about $2.65 \%$ of the trading days. The order book records all the order submissions, alternations, and deletions activities, alongside the transactions matched. On some trading days, the order activities are abnormally high. 
(A) 2-year U.S. Treasury notes (2004-2015)

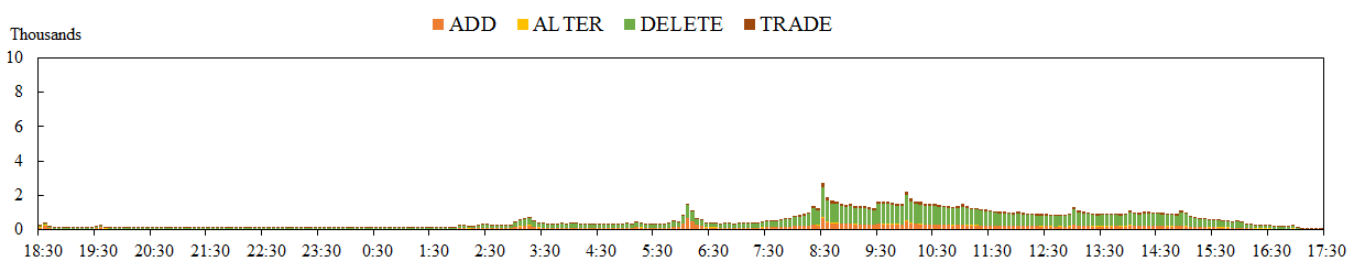

(B) 3-year U.S. Treasury notes (2011-2015)

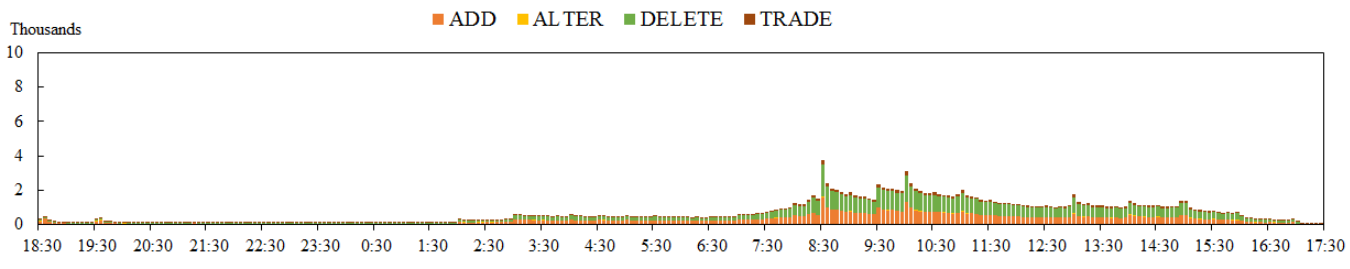

(C) 5-year U.S. Treasury notes (2004-2015)

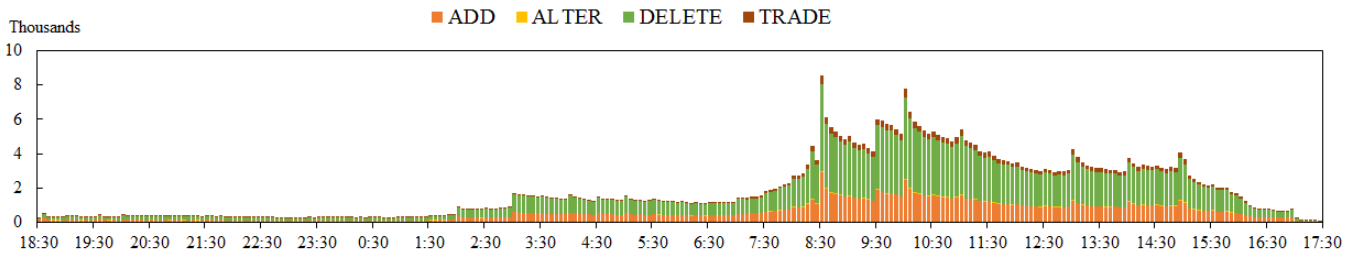

(D) 7-year U.S. Treasury notes (2011-2015)

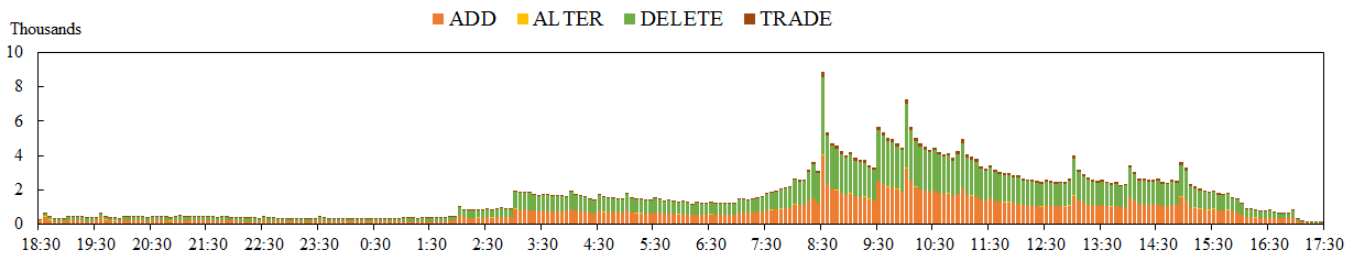

(E) 10-year U.S. Treasury notes (2004-2015)

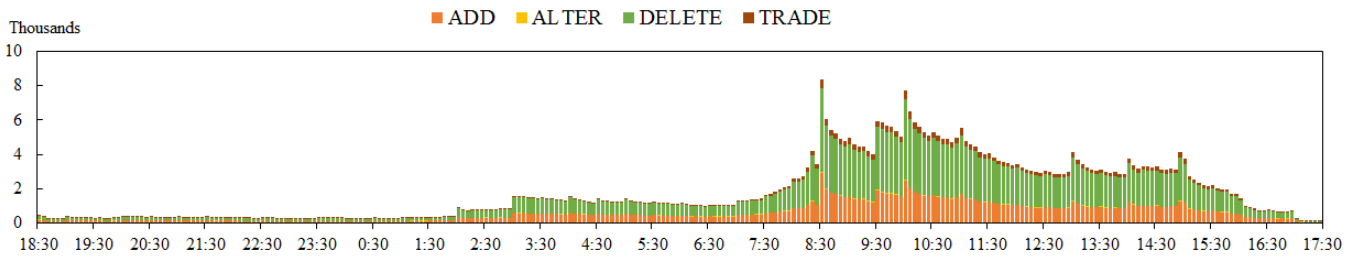

(F) 30-year U.S. Treasury bonds (2011-2015)

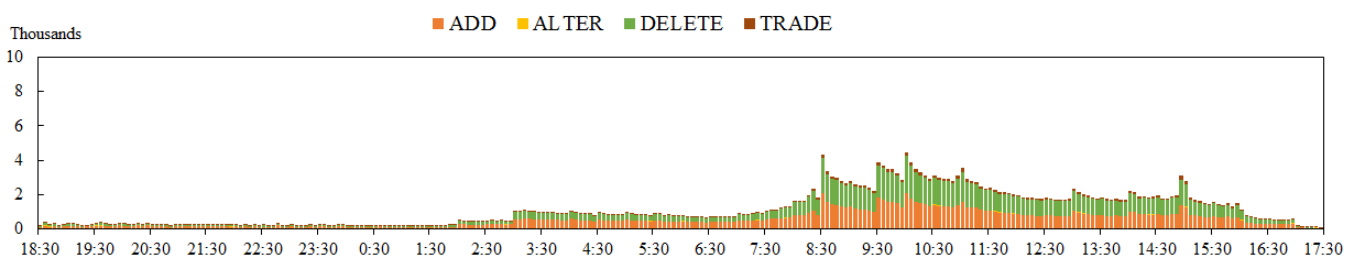

Figure 3.3: Intraday BrokerTec Order Book Activities of On-The-Run U.S. Treasury Securities. This figure shows the average 5-minute intraday order book activities within our sample period. We exclude the early-close days, which accounts for about $2.65 \%$ of the trading days. 
1-hour around the 8:30 ET significant news arrival (a 2-hour event window)

1-hour around the 10:00 ET signifciant news arrival (a 2-hour event window)
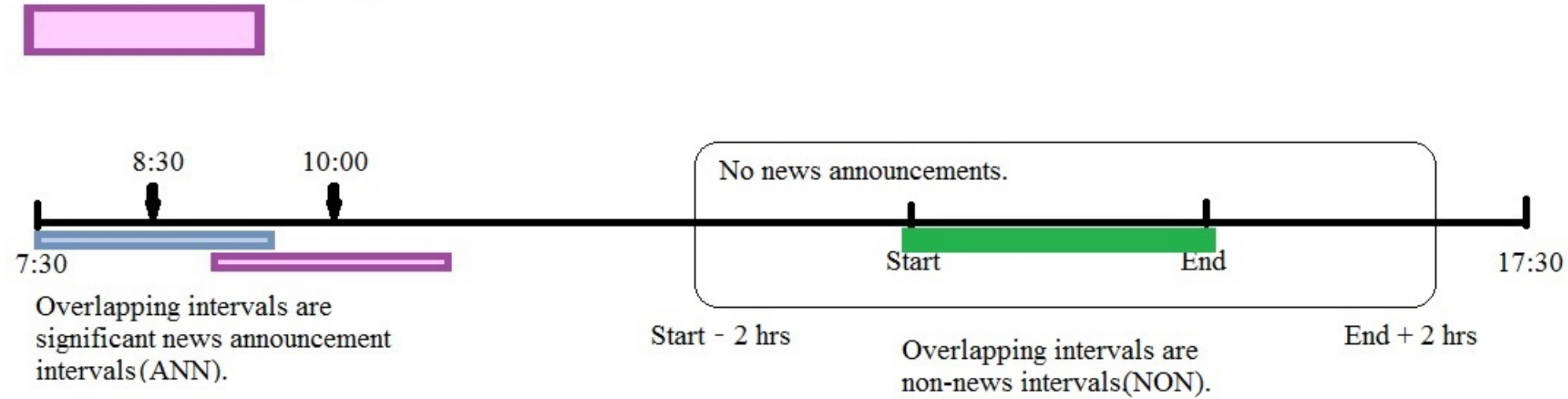

Figure 3.4: Three Categories of Intraday Intervals. This figure illustrates how we divide the intervals into three categories: (1) intervals with significant news announcements (listed in Table 3.1), ANN; (2) interval without any news announcements, NON; and (3) intervals with other announcement events, OT HER. Intervals overlapping with ANN periods or NON periods are identified as ANN intervals and NON intervals. The other intervals are identified as OTHER intervals. 
(A) 2-year U.S. Treasury notes (2004-2015)

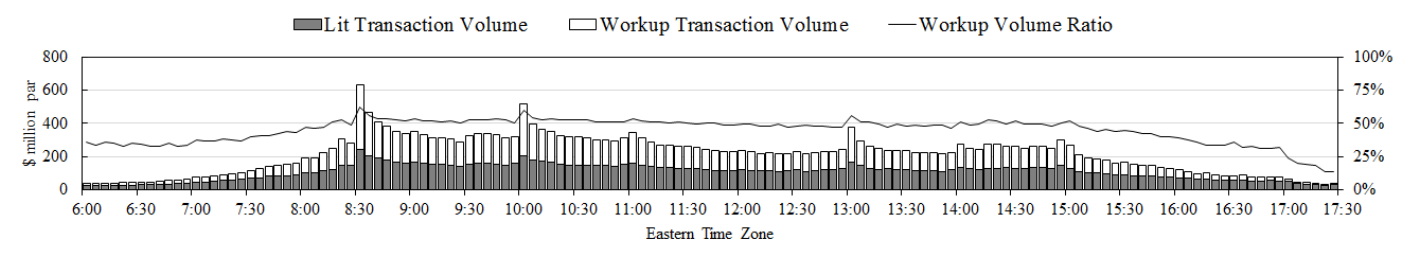

(B) 3-year U.S. Treasury notes (2011-2015)

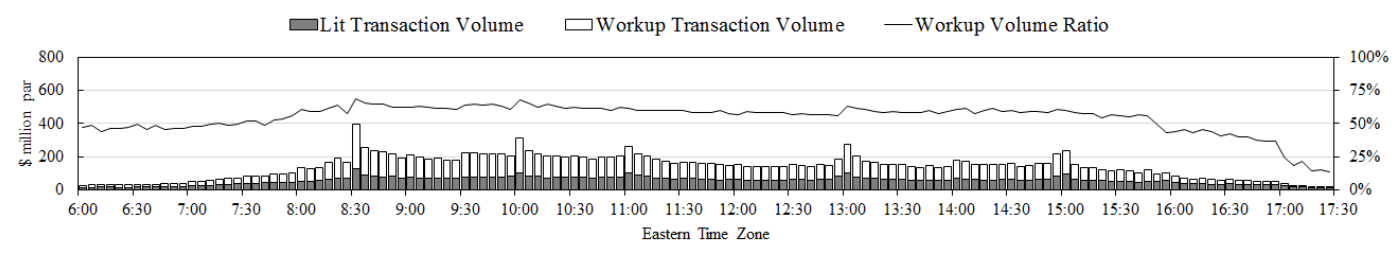

(C) 5-year U.S. Treasury notes (2004-2015)

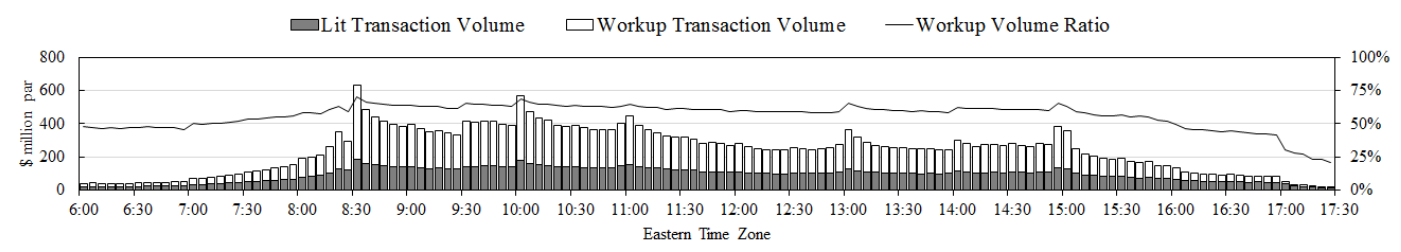

(D) 7-year U.S. Treasury notes (2011-2015)

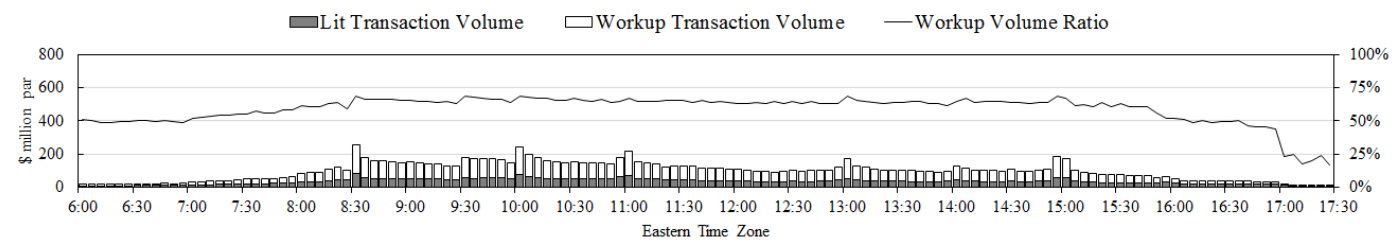

(E) 10-year U.S. Treasury notes (2004-2015)

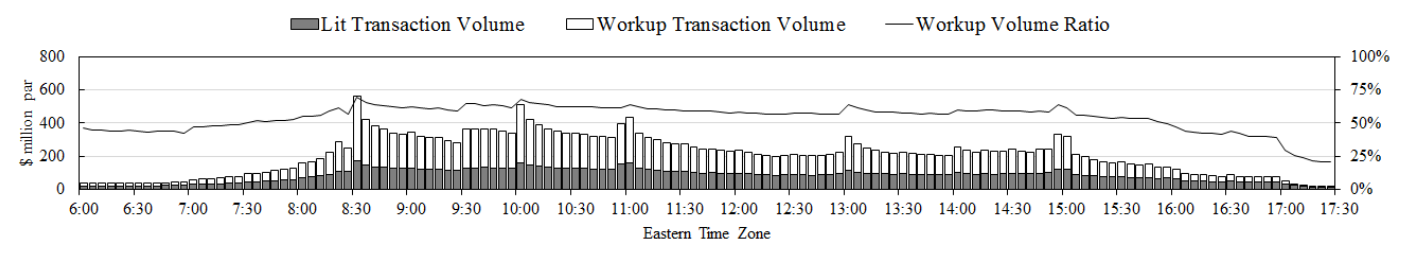

(F) 30-year U.S. Treasury bonds (2011-2015)

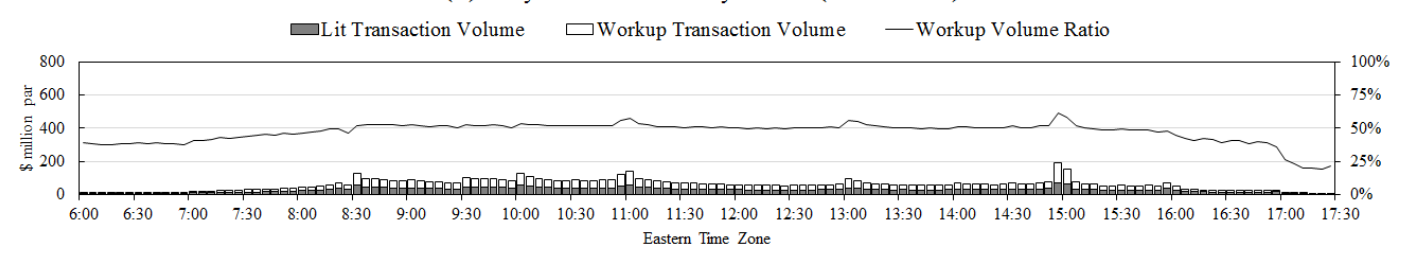

Figure 3.5: Intraday BrokerTec Trading Volumes of On-The-Run U.S. Treasury Securities. This figure reports the average intraday trading volumes in each five-minute interval on non-early-close days during our sample period. Within each interval, we report the trading volumes by trading types - lit pool transaction volume and workup transaction volume. The line reports the average intra-day workup volume ratio, which is the proportion of the workup transaction volume to the total transaction volume. 
(A) 2-year U.S. Treasury Notes

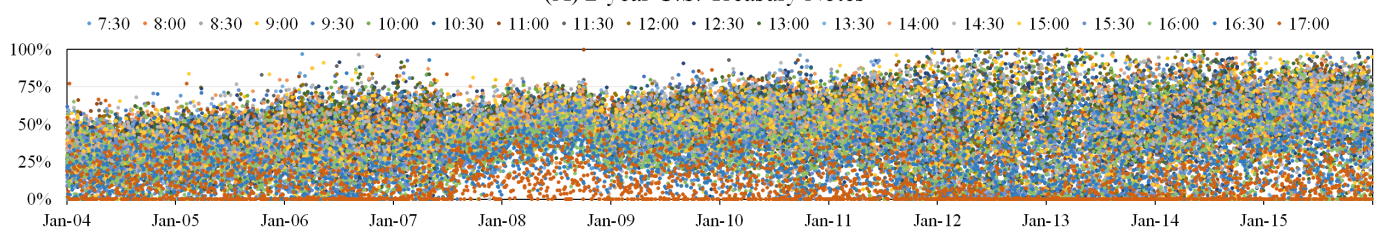

(B) 3-year U.S. Treasury Notes

$\cdot 7: 30 \cdot 8: 00 \cdot 8: 30 \cdot 9: 00 \cdot 9: 30 \cdot 10: 00 \cdot 10: 30 \cdot 11: 00 \cdot 11: 30 \cdot 12: 00 \cdot 12: 30 \cdot 13: 00 \cdot 13: 30 \cdot 14: 00 \cdot 14: 30 \cdot 15: 00 \cdot 15: 30 \cdot 16: 00 \cdot 16: 30 \cdot 17: 00$

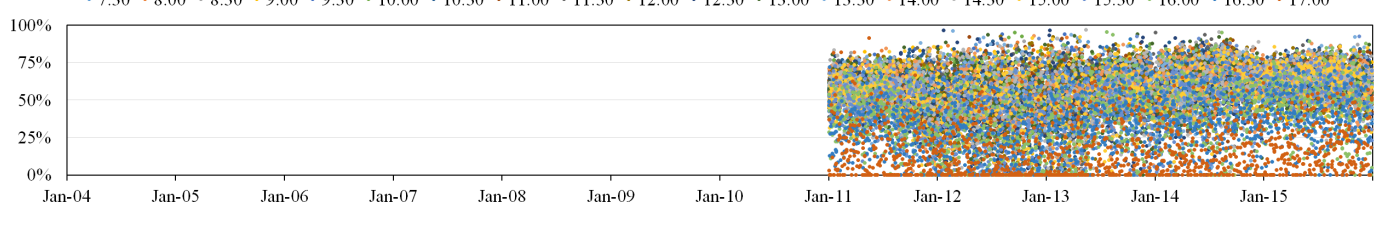

(C) 5-year U.S. Treasury Notes

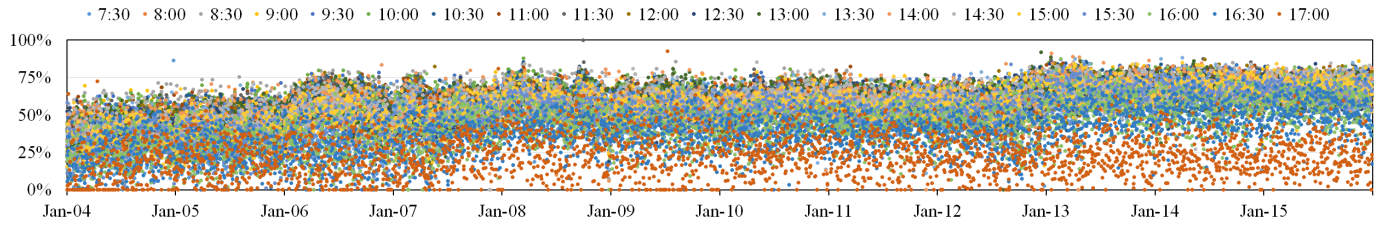

(D) 7-year U.S. Treasury Notes

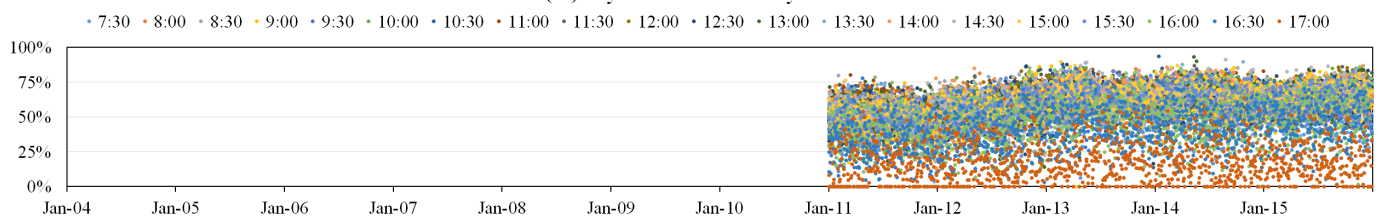

(E) 10-year U.S. Treasury Notes

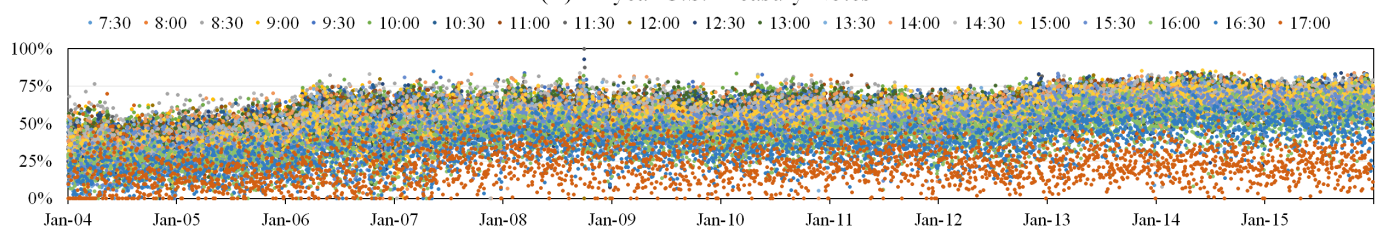

(F) 30-year U.S. Treasury bonds

$\cdot 7: 30 \cdot 8: 00 \cdot 8: 30 \cdot 9: 00 \cdot 9: 30 \cdot 10: 00 \cdot 10: 30 \cdot 11: 00 \cdot 11: 30 \cdot 12: 00 \cdot 12: 30 \cdot 13: 00 \cdot 13: 30 \cdot 14: 00 \cdot 14: 30 \cdot 15: 00 \cdot 15: 30 \cdot 16: 00 \cdot 16: 30 \cdot 17: 00$

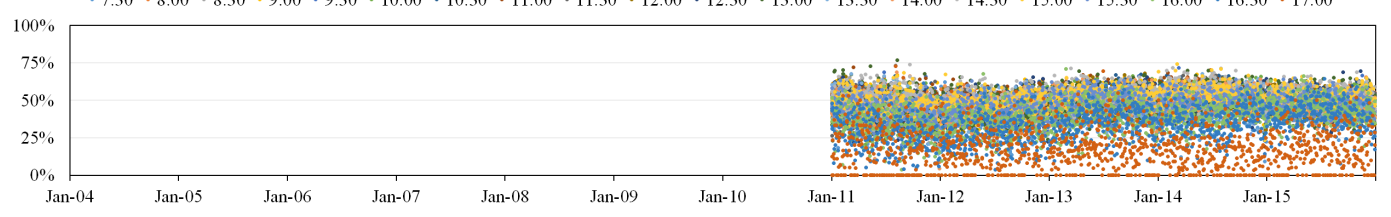

Figure 3.6: Intraday BrokerTec Workup Volume Ratios of On-The-Run U.S. Treasury Securities by 30-Minute Intervals. This figure reports the BrokerTec workup volume ratios of the on-the-run U.S. Treasury securities in twenty 30-minute intervals on each non-early-close trading days during our sample period. The workup volume ratio within an interval $j$ on the day $d$ is the workup trading volume to the total trading volume. 
(A) 10-level Quotes in the Order Book

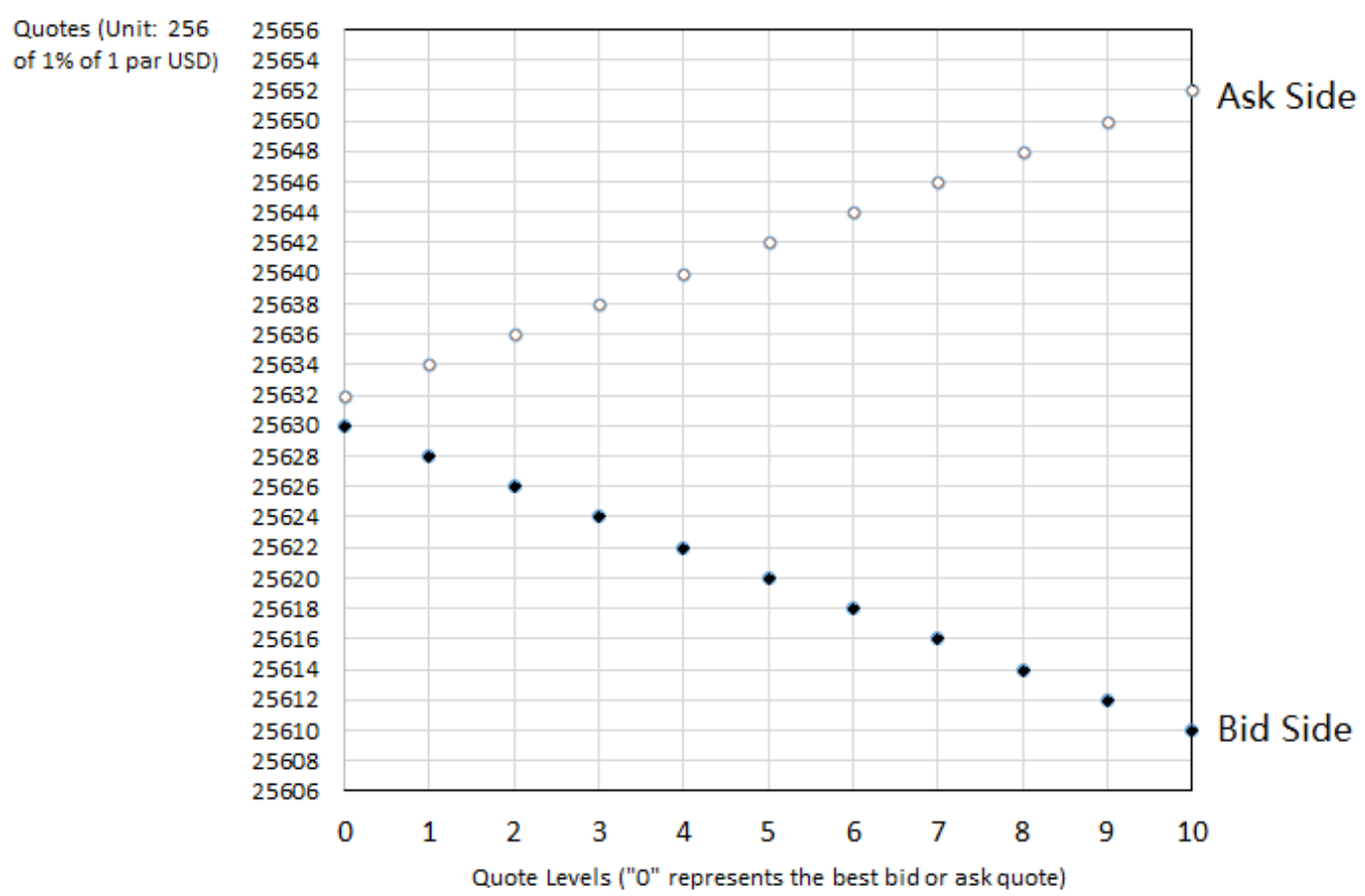

(B) Quantities at Different Levels of Depth

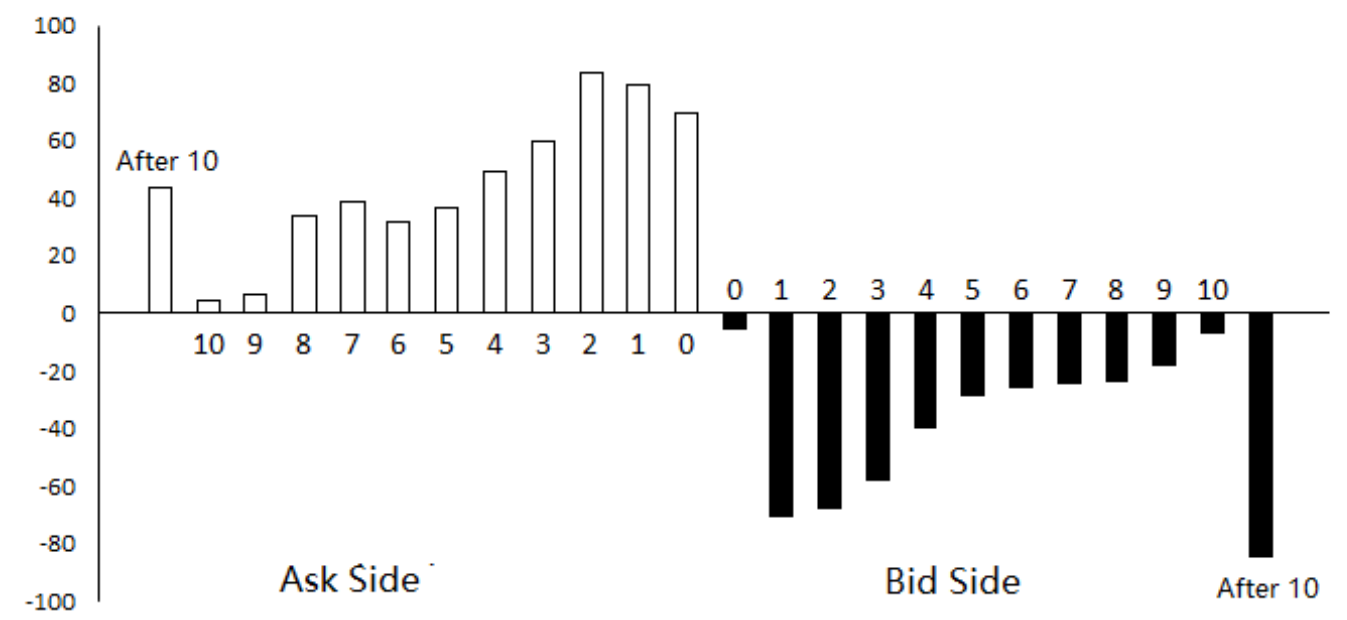

Figure 3.7: Illustration on Depth Decompositions at Different Quote-Levels. This figure illustrates the decompositions of the total depth in the order book of the 5-year U.S. Treasury notes by the ask and the bid sides. The time point is 08:45:17:434240 ET on August 10, 2015. Panel A reports the quotes. Panel B reports the quantities. White color represents the ask side of the order book, and black color represents the bid side of the order book. 
Table 3.1: Significant U.S. Macroeconomic News Announcement Events

\begin{tabular}{|c|c|c|c|c|c|}
\hline & Relevance & Macroeconomic News Index & Release Time $(s)$ & Amount & Frequency \\
\hline 1 & 99.2 & Change in Nonfarm Payrolls & $08: 30$ & 148 & Monthly \\
\hline 2 & 98.4 & Initial Jobless Claims & 08:30 & 639 & Weekly \\
\hline 3 & 97.6 & FOMC Rate Decision (Upper Bound) & $14: 15 / 14: 00 / 12: 30$ & 100 & 8 or 9 releases per year \\
\hline 4 & 96.8 & GDP Annualized QoQ (P/A/F) & 08:30 & 147 & Quarterly (Preliminary/ Advanced/ Final) \\
\hline 5 & 96.0 & ISM Manufacturing & 10:00 & 148 & Monthly \\
\hline 6 & 94.4 & CPI MoM & 08:30 & 147 & Monthly \\
\hline 7 & 94.4 & Consumer Confidence Index & $10: 00$ & 147 & Monthly \\
\hline 8 & 93.6 & U. of Mich. Sentiment* & 09:55/10:00/09:45 & 294 & Fortnightly \\
\hline 9 & 92.8 & Durable Goods Orders & $08: 30$ & 148 & Monthly \\
\hline 10 & 92.3 & MBA Mortgage Applications & 07:00 & 631 & Weekly \\
\hline 11 & 92.0 & Retail Sales Advance MoM & $08: 30$ & 147 & Monthly \\
\hline 12 & 90.4 & New Home Sales & $10: 00$ & 146 & Monthly \\
\hline 13 & 90.0 & Markit U.S. Manufacturing PMI & 08:58/09:45 & 87 & Fortnightly (started from May 2012) \\
\hline 14 & 89.6 & Housing Starts & $08: 30$ & 147 & Monthly \\
\hline 15 & 89.3 & Unemployment Rate & 08:30 & 148 & Monthly \\
\hline 16 & 88.8 & Industrial Production MoM & $09: 15$ & 147 & Monthly \\
\hline 17 & 88.0 & Existing Home Sales & $10: 00$ & 134 & Monthly \\
\hline 18 & 87.2 & Factory Orders & $10: 00$ & 148 & Monthly \\
\hline 19 & 86.4 & PPI (Final Demand) MoM & $08: 30$ & 147 & Monthly \\
\hline 20 & 85.6 & Personal Spending & $08: 30$ & 147 & Monthly \\
\hline 21 & 85.6 & Personal Income & $08: 30$ & 147 & Monthly \\
\hline 22 & 84.8 & Trade Balance & $08: 30$ & 147 & Monthly \\
\hline 23 & 84.0 & ADP Employment Change & $08: 15$ & 117 & Monthly \\
\hline 24 & 83.2 & Leading Index & $10: 00$ & 147 & Monthly \\
\hline 25 & 82.4 & Empire Manufacturing & 08:30 & 147 & Monthly \\
\hline 26 & 81.6 & Chicago Purchasing Manager & 09:45/10:00 & 147 & Monthly \\
\hline 27 & 80.8 & Wholesale Inventories MoM & $10: 00$ & 147 & Monthly \\
\hline
\end{tabular}

This table reports the summary statistics of 27 U.S. macroeconomic indexes from January 1, 2004 to December 31, 2015. All of the news are ranked according to news relevance numbers. During our sample period, the majority release times are 7:00, 8:15, 8:30, 8:58, 9:15, 9:45, 9:55, 10:00, 14:00 and 14:15 (Eastern Time, ET), which have 629, 117, 2401, 44, 147, 220, 126, 1305, 23 and 16 announcement events, respectively. 
Table 3.2: Summary Statisitcs

\begin{tabular}{|c|c|c|c|c|c|c|c|c|c|c|c|c|c|c|c|}
\hline \multicolumn{16}{|c|}{ Panel A: non-early close trading days (30-minute intervals, 2004 - 2015) } \\
\hline \multirow[b]{2}{*}{ Variable } & \multicolumn{5}{|c|}{ 2-year U.S Treasury Notes } & \multicolumn{5}{|c|}{ 5-year U.S Treasury Notes } & \multicolumn{5}{|c|}{ 10-year U.S Treasury Notes } \\
\hline & 1 & 2 & 3 & 4 & 5 & 1 & 2 & 3 & 4 & 5 & 1 & 2 & 3 & 4 & 5 \\
\hline OBActivity & 14710.851 & 7103.037 & 4123.027 & 2208.564 & 792.850 & 42145.939 & 24962.824 & 17508.578 & 10544.699 & 4291.948 & 40632.486 & 24222.568 & 17336.602 & 11257.837 & 4704.691 \\
\hline Price & 100.388 & 100.046 & 99.937 & 99.824 & 99.588 & 101.129 & 100.282 & 99.900 & 99.531 & 98.817 & 102.992 & 100.819 & 99.976 & 98.988 & 96.556 \\
\hline \$Volume & 7.773 & 7.139 & 6.721 & 6.221 & 4.468 & 7.847 & 7.367 & 7.068 & 6.756 & 6.198 & 7.710 & 7.237 & 6.946 & 6.642 & 6.073 \\
\hline \#Trade & 624.315 & 272.305 & 145.442 & 78.796 & 22.412 & 1279.405 & 753.872 & 533.333 & 360.117 & 192.681 & 1241.001 & 736.579 & 536.094 & 378.040 & 200.691 \\
\hline VolumeRatio & 0.674 & 0.520 & 0.422 & 0.310 & 0.113 & 0.695 & 0.608 & 0.546 & 0.476 & 0.347 & 0.674 & 0.589 & 0.529 & 0.460 & 0.325 \\
\hline$\mu^{\text {Volume }}$ & 0.250 & 0.113 & 0.021 & -0.082 & -0.297 & 0.132 & 0.053 & 0.004 & -0.047 & -0.134 & 0.130 & 0.051 & 0.004 & -0.045 & -0.127 \\
\hline$|A R|$ & 0.597 & 0.333 & 0.217 & 0.119 & 0.049 & 0.424 & 0.260 & 0.174 & 0.101 & 0.034 & 0.423 & 0.265 & 0.179 & 0.105 & 0.036 \\
\hline HLVolatility & 0.565 & 0.367 & 0.311 & 0.232 & 0.050 & 1.256 & 0.678 & 0.535 & 0.447 & 0.355 & 2.101 & 1.234 & 1.011 & 0.864 & 0.697 \\
\hline$O F I$ & 1014.128 & 489.250 & 306.046 & 191.505 & 97.236 & 275.134 & 150.740 & 104.797 & 73.658 & 45.116 & 293.274 & 150.526 & 102.526 & 70.305 & 41.354 \\
\hline Depth all & 8.753 & 8.328 & 8.063 & 7.630 & 6.504 & 7.588 & 7.113 & 6.779 & 6.401 & 5.575 & 7.540 & 7.010 & 6.687 & 6.388 & 5.696 \\
\hline \multicolumn{16}{|c|}{ Panel B: non-early close trading days (30-minute intervals, 2011 - 2015) } \\
\hline & \multicolumn{5}{|c|}{ 3-year U.S Treasury Notes } & \multicolumn{5}{|c|}{ 7-year U.S Treasury Notes } & \multicolumn{5}{|c|}{ 30-year U.S Treasury Notes } \\
\hline Variable & 1 & 2 & 3 & 4 & 5 & 1 & 2 & 3 & 4 & 5 & 1 & 2 & 3 & 4 & 5 \\
\hline OBActivity & 15802.660 & 8697.378 & 5980.589 & 3914.533 & 1958.625 & 34646.829 & 19964.104 & 14887.969 & 10906.681 & 5380.568 & 22775.775 & 14037.659 & 10703.211 & 7977.881 & 3938.977 \\
\hline \#Trade & 546.328 & 263.753 & 172.977 & 109.563 & 43.033 & 590.179 & 335.658 & 248.801 & 186.629 & 119.054 & 541.685 & 327.768 & 252.467 & 195.117 & 130.874 \\
\hline VolumeRatio & 0.723 & 0.615 & 0.541 & 0.454 & 0.264 & 0.710 & 0.627 & 0.567 & 0.504 & 0.396 & 0.563 & 0.503 & 0.464 & 0.421 & 0.347 \\
\hline$\mu^{\text {Volume }}$ & 0.202 & 0.093 & 0.020 & -0.061 & -0.244 & 0.141 & 0.059 & 0.005 & -0.051 & -0.147 & 0.104 & 0.043 & 0.004 & -0.037 & -0.104 \\
\hline$V R$ & 0.545 & 0.345 & 0.232 & 0.150 & 0.050 & 0.469 & 0.327 & 0.229 & 0.139 & 0.047 & 0.339 & 0.208 & 0.137 & 0.079 & 0.025 \\
\hline$|A R|$ & 0.567 & 0.323 & 0.212 & 0.118 & 0.049 & 0.441 & 0.273 & 0.185 & 0.108 & 0.037 & 0.360 & 0.208 & 0.136 & 0.077 & 0.025 \\
\hline HLVolatility & 0.559 & 0.382 & 0.336 & 0.282 & 0.138 & 1.487 & 0.948 & 0.828 & 0.747 & 0.632 & 4.022 & 2.355 & 1.892 & 1.571 & 1.216 \\
\hline OFI & 545.304 & 267.414 & 174.454 & 115.993 & 68.146 & 154.848 & 92.824 & 67.392 & 49.057 & 31.476 & 39.799 & 24.107 & 18.182 & 13.835 & 9.438 \\
\hline Depth all & 8.025 & 7.689 & 7.491 & 7.279 & 6.896 & 7.199 & 6.892 & 6.623 & 6.382 & 5.970 & 5.498 & 5.197 & 4.943 & 4.661 & 4.221 \\
\hline
\end{tabular}

This table reports the summary statistics of the U.S. Treasury securities by six maturities in our sample. We exclude early-close days and trading days around the Christmas and New Year holidays (after December 15 and before January 5 in each year.) On each non-early-close trading day, we divide the New York Trading hours (from 7:30 ET to 17:30 ET) into twenty 30-minute intervals. In each of the twenty intervals, we winsorize each variable at the $1 \%$ and $99 \%$ levels. Then, for each interval, we sort all days into quintiles by each variable, and calculate the mean values in each group. This table reports the mean values of the variables for each group across all intervals. OBActivity is the total amount of orders submitted, cancelled and matched. Price is the latest mid-quote price within each interval in percentage of 1 par US dollar. \$Volume is the natural log of traded dollar volume. \#Trade is the number of transactions, including both of the lit transactions and the workup transactions. VolumeRatio is the proportion of workup transaction volume. $\hat{\mu}^{\text {Volume }}$ is the detrended VolumeRatio by using Eq. (3.2).VR is the variance-ratio market inefficiency measure estimated by using the variance of true 5-second returns and the variance of true 1-second returns as Eq. (3.9). $|A R|$ is the autocorrelation of non-overlapping returns estimated by using the variance of true 4-second returns and the variance of true 2-second returns as Eq.(3.11). HLVolatility is the market volatility measure estimated by using Eq. (3.17). OFI is the market order flow imbalance calculated by using Eq. (3.18). Depth is the natural log of the total depth $($ Depth all $)$ in contract quantity $(1$ contract $=\$ 1$ million par). 
Table 3.3: Regressions of the Impact of Workup Volume Ratio on Informational Efficiency

\begin{tabular}{|c|c|c|c|c|}
\hline \multirow{2}{*}{ Variable } & \multicolumn{2}{|c|}{ 2-year U.S. T-notes } & \multicolumn{2}{|c|}{ 3-year U.S. T-notes } \\
\hline & $V R_{j, d}$ & $|A R|_{j, d}$ & $V R_{j, d}$ & $|A R|_{j, d}$ \\
\hline$\hat{\mu}_{j, d}^{\text {Volume }}$ & $0.045^{* *}$ & $0.008^{* * *}$ & $0.081^{* * *}$ & $0.007^{*}$ \\
\hline Adjusted $R^{2}$ & 0.001 & 0.023 & 0.004 & 0.022 \\
\hline Interval & Yes & Yes & Yes & Yes \\
\hline Day & Yes & Yes & Yes & Yes \\
\hline \multicolumn{5}{|c|}{ Panel B: 5- and 7-year U.S. Treasury notes } \\
\hline \multirow{2}{*}{ Variable } & \multicolumn{2}{|c|}{ 5-year U.S. T-notes } & \multicolumn{2}{|c|}{ 7-year U.S. T-notes } \\
\hline & $V R_{j, d}$ & $|A R|_{j, d}$ & $V R_{j, d}$ & $|A R|_{j, d}$ \\
\hline$\hat{\mu}_{j, d}^{\text {Volume }}$ & $0.127^{* * *}$ & $0.005^{*}$ & $0.104^{* * *}$ & $0.056^{* * *}$ \\
\hline Adjusted $R^{2}$ & 0.000 & 0.027 & 0.003 & 0.018 \\
\hline Interval & Yes & Yes & Yes & Yes \\
\hline Day & Yes & Yes & Yes & Yes \\
\hline \multicolumn{5}{|c|}{ Panel C: 10-year U.S. Treasury notes, and 30-year U.S. Treasury bonds } \\
\hline \multirow{2}{*}{ Variable } & \multicolumn{2}{|c|}{ 10-year U.S. T-notes } & \multicolumn{2}{|c|}{ 30-year U.S. T-notes } \\
\hline & $V R_{j, d}$ & $|A R|_{j, d}$ & $V R_{j, d}$ & $|A R|_{j, d}$ \\
\hline$\hat{\mu}_{j, d}^{\text {Volume }}$ & $0.090^{* * *}$ & $0.008^{* * *}$ & $0.104^{* * *}$ & $0.054^{* * *}$ \\
\hline Adjusted $R^{2}$ & 0.005 & 0.031 & 0.014 & 0.029 \\
\hline Interval & Yes & Yes & Yes & Yes \\
\hline Day & Yes & Yes & Yes & Yes \\
\hline
\end{tabular}

This table reports the regression estimates of the detrended workup volume, $\hat{\mu}_{j, d}^{\text {Volume }}$. We divide the New York Trading hours from 7:30 ET to 17:30 ET on each trading day into 120 5-minute intervals. The panel regression model is: $y_{j, d}=\alpha_{1, j}+\alpha_{2, d}+\beta_{1} \hat{\mu}_{j, d}^{\text {Volume }}+$ $\beta_{2}$ SVolume $_{j, d}+\beta_{3}$ HLVolatility $_{j, d}+\beta_{4} O F I_{j, d}+\gamma_{1} A N N_{j, d}+\gamma_{2} N O N_{j, d}+\varepsilon_{j, d}$, where $j$ is the interval and $d$ is the trading day. $y_{j, d}$ is the market inefficiency measure $-V R_{j, d}$ or $|A R|_{j, d}$. We control the fixed effects of different trading days and intraday intervals. In addition, we introduce two dummy variables to control the impact of U.S. macroeconomic news announcement on market quality - ANN and NON are the dummy variables for significant news announcement intervals and non-announcement intervals. For any interval on a trading day, $A N N_{j, d}+N O N_{j, d}+O T H E R_{j, d}=1 . \alpha_{1, j}$ is the unobservable fixed effect of intraday intervals, and $\alpha_{2, d}$ is the unobservable fixed effects of trading days. $\hat{\mu}_{j, d}^{\text {Volume }}$ is the detrended workup volume ratio, estimated by using Equation (3.2) in Section (3.3.3). $\$$ Volume $_{j, d}$ is the natural $\log$ of traded dollar volume (in $\$$ million par). HLVolatility $y_{j, d}$ is the high-to-low volatility as Equation (3.17). $O F I_{j, d}$ is the market order flow imbalance as Equation 3.18. $*, * *$ and $* * *$ indicate significance at the $10 \%, 5 \%$, and $1 \%$ level, respectively. 
Table 3.4: Impact of Workup Trading Volume on Liquidity Supply and Market Liquidity

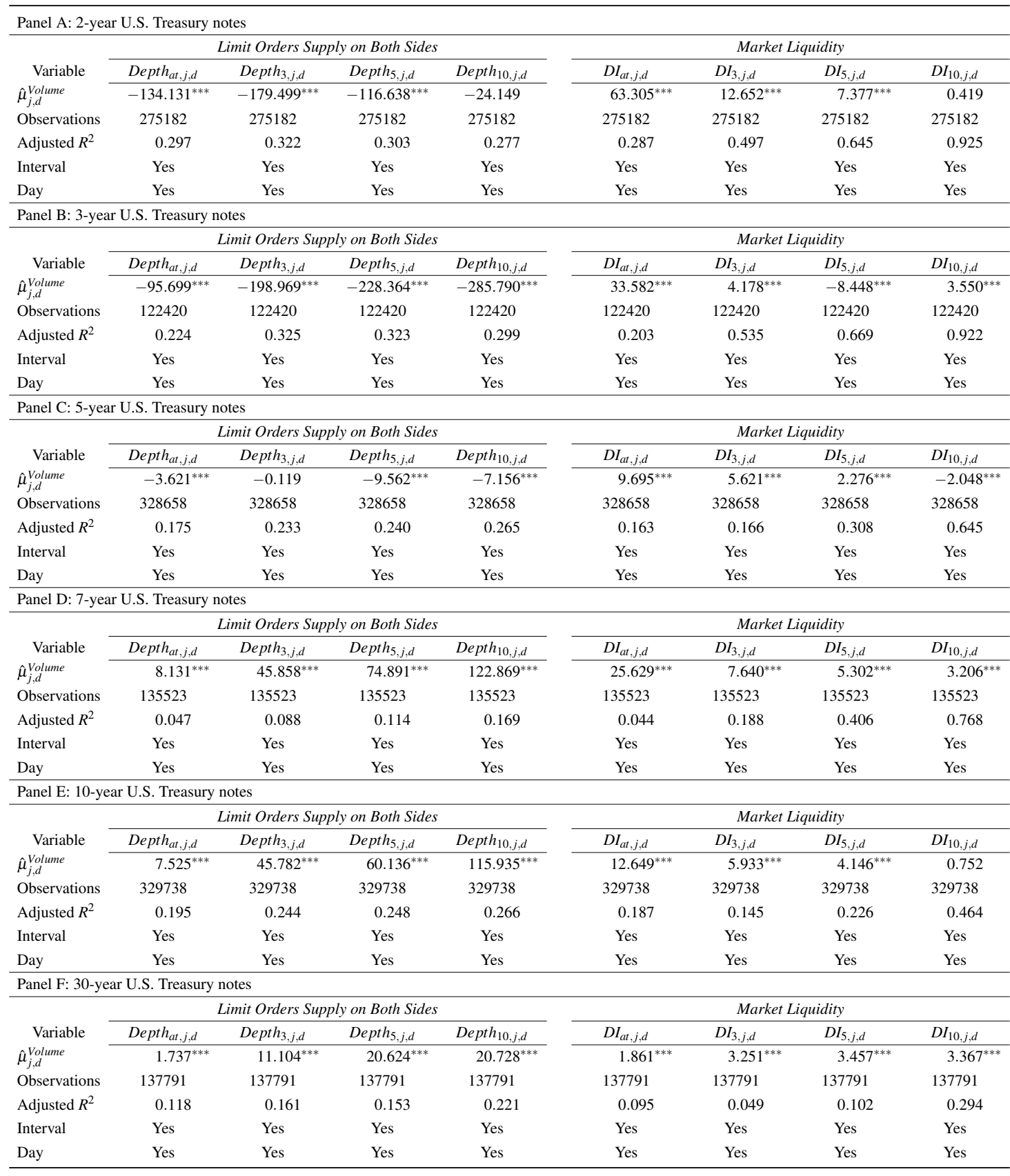

This table reports the regression estimates of the detrended workup volume, $\hat{\mu}_{j, d}^{\text {Volume }}$. We divide the New York Trading hours from 7:30 ET to 17:30 ET on each trading day into 1205 -minute intervals. The panel regression model is: $y_{j, d}=\alpha_{1, j}+\alpha_{2, d}+\beta_{1} \hat{\mu}_{j, d}^{\text {Volume }}+\beta_{2} \$$ Volume $_{j, d}+\beta_{3}$ HLVolatility $_{j, d}+\beta_{4}$ OFI $I_{j, d}+$ $\gamma_{1} A N N_{j, d}+\gamma_{2} N O N_{j, d}+\varepsilon_{j, d}$, where $j$ is the interval and $d$ is the trading day. $y_{j, d}$ is the liquidity supply measure or the market liquidity measure. We control the fixed effects of different trading days and intraday intervals. In addition, we introduce two dummy variables to control the impact of U.S. macroeconomic news announcement on market quality - $A N N$ and $N O N$ are the dummy variables for significant news announcement intervals and non-announcement intervals. For any interval on a trading day, $A N N_{j, d}+N O N_{j, d}+O T H E R_{j, d}=1 . \alpha_{1, j}$ is the fixed effect of intraday interval $j$, and $\alpha_{2, d}$ is the fixed effect of trading day $d$. $\hat{\mu}_{j, d}^{\text {Volume }}$ is the detrended workup volume ratio, estimated by using Equation (3.2) in Section (3.3.3). \$Volume $e_{j, d}$ is the natural log of traded dollar volume (in $\$$ million par). HLVolatility $y_{j, d}$ is the high-to-low volatility as Equation (3.17). OFI $I_{j, d}$ is the market order flow imbalance as Equation (3.18). *,** and $* * *$ indicate significance at the $10 \%, 5 \%$, and $1 \%$ level, respectively. 
Table 3.5: Impact of Workup Frequency Ratio on Informational Efficiency

\begin{tabular}{|c|c|c|c|c|}
\hline \multicolumn{5}{|c|}{ Panel A: 2- and 3-year U.S. Treasury notes } \\
\hline \multirow{2}{*}{ Variable } & \multicolumn{2}{|c|}{ 2-year U.S. T-notes } & \multicolumn{2}{|c|}{ 3-year U.S. T-notes } \\
\hline & $V R_{j, d}$ & $|A R|_{j, d}$ & $V R_{j, d}$ & $|A R|_{j, d}$ \\
\hline$\hat{\mu}_{j, d}^{\text {Freq }}$ & $0.054^{* *}$ & $0.030^{* * *}$ & $0.143^{* * *}$ & $0.054^{* * *}$ \\
\hline Adjusted $R^{2}$ & 0.001 & 0.024 & 0.005 & 0.023 \\
\hline Interval & Yes & Yes & Yes & Yes \\
\hline Day & Yes & Yes & Yes & Yes \\
\hline \multicolumn{5}{|c|}{ Panel B: 5- and 7-year U.S. Treasury notes } \\
\hline \multirow{2}{*}{ Variable } & \multicolumn{2}{|c|}{ 5-year U.S. T-notes } & \multicolumn{2}{|c|}{ 7-year U.S. T-notes } \\
\hline & $V R_{j, d}$ & $|A R|_{j, d}$ & $V R_{j, d}$ & $|A R|_{j, d}$ \\
\hline$\hat{\mu}_{j, d}^{F r e q}$ & $0.181^{* * *}$ & $0.083^{* * *}$ & $0.173^{* * *}$ & $0.142^{* * *}$ \\
\hline Adjusted $R^{2}$ & 0.000 & 0.031 & 0.005 & 0.025 \\
\hline Interval & Yes & Yes & Yes & Yes \\
\hline Day & Yes & Yes & Yes & Yes \\
\hline \multicolumn{5}{|c|}{ Panel C: 10-year U.S. Treasury notes, and 30-year U.S. Treasury bonds } \\
\hline \multirow{2}{*}{ Variable } & \multicolumn{2}{|c|}{ 10-year U.S. T-notes } & \multicolumn{2}{|c|}{ 30-year U.S. T-notes } \\
\hline & $V R_{j, d}$ & $|A R|_{j, d}$ & $V R_{j, d}$ & $|A R|_{j, d}$ \\
\hline$\hat{\mu}_{j, d}^{\text {Freq }}$ & $0.135^{* * *}$ & $0.072^{* * *}$ & $0.129^{* * *}$ & $0.084^{* * *}$ \\
\hline Adjusted $R^{2}$ & 0.006 & 0.033 & 0.015 & 0.031 \\
\hline Interval & Yes & Yes & Yes & Yes \\
\hline Day & Yes & Yes & Yes & Yes \\
\hline
\end{tabular}

This table reports the regression estimates of the detrended workup frequency ratio, $\hat{\mu}_{j, d}^{F r e q}$. We divide the New York Trading hours from 7:30 ET to 17:30 ET on each trading day into 120 5-minute intervals. The panel regression model is: $y_{j, d}=\alpha_{1, j}+\alpha_{2, d}+\beta_{1} \hat{\mu}_{j, d}^{\text {Freq }}+$ $\beta_{2}$ SVolume $_{j, d}+\beta_{3}$ HLVolatility $_{j, d}+\beta_{4} O F I_{j, d}+\gamma_{1} A N N_{j, d}+\gamma_{2} N O N_{j, d}+\varepsilon_{j, d}$, where $j$ is the interval and $d$ is the trading day. $y_{j, d}$ is the market inefficiency measure $-V R_{j, d}$ or $|A R|_{j, d}$. We control the fixed effects of different trading days and intraday intervals. In addition, we introduce two dummy variables to control the impact of U.S. macroeconomic news announcement on market quality - ANN and NON are the dummy variables for significant news announcement intervals and non-announcement intervals. For any interval on a trading day, $A N N_{j, d}+N O N_{j, d}+O T H E R_{j, d}=1 . \alpha_{1, j}$ is the fixed effect of intraday interval $j$, and $\alpha_{2, d}$ is the fixed effect of trading day $d . \hat{\mu}_{j, d}^{F r e q}$ is the detrended workup frequency ratio, estimated by using Equation (3.2) in Section (3.3.3). \$Volume ${ }_{j, d}$ is the natural log of traded dollar volume (in $\$$ million par). HLVolatility $j_{j, d}$ is the high-to-low volatility as Equation (3.17). $O F I_{j, d}$ is the market order flow imbalance as Equation 3.18. *, ** and *** indicate significance at the $10 \%, 5 \%$, and $1 \%$ level, respectively. 
Table 3.6: Impact of Workup Trading Frequency on Liquidity Supply and Market Liquidity

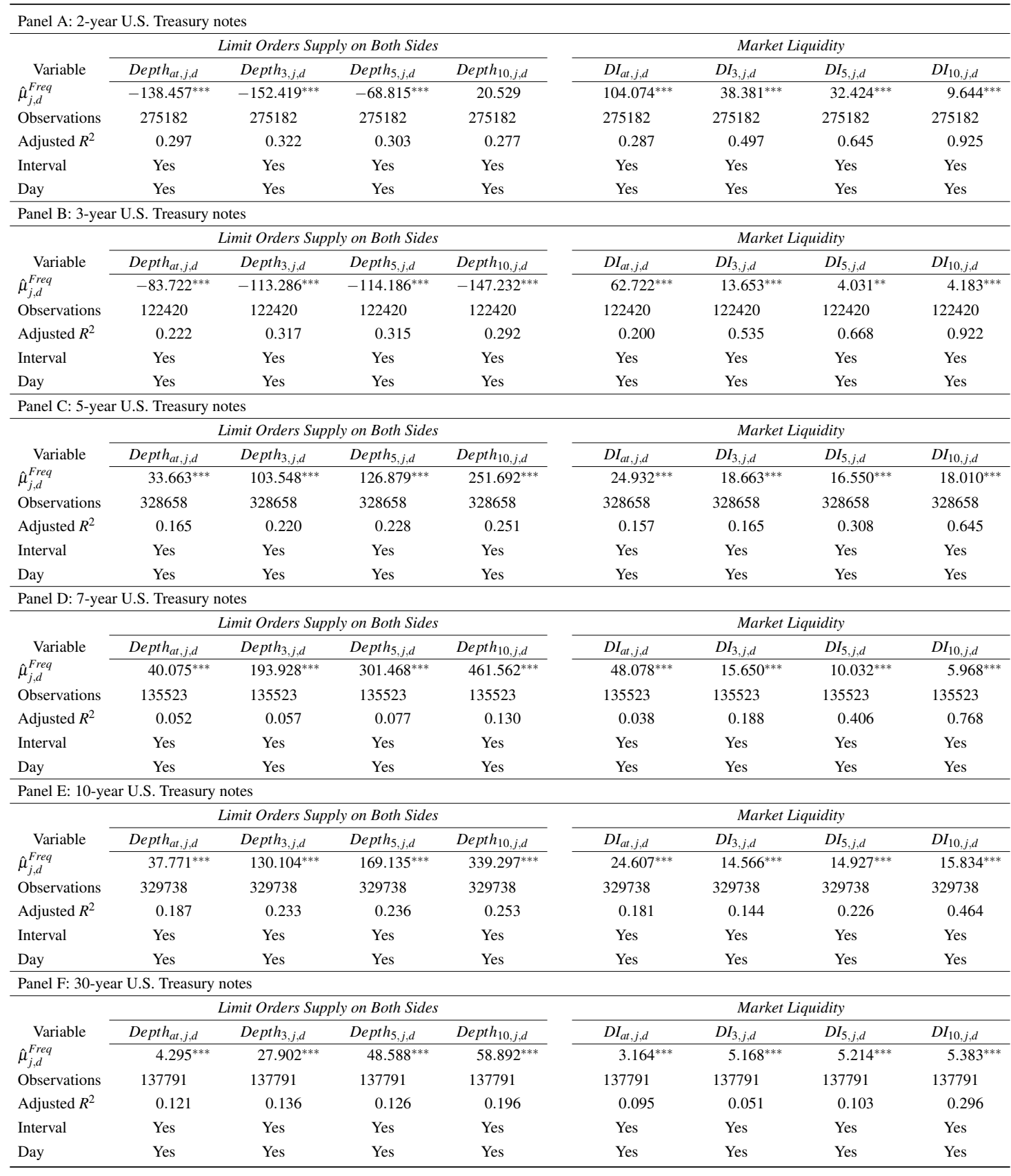

This table reports the regression estimates of the detrended workup frequency, $\hat{\mu}_{j, d}^{\text {Freq }}$. We divide the New York Trading hours from 7:30 ET to 17:30 ET on each trading day into 1205 -minute intervals. The panel regression model is: $y_{j, d}=\alpha_{1, j}+\alpha_{2, d}+\beta_{1} \hat{\mu}_{j, d}^{\text {Freq }}+\beta_{2}$ SVolume $_{j, d}+\beta_{3}$ HLVolatility $_{j, d}+\beta_{4}$ OFI I $_{j, d}+$ $\gamma_{1} A N N_{j, d}+\gamma_{2} N O N_{j, d}+\varepsilon_{j, d}$, where $j$ is the interval and $d$ is the trading day. $y_{j, d}$ is the liquidity supply measure or the market liquidity measure. We control the fixed effects of different trading days and intraday intervals. In addition, we introduce two dummy variables to control the impact of U.S. macroeconomic news announcement on market quality - $A N N$ and $N O N$ are the dummy variables for significant news announcement intervals and non-announcement intervals. For any interval on a trading day, $A N N_{j, d}+N O N_{j, d}+O T H E R_{j, d}=1 . \alpha_{1, j}$ is the fixed effect of intraday interval $j$, and $\alpha_{2, d}$ is the fixed effect of trading day $d . \hat{\mu}_{j, d}^{\text {Freq }}$ is the detrended workup frequency ratio, estimated by using Equation (3.2). $\$$ Volume $_{j, d}$ is the natural log of traded dollar volume (in $\$$ million par). HLVolatility $y_{j, d}$ is the high-to-low volatility as Equation (3.17). OF $I_{j, d}$ is the market order flow imbalance as Equation (3.18). *,** and *** indicate significance at the $10 \%, 5 \%$, and $1 \%$ level, respectively. 
Table 3.7: Impact of Workup Trading on the Market Informational Efficiency around 8:25 ET

\begin{tabular}{|c|c|c|c|c|}
\hline \multicolumn{5}{|c|}{ Panel A: $\mu_{j, d}^{X}=\mu_{j, d}^{\text {Volume }}$} \\
\hline & \multicolumn{2}{|c|}{$V R_{j, d}$} & \multicolumn{2}{|c|}{$|A R|_{j, d}$} \\
\hline & 5-year & 10-year & 5-year & 10-year \\
\hline 5-minute & $0.053^{* *}$ & $0.082^{* * *}$ & $0.044^{* *}$ & $0.036^{* *}$ \\
\hline 10-minute & $0.119^{* * *}$ & $0.102^{* * *}$ & $0.063^{* * *}$ & $0.070^{* * *}$ \\
\hline 15-minute & $0.126^{* * *}$ & $0.109^{* * *}$ & 0.037 & $0.101^{* *}$ \\
\hline \multicolumn{5}{|c|}{ Panel B: $\mu_{j, d}^{X}=\mu_{j, d}^{\text {Freq }}$} \\
\hline & \multicolumn{2}{|c|}{$V R_{j, d}$} & \multicolumn{2}{|c|}{$|A R|_{j, d}$} \\
\hline & 5-year & 10-year & 5-year & 10-year \\
\hline 5-minute & $0.054^{* *}$ & $0.096^{* * *}$ & $0.039^{*}$ & 0.012 \\
\hline 10-minute & $0.124^{* * *}$ & $0.116^{* * *}$ & $0.054^{* * *}$ & $0.051^{* *}$ \\
\hline 15-minute & $0.138^{* * *}$ & $0.110^{* * *}$ & -0.001 & $0.558^{* * *}$ \\
\hline
\end{tabular}

This table reports the regression results of $\beta_{4} \mathrm{~s}$, which measure the workup activities impact on the market informational efficiency. The model is as follows:

$y_{j, d}=\alpha+\beta_{1} A F T E R_{j, d}+\beta_{2} A N N_{d}+\beta_{3} A F T E R_{j, d} \times A N N_{d}+\beta_{4} \mu_{j, d}^{X}+\gamma_{1} s_{j, d}+\gamma_{2} s_{j, d}^{e}+$ $\gamma_{3}$ Depth $_{j, d}^{\text {Total }}+\gamma_{4}$ Depth $_{j, d}^{\text {BestFive }}+\gamma_{5}$ DI $_{a t, j, d}+\gamma_{6}$ DI $_{\text {bhd }, j, d}+\gamma_{7}$ OFI $_{j, d}+\gamma_{8}$ Analysts $_{d}+$ $\gamma_{9}$ Uncertainty $_{d}+\gamma_{10}$ Surprise $_{d}+\varepsilon_{j, d}$.

$y_{j, d}$ is the market inefficiency measure $-V R_{j, d}$ or $|A R|_{j, d} . A F T E R_{j, d}$ and $A N N_{d}$ are dummy variables for after-8:25 intervals and announcement days, respectively. If $j$ refers to an after-8:25 interval, $A F T E R_{j, d}$ equals to 1 ; otherwise, $A F T E R_{j, d}$ equals to 0. If day $d$ is an announcement day, $A N N_{d}$ equals to 1 ; otherwise, $A N N_{d}$ equals to $0 . \hat{\mu}_{j, d}^{X}$ is the detrended workup volume ratio $\left(\hat{\mu}_{j, d}^{\text {Volume }}\right)$ or the detrended workup frequenct ratio $\left(\hat{\mu}_{j, d}^{\text {Freq }}\right)$. The control variables include the quoted spread $\left(s_{j, d}\right)$, effective spread $\left(s_{j, d}^{e}\right)$, total depth $\left(D e p t h_{j, d}^{T o t a l}\right)$, best five quotes depth $\left(D e p t h_{j, d}^{\text {TopFive }}\right)$, depth imbalance at the best quote $\left(D I_{a t, j, d}\right)$, depth imbalance behind the best quote $\left(D I_{b h d, j, d}\right)$, order flow imbalance $\left(O F I_{j, d}\right)$, analyst coverage $\left(\right.$ Analyst $\left._{d}\right)$, market uncertainty (Uncertainty $\left.y_{d}\right)$, and information surprise $\left(\right.$ Surprise $_{d}$ ). Since Surprise $_{d}$ can be only calculated after the news releases at 8:30 ET, it is not used in the regression using five-minute interval around 8:25 ET. *, ** and *** indicate significance at the $10 \%, 5 \%$, and $1 \%$ level, respectively. 
Table 3.8: The Impact of Workup Ratios on Modified Depth Imbalances

\begin{tabular}{|c|c|c|c|c|c|c|}
\hline \multicolumn{7}{|c|}{ Panel A: 2-year U.S. Treasury notes } \\
\hline \multirow[b]{2}{*}{ Variable } & \multicolumn{3}{|c|}{$X=$ Volume } & \multicolumn{3}{|c|}{$X=$ Freq } \\
\hline & $D I_{a t, j, d}^{M}$ & $D I_{3, j, d}^{M}$ & $D I_{5, j, d}^{M}$ & $D I_{1, j, d}^{M}$ & $D I_{3, j, d}^{M}$ & $D I_{5, j, d}^{M}$ \\
\hline & $0.225^{* * *}$ & $0.004^{* *}$ & $-0.008^{* * *}$ & $0.280^{* * *}$ & $0.017^{* * *}$ & 0.002 \\
\hline Observations & 275182 & 275182 & 275182 & 275182 & 275182 & 275182 \\
\hline Adjusted $R^{2}$ & 0.120 & 0.027 & 0.034 & 0.130 & 0.028 & 0.035 \\
\hline Interval & Yes & Yes & Yes & Yes & Yes & Yes \\
\hline Day & Yes & Yes & Yes & Yes & Yes & Yes \\
\hline \multicolumn{7}{|c|}{ Panel B: 3-year U.S. Treasury notes } \\
\hline & \multicolumn{3}{|c|}{$X=$ Volume } & \multicolumn{3}{|c|}{$X=$ Freq } \\
\hline Variable & $D I_{a t, j, d}^{M}$ & $D I_{3, j, d}^{M}$ & $D I_{5, j, d}^{M}$ & $D I_{1, j, d}^{M}$ & $D I_{3, j, d}^{M}$ & $D I_{5, j, d}^{M}$ \\
\hline$\hat{\mu}_{i, d}^{X}$ & $0.270^{* * *}$ & $0.023^{* * *}$ & $0.009^{* * *}$ & $0.334^{* * *}$ & $0.026^{* * *}$ & $0.011^{* * *}$ \\
\hline Observations & 122420 & 122420 & 122420 & 122420 & 122420 & 122420 \\
\hline Adjusted $R^{2}$ & 0.123 & 0.180 & 0.241 & 0.120 & 0.183 & 0.243 \\
\hline Interval & Yes & Yes & Yes & Yes & Yes & Yes \\
\hline Day & Yes & Yes & Yes & Yes & Yes & Yes \\
\hline \multicolumn{7}{|c|}{ Panel C: 5-year U.S. Treasury notes } \\
\hline & \multicolumn{3}{|c|}{$X=$ Volume } & \multicolumn{3}{|c|}{$X=$ Freq } \\
\hline Variable & $D I_{a t, j, d}^{M}$ & $D I_{3, j, d}^{M}$ & $D I_{5, j, d}^{M}$ & $D I_{1, j, d}^{M}$ & $D I_{3, j, d}^{M}$ & $D I_{5, j, d}^{M}$ \\
\hline$\hat{\mu}_{j, d}^{X}$ & $0.103^{* * *}$ & $0.027^{* * *}$ & $0.020^{* * *}$ & $0.038^{* * *}$ & $0.062^{* * *}$ & $0.056^{* * *}$ \\
\hline Observations & 328658 & 328658 & 328658 & 328658 & 328658 & 328658 \\
\hline Adjusted $R^{2}$ & 0.016 & 0.128 & 0.126 & 0.012 & 0.141 & 0.143 \\
\hline Interval & Yes & Yes & Yes & Yes & Yes & Yes \\
\hline Day & Yes & Yes & Yes & Yes & Yes & Yes \\
\hline \multicolumn{7}{|c|}{ Panel D: 7-year U.S. Treasury notes } \\
\hline & \multicolumn{3}{|c|}{$X=$ Volume } & \multicolumn{3}{|c|}{$X=$ Freq } \\
\hline Variable & $D I_{a t, j, d}^{M}$ & $D I_{3, j, d}^{M}$ & $D I_{5, j, d}^{M}$ & $D I_{1, j, d}^{M}$ & $D I_{3, j, d}^{M}$ & $D I_{5, j, d}^{M}$ \\
\hline$\hat{\mu}_{j, d}^{X}$ & $0.188^{* * *}$ & $0.013^{* * *}$ & $0.002^{* *}$ & $0.200^{* * *}$ & $0.011^{* * *}$ & $-0.012^{* * *}$ \\
\hline Observations & 135523 & 135523 & 135523 & 135523 & 135523 & 135523 \\
\hline Adjusted $R^{2}$ & 0.019 & 0.095 & 0.110 & 0.009 & 0.095 & 0.101 \\
\hline Interval & Yes & Yes & Yes & Yes & Yes & Yes \\
\hline Day & Yes & Yes & Yes & Yes & Yes & Yes \\
\hline \multicolumn{7}{|c|}{ Panel E: 10-year U.S. Treasury notes } \\
\hline & \multicolumn{3}{|c|}{$X=$ Volume } & \multicolumn{3}{|c|}{$X=$ Freq } \\
\hline Variable & $D I_{a t, j, d}^{M}$ & $D I_{3, j, d}^{M}$ & $D I_{5, j, d}^{M}$ & $D I_{1, j, d}^{M}$ & $D I_{3, j, d}^{M}$ & $D I_{5, j, d}^{M}$ \\
\hline$\hat{\mu}_{j, d}^{X}$ & $0.118^{* * *}$ & $0.023^{* * *}$ & $0.017^{* * *}$ & $0.054^{* * *}$ & $0.046^{* * *}$ & $0.044^{* * *}$ \\
\hline Observations & 329738 & 329738 & 329738 & 329738 & 329738 & 329738 \\
\hline Adjusted $R^{2}$ & 0.032 & 0.131 & 0.118 & 0.026 & 0.141 & 0.133 \\
\hline Interval & Yes & Yes & Yes & Yes & Yes & Yes \\
\hline Day & Yes & Yes & Yes & Yes & Yes & Yes \\
\hline \multicolumn{7}{|c|}{ Panel F: 30-year U.S. Treasury notes } \\
\hline & \multicolumn{3}{|c|}{$X=$ Volume } & \multicolumn{3}{|c|}{$X=$ Freq } \\
\hline Variable & $D I_{a t, j, d}^{M}$ & $D I_{3, j, d}^{M}$ & $D I_{5, j, d}^{M}$ & $D I_{1, j, d}^{M}$ & $D I_{3, j, d}^{M}$ & $D I_{5, j, d}^{M}$ \\
\hline$\hat{\mu}_{j, d}^{X}$ & $0.101^{* * *}$ & $0.055^{* * *}$ & $0.031^{* * *}$ & $0.128^{* * *}$ & $0.063^{* * *}$ & $0.029^{* * *}$ \\
\hline Observations & 137791 & 137791 & 137791 & 137791 & 137791 & 137791 \\
\hline Adjusted $R^{2}$ & 0.011 & 0.072 & 0.079 & 0.007 & 0.074 & 0.080 \\
\hline Interval & Yes & Yes & Yes & Yes & Yes & Yes \\
\hline Day & Yes & Yes & Yes & Yes & Yes & Yes \\
\hline
\end{tabular}

This table reports the regression estimates of the detrended workup ratios, $\hat{\mu}_{j, d}^{\text {Volume }}$ and $\hat{\mu}_{j, d}^{\text {Freq }}$ in the following regression. We divide the New York Trading hours from 7:30 ET to 17:30 ET on each trading day into 120 5-minute intervals. The panel regression model is: $y_{j, d}=\alpha_{1, j}+\alpha_{2, d}+\beta_{1} \hat{\mu}_{j, d}^{X}+\beta_{2}$ SVolume $_{j, d}+\beta_{3}$ HLVolatility $_{j, d}+\beta_{4} O F I_{j, d}+\gamma_{1} A N N_{j, d}+\gamma_{2} N_{O N} N_{j, d}+\varepsilon_{j, d}$, where $j$ is the interval and $d$ is the trading day. $y_{j, d}$ is the modified depth imbalance measure - $D I_{a t, j, d}^{M}, D I_{t o p 3, j, d}^{M}, D I_{\text {top } 5, j, d}^{M}$. We control the fixed effects of different trading days and intraday intervals. In addition, we introduce two dummy variables to control the impact of U.S. macroeconomic news announcement on market quality - ANN and NON are the dummy variables for significant news announcement intervals and non-announcement intervals. For any interval on a trading day, $A N N_{j, d}+$ $N O N_{j, d}+O T H E R_{j, d}=1 . \alpha_{1, j}$ is the fixed effect of intraday interval $j$, and $\alpha_{2, d}$ is the fixed effect of trading day $d$. $\$$ Volume $e_{j, d}$ is the natural log of traded dollar volume (in \$ million par). HLVolatility $y_{j, d}$ is the high-to-low volatility as Equation (3.17). $O F I_{j, d}$ is the market order flow imbalance as Equation 3.18. *,** and *** indicate significance at the $10 \%, 5 \%$, and $1 \%$ level, respectively. 


\section{Chapter 4}

\section{Belief Heterogeneity, Market Liquidity, and Order Submission Strategies in the U.S. Treasury Market}

\subsection{Introduction}

Investors' beliefs (or expectations) on future information arrivals influence their trading strategies (Michaely and Vila, 1995; Wang, 1998; Goettler, Parlour, and Rajan, 2009; Xiong and Yan, 2009; Bordalo, Gennaioli, and Shleifer, 2018; Carlé et al., 2019). Rational investors might hold different opinions on the contents of scheduled public news because of their interpretations. The investors' various perspectives on the scheduled public news contents are the fountainhead of the belief heterogeneity. For example, studies on the U.S. Treasury market document that public information shocks are related to higher levels of trading volume and price volatility (Fleming and Remolona, 1999; Balduzzi et al., 2001; Brandt and Kavajecz, 2004; Jiang et al., 2011; Lucca and Moench, 2015; Fleming et al., 2018).

However, little empirical work has examined the mechanism by which this heterogeneity in beliefs affects traders' order submission decisions in a limit order market. Since individual orders are aggregated to obtain the observed limit order book and generate the dynamics in prices and trading volumes, they are the fundamental deter- 
minants of the market characteristics observed and studied by academics and practitioners. This paper aims to improve the understanding of how observed market characteristics and the market information environment influence individual traders' order submissions behaviors, and hence the observed market outcomes.

In this paper, by using the BrokerTec U.S. Treasury order books of the 5-year onthe-run U.S. Treasury notes from 2011 to 2015, we examine whether the traders' order submission decisions depend on the belief heterogeneity, market uncertainty and information shock around U.S. macroeconomic announcements. More precisely, we address the following questions. Do the levels of market uncertainty and belief heterogeneity affect order submission strategies before announcements? Do these two elements still have any impact after the announcement? If so, do these impacts depend on the magnitude of information shocks?

We use three measures to characterize the information environment - the market uncertainty $(V)$, the belief heterogeneity $(H)$, and the public information shock $(|S U R|)$. Following Barron et al. (BKLS) (1998), we construct market uncertainty measure and the belief heterogeneity measure. The public information shock associated with each news announcement is defined by the difference between the actual announcement and the median of analysts' forecasts preceding the announcement release (Balduzzi et al., 2001). We consider the major monthly 8:30 ET U.S. macroeconomic announcements discussed by Balduzzi et al. (2001) and Jiang et al. (2011), with Bloomberg relevance numbers larger than 80. These significant announcements are most relevant for the market participants. Since the announcements are scheduled and extensively studied by economists, there exists reliable survey data to characterize investors' expectations for these announcements. Using the survey data, we construct measures of market uncertainty, belief heterogeneity, and the magnitude of the surprise contained in each announcement event.

We examine how changes in the information environment affect order submission in three stages. First, we investigate how information factors affect order aggressiveness, defined as the distance between the quote of the order submitted and the best 
quote on the opposite side of the market. Before announcements, we find that uncertainty tends to increase order aggressiveness with all monthly significant announcements, including the influential announcements, and non-influential announcements. ${ }^{1}$ Thus traders tend to submit more aggressive orders under higher uncertainty. During the post-announcement period, the influence of market uncertainty on the order aggressiveness keeps the same that traders still tend to submit more aggressive orders under higher uncertainty.

One conjecture of this result is that an increase in uncertainty may potentially affect information asymmetry among market participants (Grossman and Stiglitz, 1980; Lambert, Leuz, and Verrecchia, 2011; Banerjee and Green, 2015) which in turn makes private information more valuable. Informed traders tend to place more market orders (as in Kyle, 1985) or aggressive limit orders (Roşu, 2018). On the other hand, heterogeneous beliefs tend to reduce order aggressiveness with influential announcements. To control risks of adverse selection, traders tend to submit less aggressive orders when there are wide differences in their opinion about the upcoming announcements.

As a comparison, the belief heterogeneity plays a different role in the traders' order submission behaviors. We find that the belief heterogeneity still affects the order submission but the role depends on the type of news, and the magnitude of the information shocks. During the pre- and post-announcement periods, the total effect of the traders' belief heterogeneity of all the significant news is positively correlated to the order aggressiveness, which is the same as the effects of market uncertainty. However, if we divide all the news into influential news and non-influential news, we find that the effect of influential news is opposite during the post-announcement period that the traders tend to submit less aggressive orders after the influential news arrivals under high belief heterogeneity. The effect of non-influential news is the same as the impact of all the significant news.

Comparing the $|S U R|$ s of all the significant news with the median of information

\footnotetext{
${ }^{1}$ Influential announcements have the Bloomberg relevance numbers larger than 90. Non-influential announcements have the Bloomberg relevance numbers range from 80 to 90 .
} 
shocks, we divide all the significant news announcement days into the high surprise group and the low surprise group. Decompositions of the announcement days into influential news and non-influential news are also matched with the high $|S U R|$ group and the low $|S U R|$ group, respectively. Our former finding on the impacts of market uncertainty and belief heterogeneity is robust in the low $|S U R|$ group. However, in the high $|S U R|$ group, the belief heterogeneity decreases the order aggressiveness on all significant news announcement days, influential news announcement days, and non-influential news announcement days. The market uncertainty still has a positive correlation with the order aggressiveness. Following Green (2004), we divide the postannouncement period into two 15-minute sub-periods and present the empirical results in the high and low $|S U R|$ groups. $^{2}$ The findings on market uncertainty and belief heterogeneity impact on the order aggressiveness in each group are the same as the post-announcement periods.

In the second stage of analysis, we focus on the post-announcement period and examine whether traders' order choice, such as their decision on submitting market orders or limit orders, is affected by market uncertainty and belief heterogeneity. In addition to the former tests, this allows us to tell whether an increase in order aggressiveness is due to an increase in the placement of market orders or the submission of aggressive limit orders. We find that market uncertainty is positively correlated with the order aggressiveness in the post-announcement period and its two sub-periods, which consistent with the former findings. Traders tend to submit more market orders or limit orders with an improved price when market uncertainty is high during the post-announcement periods and its two sub-periods. The finding of market uncertainty impact on increasing order aggressiveness is robust in both high and low $|S U R|$ groups. However, the belief heterogeneity increases the aggressiveness of market orders or aggressive limit orders in the low $|S U R|$ group during the post-announcement period and its two subperiods, whereas it decreases the aggressiveness of market orders or aggressive limit

\footnotetext{
${ }^{2}$ Green (2004) finds that most public information is incorporated through trading within the first 15 minutes after the macroeconomic news release.
} 
orders in the low $|S U R|$ group during the post-announcement period and its two subperiods. The impact of the belief heterogeneity is consistent across all significant news announcement days, influential news announcement days, and non-influential news announcement days within each group divided by the information shocks.

In the last stage of the analysis, we focus solely on limit orders submission and construct the limit order aggressiveness measure in the post-announcement period. We examine, conditional on a limit order being submitted, how the aggressiveness of the limit orders is affected by market uncertainty and belief heterogeneity. We find that the former findings on market uncertainty impact are robust in the post-announcement period and its two sub-periods, including within each of the high $|S U R|$ group and the low $|S U R|$ group. The former findings on the belief heterogeneity impact are also robust, but only during the post-announcement period and its two sub-periods. In the low $|S U R|$ group, traders with high levels of belief heterogeneity tend to submit more aggressive limit orders on influential news announcement days, but less aggressive orders on non-influential news announcement days. In the high $|S U R|$ group, traders with high levels of belief heterogeneity tend to submit less aggressive limit orders on all significant news announcement days, influential news announcement days and non-influential news announcement days.

This paper contributes to the literature in the following two aspects. First, by considering the influence of belief heterogeneity and uncertainty around announcements, this paper extends former studies of the significant macroeconomic news announcements impact on the U.S. Treasury market. Second, by investigating the roles of belief heterogeneity and uncertainty, our study helps better understand how traders in the U.S. Treasury market make their decisions before and after scheduled U.S. macroeconomic news announcements.

Our paper is related to Green (2004) and Pasquariello and Vega (2007), which study the price impact of order flow in the Treasury market. Green (2004) studies the influence of information contained in order to flow around announcements. Pasquariello and Vega (2007) document that order flow has higher explanatory power for bond yield 
changes when belief heterogeneity is high. We complement and extend these studies by examining the influence of belief heterogeneity and uncertainty around announcements and how they interact with public information. While Green (2004) finds a weak relationship between belief heterogeneity and price changes in the 30-minute interval following announcements, we find that belief heterogeneity significantly affects traders' order submissions decisions. Further, we identify a role played by factors not considered in these studies such as the observed changes in the order book.

The rest of the paper develops as follows. Section 4.2 presents our data. The motivation for our empirical models and discussions of the results follow in Section 4.3. Section 4.4 concludes the paper.

\subsection{Data and Variables Construction}

We utilize two data sets for our analysis. The first data set contains all traders' electronic order submissions for the 5-year on-the-run U.S. Treasury notes on all trading days from 2011 to 2015. The second data set consists of individual analysts' forecasts of the significant macroeconomic announcements in the United States, as well as the actual announcements. Below we discuss each data set in more detail.

\subsubsection{BrokerTec U.S. Treasury Data}

The U.S. Treasury data contain all of the orders submitted to the BrokerTec electronic trading platform from January 1, 2011 to December 31, 2015. The BrokerTec U.S. Treasury ECN is one of the world's largest electronic brokerage systems. According to our calculation, during our sample period, the average daily trading volume of U.S. Treasury securities on BrokerTec is about 137 billion U.S. dollars, which is roughly $26 \%$ of the U.S. Treasury primary dealer's average daily trading volume.

The BrokerTec trading platform is an electronic order book to which traders can submit either market orders or limit orders of US\$1 million and more. Traders using the system can continuously observe the five most recent transactions, the most recent 
best-quoted bid and ask prices, and the corresponding depths at each of the five levels of quotes (Fleming et al., 2018).

Using the U.S. Treasury market has several advantages over the more commonly studied equity data. ${ }^{3}$ First, unlike the equity market, the U.S. Treasury BrokerTec ECN platform is a purely order-driven market, without market maker interventions in the limit order book. Second, the electronic platform operates 22 hours a day, five days a week from 19:30 ET the day before to 17:30 ET of each trading day. The opening hours covers almost all of the significant U.S. macroeconomic news announcement times with enough time for traders to react immediately around news announcements. Thus we do not have any concerns about the effects of changes in trading behavior around market openings and closings (Hamao and Hasbrouck, 1995; Davies, 2003). Finally, unlike equity markets, where many types of announcements can influence the value of stocks, macroeconomic announcements are arguably one important factor affecting the U.S. Treasury market (Fleming and Remolona, 1999; Brenner et al., 2009; Jiang et al., 2011; Kurov, Sancetta, Strasser, and Wolfe, 2019). With all the credible analyst forecasts for the scheduled announcements, we can clearly characterize the magnitude of the divergence of beliefs and expectations for the forecasters as well as the magnitude of the information shocks that characterize the information environment before and after announcements.

\subsubsection{Bloomberg News Announcements and Economists Forecasts}

We obtain the surveys of market participants before macroeconomic announcements and the outcomes from the announcements from Bloomberg. Following Andersen, Bollerslev, Diebold, and Vega (2003) and Jiang et al. (2011), we select all of the monthly 8:30 ET news with relevance numbers larger than 80 as classified by Bloomberg. Overall we include 11 scheduled U.S. macroeconomic announcements as shown in Table 4.1.

\footnotetext{
${ }^{3}$ For example, Sadka and Scherbina (2007) find a close link between mispricing and liquidity by investigating stocks with high analyst disagreement.
} 


\section{[Place Table 4.1 about here]}

In the empirical analysis, we investigate the factors affecting traders' order submission strategies around influential announcements (with Bloomberg relevance scores of 90 or above) in our news sample, and all the 11 monthly U.S. announcements. Figure 4.1 plots the average order submission frequencies in Panel A and order quantities in Panel B within each 1-minute interval on significant 8:30 ET news announcement days from 8:00 ET to 9:00 ET during our sample period. We exclude the days with other news arrivals with 60 minutes around 8:30 ET, to control the impact of other news announcements. Black lines are the submission frequency or quantity with quotes larger than the mid quotes. Black dash lines are the submission frequency or quantity with quotes equal to the mid quotes. Grey dash lines are the submission frequency or quantity with quotes smaller than the mid quotes. We can directly observe that both of the frequencies and quantities of orders with quotes larger or smaller than the mid quotes are larger than those with quotes equal to the mid quotes. In addition, the frequencies and quantities of orders with quotes different from the mid quotes increases more sharply than those with quotes equal to the mid quotes around the news arrivals.

\section{[Place Figure 4.1 about here]}

Figure 4.2 plots the average transaction frequency and quantities within each 1minute intervals within the same sample as Figure 4.1. A transaction happens whenever one market order is submitted to the BrokerTec platform. Market orders are also grouped into three types - those better than the best quotes, those at the best quotes and those behind the best quotes. Comparing Figure 4.1 with Figure 4.2, the number of limit orders submitted is roughly 20 to 30 times the number of market orders. For both of the market orders and the limit orders, the submissions are most active in the minute interval following the release of public information and remain high in the following half-hour interval.

\section{[Place Figure 4.2 about here]}

Figure 4.3 and Figure 4.4 plots the average 1-minute frequencies and quantities 
of all orders submissions and transactions around influential announcements, respectively. Figure 4.5 and Figure 4.6 plots the average 1-minute frequencies and quantities of all orders submissions and transactions around non-influential announcements. We divide the significant monthly announcements in our sample into two categories: influential announcements and non-influential announcements. Influential announcements are significant announcements regarded as highly relevant by market participants and are defined as announcements with Bloomberg relevance of over 90 (out of 100). Noninfluential announcements are announcements otherwise, with Bloomberg relevance between 80 and 90. Comparing Figure 4.3 and Figure 4.5 with Figure 4.1, and Figure 4.4 and Figure 4.6 with Figure 4.2, we can directly observe that the order submission activities are higher around influential U.S. monthly announcements, relative to significant news and non-influential news.

\section{[Place Figure 4.3 about here]}

[Place Figure 4.4 about here]

[Place Figure 4.5 about here]

[Place Figure 4.6 about here]

\subsubsection{Variables Construction}

\subsubsection{Belief Heterogeneity, Market Uncertainty, and News Surprise}

To characterize the information environment around announcements, we use the BKLS measures which are based on the decomposition of forecast dispersion among traders. BKLS shows that the dispersion among analysts' forecasts can be expressed as a function of the divergence of opinion among analysts' forecasts (belief heterogeneity) and the overall level of market uncertainty. Formally, we follow BKLS to define dispersion, $D$, as:

$$
D=V(1-\rho)
$$


where $V$ is a measure of market-level uncertainty and $H=(1-\rho)$ is a measure of belief heterogeneity among analysts. $\rho$ and $V$ are calculated as follows. For each announcement $k$ at time $t$ :

$$
\begin{aligned}
\rho_{t}^{k} & =\frac{h_{t}^{k}}{h_{t}^{k}+s_{t}^{k}}, \\
V_{t}^{k} & =\frac{D_{t}^{k}}{1-\rho_{t}^{k}},
\end{aligned}
$$

where $h$ is the precision of common information, and $s$ is the precision of idiosyncratic information for announcement $k$ at time $t$ over the entire sample period $t=1,2, \cdots, T$. Moreover, $h$ and $s$ are calculated as:

$$
\begin{aligned}
h_{t}^{k} & =\frac{S E_{t}^{k}-\left(D_{t}^{k} / N_{t}^{k}\right)}{\left[\left(S E_{t}^{k}-\left(D_{t}^{k} / N_{t}^{k}\right)\right)+D_{t}^{k}\right]^{2}}, \\
s_{t}^{k} & =\frac{D_{t}^{k}}{\left[\left(S E_{t}^{k}-\left(D_{t}^{k} / N_{t}^{k}\right)\right)+D_{t}^{k}\right]^{2}},
\end{aligned}
$$

where $S E$ is the squared error in the mean forecast deflated by the absolute value of the actual announced value, $D$ is variance in forecasts deflated by the absolute value of the actual announced value, and $N$ is the number of forecasts.

We measure public information shocks by the standardized announcement surprise, defined as:

$$
S U R_{t}^{k}=\frac{A_{t}^{k}-E_{t}^{k}}{\hat{\sigma}^{S U R, k}}
$$

where $A_{t}^{k}$ is the actual outcome of announcement $k$ at time $t, E_{t}^{k}$ is the median forecast from the $J$ analysts for announcement $k$ at time $t$, and $\hat{\sigma}^{S U R, k}$ is the standard deviation of $\left(A^{k}-E^{k}\right)$ for announcement $k$ calculated using $\left(A^{k}-E^{k}\right)$ in the past 24 months.

Table 4.2 reports the means and variations of belief heterogeneity and uncertainty as well as their correlations with the magnitude of public information shocks during our sample period from 2011 to 2015 . In the table, $H=1-\rho$ denotes the belief heterogeneity and $V$ denotes the uncertainty. We use the absolute announcement surprise $|S U R|$ to capture the magnitude of public information shocks. 
For all the 11 types of news, belief heterogeneity $(H)$ is negatively correlated with the absolute information shocks $(|S U R|)$. $H$ measures the precision level of idiosyncratic information, in terms of all the market information. ${ }^{4}$ The correlation between $H$ and $|S U R|$ suggest that the distance between actual news content and the forecast median $(|S U R|)$ becomes shorter when the investors' beliefs are more heterogeneous. This could be explained by the increasing attention of economists. When the economist forecasts are more heterogeneous, the economists would pay much more attention to analysis the market situation to minimum adverse selection risks. As a result, the median of the economist forecasts becomes more closed to the actual announcements.

Market uncertainty $(V)$ is positively correlated with the absolute information shocks, and significant at the $10 \%$ or lower level for the nine types of news. It shows that the information shocks increases when the market uncertainty is large. The market uncertainty is measured by $\frac{D}{H}$, where $D$ is the adjusted variance in forecasts and $H$ is the belief heterogeneity. $V$ and $H$ are negatively correlated. Thus, the relation between $V$ and $|S U R|$ and the relation between $H$ and $|S U R|$ are opposite.

\section{[Place Table 4.2 about here]}

\subsubsection{Trading Characteristics}

Table 4.3 reports the summary statistics of U.S. Treasury market trading characteristics around the significant monthly 8:30 ET announcements. To focus on the role of information, we concentrate on the half-hour intervals before and after our sample announcements.

Order aggressiveness and order size are two measures of traders' orders. Order aggressiveness at time $t, I_{t}$, captures the priority of execution in a limit order market, that is, how far the order, $p_{t}$, is from being immediately executable. It is defined as the distance of the current quote from the best quote standing on the opposite side of the

\footnotetext{
${ }^{4}$ Since $H=1-\rho=1-\frac{h}{h+s}$, where $h$ is the precision of common information, and $s$ is the precision of idiosyncratic information, we have: $H=\frac{s}{h+s}$.
} 
market:

$$
\begin{aligned}
I_{t} & =\left(B_{t}-p_{t}^{a}\right) \times 1000 \text { for an ask order, } \\
& =\left(p_{t}^{b}-A_{t}\right) \times 1000 \text { for a bid order. }
\end{aligned}
$$

At the time point $t$ when an order is submitted, $A_{t}$ and $B_{t}$ are the best quote at the ask side and the best quote at the bid side, respectively. Being farther from the best price on the opposite side of the market means the order is less likely to be executed and is therefore classified as being "less aggressive." Thus, $I_{t} \leq 0$. $I_{t}$ of a market order is zero as it will be executed against the first available order on the opposite side of the market, and the $I_{t}$ of a limit order is negative as it may have to wait to be executed. Consequently, smaller values indicate less aggressive orders.

We also consider measures characterizing the state of the limit order book. Spread is defined as

$$
\operatorname{SPRD}_{t}=\frac{1}{N_{j, d}^{L}} \sum_{i \in j}\left(A_{i, d}-B_{i, d}\right),
$$

where $A_{i, d}$ and $B_{i, d}$ refer to the best ask quote and the best bid quote of the $i$ th limit order on day $d . N_{j, d}^{L}$ is the total number of limit orders within the interval $j$ on day $d$.

Two measures of the depth of the limit order book are used: $D P 0$ denotes the accumulated depth as the total absolute value of orders submitted at the best price standing on the ask and bid sides of the market; and DP denotes the cumulative depth across the entire limit order book at prices behind the best price.

$$
D P 0_{j, d}=\frac{1}{N_{j, d}^{L}} \sum_{i \in j}\left|D P 0_{i, d}^{A}+D P 0_{i, d}^{B}\right|
$$

and

$$
D P_{j, d}=\frac{1}{N_{j, d}^{L}} \sum_{i \in j}\left|D P_{i, d}^{A}+D P_{i, d}^{B}\right|,
$$

where $D P 0_{i, d}$ and $D P_{i, d}$ are the depth at the best quote and behind the best quote of the $i$ th limit order within the interval $j$ on day $d$, respectively.

Return volatility of the 30 -minute interval $j$ on day $d$ is calculated as the percentage 
of the standard deviation of one-minute log returns in the corresponding 30-minute periods before and after each announcement:

$$
V T Y_{j, d}=\sqrt{\sum_{i=1}^{30}\left[R_{1 \min , i}-\bar{R}_{1 \min , j, d}\right]^{2}} \times 100, \text { where } i \in j
$$

$\bar{R}_{1 \min , j, d}$ is the mean $\log$ return of interval $j$ on day $d$. The $i$-th 1-minute log return within interval $j$ on day $d$ is $R_{1 \min , i}$ as follows:

$$
R_{1 \text { min }, i}=\log \left(\text { MidQuote }_{i}\right)-\log \left(\text { MidQuote }_{i-1}\right) \text {. }
$$

Trading volume, $T R V L M$, is the aggregate volume of orders executed in millions of U.S. dollars in the corresponding 30-minute period. On the U.S. Treasury BrokerTec ECN, only the aggressive side pays commission fees to the trading platform. Thus, the limit orders are matched with market orders only.

\section{[Place Table 4.3 about here]}

Table 4.3 report the summary statistics for these variables. Panels A, B, and C report the statistics in two 30-minute intervals around 8:30 ET on significant monthly news announcement days, influential news announcement days, and non-influential news announcement days. To control the impact of other news announcements at other times besides 8:30 ET, we exclude the days with news arrivals within one hour around 8:30 ET. Panel D reports the corresponding values at the same time of day but on nonannouncement days. Non-announcement days are the trading days without any news arrivals from 7:30 ET to 9:30 ET. ${ }^{5}$

In Panels $\mathrm{A}$ and $\mathrm{B}$, on average, we find that orders are more aggressive in the 30 minute interval before 8:30 ET, and the trading volume is much smaller than that of the 30-minute interval after 8:30 ET. This shows that some traders on the market take more aggressive positions following their own knowledge and forecast on the news contents,

\footnotetext{
${ }^{5}$ Please see Figure 2.2 in Chapter 2 for the graph illustration on how we define the announcement days and non-announcement days.
} 
especially before the influential announcements.

Consistent with Fleming and Remolona (1999), we find that despite the increase in volatility in the post-announcement periods, the market has more depth at both the best and behind best quotes and larger trading volumes. ${ }^{6}$ The increased volatility in Panel $\mathrm{A}$ and $\mathrm{B}$ of Table 4.3 is therefore likely to be the result of the increased trading activity - trading creating volatility. Traders, therefore, appear to be more willing to participate in the market once the information uncertainty is resolved through the news arrivals. The results in Panel D demonstrate no discernable intraday seasonality to explain these patterns indicating a role for the announcements.

These results in Table 4.3 suggest significant differences in the relationships between traders' individual order submission decisions, and traders' aggregate trading activities during the pre- and post-announcement periods. We formally examine these relationships and how they correspond to changes in the overall information environment below.

\subsection{Order Submissions Strategies}

In this section, we present an analysis of the relationships between individual traders' belief heterogeneity, public information shocks, and traders' order submission choices. Because multiple announcements can occur on some trading days, our analysis uses only days with a single significant announcement on announcement days to minimize potential confounding effects. ${ }^{7}$ We first explore how the order aggressiveness is affected by belief heterogeneity and uncertainty before and after announcements. Then we examine the role of these information factors on the type of orders submitted and the aggressiveness of limit orders placed around announcements.

\footnotetext{
${ }^{6}$ Using daily data, Kruger (2019) argues that turnover and bid-ask spreads tend to increase around earnings announcements for stocks, bonds, and options.

${ }^{7}$ During the five-year sample period, there are 140 announcement days with a single significant 8:30 ET announcement, 63 days of which are influential announcement days. The rest 77 days are noninfluential announcement days with a single announcement.
} 


\subsubsection{A Multivariate Analysis of Order Aggressiveness}

To more fully understand the role of the external information environment and observable market characteristics such as the state of the limit order book in the traders order submission decisions, we start by examining the aggressiveness of order as defined in Equation (4.3). Given that the $I_{t}$ of a market order or marketable limit order is zero and that of a limit order is negative, we use a censored regression model to estimate the following equation,

$$
I_{t}=\alpha+\alpha_{H} H_{t}+\alpha_{V} V_{t}+\beta_{x} X_{t}+\varepsilon_{t}
$$

Order aggressiveness, $I$, is defined as in Equation (4.9). $H$ denotes belief heterogeneity and $V$ denotes uncertainty. Order aggressiveness is a function of belief heterogeneity, uncertainty and a set of variables capturing the state of the order book $\left(X_{t}\right)$. The measures capturing states of the limit order book are realized volatility $(V T Y)$ as Equation (4.7), spread (SPRD) as Equation (4.4), depth at the best quote on the same side of the market (SAME0), depth behind the best quote on the same side of the market $(S A M E B H D)$, depth at the best quote on the opposite side of the market $(O P P 0)$, depth behind the best quote on the opposite side of the market (OPPBHD), trading volume (TRVLM), and price impact (BETA).

The depth at the best quote on the same side of the market (SAME0) is the depth standing at the best price on the same side of the market when the limit order $i$ was submitted at time $t$ :

$$
S A M E 0_{i, t}=\text { Dept }_{0, i, t}^{\text {same }}
$$

where Dept $h_{0, i, t}^{\text {same }}$ is the depth standing at the best price on the same side of the market when the order $i$ was submitted at time $t$. Similarly, the depth at the best quote on the opposite side of the market $(O P P 0)$ is the depth standing at the best price on the opposite side of the market when the limit order $i$ was submitted at time $t$ :

$$
O P P 0_{i, t}=\operatorname{Depth}_{0, i, t}^{o p p}
$$


where Depth $h_{0, i, t}^{o p p}$ is the depth standing at the best price on the opposite side of the market when the order $i$ was submitted at time $t$.

The depth behind the best quote on the same side of the market (SAMEBHD) is the depth behind the best quote on the same side of the market when the limit order $i$ was submitted at time $t$ :

$$
S A M E B H D_{i, t}=\sum_{k=1}^{K} \operatorname{Depth}_{k, i, t}^{\text {same }},
$$

where $\sum_{k=1}^{K}$ Dept $h_{k, i, t}^{\text {same }}$ is the accumulated depth at all of the $K$ price levels behind the best quote on the same side of the market when the limit order $i$ was submitted at time $t$. Similarly, the depth behind the best quote on the opposite side of the market $(O P P B H D)$ is the depth at prices behind the best quote on the same side of the market when the limit order $i$ was submitted at time $t$ :

$$
\text { OPPBHD } D_{i, t}=\sum_{k=1}^{K} \operatorname{Depth}_{k, i, t}^{o p p},
$$

where $\sum_{k=1}^{K} \operatorname{Depth}_{k, i, t}^{o p p}$ is the accumulated depth at all of the $K$ price levels behind the best quote on the opposite side of the market when the limit order $i$ was submitted at time $t$. Since the behind best depths are not observable by market participants, these measures the unobservable level of market liquidity that are potentially correlated with traders' private information.

The price impact $\left(B E T A_{j, d}\right)$ is the beta estimates from the 1-minute log return regressions within each before- or after- 8:30 ET interval on the trading day $d$ (Harford and Kaul, 2005; Cont, Kukanov, and Stoikov, 2014).

$$
R_{1 \min , j, d}=\alpha+B E T A_{j, d} \times O F_{5 \min , \tau, j, d}+\varepsilon_{j, d},
$$

where $R_{1 \min , j, d}$ is the 1-minute $\log$ return of interval $j$ on day $d$. The order flow $\left(O F_{5 \min , \tau}\right)$ is the the quantity of trades during the past 5 -minute interval from $\tau-5 \min$ to $\tau$ of interval $j$ on day $d$.

To investigate the role of information, we look at how the arrival of announce- 
ments affect order aggressiveness by dividing the analysis into two periods: the preannouncement period and the post-announcement period. To explore the role of announcement relevance, we estimate Equation (4.9) on all the significant monthly 8:30 ET news announcement days, which can be divided into the influential 8:30 ET news announcement days, and the non-influential 8:30 ET news announcement days. Table 4.4 presents the estimation results using the censored regression as Equation (4.9).

\section{[Place Table 4.4 about here]}

In Table 4.4, during the pre-announcement period, we find that market uncertainty tends to increase order aggressiveness with all monthly significant announcements, including the influential announcements, and non-influential announcements. For example, the estimated coefficients of the market uncertainty $\left(V_{t}\right)$ are 0.015 and 0.020 on influential news announcement days and non-influential news announcement days, and significant at the $1 \%$ level, respectively. Thus informed traders tend to submit more aggressive orders under higher uncertainty before news arrivals. On the other hand, the results also show that the impact of market uncertainty on the order aggressiveness is stronger before non-influential news arrivals than that before influential news arrivals. This suggests that news types influence traders' trading strategy and their order aggressiveness choices.

During the post-announcement period, the traders still tend to submit more aggressive orders under higher uncertainty. For example, the coefficient of $V_{t}$ on all significant news announcement days is 0.034 , and significant at the $1 \%$ level. One conjecture of this result is that an increase in uncertainty may potentially affect information asymmetry among market participants (Grossman and Stiglitz, 1980) which in turn makes private information more valuable. Informed traders tend to place more market orders (Kyle, 1985) or aggressive limit orders (Roşu, 2018).

Looking at the impact of belief heterogeneity, we find that during the pre- and postannouncement periods, the total effect of the traders' belief heterogeneity of all the significant news is positively correlated to the order aggressive, which is the same as 
the effects of market uncertainty. However, if we divide all the news into influential news and non-influential news, we find that the effect of influential news is opposite during the post-announcement period that the traders tend to submit less aggressive orders after the influential news arrivals under high belief heterogeneity. The effect of non-influential news is the same as the impact of all the significant news. For example, the $\alpha_{H}$ is -0.395 , and significant at the $1 \%$ level on the influential news announcement days during the post-announcement period. As a comparison, the other significant $\alpha_{H} \mathrm{~s}$ are all positive. This confirms our explanation that news types influence traders' trading strategy and their order aggressiveness choices.

Looking at how the state of limit order book affects order submission decision, we find the impact on the order aggressiveness keeps the same on both of the preannouncement period and the post-announcement period. An increase in market volatility, spread, depth behind the best quote on the opposite side of the market, or price impact leads to a decrease in order aggressiveness, with $V T Y_{t}, S P R D_{t}, O P P B H D_{t}$, or $B E T A_{t}$ negatively significant in all significant news announcement days, influential news announcement days, and non-influential news announcement days. On the other hand, an increase in the depth on the best quote, $S A M E 0$, the depth behind the best quote on the same side of the market, $S A M E B H D_{t}$, the depth at the best quote on the opposite of the market, $O P P 0$, or trading volume, $T R V L M_{t}$, leads to a significant increase in order aggressiveness. The impact of $S P R D_{t}, S A M E 0$ and $O P P 0$ on order aggressiveness can be explained by the aggressive order clusters (Griffiths, Smith, Turnbull, and White (2000)).

Table 4.5 reports the multivariate analysis results of the order aggressiveness in the 15-minute intervals from 8:00 ET to 9:00 ET. Panel A shows the coefficients of the market uncertainty $\left(V_{t}\right)$ and the belief heterogeneity $\left(H_{t}\right)$ during the two sub-periods of the pre-announcement period. Panel B shows the coefficients of the market uncertainty $\left(V_{t}\right)$ and the belief heterogeneity $\left(H_{t}\right)$ during the two sub-periods of the post-announcement period. The sub-period analysis shows the same pattern as Table 4.4. First, the traders tend to submit more aggressive limit orders or market orders when the market uncer- 
tainty is high. In Table 4.5, all of the estimated coefficients, $\alpha_{V} \mathrm{~s}$, are positive and significant at the $1 \%$ level. Second, the impact of belief heterogeneity among different types of news varies - traders tend to submit more aggressive limit orders or market orders when the belief heterogeneity of influential news is low, whereas traders tend to submit more aggressive limit orders or market orders when the belief heterogeneity of influential news is high.

\section{[Place Table 4.5 about here]}

\subsubsection{Impact of Information Shocks}

We next study how the release of the announcement affects the role of belief heterogeneity and uncertainty during the post-announcement period. To control for the extent of information shock, we use the median $|S U R|$ and divide the sample into high $|S U R|$ and low $|S U R|$ subsamples in estimating the censored regression in Table 4.6. We further control for the effect of the passage of time by looking at the 15-minute interval immediately after announcements in Table 4.7, and 15- to 30-minute after announcements in Table 4.8. If the regression results in each of the High and Low $|S U R|$ groups is different from the results in Table 4.4, it means that the information shocks influence the order submission behaviors of investors during the post-announcement period. If the release of information resolves both belief heterogeneity and uncertainty, then these two information variables should not play any role during the post-announcement period and its subperiods.

Table 4.6 shows that the impact of the belief heterogeneity on the order aggressiveness is influenced by the information shocks level. The impact of market uncertainty on order aggressiveness are the same, and consistent with Table 4.4. However, the impact of idiosyncratic information $(H)$ on the order aggressiveness after non-influential news announcements is different between the high information shocks group and the low information shocks group. Comparing with Table 4.4, in the High $|S U R|$ group, the impact of idiosyncratic information on order aggressiveness after non-influential 
news announcements is different in that traders with idiosyncratic information tend to submit limit orders rather than market orders after the news arrivals. That is to say, when the information shocks is high, the types of news no longer influence the traders' choices of order aggressiveness. As a result, the total impact of all sample news when information shocks is high differs from that of the others. In addition, the coefficient estimates of the idiosyncratic information $(H)$ are -1.530 and -1.261 after influential and non-influential news announcements, respectively. And both of them are significant at the $1 \%$ level. The results suggest that the impact of $H$ is stronger after influential news arrivals than that after non-influential news arrivals.

\section{[Place Table 4.6 about here]}

Table 4.7 and Table 4.8 presents the regression results in sub-sample periods during the post-announcement periods by high and low $|S U R|$. Table 4.7 presents the estimation results in low $|S U R|$ and high $|S U R|$ groups during the fifteen-minute interval from 8:30 ET to 8:45 ET, and its three five-minute sub-intervals. Similar to results during the post-announcement interval in Table 4.4 and Table 4.6, we find that orders are more aggressive as the level of uncertainty increases. Information shocks do not influence how the impact of market uncertainty on the order aggressiveness. However, information shocks significantly influence the impact of belief heterogeneity and show the same pattern as Table 4.6.

Furthermore, to show changes in impacts of the market uncertainty and idiosyncratic information on the order aggressiveness by the time, we repeat the regression in each of the five-minute sub-periods from 8:30 ET to 8:45 ET in Panel B, Panel C, and

Panel D. Results in five-minute sub-periods are consistent with Panel A that the impacts of $V$ and $H$ on order aggressiveness remains the same from 8:30 ET to 8:45 ET.

\section{[Place Table 4.7 about here]}

Table 4.8 presents the estimation results in low $|S U R|$ and high $|S U R|$ groups during the fifteen-minute interval from 8:45 ET to 9:00 ET, and its three five-minute subintervals. The market uncertainty is still positively related to the order aggressiveness 
regardless of the level of information shocks on all significant news announcement days and the sub-groups. Belief heterogeneity has a significant negative relationship to aggressiveness when the magnitude of information shock is high or on influential announcement days when the level of information shock is low. The pattern is consistent with Table 4.6 and Table 4.7.

\section{[Place Table 4.8 about here]}

\subsubsection{Order Choice}

One potential issue with the previous analysis is that the order aggressiveness measure, $I$, does not identify the type of order submitted. Thus it is not possible to tell whether an increase in order aggressiveness is due to an increase in the placement of market orders or the submission of aggressive limit orders which are close to or improve the mid-quote. The former represents the consumption of liquidity while the latter represents the provision of liquidity. To address this issue, we examine the order submission decision in two stages. In the first stage, we first examine whether traders' order choice i.e. their decision on submitting market orders or limit orders is affected by belief heterogeneity and uncertainty. By estimating a probit model, we analyze whether changes in order aggressiveness is due to the submission of market orders or limit orders. In the second stage, we focus solely on limit orders submission. We examine, conditional on a limit order being submitted, how the aggressiveness of the limit orders is affected by belief heterogeneity and uncertainty.

The probit model used to examine how order choice depends on belief heterogeneity and uncertainty is specified as follows,

$$
P(m k t=1)=f\left(\alpha+\alpha_{H} H_{t}+\alpha_{V} V_{t}+\beta_{x} X_{t}\right)
$$

where an order, $M K T$, is set to 1 if the order is a market order and is set to zero otherwise. $H$ denotes belief heterogeneity and $V$ denotes uncertainty. Variables capturing the state of the order book are denoted as $X_{t}$, as in Equation (4.9). 
Table 4.9 reports the probit regression results during the pre-announcement period and its sub-periods. First, the impact of market uncertainty on traders' market order submissions varies by the type of news during the pre-announcement period and 15minute interval from 8:00 ET to 8:15 ET. If the scheduled announcement is influential, the traders tend to submit fewer market orders. However, if the scheduled announcement is non-influential, the traders tend to submit more market orders. For example, during the 15-minute interval from 8:00 ET to 8:15 ET, the $\alpha_{V}$ is -0.001 and significant at the $5 \%$ level when the scheduled news is influential, whereas the $\alpha_{V}$ is 0.001 and significant at the $1 \%$ level when the scheduled news is non-influential. Second, the belief heterogeneity has no impact on the market orders submission before influential news arrivals. If the scheduled news is non-influential, traders tend to submit more market orders when the belief heterogeneity is high. For example, the $\alpha_{H}$ is 0.039 and significant at the $1 \%$ level during the pre-announcement period, when the scheduled announcement is non-influential. Third, the impact of market liquidity on the market orders is similar to that on the order aggressiveness, except for the impact of depth behind the best quote on the same side $\left(S A M E B H D_{t}\right)$. When $S A M E B H D_{t}$ is high, traders tend to submit fewer market orders.

\section{[Place Table 4.9 about here]}

Table 4.10 reports the results of the probit model during the post-announcement period and its sub-periods. We find that the market uncertainty is positively correlated with the order aggressiveness in the post-announcement period and its two sub-periods, which is consistent with the former findings. Traders tend to submit more market orders when the market uncertainty is high during the post-announcement periods and its two sub-periods.

\section{[Place Table 4.10 about here]}

Table 4.11 reports the results of the probit model of order choice for low and high $|S U R|$ groups. The finding of the market uncertainty impact on increasing market order aggressiveness is robust in both high and low $|S U R|$ groups. However, the belief 
heterogeneity increases the aggressiveness of market orders or aggressive limit orders in the low $|S U R|$ group during the post-announcement period and its two sub-periods, whereas the belief heterogeneity decreases the aggressiveness of market orders or aggressive limit orders in the low $|S U R|$ group during the post-announcement period and its two sub-periods. The impact of the belief heterogeneity is consistent across all significant news announcement days, influential news announcement days, and noninfluential news announcement days within each group divided by the information shocks.

\section{[Place Table 4.11 about here]}

\subsubsection{Limit Order Aggressiveness}

Next, we focus on the submission of limit orders and examine how the aggressiveness of limit orders depends on belief heterogeneity and uncertainty. We estimate the following model,

$$
\operatorname{lmt}_{t}=\alpha+\alpha_{H} H_{t}+\alpha_{V} V_{t}+\beta_{x} X_{t}+\varepsilon_{t}
$$

where $l m t$ denotes the aggressiveness of limit orders. $H$ denotes belief heterogeneity and $V$ denotes uncertainty. Variables capturing the state of the order book are denoted as $X_{t}$.

The limit order aggressiveness, lmt, is defined as:

$$
\begin{aligned}
\operatorname{lmt_{t}} & =\left(p_{0 t}^{b}-p_{t}^{a}\right) \times 1000 \text { for an ask order } \\
& =\left(p_{t}^{b}-p_{0 t}^{a}\right) \times 1000 \text { for a bid order }
\end{aligned}
$$

As $l m t_{t}$ of a marketable limit order is zero, we use a censored regression model to estimate Equation (4.16).

Table 4.12 reports the results of the censored regression model of limit order aggressiveness during the pre-announcement period and its two sub-periods. First, when 
market uncertainty is high, traders tend to submit more aggressive limit orders. For example, during the pre-announcement period, the coefficients of $V_{t}$ are 0.033 and 0.036 when the scheduled news is influential and non-influential, respectively. All of the $\alpha_{V} \mathrm{~s}$ are positive and significant at the $1 \%$ level. Second, only the belief heterogeneity of the scheduled non-influential announcement has a significant impact on the limit order submissions that when the belief heterogeneity of non-influential news is high, traders tend to submit more aggressive limit orders. Third, the impact of market liquidity is the same as our findings in Table 4.4.

\section{[Place Table 4.12 about here]}

Table 4.13 reports the results of the censored regression model of limit order aggressiveness during the post-announcement period and its two sub-periods. The finding shows that market uncertainty and belief heterogeneity influence the aggressive limit order submission strategies similar to the impact on the aggregate order aggressiveness. On the market with a higher level of market uncertainty, traders intend to submit a more aggressive limit order on either influential or non-influential news announcement days. The impact of belief heterogeneity also influences the limit order submission behaviors in the same pattern as Table 4.4.

\section{[Place Table 4.13 about here]}

Table 4.14 reports the results of the censored regression model of limit order aggressiveness in the low $|S U R|$ group and the high $|S U R|$ group. We find that the former findings on the market uncertainty impact are still robust in the post-announcement period and its two sub-periods, including within each of the high $|S U R|$ group and the low $|S U R|$ group. However, the information shocks affect the impact of belief heterogeneity on the aggressive limit order submission strategies.

In the low $|S U R|$ group, traders with high levels of belief heterogeneity tend to submit more aggressive limit orders on influential news announcement days, but less aggressive orders on non-influential news announcement days. In the high $|S U R|$ group, traders with high levels of belief heterogeneity tend to submit less aggressive limit 
orders on all significant news announcement days, influential news announcement days and non-influential news announcement days. For example, in Panel B of Table 4.14, the $\alpha_{H}$ s on influential news announcement days are 3.506 and -3.526 in low $|S U R|$ group and high $|S U R|$ group, whereas the $\alpha_{H}$ s on non-influential news announcement days are -3.486 and -1.541 in low $|S U R|$ group and high $|S U R|$ group. All of the coefficients of the belief heterogeneity in Table 4.14 are significant at least the $5 \%$ level.

\section{[Place Table 4.14 about here]}

\subsection{Conclusion}

In this paper, we examine the impact of the market uncertainty, belief heterogeneity and public information shocks on traders' order submission decisions in theU.S. Treasury market. Our findings provide interesting insights into the role of the information environment in the order submission process. First, we find that during both the pre-announcement period and the post-announcement period, the traders tend to submit more market orders and aggressive limit orders when the market uncertainty is high. Second, we find that investors' belief heterogeneity influence their trading behavior and order submission strategies around news announcements. The role of the belief heterogeneity on order aggressiveness depends on the type of news, and the magnitude of the information shocks. Third, we find that the impact of market uncertainty and belief heterogeneity influence traders' submission of both of the market orders and aggressive limit orders.

\subsection{Figures and Tables}



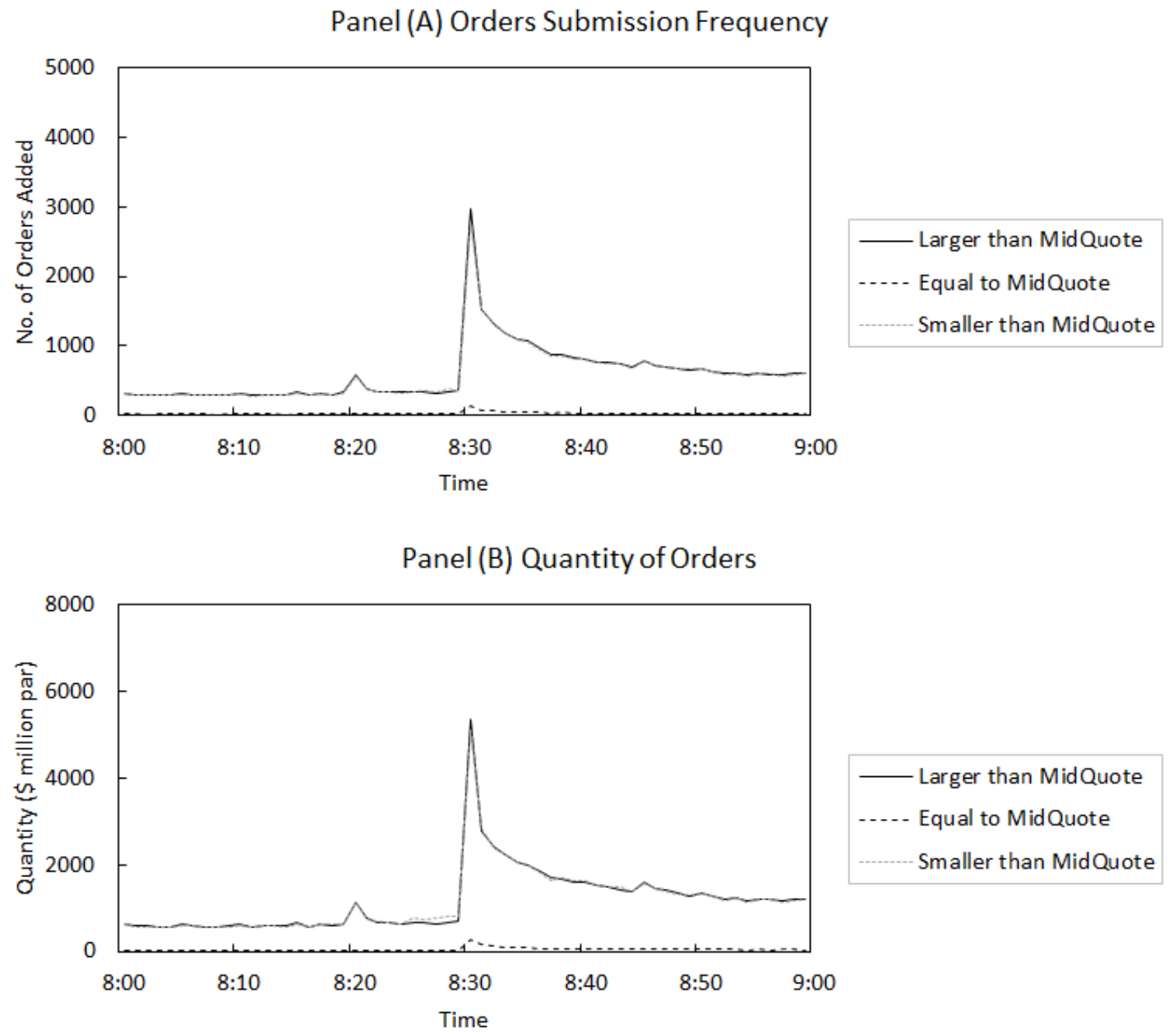

Figure 4.1: Order Submission Activities around All Sample News Announcements. This figure reports the average order submission frequency and order quantity in each 1-minute interval from 8:00 ET to 9:00 ET. In our sample period from January 5, 2011 to December 15, 2015, 259 trading days have significant monthly 8:30 ET macroeconomic news announcements, and no other news released within 60 minutes around 8:30 ET. 
Panel (A) Market Orders Submission Frequency

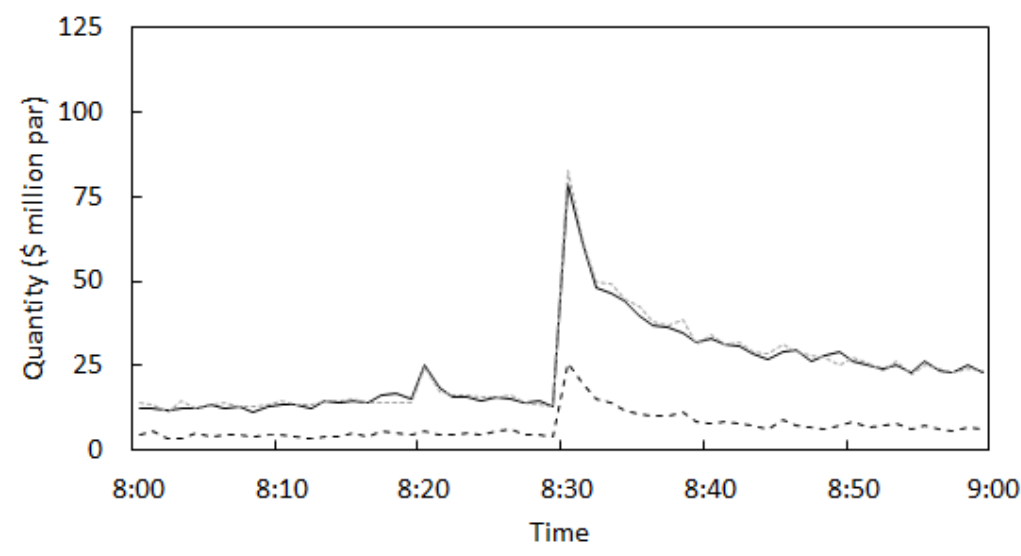

— Larger than MidQuote

.... Equal to MidQuote Smaller than MidQuote

Panel (B) Quantity of Market Orders

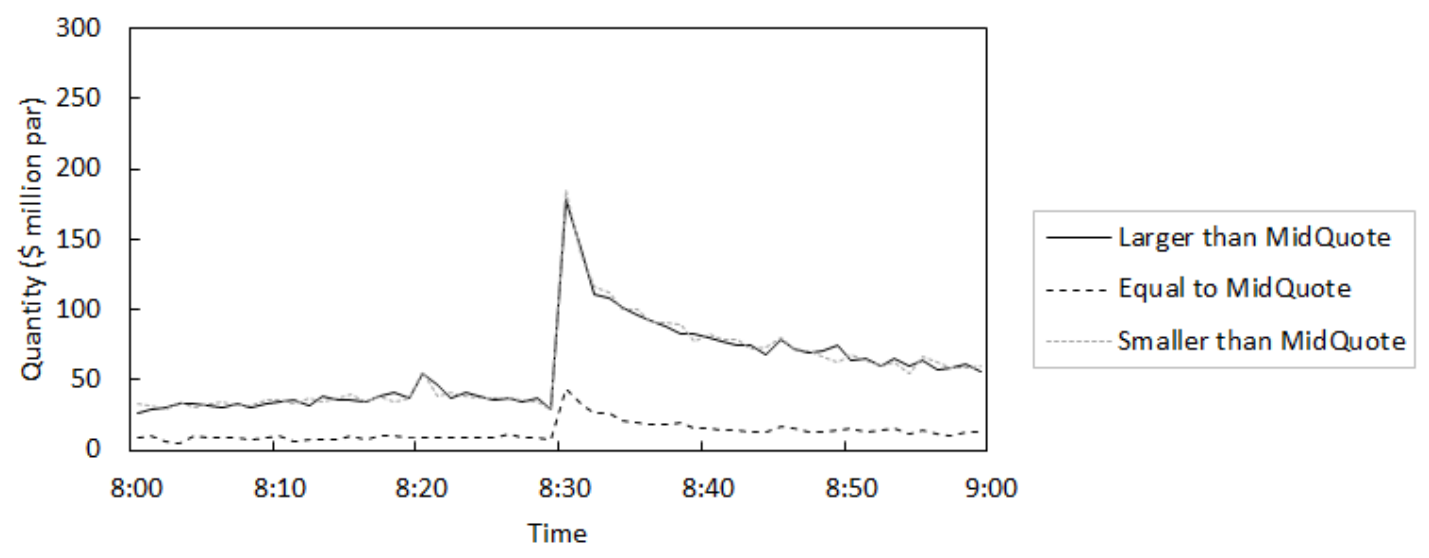

Figure 4.2: Transactions around All Sample News Announcements. This figure reports the transaction frequency and market order quantity in each 1-minute interval from 8:00 ET to 9:00 ET. In our sample period from January 5, 2011 to December 15, 2015, 259 trading days have significant monthly 8:30 ET macroeconomic news announcements, and no other news released within 60 minutes around 8:30 ET. 

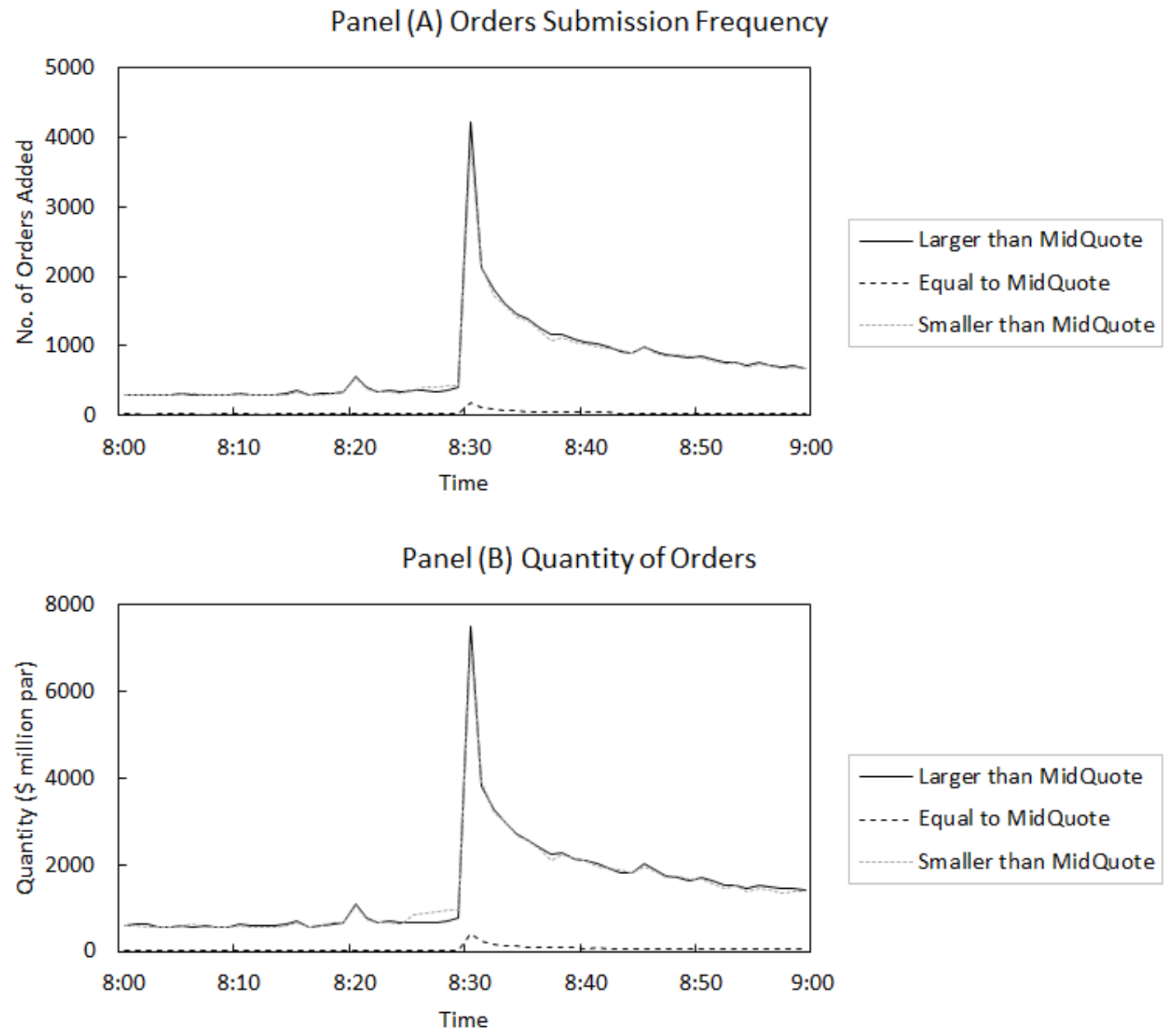

Figure 4.3: Order Submission Activities around Influencial News Announcements. This figure reports the average order submission frequency and order quantity in each 1-minute interval from 8:00 ET to 9:00 ET. In our sample period from January 5, 2011 to December 15, 2015, 143 trading days have Influencial monthly 8:30 ET macroeconomic news announcements (Bloomberg Relevance $>90$ ), and no other news released within 60 minutes around 8:30 ET. 

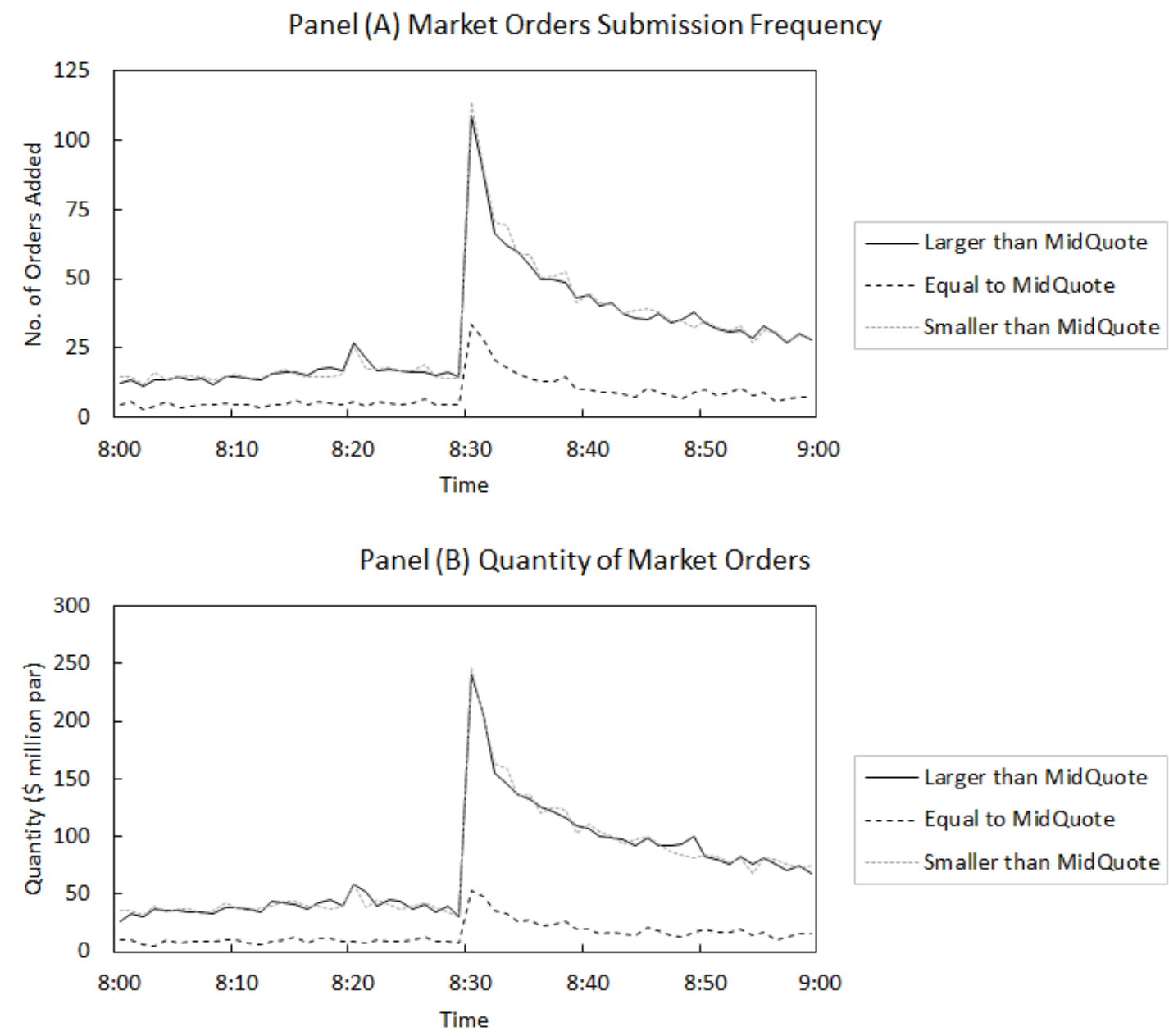

Figure 4.4: Transactions around Influencial News Announcements. This figure reports the average transaction frequency and market order quantity in each 1-minute interval from 8:00 ET to 9:00 ET. In our sample period from January 5, 2011 to December 15, 2015, 143 trading days have influential monthly 8:30 ET macroeconomic news announcements (Bloomberg Relevance $>90$ ), and no other news released within 60 minutes around 8:30 ET. 

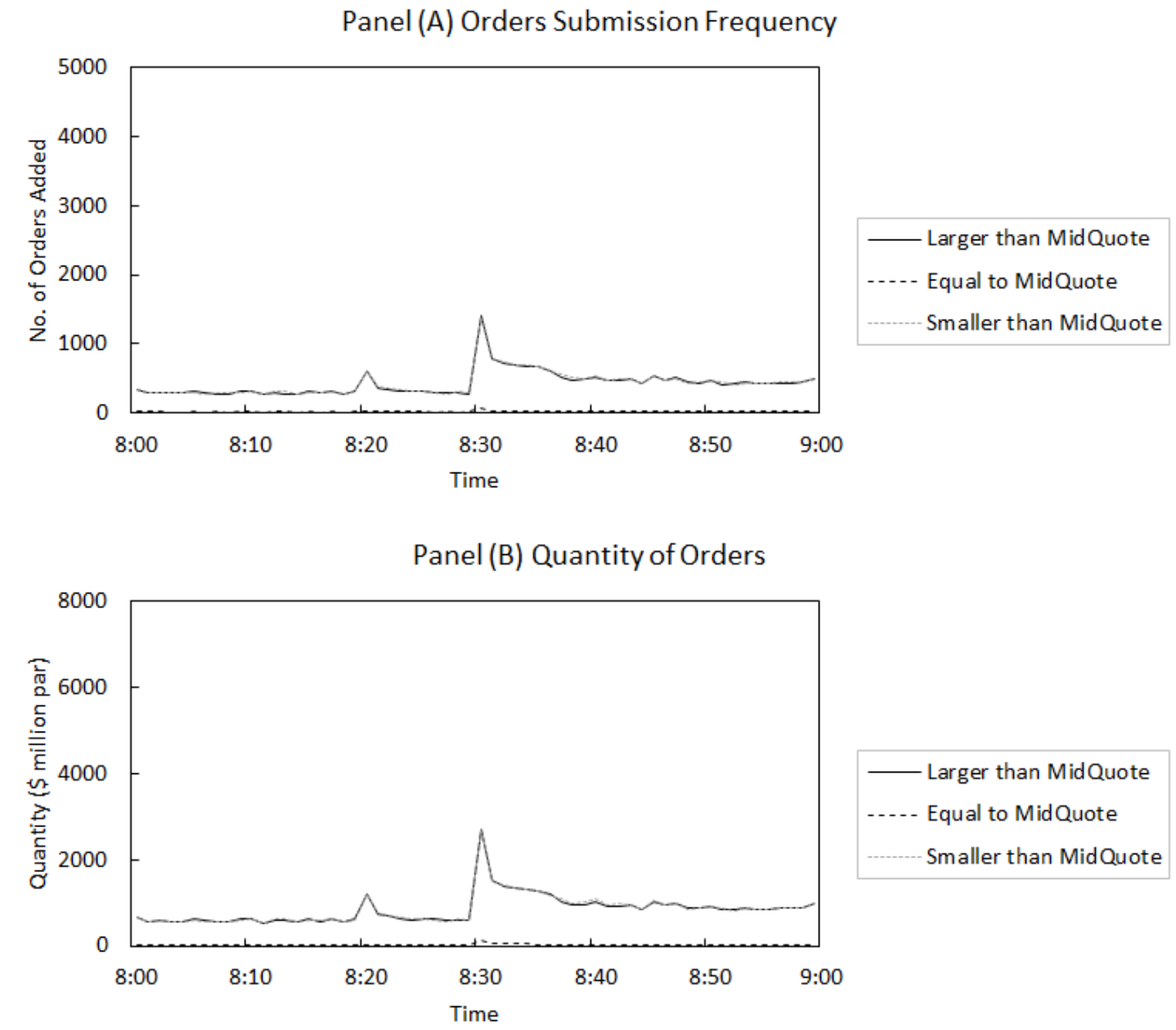

Figure 4.5: Order Submission Activities around Non-Influencial News Announcements. This figure reports the average order submission frequency and order quantity in each 1-minute interval from 8:00 ET to 9:00 ET. In our sample period from January 5, 2011 to December 15, 2015, 116 trading days have non-influential monthly 8:30 ET macroeconomic news announcements $(80<$ Bloomberg Relevance $\leq 90)$, and no other news released within 60 minutes around 8:30 ET. 

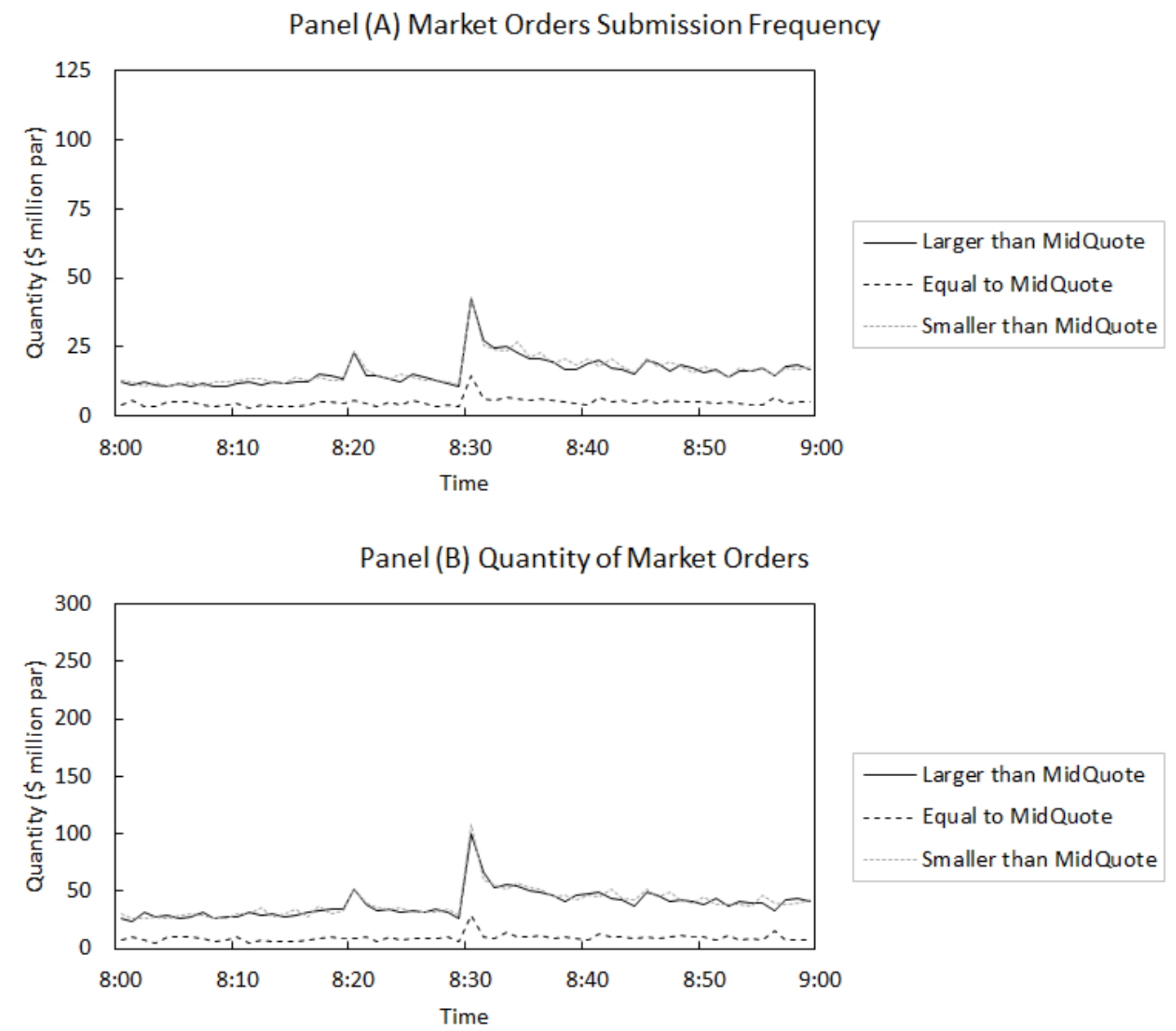

Figure 4.6: Transactions around Non-Influencial News Announcements. This figure reports the average transaction frequency and market order quantity in each 1minute interval from 8:00 ET to 9:00 ET. In our sample period from January 5, 2011 to December 15, 2015, 116 trading days have non-influential monthly 8:30 ET macroeconomic news announcements $(80<$ Bloomberg Relevance $\leq 90)$, and no other news released within 60 minutes around 8:30 ET. 
Table 4.1: Macroeconomic Announcements

\begin{tabular}{lccccc}
\hline Event & Time & $N$ & \multicolumn{1}{c}{ SUR } & $|S U R|$ & $N_{|S U R|>1}$ \\
\hline Building Permits & $8: 30: 00$ & 60 & 0.312 & 0.914 & 22 \\
Consumer Price Index $\dagger$ & $8: 30: 00$ & 60 & -0.090 & 0.674 & 17 \\
Change in Nonfarm Payrolls $\dagger$ & $8: 30: 00$ & 60 & -0.031 & 0.755 & 20 \\
Durable Goods Orders $\dagger$ & $8: 30: 00$ & 60 & -0.010 & 0.692 & 14 \\
Empire Manufacturing & $8: 30: 00$ & 60 & -0.269 & 0.795 & 19 \\
Housing Starts & $8: 30: 00$ & 60 & 0.015 & 0.878 & 23 \\
Producer Price Index & $8: 30: 00$ & 60 & -0.080 & 0.752 & 17 \\
Personal Spending & $8: 30: 00$ & 58 & -0.166 & 0.810 & 24 \\
Retail Sales $\dagger$ & $8: 30: 00$ & 60 & -0.224 & 0.752 & 18 \\
Trade Balance & $8: 30: 00$ & 60 & 0.021 & 0.716 & 18 \\
Unemployment Rate & $8: 30: 00$ & 60 & -0.429 & 0.755 & 17 \\
\hline
\end{tabular}

This table characterizes the significant monthly announced U.S. macroeconomic news. The variable Event is the specific announcement; " $\dagger$ " indicates influential events with Bloomberg relevance value higher than 90. Time denotes the time of the announcement in Eastern Time (ET); SUR denotes the sample mean of the standardized surprise; $|S U R|$ denotes the sample mean of the absolute standardized surprise; $N_{|S U R|>1}$ denotes the number of absolute announcement surprise that is one standard deviation or more away from the mean. 


\section{Table 4.2: Summary Statistics of Belief Heterogeneity and Uncertainty}

\begin{tabular}{|c|c|c|c|c|c|c|c|c|c|}
\hline \multirow{2}{*}{ Event } & \multirow{2}{*}{$N_{\text {analyst }}$} & \multicolumn{4}{|c|}{ Belief Heterogeneity } & \multicolumn{4}{|c|}{ Uncertainty } \\
\hline & & mean $(H)$ & $s t d(H)$ & $N_{H}$ & $\operatorname{corr}(H,|S U R|)$ & $\operatorname{mean}(V)$ & $\operatorname{std}(V)$ & $N_{V}$ & $\operatorname{corr}(V,|S U R|)$ \\
\hline Building Permits & 53 & 0.308 & 0.287 & 10 & $-0.617^{* * *}$ & 0.185 & 0.197 & 9 & $0.769^{* * *}$ \\
\hline Consumer Price Index $\dagger$ & 81 & 0.654 & 0.289 & 26 & $-0.893^{* * *}$ & 3.493 & 8.422 & 4 & $0.308^{* *}$ \\
\hline Change in Nonfarm Payrolls $\dagger$ & 90 & 0.404 & 0.323 & 25 & $-0.886^{* * *}$ & 0.940 & 0.900 & 13 & $0.876^{* * *}$ \\
\hline Durable Goods Orders $\dagger$ & 75 & 0.540 & 0.349 & 32 & $-0.671^{* * *}$ & 6.423 & 12.658 & 4 & 0.196 \\
\hline Empire Manufacturing & 51 & 0.322 & 0.323 & 13 & $-0.799^{* * *}$ & 17.674 & 80.973 & 1 & 0.140 \\
\hline Housing Starts & 76 & 0.283 & 0.278 & 13 & $-0.699^{* * *}$ & 0.256 & 0.290 & 9 & $0.905^{* * *}$ \\
\hline Producer Price Index & 73 & 0.470 & 0.304 & 23 & $-0.855^{* * *}$ & 5.232 & 7.062 & 6 & $0.251^{*}$ \\
\hline Personal Spending & 75 & 0.517 & 0.315 & 28 & $-0.889^{* * *}$ & 2.077 & 3.372 & 5 & $0.466^{* * *}$ \\
\hline Retail Sales $\dagger$ & 81 & 0.512 & 0.313 & 26 & $-0.850^{* * *}$ & 13.044 & 48.867 & 3 & $0.296^{* *}$ \\
\hline Trade Balance & 71 & 0.363 & 0.328 & 17 & $-0.740^{* * *}$ & 0.286 & 0.336 & 10 & $0.901^{* * *}$ \\
\hline Unemployment Rate & 82 & 0.290 & 0.315 & 12 & $-0.378^{* * *}$ & 0.107 & 0.131 & 7 & $0.827^{* * *}$ \\
\hline
\end{tabular}

This table characterizes the belief heterogeneity, $(H=1-\rho)$, and the market uncertainty, $V$, considered in the analysis. The variable Event is the specific announcement; “*” indicates a significant event with Bloomberg relevance value higher than $90 . N_{\text {analyst }}$ denotes the average number of analysts; mean $(H)$ denotes the sample mean of belief heterogeneity; STD $(H)$ denotes the standard deviation of belief heterogeneity; $N_{H}$ denotes the number of belief heterogeneity that is one standard deviation or more away from the mean of $H ; \operatorname{corr}(H,|S U R|)$ denotes the correlation of belief heterogeneity and the absolute announcement surprise $|S U R|$; mean $(V)$ denotes the sample mean of the market uncertainty; $S T D(V)$ denotes the standard deviation of the market uncertainty; $N_{V}$ denotes the number of the market uncertainty that is one standard deviation or more away from the mean of $V ; \operatorname{corr}(V,|S U R|)$ denotes the correlation of the market uncertainty and the absolute announcement surprise $|S U R| ; “ * * * ”, “ * * ”$ and “*” denote respectively significance of correlations at the $1 \%, 5 \%$ or $10 \%$ levels. 
Table 4.3: Summary Statistics of Market Activities

\begin{tabular}{|c|c|c|c|c|c|c|c|c|c|c|}
\hline & \multicolumn{5}{|c|}{$[8: 00: 00,8: 30: 00)$} & \multicolumn{5}{|c|}{$[8: 30: 00,9: 00: 00)$} \\
\hline & Mean & Median & Std. & Max. & Min. & Mean & Median & Std. & Max. & Min. \\
\hline \multicolumn{11}{|c|}{ Panel A: All Sample Monthly 8:30 ET Macroeconomic Announcements } \\
\hline$I \times 25600$ & -4.872 & -4.669 & 1.053 & -2.755 & -9.545 & -4.953 & -4.789 & 0.970 & -1.208 & -8.859 \\
\hline$S P R D \times 25600$ & 2.144 & 2.111 & 0.229 & 5.278 & 1.950 & 2.183 & 2.144 & 0.159 & 2.970 & 1.954 \\
\hline$D P 0$ & 72243.587 & 65607.000 & 38925.464 & 276282.000 & 11534.000 & 168520.911 & 125560.000 & 118336.896 & 571893.000 & 25409.000 \\
\hline$D P$ & 815831.869 & 700333.000 & 496886.801 & 3763132.000 & 83786.000 & 2534445.861 & 1780916.000 & 2154815.138 & 11639627.000 & 258903.000 \\
\hline$V T Y$ & 3.592 & 2.467 & 3.618 & 34.254 & 0.367 & 4.202 & 3.238 & 3.628 & 32.336 & 0.572 \\
\hline$T R V L M$ & 1921.490 & 1767.000 & 912.508 & 5605.000 & 462.000 & 4920.270 & 3250.000 & 4203.697 & 21320.000 & 808.000 \\
\hline \multicolumn{11}{|c|}{ Panel B: Influential Announcements } \\
\hline$I \times 25600$ & -4.894 & -4.738 & 0.998 & -2.755 & -8.458 & -5.045 & -5.009 & 0.994 & -1.208 & -8.840 \\
\hline$S P R D \times 25600$ & 2.163 & 2.111 & 0.294 & 5.278 & 1.973 & 2.222 & 2.182 & 0.178 & 2.970 & 1.954 \\
\hline$D P 0$ & 78234.503 & 67628.000 & 39646.048 & 201291.000 & 19543.000 & 215946.217 & 171318.000 & 131905.691 & 571893.000 & 42576.000 \\
\hline$D P$ & 860492.357 & 745215.000 & 486451.811 & 2889260.000 & 153851.000 & 3371685.455 & 2732227.000 & 2489053.454 & 11639627.000 & 378776.000 \\
\hline$V T Y$ & 3.646 & 2.355 & 3.359 & 22.996 & 0.367 & 4.752 & 3.866 & 3.529 & 23.708 & 0.731 \\
\hline$T R V L M$ & 2124.259 & 1925.000 & 960.201 & 5605.000 & 638.000 & 6678.147 & 5098.000 & 4854.582 & 21320.000 & 1469.000 \\
\hline \multicolumn{11}{|c|}{ Panel C: Non-Influential Announcements } \\
\hline$I \times 25600$ & -4.845 & -4.609 & 1.121 & -3.146 & -9.545 & -4.839 & -4.645 & 0.931 & -3.416 & -8.859 \\
\hline$S P R D \times 25600$ & 2.121 & 2.110 & 0.099 & 2.505 & 1.950 & 2.136 & 2.117 & 0.116 & 2.574 & 1.961 \\
\hline$D P 0$ & 64858.233 & 57664.500 & 36862.034 & 276282.000 & 11534.000 & 110056.957 & 95116.500 & 60730.239 & 375487.000 & 25409.000 \\
\hline$D P$ & 760776.267 & 626691.500 & 506138.335 & 3763132.000 & 83786.000 & 1502331.535 & 1240963.000 & 906013.919 & 4812977.000 & 258903.000 \\
\hline$V T Y$ & 3.524 & 2.499 & 3.927 & 34.254 & 0.519 & 3.523 & 2.492 & 3.649 & 32.336 & 0.572 \\
\hline$T R V L M$ & 1671.526 & 1530.000 & 784.521 & 5048.000 & 462.000 & 2753.233 & 2368.000 & 1401.847 & 9308.000 & 808.000 \\
\hline \multicolumn{11}{|c|}{ Panel D: Non-Announcement Days } \\
\hline$I \times 25600$ & -4.764 & -4.551 & 0.974 & -2.837 & -10.945 & -4.747 & -4.584 & 1.043 & -3.028 & -12.339 \\
\hline$S P R D \times 25600$ & 2.112 & 2.105 & 0.087 & 2.500 & 1.934 & 2.101 & 2.096 & 0.082 & 2.393 & 1.955 \\
\hline$D P 0$ & 67551.507 & 59240.000 & 38089.805 & 318279.000 & 13353.000 & 87902.881 & 78677.000 & 47342.858 & 345224.000 & 22956.000 \\
\hline$D P$ & 833110.078 & 719081.000 & 527401.148 & 4732634.000 & 146928.000 & 1145895.980 & 1028666.000 & 654502.311 & 4600479.000 & 233778.000 \\
\hline$V T Y$ & 3.584 & 2.489 & 3.696 & 38.964 & 0.296 & 2.990 & 2.276 & 2.932 & 37.021 & 0.452 \\
\hline$T R V L M$ & 1607.571 & 1435.000 & 723.578 & 5648.000 & 290.000 & 1949.843 & 1786.000 & 921.038 & 6769.000 & 469.000 \\
\hline
\end{tabular}

This table reports the summary statistics of order aggressiveness ( $\mathrm{I} \times 25600)$, bid-ask spread (SPRD $\times 25600)$, depth at the best bid and ask ( $\$$ millions, DP0), depth in the entire limit order book $(\$$ millions, DP), volatility (VTY), and trading volume (\$ millions par, TVM) in the U.S. Treasury market around significant monthly 8:30 ET macroeconomic announcements. The order submission data are obtained from BrokerTec and cover all trading days from January 1, 2011, to December 31, 2015. Panel A reports statistics around the significant 8:30 ET macroeconomic announcements. Panel B reports statistics around influential 8:30 ET macroeconomic announcements. Panel C reports statistics around non-influential 8:30 ET macroeconomic announcements. In Panel A, B and C, we exclude the trading days with other news influential 8:30 ET macroeconomic announcements. Panel C reports statistics around non-influen
arrivals within 60 minutes around 8:30 ET. Panel D reports statistics on non-announcement days. 
Table 4.4: Mulitvariate Analysis of Order Aggressiveness, Belief Heterogeneity, Uncertainty

\begin{tabular}{|c|c|c|c|c|c|c|}
\hline & \multicolumn{3}{|c|}{ Pre-Announcement Period } & \multicolumn{3}{|c|}{ Post-Announcement Period } \\
\hline & \multirow{2}{*}{$\begin{array}{l}\text { All Sample News } \\
(\# \text { obs }=5347821)\end{array}$} & \multicolumn{2}{|c|}{ All Sample News Decompositions } & \multirow{2}{*}{$\begin{array}{l}\text { All Sample News } \\
\text { (\#obs }=10276124)\end{array}$} & \multicolumn{2}{|c|}{ All Sample News Decompositions } \\
\hline & & Influential News & Non-Influential News & & Influential News & Non-Influential News \\
\hline$\alpha$ & $-4.529^{* * *}$ & $-5.111^{* * *}$ & $-4.165^{* * *}$ & $-8.606^{* * *}$ & $-8.193^{* * *}$ & $-7.022^{* * *}$ \\
\hline$V_{t}$ & $0.021^{* * *}$ & $0.015^{* * *}$ & $0.020^{* * *}$ & $0.034^{* * *}$ & $0.019^{* * *}$ & $0.038^{* * *}$ \\
\hline$H_{t}$ & $0.578^{* * *}$ & -0.065 & $1.071^{* * *}$ & $0.327^{* * *}$ & $-0.395^{* * *}$ & $0.665^{* * *}$ \\
\hline$V T Y_{t}$ & $-0.127^{* * *}$ & $-0.081^{* * *}$ & $-0.155^{* * *}$ & $-0.008^{* * *}$ & $-0.001^{* * *}$ & $-0.048^{* * *}$ \\
\hline$S P R D_{t}$ & $-0.538^{* * *}$ & $-0.575^{* * *}$ & $-0.498^{* * *}$ & $-0.514^{* * *}$ & $-0.506^{* * *}$ & $-0.562^{* * *}$ \\
\hline$S A M E 0_{t}$ & $5.019^{* * *}$ & $10.625^{* * *}$ & -0.165 & $8.195^{* * *}$ & $9.015^{* * *}$ & $8.834^{* * *}$ \\
\hline$S A M E B H D_{t}$ & $5.302^{* * *}$ & $9.477^{* * *}$ & $1.891^{* * *}$ & $4.125^{* * *}$ & $4.956^{* * *}$ & $2.945^{* * *}$ \\
\hline$O P P 0_{t}$ & $4.683^{* * *}$ & $4.086^{* * *}$ & $5.126^{* * *}$ & $3.726^{* * *}$ & $2.850^{* * *}$ & $5.483^{* * *}$ \\
\hline$O P P B H D_{t}$ & $-4.046^{* * *}$ & $-3.706^{* * *}$ & $-4.430^{* * *}$ & $-1.703^{* * *}$ & $-1.382^{* * *}$ & $-3.775^{* * *}$ \\
\hline$T R V L M_{t}$ & $3.877^{* * *}$ & $2.259^{* * *}$ & $5.203^{* * *}$ & $0.969^{* * *}$ & $0.904^{* * *}$ & $2.438^{* * *}$ \\
\hline$B E T A_{t}$ & $-1.218^{* * *}$ & $-1.869^{* * *}$ & $-0.918^{* * *}$ & $-2.012^{* * *}$ & $-2.512^{* * *}$ & $-2.173^{* * *}$ \\
\hline Likelihood & -13748385 & -11176898 & -13362318 & -54422387 & -24882724 & -26686839 \\
\hline
\end{tabular}

The table reports the results of censored regression model of order aggressiveness on the belief heterogenity, the market uncertainty and other control variables during the 30-minute interval around 8:30 ET. The regression model is: $I_{t}=\alpha+\alpha_{H} H_{t}+\alpha_{V} V_{t}+\beta_{x} X_{t}+\varepsilon_{t}$. The dependent variable, order aggressiveness, $I_{t}$, is defined as in Equation (4.3). The independent variables are market uncertainty $\left(V_{t}\right)$, belief heterogeneity $\left(H_{t}\right)$, and the order book state $\left(X_{t}\right)$, which includes volatility $\left(V T Y_{t}\right)$, bid-ask spread $\left(S P R D_{t}\right)$, depth at the best quote on the same side of market $\left(S A M E 0_{t}\right)$, depth behind the best quote on the same side of market $\left(S A M E B H D_{t}\right)$, depth at the best quote on the opposite side of market $\left(O P P 0_{t}\right)$, depth behind the best quote on the opposite side of market $\left(O P P B H D_{t}\right)$, trading volume $\left(T R V L M_{t}\right)$, and price impact $\left(B E T A_{t}\right)$.***,** and * indicate significance at the $1 \%, 5 \%$ and $10 \%$ respectively. The last row reports the likelihood values of the censored regressions. 
Table 4.5: Mulitvariate Analysis of Order Aggressiveness, Belief Heterogeneity, Uncertainty in Sub-Periods

\begin{tabular}{|c|c|c|c|c|c|c|}
\hline \multicolumn{7}{|c|}{ Panel A: During the Pre-Announcement Period } \\
\hline & \multicolumn{3}{|c|}{ From 8:00 ET to 8:15 ET } & \multicolumn{3}{|c|}{ From 8:15 ET to 8:30 ET } \\
\hline & $\begin{array}{l}\text { All Sample News } \\
(\# \text { obs }=2372887)\end{array}$ & \multicolumn{2}{|c|}{ All Sample News Decompositions } & $\begin{array}{l}\text { All Sample News } \\
(\# \text { obs }=2974934)\end{array}$ & \multicolumn{2}{|c|}{ All Sample News Decompositions } \\
\hline$V_{t}$ & $0.020^{* * *}$ & $0.017^{* * *}$ & $0.017^{* * *}$ & $0.022^{* * *}$ & $0.010^{* * *}$ & $0.025^{* * *}$ \\
\hline$H_{t}$ & $0.419^{* * *}$ & $-0.142^{* *}$ & $0.812^{* * *}$ & $0.722^{* * *}$ & $-0.156^{* *}$ & $1.306^{* * *}$ \\
\hline Likelihood & -10822724 & -4896143 & -5911380 & -13748385 & -6278725 & -7447825 \\
\hline \multicolumn{7}{|c|}{ Panel B: During the Post-Announcement Period } \\
\hline & \multicolumn{3}{|c|}{ From 8:30 ET to 8:45 ET } & \multicolumn{3}{|c|}{ From 8:45 ET to 9:00 ET } \\
\hline & \multirow{2}{*}{$\begin{array}{l}\text { All Sample News } \\
(\# \text { obs=6153945) }\end{array}$} & \multicolumn{2}{|c|}{ All Sample News Decompositions } & \multirow{2}{*}{$\begin{array}{l}\text { All Sample News } \\
(\# \text { obs=4122179) }\end{array}$} & \multicolumn{2}{|c|}{ All Sample News Decompositions } \\
\hline & & Influential News & Non-Influential News & & Influential News & Non-Influential News \\
\hline$V_{t}$ & $0.031^{* * *}$ & $0.008^{* * *}$ & $0.043^{* * *}$ & $0.033^{* * *}$ & $0.034^{* * *}$ & $0.027^{* * *}$ \\
\hline$H_{t}$ & $0.272^{* * *}$ & $-0.600^{* * *}$ & $0.779^{* * *}$ & $0.296^{* * *}$ & -0.017 & 0.325 \\
\hline
\end{tabular}

The table reports the results of censored regression model of order aggressiveness on the belief heterogenity, the market uncertainty and other control variables in two 15-minute sub-periods of the pre- and post-announcement periods in Panel A and Panel B, respectively. The regression model is: $I_{t}=$ $\alpha+\alpha_{H} H_{t}+\alpha_{V} V_{t}+\beta_{x} X_{t}+\varepsilon_{t}$. The dependent variable, order aggressiveness, $I_{t}$, is defined as in Equation (4.3). The independent variables are market uncertainty $\left(V_{t}\right)$, belief heterogeneity $\left(H_{t}\right)$, and the order book state $\left(X_{t}\right)$, which includes volatility $\left(V T Y_{t}\right)$, bid-ask spread $\left(S P R D_{t}\right)$, depth at the best quote on the same side of market $\left(S A M E 0_{t}\right)$, depth behind the best quote on the same side of market $\left(S A M E B H D_{t}\right)$, depth at the best quote on the opposite side of market $\left(O P P 0_{t}\right)$, depth behind the best quote on the opposite side of market $\left(O P P B H D_{t}\right)$, trading volume $\left(T R V L M_{t}\right)$, and price impact $\left(B E T A_{t}\right)$. ***, ** and $*$ indicate significance at the $1 \%, 5 \%$ and $10 \%$ respectively. 
Table 4.6: Mulitvariate Analysis of Order Aggressiveness, Belief Heterogeneity, Uncertainty During the PostAnnouncement Period

\begin{tabular}{|c|c|c|c|c|c|c|}
\hline & \multicolumn{3}{|c|}{$|S U R|_{t}<$ Median $_{|S U R|}$} & \multicolumn{3}{|c|}{$|S U R|_{t}>$ Median $_{|S U R|}$} \\
\hline & \multirow{2}{*}{$\begin{array}{l}\text { All Sample News } \\
(\# \text { obs }=5347821)\end{array}$} & \multicolumn{2}{|c|}{ All Sample News Decompositions } & \multirow{2}{*}{$\begin{array}{l}\text { All Sample News } \\
(\# \text { obs }=10276124)\end{array}$} & \multicolumn{2}{|c|}{ All Sample News Decompositions } \\
\hline & & Influential News & Non-Influential News & & Influential News & Non-Influential News \\
\hline$\alpha$ & $-9.841^{* * *}$ & $-5.672^{* * *}$ & $-9.486^{* * *}$ & $-5.611^{* * *}$ & $-6.649^{* * *}$ & $-6.673^{* * *}$ \\
\hline$V_{t}$ & $0.042^{* * *}$ & $0.042^{* * *}$ & $0.034^{* * *}$ & $0.043^{* * *}$ & $0.040^{* * *}$ & $0.178^{* * *}$ \\
\hline$H_{t}$ & $1.175^{* * *}$ & $-1.520^{* * *}$ & $1.778^{* * *}$ & $-1.743^{* * *}$ & $-1.530^{* * *}$ & $-1.261^{* * *}$ \\
\hline$V T Y_{t}$ & $-0.003^{* * *}$ & $-0.023^{* * *}$ & $0.006^{* * *}$ & $-0.031^{* * *}$ & $-0.066^{* * *}$ & 0.006 \\
\hline$S P R D_{t}$ & $-0.503^{* * *}$ & $-0.546^{* * *}$ & $-0.494^{* * *}$ & $-0.567^{* * *}$ & $-0.588^{* * *}$ & $-0.505^{* * *}$ \\
\hline$S A M E 0_{t}$ & $10.156^{* * *}$ & $7.822^{* * *}$ & $8.575^{* * *}$ & $15.240^{* * *}$ & $15.542^{* * *}$ & 2.512 \\
\hline$S A M E B H D_{t}$ & $6.022^{* * *}$ & $2.180^{* * *}$ & $5.199^{* * *}$ & $1.751^{* * *}$ & $6.045^{* * *}$ & $4.551^{* * *}$ \\
\hline$O P P 0_{t}$ & -0.093 & $8.971^{* * *}$ & $2.546^{* * *}$ & $10.595^{* * *}$ & 0.213 & $7.088^{* * *}$ \\
\hline $\mathrm{OPPBHD}_{t}$ & $-3.261^{* * *}$ & $-1.246^{* * *}$ & $-3.494^{* * *}$ & $-0.749^{* * *}$ & $-3.983^{* * *}$ & $-3.710^{* * *}$ \\
\hline$T R V L M_{t}$ & $1.650^{* * *}$ & $0.483^{* *}$ & $0.812^{* * *}$ & $1.042^{* * *}$ & $4.023^{* * *}$ & -0.333 \\
\hline$B E T A_{t}$ & $-1.918^{* * *}$ & $-2.118^{* * *}$ & $-3.337^{* * *}$ & $-1.798^{* * *}$ & $-1.603^{*}$ & -1.999 \\
\hline Likelihood & -29971943 & -24430774 & -12773968 & -12101326 & -15778705 & -10873813 \\
\hline
\end{tabular}

The table reports the results of the censored regression model of order aggressiveness on the belief heterogeneity, market uncertainty, and other control variables during the post-announcement period. All the significant news announcement days are divided into either the low $|S U R|$ group or the high $|S U R|$ group, compared with the $|S U R|$ median. The regression model is: $I_{t}=\alpha+\alpha_{H} H_{t}+\alpha_{V} V_{t}+\beta_{x} X_{t}+\varepsilon_{t}$. The dependent variable, order aggressiveness, $I_{t}$, is defined as in Equation (4.3). The independent variables are the market uncertainty $\left(V_{t}\right)$, belief heterogeneity $\left(H_{t}\right)$, and the order book state $\left(X_{t}\right)$, which includes volatility $\left(V T Y_{t}\right)$, bid-ask spread $\left(S P R D_{t}\right)$, depth at the best quote on the same side of market $\left(S A M E 0_{t}\right)$, depth behind the best quote on the same side of market $\left(S A M E B H D_{t}\right)$, depth at the best quote on the opposite side of market $\left(O P P 0_{t}\right)$, depth behind the best quote on the opposite side of market $\left(O P P B H D_{t}\right)$, trading volume $\left(T R V L M_{t}\right)$, and price impact $\left(B E T A_{t}\right)$. ***, ** and * indicate significance at the $1 \%, 5 \%$ and $10 \%$ respectively. 
Table 4.7: Mulitvariate Analysis of Order Aggressiveness, Belief Heterogeneity, Uncertainty from 8:30 ET to 8:45 ET

\begin{tabular}{|c|c|c|c|c|c|c|}
\hline & \multicolumn{3}{|c|}{$|S U R|_{t}<$ Median $_{|S U R|}$} & \multicolumn{3}{|c|}{$|S U R|_{t}>$ Median $_{|S U R|}$} \\
\hline & All Sample News & Influential News & Non-Influential News & All Sample News & Influential News & Non-Influential News \\
\hline \multicolumn{7}{|c|}{ Panel A: 15-minute period from 8:30 ET to 8:45 ET } \\
\hline$V_{t}$ & $0.040^{* * *}$ & $0.032^{* * *}$ & $0.033^{* * *}$ & $0.035^{* * *}$ & $0.044^{* * *}$ & $0.135^{* * *}$ \\
\hline$H_{t}$ & $1.156^{* * *}$ & $-1.509^{* * *}$ & $2.859^{* * *}$ & $-1.973^{* * *}$ & $-1.767^{* * *}$ & $-0.888^{* * *}$ \\
\hline Likelihood & -16011002 & -12103911 & -6492144 & -7657577 & -7968861 & -4420766 \\
\hline \multicolumn{7}{|c|}{ Panel B: 5-minute period from 8:30 ET to 8:35 ET } \\
\hline$V_{t}$ & $0.028^{* * *}$ & $0.030^{* * *}$ & $0.011^{* * *}$ & $0.056^{* * *}$ & $0.047^{* * *}$ & $0.044^{*}$ \\
\hline$H_{t}$ & $1.123^{* * *}$ & $-1.180^{* * *}$ & $2.593^{* * *}$ & $-2.002^{* * *}$ & $-1.811^{* * *}$ & -0.067 \\
\hline Likelihood & -8021739 & -5639914 & -3490372 & -3738266 & -3721691 & -1889828 \\
\hline \multicolumn{7}{|c|}{ Panel C: 5-minute period from 8:35 ET to 8:40 ET } \\
\hline$V_{t}$ & $0.053^{* * *}$ & 0.006 & $0.049^{* * *}$ & -0.007 & $0.050^{* * *}$ & $0.231^{* * *}$ \\
\hline$H_{t}$ & $1.018^{* * *}$ & $-1.031^{* * *}$ & $3.044^{* * *}$ & $-1.397^{* * *}$ & $-1.759^{* * *}$ & $-0.853^{* * *}$ \\
\hline Likelihood & -4407791 & -3522402 & -1672054 & -2154434 & -2311105 & -1361290 \\
\hline \multicolumn{7}{|c|}{ Panel D: 5-minute period from 8:40 ET to 8:45 ET } \\
\hline$V_{t}$ & $0.036^{* * *}$ & -0.007 & $0.061^{* * *}$ & $-0.022^{* *}$ & $0.032^{* * *}$ & $0.176^{* * *}$ \\
\hline$H_{t}$ & $-0.550^{* * *}$ & $-1.714^{* * *}$ & $3.744^{* * *}$ & $-2.046^{* * *}$ & $-2.993^{* * *}$ & $-1.322^{* * *}$ \\
\hline Likelihood & -3577512 & -2929936 & -1328971 & -1758001 & -1932521 & -1166484 \\
\hline
\end{tabular}

The table reports the results of the censored regression model of order aggressiveness on belief heterogeneity, market uncertainty, and other control variables during the 15-minute period from 8:30 ET to 8:45 ET. All the significant news announcement days are divided into either the low $|S U R|$ group or the high $|S U R|$ group, compared with the $|S U R|$ median. The regression model is: $I_{t}=\alpha+\alpha_{H} H_{t}+\alpha_{V} V_{t}+\beta_{x} X_{t}+\varepsilon_{t}$. The dependent variable, order aggressiveness, $I_{t}$, is defined as in Equation (4.3). The independent variables are the market uncertainty $\left(V_{t}\right)$, belief heterogeneity $\left(H_{t}\right)$, and the order book state $\left(X_{t}\right)$, which includes volatility $\left(V T Y_{t}\right)$, bid-ask spread $\left(S P R D_{t}\right)$, depth at the best quote on the same side of market $\left(S A M E 0_{t}\right)$, depth behind the best quote on the same side of market $\left(S A M E B H D_{t}\right)$, depth at the best quote on the opposite side of market $\left(O P P 0_{t}\right)$, depth behind the best quote on the opposite side of market $\left(O P P B H D_{t}\right)$, trading volume $\left(T R V L M_{t}\right)$, and price impact $\left(B E T A_{t}\right)$. Panel A report the coefficient estimates of $V_{t}$ and $H_{t}$ in the 15-minute interval after news arrivals. Panels B, C and D report the coefficient estimates of $V_{t}$ and $H_{t}$ in three five-minute intervals. $* * *, * *$ and $*$ indicate significance at the $1 \%, 5 \%$ and $10 \%$ respectively. 
Table 4.8: Mulitvariate Analysis of Order Aggressiveness, Belief Heterogeneity, Uncertainty from 8:45 ET to 9:00 ET

\begin{tabular}{|c|c|c|c|c|c|c|}
\hline & \multicolumn{3}{|c|}{$|S U R|_{t}<$ Median $_{|S U R|}$} & \multicolumn{3}{|c|}{$|S U R|_{t}>$ Median $_{|S U R|}$} \\
\hline & All Sample News & Influential News & Non-Influential News & All Sample News & Influential News & Non-Influential News \\
\hline \multicolumn{7}{|c|}{ Panel A: 15-minute period from 8:45 ET to 9:00 ET } \\
\hline$V_{t}$ & $0.040^{* * *}$ & $0.049^{* * *}$ & $0.050^{* * *}$ & $0.048^{* * *}$ & $0.026^{* * *}$ & $0.217^{* * *}$ \\
\hline$H_{t}$ & $0.681^{* * *}$ & $-1.458^{* * *}$ & $1.739^{* * *}$ & $-1.208^{* * *}$ & $-2.165^{* * *}$ & $-1.642^{* * *}$ \\
\hline Likelihood & -12583274 & -10808465 & -4779133 & -4432814 & -6866392 & -5411053 \\
\hline \multicolumn{7}{|c|}{ Panel B: 5-minute period from 8:45 ET to 8:50 ET } \\
\hline$V_{t}$ & $0.053^{* * *}$ & $0.026^{* * *}$ & $0.046^{* * *}$ & $0.046^{* * *}$ & $0.046^{* *}$ & $0.191^{* * *}$ \\
\hline$H_{t}$ & 0.923 & $-1.406^{* * *}$ & $0.795^{* * *}$ & $-0.782^{* * *}$ & -1.42 & $-1.968^{* * *}$ \\
\hline Likelihood & -4803750 & -2955823 & -1653890 & -1611705 & -2645276 & -1340645 \\
\hline \multicolumn{7}{|c|}{ Panel C: 5-minute period from 8:50 ET to 8:55 ET } \\
\hline$V_{t}$ & $0.034^{* * *}$ & $0.061^{* *}$ & $0.053^{* * *}$ & $0.051^{* * *}$ & $0.012^{* * *}$ & $0.240^{*}$ \\
\hline$H_{t}$ & $0.501^{* * *}$ & $-1.492^{* * *}$ & $2.252^{* * *}$ & $-1.397^{* * *}$ & $-2.701^{* * *}$ & $-1.542^{* *}$ \\
\hline Likelihood & -6599579 & -7204232 & -3125062 & -2821051 & -3459126 & -3639559 \\
\hline \multicolumn{7}{|c|}{ Panel D: 5-minute period from 8:55 ET to 9:00 ET } \\
\hline$V_{t}$ & $0.038^{* * *}$ & $0.055^{* * *}$ & $0.056^{* * *}$ & $0.060^{* * *}$ & $0.018^{* * *}$ & $0.215^{* * *}$ \\
\hline$H_{t}$ & $1.480^{* * *}$ & $-1.528^{* * *}$ & $3.122^{* * *}$ & $-1.272^{* * *}$ & $-1.847^{* * *}$ & $-1.622^{* * *}$ \\
\hline Likelihood & -3221182 & -2654109 & -1470500 & -1435088 & -1739982 & -1216657 \\
\hline
\end{tabular}

The table reports the results of the censored regression model of order aggressiveness on belief heterogeneity, market uncertainty, and other control variables during the 15-minute period from 8:45 ET to 9:00 ET. All the significant news announcement days are divided into either the low $|S U R|$ group or the high $|S U R|$ group, compared with the $|S U R|$ median. The regression model is: $I_{t}=\alpha+\alpha_{H} H_{t}+\alpha_{V} V_{t}+\beta_{x} X_{t}+\varepsilon_{t}$. The dependent variable, order aggressiveness, $I_{t}$, is defined as in Equation (4.3). The independent variables are the market uncertainty $\left(V_{t}\right)$, belief heterogeneity $\left(H_{t}\right)$, and the order book state $\left(X_{t}\right)$, which includes volatility $\left(V T Y_{t}\right)$, bid-ask spread $\left(S P R D_{t}\right)$, depth at the best quote on the same side of market $\left(S A M E 0_{t}\right)$, depth behind the best quote on the same side of market $\left(S A M E B H D_{t}\right)$, depth at the best quote on the opposite side of market $\left(O P P 0_{t}\right)$, depth behind the best quote on the opposite side of market $\left(O P P B H D_{t}\right)$, trading volume $\left(T R V L M_{t}\right)$, and price impact $\left(B E T A_{t}\right)$. Panel A report the coefficient estimates of $V_{t}$ and $H_{t}$ in the 15-minute interval from 8:45 ET to 9:00 ET. Panels B, C and D report the coefficient estimates of $V_{t}$ and $H_{t}$ in three five-minute intervals. ***, ** and $*$ indicate significance at the $1 \%, 5 \%$ and $10 \%$ respectively. 
Table 4.9: Mulitvariate Analysis of Order Choice During the Pre-announcement Period

\begin{tabular}{|c|c|c|c|c|c|c|c|c|c|}
\hline & \multicolumn{3}{|c|}{ Pre-Announcement Period } & \multicolumn{3}{|c|}{ From 8:00 ET to 8:15 ET } & \multicolumn{3}{|c|}{ From $8: 15 \mathrm{ET}$ to $8: 30 \mathrm{ET}$} \\
\hline & All Sample News & Inf. News & Non-inf. News & All Sample News & Inf. News & Non-inf. News & All Sample News & Inf. News & Non-inf. News \\
\hline$\alpha$ & $-1.369^{* * *}$ & $-1.328^{* * *}$ & $-1.396^{* * *}$ & $-1.319^{* * *}$ & $-1.260^{* * *}$ & $-1.387^{* * *}$ & $-1.390^{* * *}$ & $-1.379^{* * *}$ & $-1.390^{* * *}$ \\
\hline$V_{t}$ & $0.000^{* *}$ & $-0.001^{*}$ & $0.001^{* * *}$ & 0.000 & $-0.001^{* *}$ & $0.001^{* * *}$ & $0.000^{*}$ & 0.000 & 0.001 \\
\hline$H_{t}$ & $0.012^{* * *}$ & -0.008 & $0.039^{* * *}$ & $0.015^{* *}$ & -0.017 & $0.036^{* * *}$ & $0.012^{* *}$ & 0.013 & 0.040 \\
\hline$V T Y_{t}$ & $-0.009^{* * *}$ & $-0.011^{* * *}$ & $-0.008^{* * *}$ & $-0.011^{* * *}$ & $-0.011^{* * *}$ & $-0.011^{* * *}$ & $-0.008^{* * *}$ & $-0.010^{* * *}$ & $-0.007^{* * *}$ \\
\hline$S P R D_{t}$ & $-0.027^{* * *}$ & $-0.024^{* * *}$ & $-0.031^{* * *}$ & $-0.036^{* * *}$ & $-0.033^{* * *}$ & $-0.039^{* * *}$ & $-0.023^{* * *}$ & $-0.021^{* * *}$ & $-0.026^{* * *}$ \\
\hline$S A M E 0_{t}$ & $2.484^{* * *}$ & $2.684^{* * *}$ & $2.330^{* * *}$ & $2.803^{* * *}$ & $2.947^{* * *}$ & $2.759^{* * *}$ & $2.364^{* * *}$ & $2.620^{* * *}$ & $2.131^{* * *}$ \\
\hline$O P P 0_{t}$ & $0.762^{* * *}$ & $0.730^{* * *}$ & $0.794^{* * *}$ & $0.759^{* * *}$ & $0.750^{* * *}$ & $0.789^{* * *}$ & $0.754^{* * *}$ & $0.692^{* * *}$ & $0.794^{* * *}$ \\
\hline$O P P B H D_{t}$ & $-0.737^{* * *}$ & $-0.783^{* * *}$ & $-0.690^{* * *}$ & $-0.783^{* * *}$ & $-0.911^{* * *}$ & $-0.629^{* * *}$ & $-0.701^{* * *}$ & $-0.656^{* * *}$ & $-0.736^{* * *}$ \\
\hline$T R V L M_{t}$ & $0.829^{* * *}$ & $0.809^{* * *}$ & $0.840^{* * *}$ & $1.205^{* * *}$ & $0.994^{* * *}$ & $1.620^{* * *}$ & $0.539^{* * *}$ & $0.538^{* * *}$ & $0.538^{* * *}$ \\
\hline$B E T A_{t}$ & $-0.336^{* * *}$ & $-0.353^{* * *}$ & $-0.309^{* * *}$ & $-0.300^{* * *}$ & $-0.341^{* * *}$ & $-0.248^{* * *}$ & $-0.355^{* * *}$ & $-0.365^{* * *}$ & $-0.309^{* * *}$ \\
\hline Likelihood & -406203 & -188626 & -217454 & -173171 & -81708 & -91311 & -232829 & -106831 & -125914 \\
\hline
\end{tabular}

This table reports the results of probit model of order choice on belief heterogenity, market uncertainty and other control variables during the pre-announcement period. The probit model is: $P(m k t=1)=$ $f\left(\alpha+\alpha_{H} H_{t}+\alpha_{V} V_{t}+\beta_{x} X_{t}\right)$. The dependent variable is equal to 1 if it is a market order, and 0 if it is a limit order. The independent variables are the market uncertainty $\left(V_{t}\right)$, belief heterogeneity $\left(H_{t}\right)$, and the order book state $\left(X_{t}\right)$, which includes volatility $\left(V T Y_{t}\right)$, bid-ask spread $\left(S P R D_{t}\right)$, depth at the best quote on the same side of market $\left(S A M E 0_{t}\right)$, depth behind the best quote on the same side of market $\left(S A M E B H D_{t}\right)$, depth at the best quote on the opposite side of market $\left(O P P 0_{t}\right)$, depth behind the best quote on the opposite side of market $\left(O P P B H D_{t}\right)$, trading volume $\left(T R V L M_{t}\right)$, and price impact $\left(B E T A_{t}\right)$. ***, ** and * indicate significance at the $1 \%, 5 \%$ and $10 \%$ respectively. 
Table 4.10: Mulitvariate Analysis of Order Choice During the Post-announcement Period

\begin{tabular}{|c|c|c|c|c|c|c|c|c|c|}
\hline & \multicolumn{3}{|c|}{ Post-Announcement Period } & \multicolumn{3}{|c|}{ From $8: 30$ ET to $8: 45 \mathrm{ET}$} & \multicolumn{3}{|c|}{ From 8:45 ET to 9:00 ET } \\
\hline & All Sample News & Inf. News & Non-inf. News & All Sample News & Inf. News & Non-inf. News & All Sample News & Inf. News & Non-inf. News \\
\hline$\alpha$ & $-1.626^{* * *}$ & $-1.594^{* * *}$ & $-1.609^{* * *}$ & $-1.663^{* * *}$ & $-1.619^{* * *}$ & $-1.691^{* * *}$ & $-1.447^{* * *}$ & $-1.440^{* * *}$ & $-1.403^{* * *}$ \\
\hline$V_{t}$ & $0.002^{* * *}$ & $0.001^{* * *}$ & $0.001^{* * *}$ & $0.001^{* * *}$ & -0.000 & $0.002^{* * *}$ & $0.001^{* * *}$ & $0.002^{* * *}$ & 0.000 \\
\hline$H_{t}$ & $0.011^{* * *}$ & $-0.042^{* * *}$ & $0.036^{* * *}$ & 0.005 & $-0.069^{* * *}$ & $0.056^{* * *}$ & $0.014^{* * *}$ & 0.009 & 0.001 \\
\hline$V T Y_{t}$ & $-0.001^{* * *}$ & $-0.000^{* * *}$ & $-0.002^{* * *}$ & 0.000 & -0.000 & -0.000 & $-0.006^{* * *}$ & $-0.004^{* * *}$ & $-0.007^{* * *}$ \\
\hline$S P R D_{t}$ & $-0.025^{* * *}$ & $-0.024^{* * *}$ & $-0.025^{* * *}$ & $-0.023^{* * *}$ & $-0.022^{* * *}$ & $-0.024^{* * *}$ & $-0.028^{* * *}$ & $-0.033^{* * *}$ & $-0.026^{* * *}$ \\
\hline$S A M E 0_{t}$ & $1.527^{* * *}$ & $1.599^{* * *}$ & $1.487^{* * *}$ & $1.216^{* * *}$ & $1.055^{* * *}$ & $1.470^{* * *}$ & $1.800^{* * *}$ & $2.672^{* * *}$ & $1.421^{* * *}$ \\
\hline $\mathrm{OPPO}_{t}$ & $0.493^{* * *}$ & $0.357^{* * *}$ & $1.080^{* * *}$ & $0.611^{* * *}$ & $0.293^{* * *}$ & $1.253^{* * *}$ & $0.771^{* * *}$ & $0.646^{* * *}$ & $0.896^{* * *}$ \\
\hline$O P P B H D_{t}$ & $-0.432^{* * *}$ & $-0.353^{* * *}$ & $-0.911^{* * *}$ & $-0.332^{* * *}$ & $-0.261^{* * *}$ & $-1.010^{* * *}$ & $-0.738^{* * *}$ & $-0.722^{* * *}$ & $-0.832^{* * *}$ \\
\hline$T R V L M_{t}$ & $0.238^{* * *}$ & $0.263^{* * *}$ & $0.199^{* * *}$ & $0.222^{* * *}$ & $0.268^{* * *}$ & $0.094^{* * *}$ & $0.452^{* * *}$ & $0.392^{* * *}$ & $0.512^{* * *}$ \\
\hline$B E T A_{t}$ & $-0.485^{* * *}$ & $-0.503^{* * *}$ & $-0.446^{* * *}$ & $-0.334^{* * *}$ & $-0.395^{* * *}$ & $-0.234^{* * *}$ & $-0.670^{* * *}$ & $-0.668^{* * *}$ & $-0.755^{* * *}$ \\
\hline Likelihood & -775424 & -431645 & -342325 & -462457 & -267835 & -193280 & -312118 & -163187 & -148758 \\
\hline
\end{tabular}

This table reports the results of probit model of order choice on belief heterogenity, market uncertainty and other control variables during the post-announcement period. The probit model is: $P(m k t=1)=$ $f\left(\alpha+\alpha_{H} H_{t}+\alpha_{V} V_{t}+\beta_{X} X_{t}\right)$. The dependent variable is equal to 1 if it is a market order, and 0 if it is a limit order. The independent variables are the market uncertainty $\left(V_{t}\right)$, belief heterogeneity $\left(H_{t}\right)$, and the order book state $\left(X_{t}\right)$, which includes volatility $\left(V T Y_{t}\right)$, bid-ask spread $\left(S P R D_{t}\right)$, depth at the best quote on the same side of market $\left(S A M E 0_{t}\right)$, depth behind the best quote on the same side of market $\left(S A M E B H D_{t}\right)$, book state $\left(X_{t}\right)$, which includes volatility $\left(V T Y_{t}\right)$, bid-ask spread $\left(S P R D_{t}\right)$, depth at the best quote on the same side of market $\left(S A M E 0_{t}\right)$, depth behind the best quote on the same side of market $\left(S A M E B H D_{t}\right)$,
depth at the best quote on the opposite side of market $\left(O P P 0_{t}\right)$, depth behind the best quote on the opposite side of market $\left(O P P B H D_{t}\right)$, trading volume $\left(T R V L M_{t}\right)$, and price impact $\left(B E T A_{t}\right)$. ***, ** and * indicate significance at the $1 \%, 5 \%$ and $10 \%$ respectively. 
Table 4.11: Mulitvariate Analysis of Order Choice During the Post-announcement Period and Sub-Periods

\begin{tabular}{|c|c|c|c|c|c|c|}
\hline & \multicolumn{3}{|c|}{$|S U R|_{t}<$ Median $_{|S U R|}$} & \multicolumn{3}{|c|}{$|S U R|_{t}>$ Median $_{|S U R|}$} \\
\hline & All Sample News & Influential News & Non-Influential News & All Sample News & Influential News & Non-Influential News \\
\hline \multicolumn{7}{|c|}{ Panel A: Post-Announcement Period } \\
\hline$H_{t}$ & $0.103^{* * *}$ & $0.029^{* *}$ & $0.105^{* * *}$ & $-0.130^{* * *}$ & $-0.167^{* * *}$ & $-0.120^{* * *}$ \\
\hline Likelihood & -426924 & -224539 & -201919 & -346706 & -206071 & -140063 \\
\hline \multicolumn{7}{|c|}{ Panel B: 15-minute period from 8:30 ET to 8:45 ET } \\
\hline$V_{t}$ & $0.002^{* * *}$ & -0.000 & $0.002^{* * *}$ & $0.007^{* * *}$ & $0.008^{* * *}$ & $0.015^{* * *}$ \\
\hline$H_{t}$ & $0.102^{* * *}$ & 0.017 & $0.091^{* * *}$ & $-0.146^{* * *}$ & $-0.165^{* * *}$ & $-0.113^{* * *}$ \\
\hline Likelihood & -259543 & -140558 & -118629 & -201433 & -126647 & -74326 \\
\hline \multicolumn{7}{|c|}{ Panel C: 15-minute period from 8:45 ET to 9:00 ET } \\
\hline$V_{t}$ & $0.001^{* * *}$ & $0.003^{* * *}$ & 0.000 & $0.006^{* * *}$ & $0.005^{* * *}$ & $0.012^{* * *}$ \\
\hline$H_{t}$ & $0.054^{* * *}$ & 0.021 & $0.063^{* * *}$ & $-0.102^{* * *}$ & $-0.148^{* * *}$ & $-0.115^{* * *}$ \\
\hline Likelihood & -167059 & -83862 & -83049 & -144840 & -79093 & -65553 \\
\hline
\end{tabular}

This table reports the results of probit model of order choice on belief heterogenity, market uncertainty and other control variables during the post-announcement period. All the significant news, influential news and non-influential news announcement days are divided into either the low $|S U R|$ group or the high $|S U R|$ group, compared with the $|S U R|$ median. The probit model is: $P(m k t=1)=f\left(\alpha+\alpha_{H} H_{t}+\alpha_{V} V_{t}+\beta_{x} X_{t}\right)$. The dependent variable is equal to 1 if it is a market order, and 0 if it is a limit order. The independent variables are the market uncertainty $\left(V_{t}\right)$, belief heterogeneity $\left(H_{t}\right)$, and the order book state $\left(X_{t}\right)$, which includes volatility $\left(V T Y_{t}\right)$, bid-ask spread $\left(S P R D_{t}\right)$, depth at the best quote on the same side of market $\left(S A M E 0_{t}\right)$, depth behind the best quote on the same side of market $\left(S A M E B H D_{t}\right)$, depth at the best quote on the opposite side of market $\left(O P P 0_{t}\right)$, depth behind the best quote on the opposite side of market $\left(O P P B H D_{t}\right)$, trading volume $\left(T R V L M_{t}\right)$, and price impact $\left(B E T A_{t}\right)$. ***, ** and * indicate significance at the $1 \%, 5 \%$ and $10 \%$ respectively. 
Table 4.12: Mulitvariate Analysis of Limit Order Aggressiveness During the Pre-announcement Period

\begin{tabular}{|c|c|c|c|c|c|c|c|c|c|}
\hline & \multicolumn{3}{|c|}{ Pre-Announcement Period } & \multicolumn{3}{|c|}{ From 8:00 ET to 8:15 ET } & \multicolumn{3}{|c|}{ From 8:15 ET to 8:30 ET } \\
\hline & All Sample News & Inf. News & Non-inf. News & All Sample News & Inf. News & Non-inf. News & All Sample News & Inf. News & Non-inf. News \\
\hline$\alpha$ & $-13.318^{* * *}$ & $-14.755^{* * *}$ & $-12.512^{* * *}$ & $-14.358^{* * *}$ & $-15.721^{* * *}$ & $-12.631^{* * *}$ & $-13.643^{* * *}$ & $-15.612^{* * *}$ & $-12.865^{* * *}$ \\
\hline$V_{t}$ & $0.039^{* * *}$ & $0.033^{* * *}$ & $0.036^{* * *}$ & $0.040^{* * *}$ & $0.036^{* * *}$ & $0.032^{* * *}$ & $0.041^{* * *}$ & $0.023^{* * *}$ & $0.043^{* * *}$ \\
\hline$H_{t}$ & $1.235^{* * *}$ & -0.061 & $2.131^{* * *}$ & $0.933^{* * *}$ & -0.117 & $1.633^{* * *}$ & $1.571^{* * *}$ & -0.162 & $2.686^{*}$ \\
\hline$V T Y_{t}$ & $-0.234^{* * *}$ & $-0.126^{* * *}$ & $-0.300^{* * *}$ & $-0.245^{* * *}$ & -0.170 & $-0.315^{* * *}$ & $-0.234^{* * *}$ & $-0.101^{* * *}$ & $-0.311^{* * *}$ \\
\hline$S P R D_{t}$ & $-0.829^{* * *}$ & $-0.949^{* * *}$ & $-0.704^{* * *}$ & $-0.566^{* * *}$ & $-0.536^{* * *}$ & $-0.600^{* * *}$ & $-0.917^{* * *}$ & $-1.063^{* * *}$ & $-0.747^{* * *}$ \\
\hline$S A M E 0_{t}$ & $25.773^{* * *}$ & $38.255^{* * *}$ & $14.266^{* * *}$ & $10.776^{* * *}$ & $14.526^{* * *}$ & $8.569^{* * *}$ & $31.640^{* * *}$ & $48.606^{* * *}$ & $16.456^{* * *}$ \\
\hline$O P P 0_{t}$ & $8.093^{* * *}$ & $6.829^{* * *}$ & $9.037^{* * *}$ & $8.482^{* * *}$ & $7.972^{* * *}$ & $8.439^{* * *}$ & $8.356^{* * *}$ & $6.914^{* * *}$ & $9.563^{* * *}$ \\
\hline$O P P B H D_{t}$ & $-6.767^{* * *}$ & $-6.148^{* * *}$ & $-7.496^{* * *}$ & $-6.350^{* * *}$ & $-5.411^{* * *}$ & $-7.913^{* * *}$ & $-6.525^{* * *}$ & $-5.836^{* * *}$ & $-6.981^{* * *}$ \\
\hline$T R V L M_{t}$ & $6.394^{* * *}$ & $3.116^{* * *}$ & $9.045^{* * *}$ & $7.478^{* * *}$ & $1.108^{* *}$ & $16.474^{* * *}$ & $7.628^{* * *}$ & $5.966^{* * *}$ & $9.158^{* * *}$ \\
\hline$B E T A_{t}$ & $-1.082^{* * *}$ & $-2.083^{* * *}$ & $-0.742^{*}$ & $-1.741^{* * *}$ & $-1.581^{* * *}$ & $-1.497^{* * *}$ & -0.448 & $-2.923^{* * *}$ & $-1.664^{*}$ \\
\hline Likelihood & -12148664 & -5493033 & -6626357 & -5416899 & -2437283 & -2967919 & -6727290 & -3053808 & -3655634 \\
\hline
\end{tabular}

This table reports the results of censored regression model of limit order aggressiveness during the pre-announcement period and its sub-periods. The regression model is: $l m t_{t}=\alpha+\alpha_{H} H_{t}+\alpha_{V} V_{t}+\beta_{x} X_{t}+\varepsilon_{t}$ The dependent variable, limit order aggressiveness, $l m t$, is defined as in Equation (4.17). The independent variables are the market uncertainty $\left(V_{t}\right)$, belief heterogeneity $\left(H_{t}\right)$, and the order book state $\left(X_{t}\right)$, which includes volatility $\left(V T Y_{t}\right)$, bid-ask spread $\left(S P R D_{t}\right)$, depth at the best quote on the same side of market $\left(S A M E 0_{t}\right)$, depth behind the best quote on the same side of market $\left(S A M E B H D_{t}\right)$, depth at the best quote on the opposite side of market $\left(O P P 0_{t}\right)$, depth behind the best quote on the opposite side of market $\left(O P P B H D_{t}\right)$, trading volume $\left(T R V L M_{t}\right)$, and price impact $\left(B E T A_{t}\right)$. ***, ** and * indicate significance at the $1 \%, 5 \%$ and $10 \%$ respectively. 
Table 4.13: Mulitvariate Analysis of Limit Order Aggressiveness During the Post-announcement Period

\begin{tabular}{|c|c|c|c|c|c|c|c|c|c|}
\hline & \multicolumn{3}{|c|}{ Post-Announcement Period } & \multicolumn{3}{|c|}{ From 8:30 ET to 8:45 ET } & \multicolumn{3}{|c|}{ From 8:45 ET to 9:00 ET } \\
\hline & All Sample News & Inf. News & Non-inf. News & All Sample News & Inf. News & Non-inf. News & All Sample News & Inf. News & Non-inf. News \\
\hline$\alpha$ & $-19.426^{* * *}$ & $-18.471^{* * *}$ & $-17.503^{* * *}$ & $-19.221^{* * *}$ & $-18.052^{* * *}$ & $-16.672^{* * *}$ & $-18.315^{* * *}$ & $-20.180^{* * *}$ & $-16.879^{* * *}$ \\
\hline$V_{t}$ & $0.063^{* * *}$ & $0.034^{* * *}$ & $0.074^{* * *}$ & $0.058^{* * *}$ & $0.012^{* * *}$ & $0.082^{* * *}$ & $0.063^{* * *}$ & $0.062^{* * *}$ & $0.053^{* * *}$ \\
\hline$H_{t}$ & $0.722^{* * *}$ & $-0.665^{* * *}$ & $1.454^{* * *}$ & $0.640^{* * *}$ & $-1.003^{* * *}$ & $1.695^{* * *}$ & $0.621^{* * *}$ & 0.006 & $0.781^{*}$ \\
\hline$V T Y_{t}$ & $-0.019^{* * *}$ & $-0.003^{* * *}$ & $-0.104^{* * *}$ & $-0.013^{* * *}$ & -0.001 & $-0.098^{* * *}$ & $-0.145^{* * *}$ & $-0.073^{* * *}$ & $-0.183^{* * *}$ \\
\hline$S P R D_{t}$ & $-0.846^{* * *}$ & $-0.872^{* * *}$ & $-0.781^{* * *}$ & $-0.894^{* * *}$ & $-0.904^{* * *}$ & $-0.891^{* * *}$ & $-0.485^{* * *}$ & $-0.473^{* * *}$ & $-0.508^{* * *}$ \\
\hline$S A M E 0_{t}$ & $29.198^{* * *}$ & $32.476^{* * *}$ & $25.096^{* * *}$ & $36.641^{* * *}$ & $36.189^{* * *}$ & $38.359^{* * *}$ & $10.925^{* * *}$ & $16.626^{* * *}$ & 6.548 \\
\hline$O P P 0_{t}$ & $6.485^{* * *}$ & $4.995^{* * *}$ & $9.419^{* * *}$ & $4.707^{* * *}$ & $3.507^{* * *}$ & $8.269^{* * *}$ & $10.676^{* * *}$ & $10.915^{* * *}$ & $10.316^{* * *}$ \\
\hline$O P P B H D_{t}$ & $-3.280^{* * *}$ & $-2.838^{* * *}$ & $-6.392^{* * *}$ & $-1.836^{* * *}$ & $-1.292^{* * *}$ & $-6.452^{* * *}$ & $-6.762^{* * *}$ & $-7.165^{* * *}$ & $-6.408^{* * *}$ \\
\hline$T R V L M_{t}$ & $1.838^{* * *}$ & $1.490^{* * *}$ & $5.468^{* * *}$ & $2.177^{* * *}$ & $1.489^{* * *}$ & $6.661^{* * *}$ & $4.793^{* * *}$ & $3.340^{* * *}$ & $4.795^{* * *}$ \\
\hline$B E T A_{t}$ & $-4.418^{* * *}$ & $-5.671^{* * *}$ & $-3.641^{* *}$ & $-3.275^{* * *}$ & $-2.202^{* * *}$ & $-5.574^{* * *}$ & $-4.608^{* *}$ & $-11.515^{* * *}$ & -1.623 \\
\hline Likelihood & -27683833 & -12367276 & -13594132 & -14120818 & -7815744 & -6293600 & -11816938 & -4543427 & -6201914 \\
\hline
\end{tabular}

This table reports the results of censored regression model of limit order aggressiveness during the post-announcement period and its sub-periods. The regression model is: $\operatorname{lm} t_{t}=\alpha+\alpha_{H} H_{t}+\alpha_{V} V_{t}+\beta_{x} X_{t}+\varepsilon_{t}$ The dependent variable, limit order aggressiveness, $l m t$, is defined as in Equation (4.17). The independent variables are the market uncertainty $\left(V_{t}\right)$, belief heterogeneity $\left(H_{t}\right)$, and the order book state $\left(X_{t}\right)$, which includes volatility $\left(V T Y_{t}\right)$, bid-ask spread $\left(S P R D_{t}\right)$, depth at the best quote on the same side of market $\left(S A M E 0_{t}\right)$, depth behind the best quote on the same side of market $\left(S A M E B H D_{t}\right)$, depth at the best quote on the opposite side of market $\left(O P P 0_{t}\right)$, depth behind the best quote on the opposite side of market $\left(O P P B H D_{t}\right)$, trading volume $\left(T R V L M_{t}\right)$, and price impact $\left(B E T A_{t}\right)$. ***, ** and * indicate significance at the $1 \%, 5 \%$ and $10 \%$ respectively. 
Table 4.14: Multivariate Analysis of Limit Order Aggressiveness During the Post-announcement Period and Sub-Periods

\begin{tabular}{|c|c|c|c|c|c|c|}
\hline & \multicolumn{3}{|c|}{$|S U R|_{t}<$ Median $_{|S U R|}$} & \multicolumn{3}{|c|}{$|S U R|_{t}>$ Median $_{|S U R|}$} \\
\hline & All Sample News & Influential News & Non-Influential News & All Sample News & Influential News & Non-Influential News \\
\hline \multicolumn{7}{|c|}{ Panel A: Post-Announcement Period } \\
\hline$V_{t}$ & $0.079^{* * *}$ & $0.064^{* * *}$ & $0.077^{* * *}$ & $0.058^{* * *}$ & $0.059^{* * *}$ & $0.336^{* * *}$ \\
\hline$H_{t}$ & $2.100^{* * *}$ & $3.327^{* * *}$ & $-3.035^{* * *}$ & $-2.691^{* * *}$ & $-3.065^{* * *}$ & $-2.219^{* * *}$ \\
\hline Likelihood & -15239722 & -6315612 & -8052683 & -12432423 & -6044303 & -5522473 \\
\hline \multicolumn{7}{|c|}{ Panel B: 15 -minute period from 8:30 ET to $8: 45 \mathrm{ET}$} \\
\hline$V_{t}$ & $0.074^{* * *}$ & $0.045^{* * *}$ & $0.084^{* * *}$ & $0.041^{* * *}$ & $0.045^{* * *}$ & $0.267^{* * *}$ \\
\hline$H_{t}$ & $2.051^{* * *}$ & $3.506^{* * *}$ & $-3.486^{* * *}$ & $-2.699^{* * *}$ & $-3.526^{* * *}$ & $-1.541^{* * *}$ \\
\hline Likelihood & -8036920 & -3957151 & -4039316 & -6069287 & -3850448 & -2197559 \\
\hline \multicolumn{7}{|c|}{ Panel C: 15 -minute period from 8:45 ET to 9:00 ET } \\
\hline$V_{t}$ & $0.076^{* * *}$ & $0.090^{* * *}$ & $0.052^{* * *}$ & $0.073^{*}$ & $0.071^{* * *}$ & $0.390^{* *}$ \\
\hline$H_{t}$ & $1.071^{* *}$ & $3.034^{* * *}$ & $-4.293^{* * *}$ & $-2.571^{* * *}$ & $-1.886^{* * *}$ & $-2.945^{* *}$ \\
\hline Likelihood & -6363086 & -2357275 & -3475164 & -5448917 & -2185688 & -2721311 \\
\hline
\end{tabular}

This table reports the results of censored regression model of limit order aggressiveness during the post-announcement period and its sub-periods. All the significant news, influential news and non-influential news announcement days are divided into either the low $|S U R|$ group or the high $|S U R|$ group, compared with the $|S U R|$ median. The regression model is: $l m t_{t}=\alpha+\alpha_{H} H_{t}+\alpha_{V} V_{t}+\beta_{x} X_{t}+\varepsilon_{t}$. The dependent variable, limit order aggressiveness, $\operatorname{lm} t$, is defined as in Equation (4.17). The independent variables are the market uncertainty $\left(V_{t}\right)$, belief heterogeneity $\left(H_{t}\right)$, and the order book state $\left(X_{t}\right)$, which includes volatility $\left(V T Y_{t}\right)$, bid-ask spread $\left(S P R D_{t}\right)$, depth at the best quote on the same side of market $\left(S A M E 0_{t}\right)$, depth behind the best quote on the same side of market $\left(S A M E B H D_{t}\right)$, depth at the best quote on the opposite side of market $\left(O P P 0_{t}\right)$, depth behind the best quote on the opposite side of market $\left(O P P B H D_{t}\right)$, trading volume $\left(T R V L M_{t}\right)$, and price impact $\left(B E T A_{t}\right)$.***, ** and * indicate significance at the $1 \%, 5 \%$ and $10 \%$ respectively. 


\section{Chapter 5}

\section{Summary}

The three essays investigate a few interesting research questions on the U.S. Treasury market by using BrokerTec order books from 2004 to 2015. The U.S. Treasury market is one of the largest financial markets. It is of great importance to many investors. BrokerTec U.S. Treasury market is an interdealer market. The average daily trading volume of the 2-, 3-, 5-, 7-, 10- and 30-year U.S. Treasury securities accounts for about a quarter of the average daily trading volume of the U.S. Treasury market.

\subsection{Research Questions}

The main research questions of each essay are as follows. We also test the robustness by adopting alternative measures or using sub-sample groups.

(1) Whether the scheduled U.S. macroeconomic announcements affect the U.S. Treasury market efficiency? If so, how? (2) Whether the workup trading protocol influences the U.S. Treasury market quality? If so, how? (3) Whether the traders order submission decisions depend on the belief heterogeneity, market uncertainty, and information shock around U.S. macroeconomic announcements? If so, how?

\subsection{Findings and Contributions}

In this section, we summarize the findings and contributions of each essay. 


\subsubsection{Macroeconomic News Announcements and Market Efficiency}

The main finding of this paper is that the BrokerTec U.S. Treasury market efficiency decreases significantly starting from five minutes before scheduled major U.S. macroeconomic news announcements, and the impact becomes stronger during the Global Financial Crisis (GFC) period. The main measure of the market inefficiency is the distance between the variance ratio and 1 . We also show the robustness of this finding by using the absolute value of the first-order autocorrelation of returns as the alternative market inefficiency measure.

First, in literature, several papers have investigated the price impact of the U.S. macroeconomic news on the U.S. Treasury market. For example, Fleming and Remolona (1999) find that logarithmic return volatility of the five-year on-the-run U.S. Treasury notes increases sharply in the five-minute interval before the scheduled 8:30 ET news arrivals. Their GovPX data is from 23 August 1993 to 19 August 1994. Balduzzi et al. (2001) examine the impact of the scheduled news announcements on the U.S. Treasury market by using GovPX data between 1 July 1991 and 29 September 1995. For the 10-year on-the-run U.S. Treasury notes, they find the change in price deviations $\left(=\frac{\text { Price }_{2}-\text { Price }_{1}}{\text { Price }_{1}} \times 100 \%\right)$ between announcement days and non-announcement days become significantly positive before news arrivals. Nguyen, Engle, Fleming, and Ghysels (2020) find that the scheduled U.S. macroeconomic announcements affect the U.S. Treasury market liquidity and volatility in the five-minute intervals before news arrivals by using BrokerTec U.S. Treasury order books from 2006 to 2015. They also find that the effects become stronger during the GFC period.

Our finding is consistent with the former literature that the U.S. Treasury market starts to react to the U.S. macroeconomic news announcements before the scheduled release times. However, to the best of our knowledge, this is the first paper documents the robust impact of U.S. macroeconomic news on the U.S. Treasury market efficiency before scheduled news releases by using BrokerTec U.S. Treasury order books from 2004 to 2015. 
Second, this paper explains the decrease in the U.S. Treasury market efficiency before scheduled news arrivals - belief heterogeneity. During the embargo period before the news arrivals, liquidity traders would prefer to trade after the price adjustments to the new information in the U.S. Treasury market. Thus, only investors with private information would participate in trading activities during the embargo period. We observe that in the five-minute interval before news arrivals, the average 1-minute transaction volumes have been at the same level without experiencing any drops, which indicates that the investors with private information trade actively against each other. And the only motivation for continuous trading during the embargo period among investors with private information is that their information is heterogeneous.

Some researches have been done on the impact of belief heterogeneity on the market price, return, and volatility. Beaver (1981) discusses the impact of heterogeneous beliefs on increasing the distance between a security's price from its intrinsic value. Wang (1998) develops an informed trading model, which distinguishes the sources of information into two categories - the asymmetric information, and the heterogeneous prior beliefs. Both of the two information sources have significant impacts on market volatility. Brandt and Kavajecz (2004) suggest that the heterogeneity of investors' private information (price discovery) affects the U.S. Treasury market returns and volatility by using GovPX data from 1992 to 1999. They also find that the impact becomes stronger when the market liquidity is lower. Pasquariello and Vega (2007) show that the information heterogeneity increases the risk of adverse selection in the U.S. Treasury market, and decreases the market liquidity. Their GovPX data on 2-, 5- and 10-year on-the-run U.S. Treasury notes range from 1992 to 2000.

Our paper extends the existing literature on the impact of investors' heterogeneous private information on the U.S. Treasury market efficiency before the scheduled U.S. macroeconomic news arrivals. Moreover, we obtain the U.S. Treasury market data from the BrokerTec order books, ranging from 2004 to 2015. BrokerTec U.S. Treasury market is one of the largest electronic communication networks (ECNs) of the U.S. 
Treasury securities. ${ }^{1}$ This paper provides the robust empirical evidence that the belief heterogeneity becomes larger during the embargo period, after controlling the impact of market liquidity. The increased heterogeneous beliefs explain the decreased market efficiency before news arrivals.

Third, this paper shows the robustness of a two-step method to estimate the variances of true market returns: (1) to calculate the logarithmic returns based on mid quotes (Chen and Ghysels, 2011; Han and Lesmond, 2011); and (2) following AïtSahalia and Yu (2009), to estimate the variances of the unobservable true returns by using the generalized method of moments (GMM) (Madhavan et al., 1997). This paper also provides empirical evidence on the necessity of adopting both of the two steps to control the market microstructure noises when analyzing high-frequency data.

Besides, focusing on announcement days only, this paper also compares the news impact on market efficiency between the good news and the bad news. We find little difference in news impact on the market efficiency between good news and bad news before news arrivals. However, after the news releases, the results of the 10-year U.S. Treasury notes suggest that the market prices incorporate good news faster, with a lower level of market inefficiency. This finding is consistent with the literature that the market reacts to new information differently by good news and bad news. Brenner et al. (2009) find that the U.S. Treasury market becomes more volatile after bad news arrivals. Bernile et al. (2016) find that the traders' trading activities differ in the embargo period before U.S. macroeconomic news arrivals between good news and bad news in the 2-year and 10-year U.S. Treasury futures market. Furthermore, our paper tests whether the good news or the bad news influence the market efficiency more, as a continued discussion after our main finding in the robustness test section.

\footnotetext{
${ }^{1}$ According to our calculation based on the BrokerTec order books and the summary statistics of SIFMA, the average daily trading volume of the 2-, 3-, 5-, 7-, 10- and 30-year on-the-run U.S. Treasury securities on BrokerTec accounts for about $26 \%$ of the average daily trading volume in the U.S. Treasury market over the five years from 2011 to 2015.
} 


\subsubsection{Workup and Market Quality}

We find that workup trading decreases the market quality in the aspects of informational efficiency and market liquidity. Working trading in the U.S. Treasury market is a special type of dark trading, the trading volume of which is hidden from the public whereas the workup transaction price is pre-known to every trader and fixed at the same price as the pre-workup transaction that opens the workup window. Besides, the BrokerTec platform continuous to accept order submissions, alterations, or cancellation, but only matches workup orders while the workup window opens. These characteristics of the workup protocol are different from most of the dark trading protocols on equity markets. As a result, the workup trading accounts for more than half of the total trading volume on each trading day, which is about four times that of many equity markets.

This paper contributes to the literature with some novel findings on the BrokerTec U.S. Treasury market. We find that the workup trading decreases the market efficiency and market liquidity, which is different from the findings on the equity market. Former studies fail to reach an agreement on the impacts of dark pools. Some papers suggest that dark pools of equity markets are no harm or beneficial (Zhu, 2014; Robert et al., 2015; Foley and Putninšs, 2016; Buti et al., 2017; Gresse, 2017); some papers show that dark pool trading or dark trading could be harmful (Comerton-Forde and Putniņš, 2015; Degryse et al., 2015). ${ }^{2}$

This paper provides evidence for regulation authorities to reconsider the trading protocol setting. Dark trading provides benefits for traders who do not want to expose their trading interests. If these traders who need to transact a huge amount of securities and participate in lit pool transactions, their trading behavior will create the price pressure. Dark trading resolves this problem. But dark trading on equity markets has the minimum price improvement rule, which could effectively protect the fairness of trading by increasing the information costs. But on the BrokerTec U.S. Treasury market,

\footnotetext{
${ }^{2}$ Degryse et al. (2015) define dark trading as all of the trading activities on markets without pre-trade transparency, including dark pools, internalized trades, and over-the-counter (OTC) trading.
} 
all workup trades within the same workup window have the same transaction prices. Only the aggressive side pays the commission fees.

The workup protocol creates an opportunity for traders to take informational advantage of others by strategically submitting orders. For example, if the traders have private knowledge on the upcoming scheduled news announcement and they expect the price will increase. These traders would like to buy the securities now and sell later. To save trading costs and waiting time, they would submit a sell market order to trade at the lit pool and opens a workup window. Then, those traders buy the securities at the pre-fixed transaction price and become the passive side in the workup window. This strategy works as long as the traders' beliefs are heterogeneous. According to Dungey et al. (2013), the average workup duration increases around scheduled news announcements.

\subsubsection{Belief Heterogeneity, Market Liquidity, and Order Submis- sion Strategies}

In this paper, first, we investigate how information factors affect order aggressiveness. We find that uncertainty tends to increase order aggressiveness around our sample monthly U.S. macroeconomic news announcements, but the impact of investors' idiosyncratic information varies by the news types. Around non-influential announcements, investors with idiosyncratic information tend to submit aggressive orders. But the impact of investors' idiosyncratic information reverses that they tend to submit less aggressive orders after influential news announcements. Sub-period analysis shows the robustness of the finding. We also find that information shocks change the impact of $H$ on order aggressiveness during post-announcement periods. When the information shocks are high $\left(|S U R|_{t}>\right.$ Median $\left._{S U R}\right)$, traders' idiosyncratic information decreases the order aggressiveness after both influential and non-influential news announcements. The finding is consistent with

Second, we focus on the post-announcement period and examine whether traders' 
order choice, such as their decision on submitting market orders or limit orders, is affected by market uncertainty and belief heterogeneity. In addition to the former tests, this allows us to tell whether an increase in order aggressiveness is due to an increase in the placement of market orders or the submission of aggressive limit orders. We find that market uncertainty is positively correlated with the order aggressiveness in the post-announcement period and its two sub-periods, which consistent with the former findings. Traders tend to submit more market orders or limit orders with an improved price when market uncertainty is high during the post-announcement periods and its two sub-periods. The finding of market uncertainty impact on increasing order aggressiveness is robust in both high and low $|S U R|$ groups. However, the belief heterogeneity increases the aggressiveness of market orders or aggressive limit orders in the low $|S U R|$ group during the post-announcement period and its two sub-periods, whereas it decreases the aggressiveness of market orders or aggressive limit orders in the low $|S U R|$ group during the post-announcement period and its two sub-periods. The impact of the belief heterogeneity is consistent across all significant news announcement days, influential news announcement days, and non-influential news announcement days within each group divided by the information shocks.

Third, we focus solely on limit orders submission and construct the limit order aggressiveness measure in the post-announcement period. We examine, conditional on a limit order being submitted, how the aggressiveness of the limit orders is affected by market uncertainty and belief heterogeneity. We find that the former findings on market uncertainty impact are robust in the post-announcement period and its two subperiods, including within each of the high $|S U R|$ group and the low $|S U R|$ group. The former findings on the belief heterogeneity impact are also robust, but only during the post-announcement period and its two sub-periods. In the low $|S U R|$ group, traders with high levels of belief heterogeneity tend to submit more aggressive limit orders on influential news announcement days, but less aggressive orders on non-influential news announcement days. In the high $|S U R|$ group, traders with high levels of belief heterogeneity tend to submit less aggressive limit orders on all significant news 
announcement days, influential news announcement days, and non-influential news announcement days.

By considering the influence of belief heterogeneity and uncertainty around announcements, this paper extends former studies of the significant macroeconomic news announcements impact on the U.S. Treasury market. Ranaldo (2004) study the order aggressiveness in a pure order-driven market. He finds that the order book state affects the trader's order submission strategy. Our paper extends this paper by looking at how the other factors affect traders' order submission decisions while controlling the order book state.

To the best of our knowledge, this is the first paper investigating traders' order aggressiveness on the U.S. Treasury market around scheduled news announcements. By investigating the roles of belief heterogeneity and uncertainty, our study helps better understand how traders in the U.S. Treasury market make their decisions before and after scheduled U.S. macroeconomic news announcements. 


\section{Bibliography}

Aït-Sahalia, Y., Mykland, P. A., Zhang, L., 2005. How often to sample a continuoustime process in the presence of market microstructure noise. Review of Financial Studies 18, 351-416.

Aït-Sahalia, Y., Yu, J., 2009. High frequency market microstructure noise estimates and liquidity measures. Annals of Applied Statistics 3, 422-457.

Álvaro Cartea, Payne, R., Penalva, J., Tapia, M., 2019. Ultra-fast activity and intraday market quality. Journal of Banking \& Finance 99, 157-181.

Andersen, T. G., Bollerslev, T., 1998. Deutsche markdollar volatility: Intraday activity patterns, macroeconomic announcements, and longer run dependencies. Journal of Finance 53, 219-265.

Andersen, T. G., Bollerslev, T., Diebold, F. X., Vega, C., 2003. Micro effects of macro announcements: Real-Time price discovery in foreign exchange. American Economic Review 93, 38-62.

Balduzzi, P., Elton, E. J., Green, T. C., 2001. Economic news and bond prices: Evidence from the U.S. Treasury market. Journal of Finance 36, 523-543.

Balduzzi, P., Moneta, F., 2017. Economic risk premia in the fixed-income markets: The intraday evidence. Journal of Financial and Quantitative Analysis 52, 1927-1950.

Bandi, F. M., Russell, J. R., 2006. Separating microstructure noise from volatility. Journal of Financial Economics 79, 655-692. 
Banerjee, S., Green, B., 2015. Signal or noise? Uncertainty and learning about whether other traders are informed. Journal of Financial Economics 117, 398-423.

Barclay, M. J., Litzenberger, R. H., 1988. Announcement effects of new equity issues and the use of intraday price data. Journal of Financial Economics 21, 71-99.

Barron, O. E., Kim, O., Lim, S. C., Stevens, D. E., 1998. Using analysts' forecasts to measure properties of analysts' information environment. Accounting Review 73, $421-433$.

Beaver, W. H., 1981. Market efficiency. Accounting Review 56, 23-37.

Ben-David, I., Franzoni, F., Moussawi, R., 2018. Do ETFs increase volatility? Journal of Finance 73, 2471-2535.

Bernile, G., Hu, J., Tang, Y., 2016. Can information be locked up? Informed trading ahead of macro-news announcements. Journal of Financial Economics 121, 496520.

Boehmer, E., Kelley, E. K., 2009. Institutional investors and the informational efficiency of prices. Review of Financial Studies 22, 3563-3594.

Bordalo, P., Gennaioli, N., Shleifer, A., 2018. Diagnostic expectations and credit cycles. Journal of Finance 73, 199-227.

Boudt, K., Petitjean, M., 2014. Intraday liquidity dynamics and news releases around price jumps: Evidence from the DJIA stocks. Journal of Financial Markets 17, 121149.

Bradley, D., Clarke, J., Lee, S., Ornthanalai, C., 2014. Are analysts recommendations informative? Intraday evidence on the impact of time stamp delays. Journal of Finance $69,645-673$. 
Brandt, M. W., Kavajecz, K. A., 2004. Price discovery in the U.S. Treasury market: The impact of orderflow and liquidity on the yield curve. Journal of Finance 59, 2623-2654.

Brenner, M., Pasquariello, P., Subrahmanyam, M., 2009. On the volatility and comovement of U.S. financial markets around macroeconomic news announcements. Journal of Financial and Quantitative Analysis 44, 1265-1289.

Brogaard, J., Hendershott, T., Riordan, R., 2019. Price discovery without trading: Evidence from limit orders. Journal of Finance 74, 1621-1658.

Brown, K. C., Harlow, W., Tinic, S. M., 1988. Risk aversion, uncertain information, and market efficiency. Journal of Financial Economics 22, 355-385.

Buti, S., Rindi, B., Werner, I. M., 2017. Dark pool trading strategies, market quality and welfare. Journal of Financial Economics 124, 244-265.

Carlé, T. A., Lahav, Y., Neugebauer, T., Noussair, C. N., 2019. Heterogeneity of beliefs and trade in experimental asset markets. Journal of Financial and Quantitative Analysis 54, 215245.

Chan, K., Fong, W., 2000. Trade size, order imbalance, and the volatility-volume relation. Journal of Financial Economics 57, 247-273.

Chen, X., Ghysels, E., 2011. News - good or bad - and its impact on volatility predictions over multiple horizons. Review of Financial Studies 24, 46-81.

Chordia, T., Roll, R., Subrahmanyam, A., 2001. Market liquidity and trading activity. Journal of Finance 56, 501-530.

Chordia, T., Roll, R., Subrahmanyam, A., 2008. Liquidity and market efficiency. Journal of Financial Economics 87, 249-268.

Chordia, T., Sarkar, A., Subrahmanyam, A., 2005. An empirical analysis of stock and bond market liquidity. Review of Financial Studies 18, 85-129. 
Chung, K. H., Chuwonganant, C., 2014. Uncertainty, market structure, and liquidity. Journal of Financial Economics 113, 476-499.

Comerton-Forde, C., Putninšs, T. J., 2015. Dark trading and price discovery. Journal of Financial Economics 118, 70-92.

Cont, R., Kukanov, A., Stoikov, S., 2014. The price impact of order book events. Journal of Financial Econometrics 12, 4788.

Corwin, S. A., Harris, J. H., Lipson, M. L., 2004. The development of secondary market liquidity for NYSE-listed IPOs. Journal of Finance 59, 2339-2374.

Davies, R. J., 2003. The Toronto Stock Exchange preopening session. Journal of Financial Markets 6, 491-516, order form, trading protocol, and price formation.

Degryse, H., de Jong, F., van Kervel, V., 2015. The impact of dark trading and visible fragmentation on market quality. Review of Finance 19, 1587-1622.

Dick-Nielsen, J., Feldhtter, P., Lando, D., 2012. Corporate bond liquidity before and after the onset of the subprime crisis. Journal of Financial Economics 103, 471-492.

Dungey, M., Henry, O., McKenzie, M., 2013. Modeling trade duration in U.S. Treasury markets. Quantitative Finance 13.

Ederington, L. H., Lee, J. H., 1993. How markets process information: News releases and volatility. Journal of Finance 48, 1161-1191.

Ederington, L. H., Lee, J. H., 1995. The short-run dynamics of the price adjustment to new information. Journal of Financial and Quantitative Analysis 30, 117-134.

Engle, R., Fleming, M. J., Ghysels, E., Nguyen, G., 2012. Liquidity, volatility, and flights to safety in the U.S. Treasury market: Evidence from a new class of dynamic order book models. Staff Reports 590, Federal Reserve Bank of New York. 
Evans, M. D., Lyons, R. K., 2008. How is macro news transmitted to exchange rates? Journal of Financial Economics 88, 26-50.

Fleckenstein, M., Longstaff, F. A., Lustig, H., 2014. The TIPS-Treasury bond puzzle. Journal of Finance 69, 2151-2197.

Fleming, M. J., 1997. The round-the-clock market for U.S. Treasury securities. Economic Policy Review 3, 9-32.

Fleming, M. J., Mizrach, B., Nguyen, G., 2018. The microstructure of a U.S. Treasury ECN: The BrokerTec platform. Journal of Financial Markets 40, 2-22.

Fleming, M. J., Nguyen, G., 2018. Price and size discovery in financial markets: Evidence from the U.S. Treasury securities market. Review of Asset Pricing Studies, Forthcoming .

Fleming, M. J., Remolona, E. M., 1999. Price formation and liquidity in the U.S. Treasury market: The response to public information. Journal of Finance 54, 1901-1915.

Foley, S., Putniņš, T. J., 2016. Should we be afraid of the dark? Dark trading and market quality. Journal of Financial Economics 122, 456-481.

Goettler, R. L., Parlour, C. A., Rajan, U., 2009. Informed traders and limit order markets. Journal of Financial Economics 93, 67-87.

Goldstein, M. A., Kavajecz, K. A., 2000. Eighths, sixteenths, and market depth: changes in tick size and liquidity provision on the NYSE. Journal of Financial Economics 56, 125-149.

Green, T. C., 2004. Economic news and the impact of trading on bond prices. Journal of Finance 59, 1201-1233.

Gresse, C., 2017. Effects of lit and dark market fragmentation on liquidity. Journal of Financial Markets 35, 1-20. 
Griffin, J. M., Kelly, P. J., Nardari, F., 2010. Do market efficiency measures yield correct inferences? A comparison of developed and emerging markets. Review of Financial Studies 23, 3225-3277.

Griffiths, M. D., Smith, B. F., Turnbull, D. S., White, R. W., 2000. The costs and determinants of order aggressiveness. Journal of Financial Economics 56, 65-88.

Grossman, S. J., Stiglitz, J. E., 1980. On the impossibility of informationally efficient markets. American Economic Review 70.

Hamao, Y., Hasbrouck, J., 1995. Securities trading in the absence of dealers: Trades and quotes on the Tokyo Stock Exchange. Review of Financial Studies 8, 849-878.

Han, Y., Lesmond, D., 2011. Liquidity biases and the pricing of cross-sectional idiosyncratic volatility. Review of Financial Studies 24, 1590-1629.

Harford, J., Kaul, A., 2005. Correlated order flow: Pervasiveness, sources, and pricing effects. Journal of Financial and Quantitative Analysis 40, 29-55.

Harris, L. E., 1994. Minimum price variations, discrete bid-ask spreads, and quotation sizes. Review of Financial Studies 7, 149-178.

Hasbrouck, J., 1991. The summary informativeness of stock trades: An econometric analysis. Review of Financial Studies 4, 571-595.

Hautsch, N., Horvath, A., 2019. How effective are trading pauses? Journal of Financial Economics 131, 378-403.

He, Y., Lin, H., Wang, J., Wu, C., 2009. Price discovery in the round-the-clock U.S. Treasury market. Journal of Financial Intermediation 18, 464-490.

Hendershott, T., Jones, C. M., Menkveld, A. J., 2011. Does algorithmic trading improve liquidity? Journal of Finance 66, 1-33. 
Hirshleiger, D., Lim, S. S., Teoh, S. H., 2009. Driven to distraction: Extraneous events and underreaction to earnings news. Journal of Finance 64, 2289-2325.

Hong, H., Lim, T., Stein, J. C., 2002. Bad news travels slowly: Size, analyst coverage, and the profitability of momentum strategies. Journal of Finance 55, 265-295.

Huang, R. D., Cai, J., Wang, X., 2002. Information-based trading in the Treasury Note interdealer broker market. Journal of Financial Intermediation 11, 269-296.

Jiang, G. J., Lo, I., Verdelhan, A., 2011. Information shocks, liquidity shocks, jumps, and price discovery: Evidence from the U.S. Treasury market. Journal of Financial and Quantitative Analysis 46, 527-551.

Joint Staff Report, 2015. The U.S. Treasury market on October 15, 2014. Tech. rep., U.S. Department of the Treasury, Board of Governors of the Federal Reserve System, Federal Reserve Bank of New York, U.S. Securities and Exchange Commission, and U.S. Commodity Futures Trading Commission.

Jones, C. M., Lamont, O., Lumsdaine, R. L., 1998. Macroeconomic news and bond market volatility. Journal of Financial Economics 47, 315-337.

Kelley, E. K., Tetlock, P. C., 2013. How wise are crowds? Insights from retail orders and stock returns. Journal of Finance 68, 1229-1265.

Kruger, S., 2019. Disagreement and liquidity. Working paper.

Kurov, A., Sancetta, A., Strasser, G., Wolfe, M. H., 2019. Price drift before U.S. macroeconomic news: Private information about public announcements? Journal of Financial and Quantitative Analysis 54, 449479.

Kyle, A. S., 1985. Continuous auctions and insider trading. Econometrica 53.

Lambert, R. A., Leuz, C., Verrecchia, R. E., 2011. Information asymmetry, information precision, and the cost of capital. Review of Finance 16, 1-29. 
Lee, C. M. C., Mucklow, B., Ready, M. J., 1993. Spreads, depths, and the impact of earnings information: An intraday analysis. Review of Financial Studies 6, 345-374.

Lee, C. M. C., Ready, M. J., 1991. Inferring trade direction from intraday data. Journal of Finance 46, 733-746.

Lo, A. W., MacKinlay, A. C., 1988. Stock market prices do not follow random walks: Evidence from a simple specification test. Review of Financial Studies 1, 41-66.

Lo, A. W., Wang, J., 2015. Trading volume: Definitions, data analysis, and implications of portfolio theory. Review of Financial Studies 13, 257-300.

Lucca, D. O., Moench, E., 2015. The pre-FOMC announcement drift. Journal of Finance $70,329-371$.

Madhavan, A., Richardson, M., Roomans, M., 1997. Why do security prices change? A transaction-level analysis of NYSE stocks. Review of Financial Studies 10, 10351064.

Malinova, K., Park, A., 2015. Subsidizing liquidity: The impact of make/take fees on market quality. Journal of Finance 70, 509-536.

Man, K., Wang, J., Wu, C., 2013. Price discovery in the US Treasury market: Automation vs. intermediation. Management Science 59, 695-714.

McQueen, G., Pinegar, M., Thorley, S., 1996. Delayed reaction to good news and the cross-autocorrelation of portfolio returns. Journal of Finance 51, 889-919.

Michaely, R., Vila, J.-L., 1995. Investors' heterogeneity, prices, and volume around the ex-dividend day. Journal of Financial and Quantitative Analysis 30, 171198.

Mizrach, B., Neely, C. J., 2006. The transition to electronic communications networks in the secondary Treasury market. Federal Reserve Bank of St. Louis Review 88, $527-541$. 
Musto, D., Nini, G., Schwarz, K., 2018. Notes on bonds: Illiquidity feedback during the financial crisis. Review of Financial Studies 31, 2983-3018.

Nguyen, G., Engle, R., Fleming, M., Ghysels, E., 2020. Liquidity and volatility in the U.S. Treasury market. Journal of Econometrics .

Parkinson, M., 1980. The extreme value method for estimating the variance of the rate of return. Journal of Business 53, 61-65.

Pasquariello, P., Vega, C., 2007. Informed and strategic order flow in the bond markets. Review of Financial Studies 20, 1975-2019.

Ranaldo, A., 2004. Order aggressiveness in limit order book markets. Journal of Financial Markets 7.

Rapach, D. E., Ringgenberg, M. C., Zhou, G., 2016. Short interest and aggregate stock returns. Journal of Financial Economics 121, 46-65.

Rigobon, R., Sack, B., 2008. Noisy macroeconomic announcements, monetary policy, and asset prices, University of Chicago Press, pp. 335-370.

Robert, B., Maureen, O., Gideon, S., 2015. Hidden liquidity: Some new light on dark trading. Journal of Finance 70, 2227-2274.

Romano, J. P., Wolf, M., 2001. Subsampling intervals in autoregressive models with linear time trend. Econometrica 69, 1283-1314.

Roşu, I., 2018. Liquidity and information in order driven markets. Working paper.

Sadka, R., Scherbina, A., 2007. Analyst disagreement, mispricing, and liquidity. Journal of Finance 62, 2367-2403.

Wang, F. A., 1998. Strategic trading, asymmetric information and heterogeneous prior beliefs. Journal of Financial Markets 1, 321-352. 
Xiong, W., Yan, H., 2009. Heterogeneous expectations and bond markets. Review of Financial Studies 23, 1433-1466.

Zhang, X. F., 2006. Information uncertainty and stock returns. Journal of Finance 61, 105-137.

Zhu, H., 2014. Do dark pools harm price discovery? Review of Financial Studies 27, 747-789. 